Applications of Research from the U.S. Geological Survey Program, Assessment of Regional Earthquake Hazards and Risk Along the Wasatch Front, Utah

U.S. GEOLOGICAL SURVEY PROFESSIONAL PAPER 1519

Contributions from Utah Geological Survey, Utah Division of Comprehensive

Emergency Management, University of Utah, and Utah State University 
Cover PHOTOGRAPH - Oblique aerial view looking east at theWasatch fault zone below Spanish Fork Peak near Mapleton, Utah. The fault is the high west-facing curvilinear scarp. The flat bench at the base of the faceted range front is the Bonneville shoreline. Geological studies at this location indicate that the most recent large magnitude surface faulting earthquake occurred about 650 years ago. (Photograph by Woodward-Clyde and Associates, 1969.) 


\section{Applications of Research from the U.S. Geological Survey Program, Assessment of Regional Earthquake Hazards and Risk Along the Wasatch Front, Utah}

Edited by PAULA L. GORI

U.S. GEOLOGICAL SURVEY PROFESSIONAL PAPER 1519

Contributions from

Utah Geological Survey, Utah Division of Comprehensive Emergency Management, University of Utah, and Utah State University

This report documents how pertinent

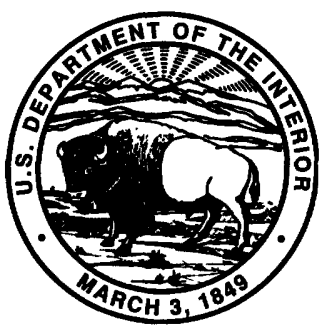
information about earthquake hazards along the Wasatch Front, Utah, was transferred to researchers, public officials, design professionals, land-use planners, and emergency managers as part of the U.S. Geological Survey's effort to mitigate the effects of earthquake hazards. 


\section{U.S. DEPARTMENT OF THE INTERIOR \\ BRUCE BABBITT, Secretary}

\section{U.S. GEOLOGICAL SURVEY}

Dallas L. Peck, Director

Any use of trade, product, or firm names in this publication is for descriptive purposes only and does not imply endorsement by the U.S. Government

\section{Library of Congress Cataloging in Publication Data}

Applications of research from the U.S. Geological Survey program, assessment of regional earthquake hazards and risk along the Wasatch Front, Utah/edited by Paula L. Gori.

p. $\quad$ cm. - (U.S. Geological Survey professional paper ; 1519)

Includes bibliographical references.

1. Earthquake hazard analysis - Wasatch Range (Utah and Idaho) 2. Seismology-Wasatch Range (Utah and Idaho)

3. Natural disasters-Utah. 4. Faults (Geology)-Wasatch Range (Utah and Idaho) 5. Geology, Stratigraphy.

6. Geology - Wasatch Range (Utah and Idaho) I. Gori, Paula. II. Series.

QE535.2.U6A66 1993

$551.2^{\prime} 2^{\prime} 09792201-\mathrm{dc} 20$

91-4180

For sale by U.S. Geological Survey, Map Distribution

Box 25286, Bldg. 810, Federal Center

Denver, CO 80225 


\section{PREFACE}

In 1983, the U.S. Geological Survey (USGS) targeted the Wasatch Front, Utah, for a multiyear program that focused on earthquake hazards research and hazards reduction. This report represents the transfer of pertinent information about earthquake hazards along the Wasatch Front to researchers, public officials, design professionals, land-use planners, and emergency managers as part of the USGS effort to mitigate the effects of earthquake hazards. An earlier report, USGS Professional Paper 1500, "Assessment of Regional Earthquake Hazards and Risk Along the Wasatch Front, Utah, A-J and K-Z," contained the results of much of the research and experiences of the program from 1983 to 1988. This report contains the results of research and experiences undertaken during the later phases of the Wasatch Front program.

Professional Paper 1500 defined the nature of the earthquake hazards in the Wasatch Front, including tectonic framework and earthquake potential, groundshaking hazards and the estimated losses, and the use of earthquake hazards information for urban and regional planning. This Professional Paper complements the first report by presenting examples of how the research and experiences were applied at the local level.

Application of scientific information to further earthquake hazards reduction was one of the goals of the USGS program in the Wasatch Front. Presented in this report is an explanation of how new information was incorporated into policy and practice and how new information about the earthquake hazards was specifically applied in Utah. This report, therefore, is a compendium of information developed at the local level to reduce the earthquake hazards of surface-fault rupture, landslides and debris flows, liquefaction, and tectonic subsidence with an explanation of the methodologies followed to encourage the organization and application of scientific information. The authors who have contributed to this report represent the many disciplines and levels of government that participated in this multidisciplinary cooperative program.

Paula L. Gori, Editor 


\section{CONTENTS}

Preface

Interactive Workshops: Essential Elements of the Earthquake Hazards Research and Reduction Program in the Wasatch Front, Utah

By Paula L. Gori

Introduction.

Utah Regional Earthquake Hazards Assessment Program...

The Role of Interactive Workshops..................................

Interactive Workshops in Utah .

Conclusion

Appendix A …................................................... 12

Reducing Earthquake Hazards in Utah: The Crucial Connection Between Researchers and Practitioners

By William J. Kockelman.

Introduction and Purpose

Acknowledgments.

Toward the Connection in Utah

Translation for Practitioners.

Examples of Successful Translation in Utah .................... 30

Transfer to Nontechnical Users.

Examples of Successful Transfer in Utah........................ 45

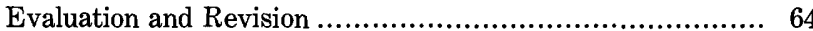

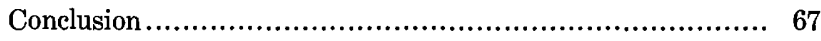

References ..................................................... 68

Public Perceptions of the Implementation of Earthquake Mitigation Policies Along the Wasatch Front in Utah By Gary E. Madsen, Loren R. Anderson, Jerold H.

Barnes, and Genevieve Atwood

Introduction

Acknowledgments .

Methodology

Results of the Surveys ...

Application of Research Findings to Implementation of Earthquake Hazard Reduction on the Wasatch Front .... 80 References

A Data Base Designed for Urban Seismic Hazards Studies By Arthur C. Tarr

Introduction

Acknowledgments.

Summary of Methods

Data Base Management System

Benefits and Costs of a Data Base Management System........

Design Objectives

Data Base Design Considerations

Example of Relational Organization

Data Files in the Data Base

Implementation of the Data Base ................................... 88

References ............................................................ 88

Appendix A: Urban Hazards Data Base File Structures...... 89
A Mapping of Ground-Shaking Intensities for Salt Lake County, Utah

By Philip C. Emmi ......................................... 91

Introduction................................................ 91

Acknowledgments.............................................. 91

Measurement of Ground Shaking................................ 91

General Model for the Assessment of Ground-Shaking Hazards

Departure-Data and Relationships................. 96

Comparison of Alternative Methods ............................ 100

References ........................................................ 106

Appendix A: Abbreviated Description of the Modified Mercalli Intensity Scale .................................. 109

Appendix B: The Interpretation of Technical Statements of Risk.

Appendix C: Use of Computer Mapping and GIS Methodologies ....

Wasatch Front County Hazards Geologist Program

By Gary E. Christenson ................................... 114

Introduction ................................................... 114

Acknowledgments............................................. 115

Description of the Program ...................................... 115

Accomplishments ............................................ 117

Evaluation and Suggestions................................... 119

Conclusions........................................................ 119

References ...................................................... 120

Surface-Fault Rupture: A Guide for Land-Use Planning, Utah and Juab Counties, Utah

By Robert M. Robison ........................................ 121

Introduction..................................................... 121

Acknowledgments............................................. 122

Characteristics of the Wasatch Fault Zone......................... 122

Consequences of Surface-Fault Ruptures and Reduction of Hazards

125

Use of Special Study Zone Maps ................................ 125

Scope of Site Investigations..................................... 125

References .................................................... 128

Landslide Hazards: A Guide for Land-Use Planning, Davis

County, Utah

By Robert M. Robison and Mike Lowe ................... 129

Introduction..................................................... 129

Acknowledgments........................................... 129

Landslide Characteristics ...................................... 129

Consequences................................................... 130

Landslide Susceptibility .......................................... 131

Reducing Landslide Hazards ................................... 131

Summary of Methods Used in Map Preparation ............... 131

Recommended Use of Maps for Land-Use Planning and Development. 
Landslide Hazards: A Guide for Land-Use Planning, Davis County, Utah-Continued

Scope of Site Investigations.

References ....

Rockfall Hazards: A Guide for Land-Use Planning, Salt Lake County, Utah

By Craig V. Nelson

Introduction.

Acknowledgments................................................ 138

Characteristics of Rockfalls ................................... 138

Effects of Rockfalls .............................................. 138

Evaluating Rockfall Susceptibility ........................... 139

Reducing Rockfall Hazards....................................... 139

Use of Rockfall Hazard Special Study Area Maps ............ 140

Scope of Site Investigations.................................. 141

Summary ......................................................... 142

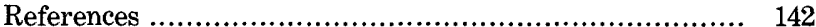

Debris-Flow Hazards: A Guide for Land-Use Planning, Davis County, Utah

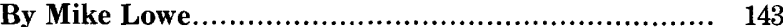

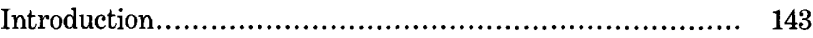

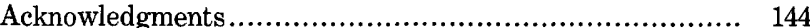

Nature and Causes of Debris Flows............................ 144

Effects of Debris Flows ......................................... 144

Debris-Flow Hazard Reduction ................................... 145

Summary of Methods Used in Map Preparation .............. 148

Recommended Use of Maps in Land-Use Planning ........... 148

Scope of Site Investigations.................................. 149

References ............ 150

Liquefaction Hazards: A Guide for Land-Use Planning, Davis

County, Utah

By Mike Lowe................................................... 151

Introduction.................................................... 151

Acknowledgments........................................... 151
Liquefaction Hazards: A Guide for Land-Use Planning, Davis County, Utah-Continued

Nature of the Liquefaction Hazard ............................... 152

Reduction of Liquefaction Hazards ............................ 153

Information for Davis County on Liquefaction Potential ..... 154

Recommended Use of Maps in Land-Use Planning ........... 155

Scope of Site Investigations.................................... 156

References ................................................ 156

Tectonic Subsidence Hazard: A Guide for Land-Use Planning,

Utah and Juab Counties, Utah

By Robert M. Robison ................... 158

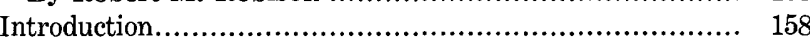

Acknowledgments................................................ 158

Characteristics of Tectonic Subsidence ....................... 158

Mitigation................................................. 159

Use of Hazard Maps............................................ 162

Scope of Site Investigations................................... 162

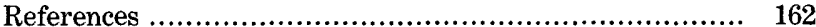

Hazards from Earthquake-Induced Ground Failure in

Sensitive Clays, Vibratory Settlement, and Flooding

Due to Seiches, Surface-Drainage Disruptions, and

Increased Ground-Water Discharge, Davis County, Utah

By Mike Lowe.

Introduction.................................................... 163

Acknowledgments............................................... 163

Ground Failure Due to Loss of Strength in Sensitive

Clays .......................................................... 163

Subsidence Caused by Vibratory Settlement in Granular Materials.....

Flooding Caused by Seiches in Great Salt Lake ...............

Flooding Due to Surface-Drainage Disruptions During

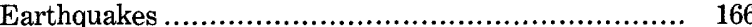

Increased Ground-Water Discharge Due to Earthquakes.... 166

Conclusions and Recommendations ............................ 166

References .................... 166

\section{ILLUSTRATIONS}

1. Five components needed for an effective comprehensive earthquake hazard reduction program

2. Example of a table showing average recurrence intervals

3. Part of a cadastral map of Salt Lake County showing a surface-fault rupture zone and the potential liquefaction areas ...

4. Map showing three levels of ground shaking on alluvium relative to bedrock .....

5-8. Parts of topographic maps showing:

5. Utah County, areas with high, moderate, low, and very low potential for liquefaction corresponding to the probability of exceeding a critical acceleration

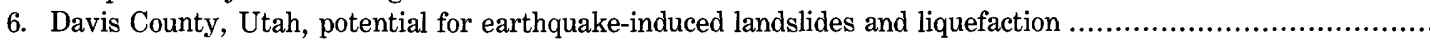

7. Salt Lake and Tooele Counties, mountain spur areas susceptible to rockfalls .....

8. Northern Juab Valley, Utah, potential consequences of tectonic deformation along the Nephi segment of the Wasatch fault

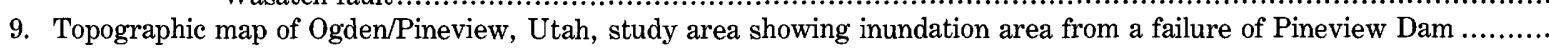

10. Part of a final performance report on educational, advisory, and review services over a 6 -month period ...................... 11-17. Illustrations of transfer techniques:

11. Part of the table of contents from a workshop proceedings

12. Typical cover of a serial publication that addresses geologic hazard and resource issues

13. Typical article reporting on the status of the Utah Earthquake-Hazard Reduction Program in the Wasatch Front Forum

14. Example of materials provided to students, teachers, and the general public under an outreach program by the Utah Museum of Natural History

15. Example of a general fact sheet widely distributed in Utah 
16. Typical press release by the USGS Public Affairs Office

17. Typical local newspaper coverage of earthquake hazard reduction activities......................................

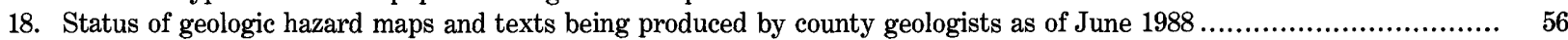

19-22. Examples of transfer and/or reduction techniques:

19. Letter addressing a specific issue in Utah

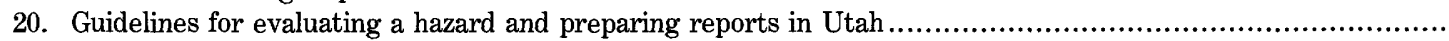

21. Matrix with recommendations for site-specific stability analysis for critical facilities and other land uses in several hazard zones.

22. Topical outline for geologic hazards ordinances in areas with and without geologic hazards maps

23. Rankings by key public and private decisionmakers as to the relative seriousness of 18 State and local issues for three States and three cities.....

24. Cross section of hypothetical seismic ground response study area

25. Relationships of terms used in three different representations of data in a data base....

26. Seismic stations and boreholes in a hypothetical area where seismic response studies are conducted.....

27. Tables showing station and borehole data.....

28. Examples of many-to-one and one-to-many pointer relationships among records in hypothetical STATION, RESPONSE, and EVENT relations .....

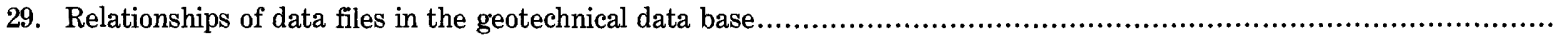

30. The $\mathrm{S} 16^{\circ} \mathrm{E}$ component horizontal accelerogram recorded at Pacoima Dam and the velocity and displacement

31. Derivation of the harmonic oscillator response at $0.33-\mathrm{Hz}$ and $2.0-\mathrm{Hz}$ frequency from a velocity seismogram and the role in the construction of a pseudo-relative velocity response spectrum.....

32. Velocity seismograms for three Salt Lake City locations exemplifying site amplification during low-amplitude ground motions initiated by a low-strain event that induced linearly elastic relative site responses .... horizontal acceleration measured in:

$33 A$ and $B$. Units of gravity

34. Centimeters per second

35-37. Graphs showing:

35. A functional relationship between ground-motion amplification ratios and intensity increments for nearby soil sites that can be added to estimates of MMI at the reference rock site to obtain MMI estimates for soil sites

36. A comparison of curves defining the relationship between ground-motion amplification ratios and rock-site intensity increments.

37. A comparison of estimates of MMI with a 10 percent chance of being exceeded over a $10-$, a $50-$, and a $250-\mathrm{yr}$ exposure period by valley location within Salt Lake County, Utah............................
aps showing microzonations of MMI for the urbanizable area of Salt Lake County, Utah...

athors to show functional relationships between MMI and the logarithm of peak

38. Maps showing microzonations of
40. Graphs showing estimated loss to:

39. Selected structures as a function of MMI

40. Selected lifelines as a function of MMI

41. Functions describing the probabilities with which events of different intensity might occur over various exposure periods.

42. Illustration of a graphic overlay technique using a geographic information system .....

43. Location map.....

44. Map showing the location of Utah and eastern Juab Counties, Utah ....

45. Schematic diagram of the Wasatch fault zone showing the relation of the epicenter to the focus and the trace of the surface-fault rupture.

46. Sketch showing schematic diagram of a normal fault showing features typical of the Wasatch fault zone near the ground surface.

47, 48. Maps showing:

47. Boundaries and names for the Wasatch fault zone segments

48. The Wasatch fault zone at the mouth of Rock Canyon, Utah....

ematic diagram of recommended minimum setback distances relative to fault scarps in areas where trenching studies are not performed.....

50. Block diagram of a rotational landslide.

51. Location map for figures 52,53 , and 54 .

52-54. Maps showing:

52. Landslide inventory for the Centerville and northern Bountiful area of southern Davis County, Utah

53. Landslide hazards for the Centerville and northern Bountiful area of southern Davis County, Utah....

54. Earthquake-induced landslide potential for the Centerville and northern Bountiful area of southern Davis

55, 56. Location maps of: County, Utah 
FIgURE 57. Article from the Utah Geological and Mineral Survey Survey Notes, spring 1987.

58. Example of the output model generated by the computer program ROCKFALL for a rockfall event on a generalized slope...

59. Portion of the rockfall hazards special study area map in the Draper Quadrangle, southeast of Salt Lake City, Utah.....

60, 61. Location maps for:

60. Debris basins in Davis County

61. Figure 62 ...

62. Example of a debris-flow hazard special study zone map for the east Layton area of northern Davis County, Utah.......

63-66. Diagrams showing:

63. Tilting of a building due to liquefaction and loss of bearing strength in the underlying soil..................... 152

64. Liquefaction-induced ground oscillation

65. Lateral spread

66. Flow failure

67-71. Maps showing:

67. Location for figure 68

68. Liquefaction-potential map for the Centerville and northern Bountiful area of southern Davis County .................

69. Location of Utah and northeastern Juab Counties .

70. Surface rupture and tectonic subsidence accompanying a hypothetical earthquake along the Wasatch fault zone

71. Area of potential tectonic subsidence in part of Utah Valley

11. Area of potential tectonic subsidence in part of Utah Valley ...

\title{
TABLES
}

\begin{abstract}
$-$
\end{abstract}
TABLE 1. Rankings by local government planners and building officials as to potential damage from earthquake hazards in Salt Lake

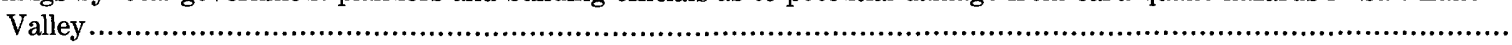

2. Perceptions of the likelihood of a future damaging earthquake in the Salt Lake Valley: Comparison of local technical officials and public residents

3. Concern of public residents about a future serious earthquake occurring in Salt Lake Valley

4. Policies to reduce earthquake risks in the Salt Lake Valley: Comparison of local technical officials and public residents

5. Estimates of Modified Mercalli Intensity for the edge and center of the Jordan River Valley, Utah, using six different methods of estimation.

6. A cross classification of surficial geologic units with site amplification factors

7. Percentage of time spent on various tasks by the county geologists

8. Data for the Wasatch fault zone in Utah and northeastern Juab Counties

9. Relationship between ground displacement and damage to structures....

10. Earthquake-induced landslide potential categories, soil moisture levels considered, probability of exceedence of critical acceleration needed to cause failure during 100-yr period, and possible magnitudes of displacement

11. Recommended requirement for site-specific investigations of slope stability for various classes of facilities proposed within Davis County, Utah.

12. Recommended requirement for site-specific investigations of seismic slope stability for various classes of facilities in different earthquake-induced landslide-potential zones

13. Historical Davis County debris flows

14. Alluvial-fan sedimentation intensity scale.

15. Matrix indicating recommended report requirements for debris-flow hazards, Davis County, Utah

16. Ground slope and expected failure mode resulting from liquefaction

17. Relationship between ground displacement and damage to structures.

18. Criteria used to evaluate liquefaction potential

19. Matrix indicating recommended report requirements for liquefaction hazards, Davis County, Utah 


\title{
APPLICATIONS OF RESEARCH FROM THE U.S. GEOLOGICAL SURVEY PROGRAM, ASSESSMENT OF REGIONAL EARTHQUAKE HAZARDS AND RISK ALONG THE WASATCH FRONT, UTAH
}

\author{
INTERACTIVE WORKSHOPS: ESSENTIAL ELEMENTS OF THE \\ EARTHQUAKE HAZARDS RESEARCH AND REDUCTION PROGRAM \\ IN THE WASATCH FRONT, UTAH
}

\author{
By Paula L. Gori
}

\begin{abstract}
Interactive workshops provided the forum and stimulus necessary to foster collaboration among the participants in the multidisciplinary, 5-yr program of earthquake hazards reduction in the Wasatch Front, Utah. The workshop process validated well-documented social science theories on the importance of interpersonal interaction, including interaction between researchers and users of research to increase the probability that research will be relevant to the user's needs and, therefore, more readily used.
\end{abstract}

\section{INTRODUCTION}

Communication and collaboration between researchers and users of research are essential in a complex, multidisciplinary, multiyear program. The program of earthquake hazards research and reduction focused in the Wasatch Front, Utah, was such a program. In the early planning phase of the program, it was evident immediately that, if hazards reduction was to be successful, researchers from the U.S. Geological Survey (USGS), the Utah Geological Survey ${ }^{1}$ (UGS), the University of Utah, and other State and academic institutions, as well as officials from State and local governments, Federal agencies, and private organizations, would need to play active roles in the 5-yr research and implementation program. Coordination of USGS efforts would be a complex undertaking in and of itself, with researchers

\footnotetext{
Manuscript approved for publication April 15, 1991.

${ }^{1}$ The Utah Geological Survey was previously called the Utah Geological and Mineral Survey (UGMS).
}

from Menlo Park, Calif.; Golden, Colo.; Reston, Va.; and Salt Lake City, Utah, representing many different parts and tasks of the agency.

At the onset of the program in 1983, representatives of the major institutions in the program (USGS, UGS, Utah Federal Emergency Management Agency (FEMA), Utah Comprehensive Emergency Management (CEM), and University of Utah) endorsed a strategy of convening annual, interactive workshops to review progress of the program and to recommend further research and implementation activities. Proceedings of annual workshops were chosen as vehicles to communicate findings of researchers and experiences of public officials and professionals to others who were unable to attend.

The annual workshop was not a new experience for USGS or FEMA. Both agencies had, since 1980, convened earthquake-related workshops responding in part to an Office of Science and Technology report that stated, "It is crucial, then, that Federal agencies that produce hazards information collaborate with program and local officials as they develop policies and procedures. Furthermore, research shows that, whenever possible, interaction among Federal, State, and local officials should take place on a face-to-face basis" (Office of Science and Technology Policy, p. 182). Prior success with the process of convening interactive workshops and the shortage of travel funds for non-Utah-based participants mandated the use of large, annual workshops to communicate findings and experiences, recommend 
future research and implementation activities, galvanize support for earthquake-related policy, and energize the participants and communities in the program.

This paper evaluates the effectiveness and importance of the workshop process in the overall program by providing an assessment of the role and value of the interactive workshops in the 5-yr program of hazards research and hazards reduction in the Wasatch Front area. The assessment will be valuable to (1) USGS in its long-term planning of future multidisciplinary focused research and implementation programs, (2) participants in the ongoing Utah program, and (3) other institutions that will be undertaking long-term, complex programs that involve information transfer. This paper is not an evaluation of the focused research and implementation program in the Wasatch Front area. That evaluation will be best undertaken at a later date, upon completion of the program and after sufficient time has elapsed to allow for implementation of earthquake hazards information and research into public and private policy.

This paper shows that interactive workshops during the Utah program provided the forum and stimulus necessary to foster collaboration between participants in the program, energized the participants, and reduced the time necessary to implement a complex interdisciplinary program of earthquake hazards reduction. The next section describes the Utah Regional Earthquake Hazards Assessment Program. Literature regarding the effectiveness of workshops in facilitating collaboration between users of research and researchers is reviewed, and the workshop process and the results of interviews and surveys of participants in the program are described in context. In the final section, conclusions are drawn from interviews and surveys, and observations are made about the usefulness and importance of interactive workshops to the focused earthquake hazards research and reduction program in the Wasatch Front, Utah.

\section{UTAH REGIONAL EARTHQUAKE HAZARDS ASSESSMENT PROGRAM}

More than 80 percent of Utah's 2 million people are located along the Wasatch Front. A large earthquake centered near Salt Lake City has the potential to cause extensive damage to buildings, lifelines, and public facilities. The October 28, 1983, Borah Peak, Idaho, magnitude $\left(\mathrm{M}_{\mathrm{s}}\right) 7.3$ earthquake demonstrated that large earthquakes occur in the Intermountain Seismic Belt, where the Wasatch Front is situated.

In 1983, USGS targeted the Wasatch Front for the 5-yr Utah Regional Earthquake Hazards Assessment Program. The goals of the program were to (1) accelerate the development of a knowledge base on seismic sources, size, frequency of occurrence, and physical effects of earthquakes in a 10-county area along the Wasatch Front, including Salt Lake, Davis, Juab, Weber, Wasatch, Summit, Morgan, Cache, Utah, and Box Elder Counties, and (2) foster implementation of earthquake hazards mitigation measures (Hays and Gori, 1984, p. 17-22). The goals were to be tackled simultaneously by subdividing the effort into the following five components:

1. Development of information systems for use in earthquake hazards evaluations, risk assessment, and implementation of loss reduction measures.

2. Synthesis of new and existing geological and geophysical data needed for the evaluation of earthquake hazards.

3. Development of ground-motion models and maps of the ground-shaking hazard.

4. Development of models for loss and casualty estimates for urban areas.

5. Implementation of measures to mitigate earthquake hazards.

To carry out these objectives successfully, the program required the participation of a diverse set of institutions. The major institutions that participated in the program were

\section{U.S. Geological Survey Geologic Division Mapping Division}

Federal Emergency Management Agency National Headquarters

Region VIII

Utah Geological Survey

Utah Division of Comprehensive Emergency Management

University of Utah

Utah State University

Numerous other organizations and individuals participated in the program from its inception in 1983, including but not limited to county and city planners; State, county, and local government officials; engineers; consulting geologists; and representatives from USGS Division of Water Resources, U.S. Bureau of Reclamation, U.S. Corps of Engineers, local utilities, private colleges and universities, and the media.

The major participants agreed on six strategies to meet their shared goals of increasing the level of understanding of the seismic hazards in the Wasatch Front and implementing earthquake hazards mitigation measures. The six strategies were as follows:

1. USGS and UGS would foster strong partnerships with universities, the private sector, units of local government, and other State and Federal agencies. 
2. Results of past research studies would be used to the fullest extent possible.

3. Ten counties along the Wasatch Front would be studied. Although Salt Lake, Davis, Utah, and Weber Counties would receive primary attention because of their population density, potential risk, and the availability of information from prior and ongoing research studies, Cache, Box Elder, Summit, Wasatch, and Juab Counties would also be studied.

4. Each year, a workshop would be held in Salt Lake City to review the year's progress and recommend future research.

5. Proceedings of the workshops, which would include papers documenting results from all research projects in the Wasatch Front, would be published as USGS open-file reports. A USGS professional paper, including the major research findings, would be published at the conclusion of the program.

6. Knowledge gained from earthquakes such as the one at Borah Peak, Idaho, in October 1983 would be used to improve the methodology currently used to evaluate earthquake hazards and to assess risk in the Wasatch Front area. Earthquakes in other parts of the world that share a similar tectonic setting would be investigated to provide insight into the characteristics of ground-shaking and the physical effects that might occur in a major earthquake (Hays and Gori, 1984, p. 21-22).

Especially significant is the fact that planners of the Regional Earthquake Hazards Assessment Program decided early in the process to convene annual workshops in Salt Lake City to review accomplishments each year and to plan future activities. In fact, three of the six strategies depended on workshops. Strategy 1, formation of partnerships, relied on the workshop process because only through an interactive process could strong partnerships be initiated and maintained. Workshops provided that arena and, as will be discussed below, helped form bonds between participants. Strategy 4 called for annual workshops to be convened, and strategy 5 suggested that proceedings from the annual workshops be used to disseminate research results and results from hazard mitigation activities. Therefore, workshops were designated from the beginning of the program to fulfill important functions.

The Regional Earthquake Hazards Assessment Program constituted a major effort of the USGS Office of Earthquakes, Volcanoes, and Engineering and of UGS and resulted in programmatic changes. A large number of scientists from the USGS Branch of Geologic Risk Assessment and scientists from other branches conducted research on the Wasatch Front area during the program. UGS, with funds from USGS and the State, substantially increased its efforts of earthquake hazards assessment, mapping, and information dissemination during the program. Similarly, FEMA and CEM increased attention on and funding for earthquake hazards. During the program, the Office of Earthquakes, Volcanoes, and Engineering funded universities and private firms through its external research program to conduct research in the Wasatch Front area in tandem with its internal research program. FEMA funded State and local organizations to implement loss reduction activities in the area. As an indication of how many were intimately involved in the program, 60 individuals contributed one or more articles to the USGS professional paper on Assessment of Regional Earthquake Hazards and Risk Along the Wasatch Front Utah.

A major scientific contribution of the Regional Earthquake Hazards Assessment Program was a refinement of the explanation for seismicity along the Wasatch Front to include a greater understanding of the Wasatch fault and its 12 segments that had been identified. Scientists also identified the "characteristic" earthquake for the region to be similar to the 1983 Borah Peak, Idaho, magnitude $\left(M_{s}\right) 7.3$, earthquake and concurred that moderate, but potentially damaging earthquakes, without surface rupture $(M=5.5-6.5)$, might occur anywhere within the Wasatch Front on known or unknown faults. Researchers had stressed the possibility of a large earthquake centered near Salt Lake City causing numerous injuries, loss of life, and extensive damage to buildings, lifelines, and public facilities as a result of (1) peak ground acceleration expected to be $0.2-0.4 g$, (2) surface fault rupture, (3) tectonic deformation, (4) landslides including rockfalls and rockslides, and (5) liquefaction. At the close of the 5-yr program of focused research, the participants drafted a consensus document that specified the extent of the earthquake hazards and types of mitigation measures that were appropriate to minimize damage and losses from future earthquakes. Federal, State, and local governments, as well as private institutions and individuals, had begun to act on the information provided from the program. By 1989 , the program moved into a second phase, which emphasized implementation of loss reduction measures at the State, local, and individual level, although the participants recognized the need to continue assessing and mapping the earthquake hazards.

\section{THE ROLE OF INTERACTIVE WORKSHOPS}

The USGS, in planning for the Regional Earthquake Hazard Assessment Program, followed the welldocumented assumption that interaction between researchers and users of research increases the probability that research will be relevant to the user's needs 
and, therefore, will be more readily used (Nigg, 1988; Yin and Moore, 1985; Yin and Gwaltney, 1981; Glaser and others, 1983). Researchers agree that knowledge is likely to be utilized where interpersonal communication networks have been established and maintained. The network of researchers and users must be supported during the life of the research, even as knowledge production is occurring and after it has been completed, to assist in utilization of that knowledge (Yin and Gwaltney, 1981; Yin and Moore, 1985; Yin and Andranovich, 1987).

The focus of utilization is people, not maps and reports. When researchers interact with users, there is two-way communication. Preliminary information is transmitted to potential users, who in turn communicate their needs and explain how to modify the research to meet those needs. Individuals develop working relationships with each other. Not only do users become acquainted with the authors of reports, they also become acquainted with other research that may be useful. The researchers, in turn, benefit from refined problem identification and, by participation in a network of other scientists and users, help create an audience and a market for their information and products.

Knowledge utilization is enhanced through the networking process, which can sometimes be defined as collaboration. The numerous arenas where collaboration can take place include interactive workshops, advisory committees, interdisciplinary research projects, information centers, and professional societies. USGS chose interactive workshops as one of the arenas to foster collaboration between researchers and users of research because, during interactive workshops, individuals from many different disciplines meet, learn to appreciate each other's needs, learn about concurrent research and implementation of research, and finally, form ongoing networks to enhance the utilization of research.

Because of the importance of maximizing the resources allocated to research and because of society's need for new and better ways to solve problems, social science research has focused for the past $2 \frac{1}{2}$ decades on how new information is incorporated into policy. During that time, researchers and practitioners have reached a similar conclusion: personal interaction between investigators doing the research and potential users of the research is essential to knowledge utilization.

Three of several theories (Glaser and others, 1983) that explain how research is utilized are as follows:

1. Knowledge-driven theory: Utilization of research is characterized by a sequence of activities where research discovery moves through various phases. This theory is also called the "research development and diffusion theory."
2. Problem-solving theory: Utilization of research occurs when users identify a need or problem and research is initiated in response to that need.

3. Social interaction theory: Utilization of research occurs as a result of interaction between knowledge producers and knowledge users prior to, during, and following the research.

Yin and Moore (1985) scrutinized the natural hazards field to ascertain which of the above theories or combination of theories best explained why and how research gets used in the natural hazards field. They based their findings on case studies of natural hazards projects that experts had rated as exemplary.

In cases where knowledge from the research projects was utilized, the investigators found strong support for the social interaction theory, as evidenced by the following conditions:

1. Research producers and research users belonged to overlapping networks.

2. During early stages of research projects, communications and interactions resulted in modification of research design as a result of information obtained from users.

3. During the course of the project, communication occurred before, during, and after completion of the project.

4. Results were disseminated through some medium catering to users, not to other researchers (Yin and Moore, 1985).

Yin and Moore's work reinforces the importance of maintaining persistent interaction (two-way communication) between investigators doing the research and potential users of the research, so that their concept of a "marketplace of ideas" can develop in which the researchers and users of research exchange ideas, information, and experiences.

Yin and Moore's research is based in part on the theories and research findings presented by Glaser and others (1983). In the authors' encyclopedia of research on applications of knowledge for planned change, the role of personal interaction is explored, the importance of informal contact is documented, and the conclusion is reached that the most effective way to increase information is through personal interaction. A well-informed colleague serves to channel information to coworkers (Glaser and others, 1983, p. 302). For example, "as much as 85 percent of useful scientific information is exchanged informally before the usual bibliographical sources are consulted to ascertain whether published information is available" (Glaser and others, 1983, p. 304). In fact, the studies showed that researchers depend heavily on informal networks and interaction with applied scientists who are in touch with colleagues from different disciplines. To increase information exchange, one researcher recom- 
mended that isolated scientists be brought into closer contact with scientists who are the foci of information networks (Glaser and others, 1983, p. 303).

Glaser and others (1983) document how workshops and seminars that include users as well as producers of research serve to effectively increase utilization of knowledge. Workshops and seminars contribute to utilization by providing an arena for practitioners to acknowledge the implications of research findings and researchers to obtain feedback from those who would use their findings. The authors also document the effectiveness of conferences and workshops to link research to practice through the personal bonds that are formed at these meetings.

Utilization of new information is further enhanced when the conference or workshop provides a publication of the conference proceedings and when the conference is one of a series of annual meetings on the same topic (Glaser and others, 1983, p. 306). In addition, when attendees participate in the formation of action plans to implement research results, utilization of research tends to occur at a quicker pace (Glaser and others, 1983, p. 306).

Participants at a workshop entitled "A Synthesis of Technology Transfer Methodologies" sponsored by the U.S. Department of Energy in 1984 documented similar experiences and prescribed similar actions to increase the use of scientific information. The participants at this workshop, who were interested in the transfer of technical information not related to natural hazards, found that the transfer process is a human activity conducted by "enthusiastic people!" (Traeger, 1984, p.181).

Robbins (1984) suggested five principles necessary for successful technology transfer:

1. Access to information is necessary but not sufficient.

2. Information must be translated.

3. Personal contact is the most important channel through which technical information is obtained.

4. Solutions must be adapted to user's problems.

5. Products must meet the needs of users, not producers (Robbins, 1984, p. 72-74).

Others at the workshop emphasized the interpersonal aspect of technology transfer. "Information dissemination is a human function. While it is essential to incorporate a large resource base, including printed reports, library services, data bases, technical experts, consultants, as well as private, public, and governmental agencies, our experience has demonstrated that the amount of technology actually transferred is directly proportionate to the amount of face-to-face activity" (Marlow, 1984, p. 143). Participants recommended many different ways to increase face-to-face activities, including professional society meetings, conferences, and workshops. In fact, Traeger, a workshop participant, related that when individuals at Sandia National Laboratories were asked to identify the catalyst that initiated transfer of technology from 1981 to 1983 , they cited meetings and workshops as among the most important (Traeger, 1984, p. 176).

Greene and Gori (1982) also documented the fact that hazard information was obtained by Charleston decisionmakers through personal contacts and that workshops were effective catalysts for stimulating action (Greene and Gori, 1982, p. 27-28). In presentations at the conference on "A Review of Earthquake Research Applications in the National Earthquakes Hazards Reduction Program" (Hays, 1988), workshops were cited as important areas for the exchange of new information on need for and measures to reduce earthquake vulnerability. Whitehead (1988) from Kentucky, Molinelli-Freytes (1988) from Puerto Rico, Johnston-Fischer (1988) from the U.S. Virgin Islands, and Olson (1988), Bagwell (1988), and Lindbergh (1988) from South Carolina referenced one or more interactive workshops conducted by the USGS as important factors in increasing the concern and knowledge that they and others had about earthquake hazards reduction in their region.

\section{INTERACTIVE WORKSHOPS IN UTAH}

\section{METHODOLOGY OF THE STUDY}

To gage the effectiveness of workshops in Utah, the opinions and experiences of participants in the program were sought and analyzed in two ways. First, the opinions and experiences of the leaders of the program were recorded during two lengthy roundtable conversations in Salt Lake City during an annual workshop. Second, the author completed a systematic survey of researchers, public officials, and private individuals participating in the program. Responses from recorded conversations and written questionnaires form the basis of the findings.

\section{THE WORKSHOP PROCESS}

Each workshop followed essentially the same model. A steering committee was established to formulate the basic working concepts and procedures for the meeting. The steering committee, made up of representatives from the sponsoring groups, then formulated an agenda, a list of speakers, and a list of invitees, all chosen to represent many disciplines, as well as the local experience. The workshop was organized to exchange information and to develop recommendations or "action plans" that could be implemented once the workshop had adjourned. Proceedings from each workshop, made up of 
the talks given at the workshop and the recommendations of the participants, were published as open-file reports by the USGS and disseminated to the participants of the workshop and the public.

Following this model, seven workshops were convened in Utah between 1984 and 1989. Four of the workshops were objects of this study:

- August 14-16, 1984: Workshop on "Evaluation of Earthquake Hazards and Risk in Utah."

- July 10-11, 1985: Workshop on "Earthquake and Landslide Hazards in the Wasatch Front Region of Utah" (hosted by Utah Geological Survey).

- July 30-September 1, 1985: Workshop on "Earthquake and Landslide Hazards in the Wasatch Front Region of Utah" (hosted by Utah Division of Comprehensive Emergency Management).

- July 14-18, 1986: Workshop on "Earthquake Hazards Along the Wasatch Front, Utah."

(The 1985 workshops were organized by the State agencies and dealt with topics pertinent to the host agency. Individuals participating in the Utah program were invited to one meeting or the other.)

The workshops in Utah were designed as important yearly events - milestones in the program. Participation was open and well publicized. Lists of invitees and speakers, as well as the workshop agenda, were formulated by the steering committee, which was made up of representatives from the participating organizations. Workshop agendas were intended to involve the diverse interests in Utah in a way that would allow the exchange of new information that had been gathered through research and experience during the year. The other general objectives of the workshops were to

1. Set goals for research and implementation through consensus.

2. Energize participants, both in research and implementation communities.

3. Recruit allies and formulate advocates for earthquake hazard reduction.

Typically, workshops were a mix of formal presentations, small discussion groups, and informal gatherings. A quarterly newsletter, "The Wasatch Front," edited and published by UGS, communicated with participants in the program during the year and offered the participants an informal method of disseminating new findings and experiences. Proceedings of the workshops, which included a summary of the workshop, papers presented, small discussion group reports, and list of participants, were published 6 months to a year following each workshop.

\section{RESULTS FROM RECORDED CONVERSATIONS}

Leaders in the program were invited to share their thoughts regarding the role of the workshops at two luncheons held during the annual workshop in the summer of 1986. The first group consisted of scientists and the second of public officials and other nonscientists. The leaders were divided into two groups to make the conversations manageable and to give each individual a chance to focus on the conversation and to respond.

The following individuals took part in the conversations, which lasted approximately 11/2 hours each:

\section{GROUP I:}

David Schwartz, USGS, Menlo Park, Calif. (formerly Woodward Clyde Consultants)

Robert Smith, University of Utah, Dean, Department of Geology and Geophysies and formerly Director, University of Utah Seismograph Stations

Al Rogers, USGS, Branch Chief, Golden, Colo.

Jeff Keaton, Dames and Moore, Salt Lake City, Utah

Walter Hays, USGS, Office of Earthquakes, Volcanoes, and Engineering, Reston, Va.

Don Mabey, Deputy Director, UGS, Salt Lake City, Utah

Wendy Hassibe, USGS, Director, Public Information Office and Editor of Wasatch Front Forum, Salt Lake City, Utah

\section{GROUP II:}

Loren Anderson, College of Engineering, Utah State University, Logan, Utah

Ralph Finlay, ${ }^{2}$ CEM, Salt Lake City, Utah

Lawrence Reaveley, Reaveley Engineers and Associates, Inc., Salt Lake City, Utah

Walter Hays, USGS, Office of Earthquakes, Volcanoes, and Engineering, Reston, Va.

Genevieve Atwood, State Geologist and Director, UGS, Salt Lake City, Utah

Jim Tingey, CEM, Salt Lake City, Utah

Lorayne Tempest Frank, Director, CEM, Salt Lake City, Utah

Gary Johnson, FEMA, Washington, D.C.

Delbert Ward, Structural Facilities, Inc., Salt Lake City, Utah

Each group of leaders was asked to reflect on what happened at the workshops, what people they met, what they learned, and what they did differently following the workshop that they could attribute to what they learned. The two groups had similar views of the workshops, and therefore, their opinions will be reported together.

People responded to general questions or topics that the author had outlined, centering on the workshop's role in introducing new sources of information, research findings, and methodologies. Individuals spoke without

\footnotetext{
2 Deceased.
} 
much prompting or interference from the author except when it was necessary to move on to the next topic.

The leaders all remarked that the workshops gave them an opportunity to meet and communicate with new people. Individuals were able to identify those with information that they needed. Researchers met others conducting similar research, and they also met individuals whose work they knew but with whom they had never had a chance to talk. Researchers met the public officials and design professionals who depended on their work. Everyone met individuals from different parts of the country whom they might otherwise never have had the opportunity to meet. One Federal official stated that he met individuals from Utah whom he would call on to teach courses in other regions; he also stated that he would use demonstrations that he saw in the workshops at future training courses.

Both the researchers and practitioners agreed that the workshops were excellent forums to communicate with individuals "inside" and "outside" their fields. For some researchers, it was the first opportunity in their careers to hear from the users of scientific information. This opportunity resulted, in some cases, in redirection of the research into new areas. A university scientist stated that, from the workshops, he learned about scientific areas that were not being addressed and problems that needed to be solved. He therefore embarked on a new area of research in order to do something "brand new."

The workshop was seen as a mechanism to place individuals and their work into the larger program. Each year attendance at the workshop increased, and the areas of expertise and interest expanded. Local participants could see their relationship to Federal and State representatives, and vice versa. The contacts made in the workshop increased the likelihood that individuals would be called on during the year for assistance. A university scientist stated that he could not overestimate the importance of making contacts with people with common objectives. Contacts formed at the workshops made it easier to approach those people later for information or to get problems solved.

For the participants, especially the local scientists and design professionals, the workshops brought them "upto-date" quickly. The Director of UGS stated that the workshops gave her and her staff an opportunity to be up-to-date on scientific research. A geotechnical engineer stated that the workshop gave him an opportunity to have one-on-one discussions with scientists he may never have met. The workshops allowed the local scientists at UGS to learn what USGS scientists were discovering and what university and individual researchers funded by USGS were learning.

The researchers valued the time constraint that the workshops placed on them, forcing them to put their findings down on paper for everyone to review. At the same time, the workshops gave the scientists a regional forum in which to relate their findings and an immediate method of disseminating their results. A university scientist remarked that the workshops may have lowered the cost of the program by getting "more bang for the buck," in that the workshops inspired other research that the university undertook on its own. An architect stated that the workshop brought the participants new information in a meaningful way because it showed them how to use that information. A university scientist remarked that, as a result of the workshop, he changed the earthquake engineering course that he teaches. An emergency manager stated that not only did the workshops keep him "current," but they made his job easier, especially in his contacts with the news media.

The conversations reinforced the theories previously discussed. The leaders emphasized the importance of the workshops to introduce the participants and their research, experiences, and responsibilities to each other. A representative from UGS stated that the workshops were a bonding experience, and a university scientist stated that the workshops served as a forum to present work, get recognition, and interact with people who would use the information. A practicing architect identified the important aspect of the workshop as the "driving mechanism for coordination of random research." Finally, representatives from the State government stated that the intangible benefit of the workshops was the commitment they instilled in the participants to the goals of the program.

The scientists valued the sense of involvement in reducing hazards. They were cajoled into putting their results into a form that would be usable to planners. A scientist from the Federal government stated that scientists were forced to talk to planners in a hitherto unaccustomed lay language. A university professor related his experience of sitting down with an engineer and showing him how to use the data in his model.

The proceedings of the workshops were also seen as important topical references of what was being done in Utah and by whom. Conversations with the leaders in the program showed that they valued the workshops not only as arenas to meet new people and learn new ideas, but as an essential ingredient in the overall program, coordinating and focusing the research, expanding the uses of the research, focusing the participants on the goals of the program, and finally, tying the program and its diverse participants together.

\section{RESULTS FROM QUESTIONNAIRE}

Participants were asked to assist in evaluating the role of the workshops by completing a questionnaire mailed 
late in 1986. (See Appendix A for a copy of the questionnaire.) The mailing list for the Wasatch Front Forum newsletter was used because it included all past workshop participants and others interested in earthquake hazards in the Wasatch Front. (Individuals who had attended the luncheons and recorded conversations were not mailed a questionnaire.) Of the 250 questionnaires mailed, 91 responses were received ( 79 from individuals who had attended one or more workshops and 13 from individuals who had not attended the workshops). Only the responses from those who attended the workshops were used for this study. Some respondents chose not to answer all questions, and respondents were not asked to identify themselves. The response rate was approximately 37 percent. Responses to the questionnaire were used to corroborate opinions that the leaders had expressed in the recorded conversations.

Respondents represented all sectors of the Utah earthquake hazards community in terms of affiliation and profession. Most respondents worked for a county, city, or State government agency; however, many worked for the Federal Government, a university, or the private sector. The following is a breakdown of how the respondents characterized their workplaces:

$\begin{array}{lr}\text { City or county } & 24 \\ \text { State } & 20 \\ \text { Federal Government } & 17 \\ \text { University } & 9 \\ \text { Private } & 9\end{array}$

Respondents represented many different disciplines involved in the program. The majority were scientists and engineers, but there was a good response from land-use planners and emergency service professionals. Respondents described their agency or office as follows:

$\begin{array}{lr}\text { Scientific } & 25 \\ \text { Planning } & 21 \\ \text { Emergency services } & 14 \\ \text { Geotechnical engineering } & 8 \\ \text { Structural engineering } & 3 \\ \text { Building department } & 1 \\ \text { Architectural } & 1 \\ \text { Other } & 6\end{array}$

Most of the respondents had attended two or three workshops, although many had attended only one, and a smaller number had attended all four. The responses were as follows:

$\begin{array}{lr}\text { Attended } 1 \text { workshop } & 24 \\ \text { Attended } 2 \text { workshops } & 27 \\ \text { Attended } 3 \text { workshops } & 19 \\ \text { Attended } 4 \text { workshops } & 9\end{array}$

Participants in the workshops were asked questions concerning who they met at the workshops, what they learned at the workshops, and what use they made of their new contacts and information. In addition, they were asked a series of questions to document what other needs and functions the workshops fulfilled.

Most respondents met new people within their field at the workshops. Of the respondents, 41 met between 1 and 5 new individuals, 15 met between 6 and 10, and 9 met more than 10 . Only 14 individuals responded that they met no one new in their own field at the workshops. The new people the respondents met were from the following locations:

$\begin{array}{ll}\text { Salt Lake City } & 42 \\ \text { Other parts of Utah } & 30 \\ \text { Washington, D.C. } & 27 \\ \text { Other parts of country } & 28\end{array}$

Denver and California were mentioned frequently under "other parts of country." The concentration of responses in Utah and Salt Lake City (72) points out that attendees of the workshops (the majority of whom were from Utah and Salt Lake City) met other individuals in their field of interest who were from the Wasatch Front study area. In fact, when asked if they had called on these new contacts after the workshops, 48 individuals responded that they had contacted between 1 and 10 or more individuals for information. The responses were as follows:

$\begin{array}{lr}\text { Contacted none } & 31 \\ \text { Contacted } 1-5 & 40 \\ \text { Contacted } 5-10 & 6 \\ \text { Contacted } 10 \text { or more } & 2\end{array}$

The respondents were also asked how many new people they met at the workshops from other fields. The majority of individuals met more new people outside than within their own fields. Only four individuals stated that they met no one new outside their own discipline. Twenty respondents met over 10 new individuals, 21 met between 6 and 10 new individuals, and 34 met between 1 and 5 new individuals outside their own field. Respondents were asked to identify one or more of the following disciplines as the fields represented by the new individuals:

\section{Scientific}

Geotechnical engineering

Structural engineering

Architecture

Planning

Emergency services

Building department

Other

The respondents selected between zero and 8 areas from which they met new individuals. Of these, 34 met individuals in 2 or 3 other disciplines, 31 met individuals in 4 or 6 other disciplines, and 5 met individuals in 7 or 8 new fields. The actual responses are as follows: 
No new disciplines

1 new discipline

2 new disciplines

3 new disciplines

4 new disciplines

5 new disciplines

6 new disciplines

7 new disciplines

8 new disciplines
4

5

16

18

15

11

5

3

2

A major conclusion of the questionnaire is that a large number of participants at the workshops met individuals outside their immediate profession or discipline.

Respondents were then asked to rank new sources of information they encountered at the workshop. The responses were grouped into very useful, useful, and not useful. To be counted as very useful, an answer would need to use an adjective such as extremely, very useful, or, in some cases, contain an explanation as to how the information was subsequently used. To be characterized as useful, the respondent would need to use adjectives such as helpful or useful. No response to the question or responses with "not" as the adjective were characterized as not useful. Of the respondents, 38 characterized their new sources of information as very useful, 17 as useful, and 24 as not useful or not a source.

Explanations of how the new information sources were used were also given by respondents. A Utah State scientist stated that it was "extremely useful to meet and ask questions of authors of reports he had previously read." An official from a Utah State emergency services department stated, "Even though we receive the printed material in our office, the people making the presentations added to my understanding of the earthquake threat." A geotechnical engineer with the State wrote, "The contacts have been useful in exchanging information and acquiring technical assistance." Another individual with the State emergency services department commented, "I refer questions to contacts that I have made or back up my reply with a reference to such a contact. Also, I ask people whom I met at the workshops to speak at local workshops." A local land-use planner said that he has a "better idea of what agencies I can contact for assistance or technical expertise." And finally, a journalist answered that the workshops provided "new sources for news stories and personal contacts with people who had previously been only names."

Many of the Federal scientists at the workshop also found the new contacts useful. A Federal scientist stated, "The workshops were most helpful in knowing who's doing what in Utah. Being located out of Salt Lake City is a hindrance, so this aspect of workshops is very beneficial." Another Federal scientist found the workshops to be useful for "renewing contacts with colleagues

in order to remain current on the directions and results of their research."

Approximately two-thirds of the participants responding to the questionnaire characterized the new contacts they met at the workshop as useful, and many of these contacts were from different fields. Thus respondents agreed with the leaders' recorded conversation about meeting new people at the workshops.

Participants were also questioned about new information obtained at the workshop. In terms of earthquake hazards in Utah, respondents were specifically asked to identify new information they had acquired about segmentation of the Wasatch fault system, recurrence intervals, maximum size of the expected earthquakes, the characteristic earthquake, liquefaction, and landslides. Of those who responded, 63 were capable of describing, in their own words, much of the new information that they acquired. Of these, 45 were able to identify and describe one or more of the above topics, and 18 identified only one; 16 were either unable or did not attempt to answer the question. With 80 percent of those responding to the questionnaire capable of stating what they learned, the workshop participants, like the leaders in the program, clearly came away with new knowledge about the earthquake hazards of the Wasatch Front.

It is important for new information to be applied if it is to be of value. Therefore, participants were asked if they used the information in their research, job, or private life. Of the 62 individuals (approximately 80 percent) who stated that they had an opportunity to apply the new information, 50 used the information on the job, 30 in research, and 18 in private life.

Nearly two-thirds of the respondents found the information learned at the workshops to be useful. Of those who responded, 41 characterized the information as very useful, 12 as somewhat useful, and 26 as not useful or no response. The following comments exemplify how the new information was used. A building department official stated that he used the new information in "siting new State buildings and preparing environmental assessments." A State land-use planner said that the new information was used in "promoting a comprehensive earthquake hazard mitigation program." A State emergency services official used the information to "better inform the public and private industry of the possibility of damage to their particular facilities and how they might mitigate such damage." A Federal scientist used the information in a risk-based evaluation of dams. Another Federal scientist stated, "The awareness of other researchers' work has contributed to applying new ideas to my area of study." A university scientist bought earthquake insurance after attending one of the workshops, and a county land-use planner used the information to design a sensitive-land ordinance for geologic 
hazards and to designate which areas would require regulation.

Finally, the respondents were asked what other needs and functions the workshops fulfilled. They were asked to respond to a list of statements by ranking their answers from 1-5, with 1 representing low agreement and 5 representing high agreement with the statement. By selecting 5, 4, or 3 , more than 80 percent of the respondents registered their beliefs that the workshops:

- Enhanced appreciation of other disciplines.

- Provided focus for news media.

- Enhanced public awareness of earthquake hazards.

- Provided a forum for recognition of individual research.

- Set an agenda for research.

- Provided a timely document for research or implementation (the proceedings).

- Renewed commitment to solving problems or implementing policy.

The majority of respondents did not believe that the workshops "provided a deadline for adoption of mitigation" nor that they "provided a deadline for completion of research." However, most respondents (27 and 32, respectively) gave these questions a rank of 3 . The actual responses to all the statements follow.

Workshops also may have fulfilled other needs and functions for you, your community, or State. Please rate how well the workshops may have contributed to the following: $\begin{array}{cccccc}\text { Low } & & & & \text { High } \\ 1 & 2 & 3 & 4 & 5\end{array}$

1. Enhanced appreciation of other $\begin{array}{lllllll}\text { disciplines................... } & 0 & 6 & 20 & 7 & 15\end{array}$

$\begin{array}{lllllll}\text { 2. Provided focus for news media .... } & 1 & 14 & 18 & 29 & 15\end{array}$

3. Enhanced public awareness of $\begin{array}{lllllll}\text { earthquake hazards. ............. } & 3 & 9 & 23 & 27 & 17\end{array}$

4. Provided forum for recognition of

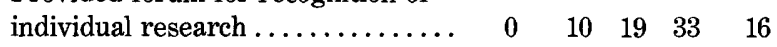

5. Set agenda for research.......... $\quad 1 \quad \begin{array}{rrrrrr}9 & 1 & 28 & 25 & 8\end{array}$

6. Set agenda for action ...........

7. Provided deadline for completion of research......................

8. Provided deadline for adoption or implementation of policy ..........

9. Provided a timely document for research and/or implementation (the proceedings)................

10. Renewed commitment to solving problems or implementing policy...

$\begin{array}{lllll}6 & 16 & 32 & 2 & 5\end{array}$

$\begin{array}{lllll}9 & 2 & 27 & 7 & 3\end{array}$

$\begin{array}{lllll}0 & 8 & 20 & 34 & 11\end{array}$

The respondents were also asked to list other contributions, not previously addressed, that the workshops may have made. Most respondents chose not to answer the question; however, of the 11 who answered, nine identified contributions to understanding and two identified contributions to research. The following are some of the Federal scientists' comments.
- I gained appreciation of the need for clearer communication of scientific results in terms that users can understand and apply.

- I understand better than before the importance of subtleties of implementing scientific information.

- From a scientific point of view, the information was very useful to me. Focused scientific sessions which bring together people who are working on the same problem or related problems are much more effective means of communication than ordinary scientific meetings.

A university geotechnical engineer and a private structural engineer stated:

- The workshops provided opportunity to determine what was needed by nontechnical people regarding geotechnical issues.

- Without the workshops, the Utah community would be years behind in seismic awareness and planning issues.

Possibly one of the best explanations of the role of the workshops was expressed by a State planner:

\begin{abstract}
Workshops provide one of the few forums where individuals from many disciplines can exchange information and ideas directed toward a specific goal. Through concerned experts, earthquake problems and solutions have been better defined. For myself, the contacts with these experts instill confidence and reassurance that I can influence earthquake hazard mitigation.
\end{abstract}

\section{CONCLUSION}

The survey of participants was conducted to gage whether leaders' opinions were shared by the participants. The respondents' answers to the questionnaire were indeed similar to those expressed by the leaders. According to the participants' responses, the workshops served as arenas where individuals met others working on earthquake hazard reduction in the Wasatch Front. The individuals expanded their circle of colleagues to include individuals from other disciplines, other agencies, and other regions of the country. The new sources of information were contacted for many reasons, and most of the respondents judged these contacts useful.

Like the leaders, the participants learned new information about earthquake hazards in the Wasatch Front and used the information in their research, their jobs, and their private lives. The respondents' explanations of how they used the information replicated many of the statements made by the leaders of the program. Like the leaders, the participants believed that the workshops fulfilled a role of broadening their appreciation and understanding of the many different disciplines and individuals involved in the program. The respondents agreed also that the workshops provided a forum for recognition of individual researchers, as well as a method for disseminating timely information in the form of workshop proceedings. Many individuals also saw the workshops as tools for influencing the research agenda. In terms of increasing awareness and commitment to 
solving problems and implementing policy, most participants gave high marks to the workshops, as did the program leaders.

The representatives of institutions involved in planning earthquake hazards research and reduction programs were correct to give the annual workshops a prominent role in the program. The interviews and questionnaires verified the effectiveness of interaction between researchers and users of research and the use of workshops to encourage implementation. The workshop process set up a "marketplace" of ideas that did not begin or end with the workshop itself, but was carried on throughout the 5-yr program. What individuals gained at the workshops and how contacts and information were later applied in research and implementation activities lead to the conclusion that the workshop process was an invaluable element in the 5-yr program. Any plans for future, complex, multidisciplinary programs would do well to follow the example of this program and incorporate the use of frequent interactive workshops.

The use of workshops was valuable to the earthquake hazards research and reduction program. The workshop process also may have facilitated the incorporation of hazards information into public and private practice. This assessment can only take place after sufficient time has elapsed to allow for implementation of public and private policy. The evaluation of the influence of the earthquake hazards research and reduction program focused in the Wasatch Front will be an important future research topic.

\section{REFERENCES}

Bagwell, J.B., 1988, Application of the National Earthquake Hazards Reduction Program through an earthquake education center at Charleston, South Carolina, in Hays, W.W., ed., A review of earthquake research applications in the National Earthquake Hazards Reduction Program, 1977-1987: U.S. Geological Survey Open-File Report 88-13A, p. 106-114.

Glaser, E.M., Abelson, H.H., and Garrison, K.N., 1983, Putting knowledge to use, Facilitating the diffusion of knowledge and implementation of planned change: San Francisco, Jossey-Bass, $636 \mathrm{p}$.

Greene, M.R., and Gori, P.L., 1982, Earthquake hazards information dissemination, A study of Charleston, South Carolina: U.S. Geological Survey Open-File Report 82-233, $57 \mathrm{p}$.

Hays, W.W., ed., 1988, A review of earthquake research applications in the National Earthquake Hazards Reduction Program, 1977-1987: U.S. Geological Survey Open-File Report 88-13A, $583 \mathrm{p}$.

Hays, W.W., and Gori, P.L., 1984, Regional and urban earthquake hazards, evaluation, Wasatch Front, Utah, Draft work plan, FY 84-85, in Hays, W.W., and Gori, P.L., eds., Proceedings of conference XXVI, A workshop on "Evaluation of regional and urban earthquake hazards and risk in Utah": U.S. Geological Survey Open-File Report 84-763, p. 17-22.
Johnston-Fischer, P., 1988, Earthquake vulnerability and risk ass'ssment in the U.S. Virgin Islands, in Hays, W.W., ed., A reviev of earthquake research applications in the National Earthquake Hazards Reduction Program, 1977-1987: U.S. Geological Survey Open-File Report 88-13A, p. 309-314.

Lindbergh, C., 1988, Southeastern United States, in Hays, W.W., ed., A review of earthquake research applications in the National Earthquake Hazards Reduction Program, 1977-1987: U.S. Geological Survey Open-File Report 88-13A, p. 118-129.

Marlow, H.L., 1984, Another perspective on technology transfer-'The PENNTAP experience, in U.S. Department of Energy, Proce edings, A synthesis of technology transfer methodologies, Ui.S. Department of Energy Technology Transfer Workshop: Washington, D.C., U.S. Department of Energy, p. 135-160.

Molinelli-Freytes, J., 1988, The earthquake vulnerability study for the metropolitan area of San Juan, Research applications, in Hays, W.W., ed., A review of earthquake research applications in the National Earthquake Hazards Reduction Program, 1977-1987: U.S. Geological Survey Open-File Report 88-13A, p. 304-308.

Nigg, J.M., 1988, Framework for understanding knowledge dissemination and utilization, Applications for the National Earthquake Hazards Reduction Program, in Hays, W.W., ed., A review of earthquake research applications in the National Earthquake Hazards Reduction Program, 1977-1987: U.S. Geological Survey Open-File Report 88-13A, p. 13-33.

Office of Science and Technology Policy, 1978, Earthquake hazards reduction, Issues for an implementation plan: Washington, D.C., Executive Office of the President, $229 \mathrm{p}$.

Olson, N.K., 1988, Applications: Seismic safety organizations-South Carolina seismic safety consortium, in Hays, W.W., ed., A review of earthquake research applications in the National Earthquake Hazards Reduction Program, 1977-1987: U.S. Geological Survey Open-File Report 88-13A, p. 259-271.

Robbins, M.D., 1984, Technology transfer-an overview, in U.S. Department of Energy, Proceedings, A synthesis of technology transfer methodologies, U.S. Department of Energy Technology Transfer Workshop: Washington, D.C., U.S. Department of Energy, p. 65-76.

Trager, R.L., 1984, Technology transfer revisited, in U.S. Department of Energy, Proceedings, A synthesis of technology transfer methodologies, U.S. Department of Energy Technology Transfer Workshop: Washington, D.C., U.S. Department of Energy, p. 173-200.

U.S. Department of Energy, 1984, Proceedings, A synthesis of technology transfer methodologies, U.S. Department of Energy Technology Transfer Workshop: Washington, D.C., U.S. Department of Energy, $432 \mathrm{p}$.

Whitehead, C., 1988, Earthquake hazards research applications in Kentucky, in Hays, W.W., ed., A review of earthquake research applications in the National Earthquake Hazards Reduction Program, 1977-1987: U.S. Geological Survey Open-File Report 88-13A, p. 315-319.

Yin, R.K., and Andranovich, G.O., 1987, Getting research used in the natural hazards field, The role of professional associations: Washington, D.C., Cosmos Corporation, p. 1-172.

Yin, R.K., and Gwaltney, M.K., 1981, Knowledge utilization as a networking process, in Knowledge, Creation, diffusion, utilization, vol. 2, no. 4: Beverly Hills, Calif., Sage Publications, Inc., p. 555-580.

Yin, R.K., and Moore, G.B., 1985, The utilization of research, Lessons from the natural hazards field: Washington, D.C., Cosmos Corporation, $101 \mathrm{p}$. 


\title{
APPENDIX A
}

\section{United States Department of the Interior}

\author{
GEOLOGICAL SURVEY \\ RESTON, VA. 22092
}

In Reply Refer To:

Mail Stop 905

November 24,1986

Dear Colleague:

For the past 3 years, the Wasatch front has been the focus of an integrated seismic hazard assessment study. The study has been conducted by the U.S. Geological Survey in cooperation with the Utah Geological and Mineral Survey. Many other government agencies, universities, and practicing architects and engineers have taken part in this study which has 3 principal goals:

1) Determination of recurrence rates and maximum size of earthquakes.

2) Estimation of the nature and severity of the expected ground shaking.

3) Identification and mapping of areas where earthquake ground shaking may induce landslides, liquefaction, settlement, and other ground failures.

In conjunction with the study, workshops were held annually since 1984 in Salt Lake City to review each year's accomplishments, identifying program needs, and stimulating research and implementation of research findings. Currently I am evaluating the role these workshops played in facilitating the progress of the integrated seismic hazards assessment study in the Wasatch front.

To understand what role the workshop process has played, I am requesting your help. Please take a few minutes to answer the questions on the following pages and return the entire form in the enclosed self-addressed stamped envelope by December 19, 1986.

This systematic survey of researchers, public officials, and private individuals active in the three-year effort in the Wasatch front will form the basis of a publication on the role of the workshops and also contribute to planning future integrated seismic hazard assessment studies in other regions of the country.

Thank you for responding to this survey and returning it promptly.

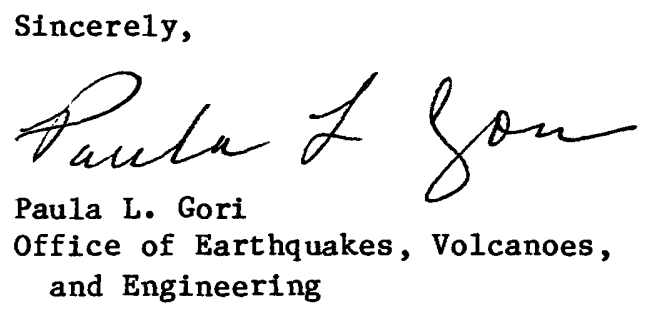

Enclosure 


\section{Wasatch Front Questionnaire}

1) How would you best describe your agency or office:

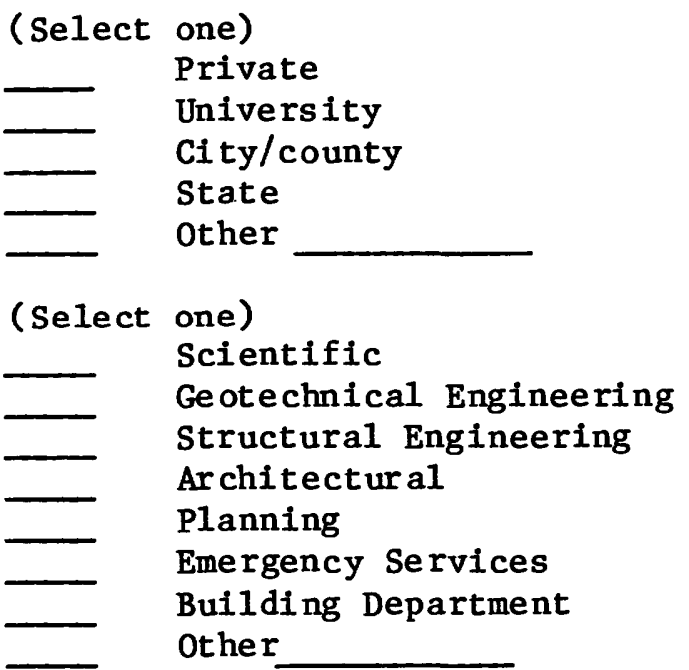

2) Which of the following workshops or meetings did you attend?

(Select one or more)

August 14-16, 1984; Workshop on "Evaluation of Earthquake Hazards and Risk in Utah."

July 10-11, 1985; Workshop on "Earthquake and Landslide Hazards in the Wasatch Front Region of Utah," (hosted by Utah Geological and Mineral Survey).

July 30-September 1, 1985; Workshop on "Earthquake and Landslide Hazards in the Wasatch Front Region of Utah," (hosted by Utah Division of Comprehensive Emergency Management).

July 14-18, 1986; Workshop on "Earthquake Hazards Along the Wasatch Front, Utah."

3) At the workshop(s) did you meet people in your field whom you had never met previously?
- yes
no
about how many

4) Where were these people from?

(Select one or more)

Salt Lake City Area __ Utah

Washington, D.C. Area $\longrightarrow$ Other

5) Have you had an opportunity to call on any of these people in your field for information? 
6) At the workshop did you meet people in other fields whom you had never met previously?

yes no no about how many

7) What fields did these people represent?

(Select one or more)

scientific

- geotechnical engineering

- structural engineering

- architectural

- planning

- emergency services

- building department

other

8) Please comment on the usefulness of any of the new sources of information (i.e., experts, colleagues, etc.) who you met at the workshop(s).

9) At the workshop(s) did you learn something new about earthquake hazards in Utah?

- yes

10) Please state in a few words some of these new ideas.

11) Have you had an opportunity to apply any of the new information?

yes

12) How?

In your research?

In your job?

In your private life? 
13) Please comment on the usefulness of this information.

14) Workshop(s) also may have fulfilled other needs and functions for you, your community, or state. Please rate how well the workshop(s) may have contributed to the following:

(where 1 is the lowest and 5 is the highest rating.)

$$
\begin{array}{ccccc}
\text { Low } & & & \text { High } \\
1 & 2 & 3 & 4 & 5
\end{array}
$$

1) Enhanced appreciation of other disciplines.......... 1 2 3445

2) Provided focus for news media...................... 124345

3) Enhanced public awareness of earthquake hazards...................................... 12434

4) Provided forum for recognition of individual research....................................... 12234

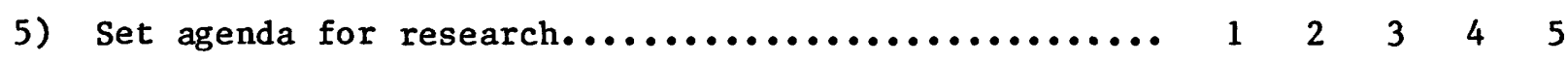

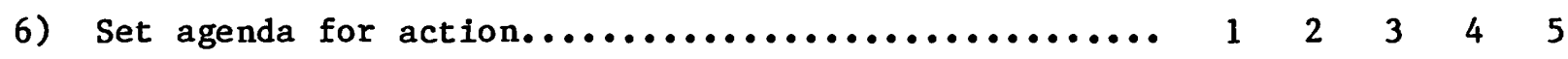

7) Provided deadline for completion of research......... 1 2 23445

8) Provided deadline for adoption or implementation of policy.................................... 12 34

9) Provided a timely document for research and or implementation (the proceedings).............. 1 2 3445

10) Renewed committment to solving problems or implementing policy......................... 12234

11) Please list other contributions workshop(s) may have had which have not been addressed above. 


\title{
REDUCING EARTHQUAKE HAZARDS IN UTAH: THE CRUCIAL CONNECTION BETWEEN RESEARCHERS AND PRACTITIONERS
}

\author{
By William J. Kockelman
}

\begin{abstract}
Complex scientific and engineering studies must be translated for and transferred to nontechnical personnel for use in reducing earthquake hazards in Utah. The three elements needed for effective translation, likelihood of occurrence, location, and severity of potential hazards, and the three elements needed for effective transfer, delivery, assistance, and encouragement, are described and illustrated for Utah. The importance of evaluating and revising earthquake hazard reduction programs and their components is emphasized. More than 30 evaluations of various natural hazard reduction programs and techniques are introduced.

This report was prepared for research managers, funding sources, and evaluators of the Utah earthquake hazard reduction program who are concerned about effectiveness. An overview of the Utah program is provided for those researchers, engineers, planners, and decisionmakers, both public and private, who are committed to reducing human casualties, property damage, and interruptions of socioeconomic systems.
\end{abstract}

\section{INTRODUCTION AND PURPOSE}

Effective comprehensive programs having earthquake hazard reduction as a goal need five components, each a prerequisite for its successor:

1. Conducting scientific and engineering studies of the physical processes of earthquake phenomena, including source, location, size, likelihood of occurrence, severity, triggering mechanism, path, ground response, and the effects on man-made structures and equipment.

2. Translating the results of such studies into reports and onto maps at an appropriate scale so that the nature and extent of the hazards and their effects are understood by nontechnical users.

3. Transferring this translated information to those who will or are required to use it, and assisting and encouraging them in its use through educational, advisory, and review services.

4. Selecting and using appropriate hazard reduction techniques, such as legislation, regulations, design criteria, education, incentives, public plans, and corporate policies.
5. Evaluating the effectiveness of the hazard reduction techniques after a period of use and making revisions, if necessary. Evaluation and revision of the entire program as well as the basic studies and the translation and transfer components may also be undertaken.

These five components (fig. 1) encompass a broad range of activities that are often described or divided differently. Examples include the 48 resolutions by the United Nations Educational, Scientific, and Cultural Organization (1976), six general topics and 37 issues by the U.S. Office of Science and Technology Policy (1978), 48 detailed initiatives recommended by the California Seismic Safety Commission (1986), and 171 action items at a state governor's conference on geologic hazards (Utah Geological and Mineral Survey, 1983).

The purpose of this report is to emphasize the crucial connection between scientific and engineering studies and their ultimate use for hazard reduction by Utahans. The connection consists of two of the five components shown in figure 1: translation and transfer. Emphasis on this crucial connection is provided by a discussion of the problem-failure to translate and transfer-and efforts toward making the connection in Utah. Translation and transfer are defined, described, and then illustrated, first by the use of general examples and then by the use of specific examples in Utah.

\section{SCIENTIFIC AND ENGINEERING STUDIES}

A prerequisite for a successful Utah earthquake hazard reduction program is adequate and reliable scientific and engineering information about potential earthquake hazards-surface-fault rupture, ground shaking, liquefaction, landsliding, seiches, tsunamis, subsidence, and the effects of each. Actual hazards occur when land uses, structures, or equipment are located, constructed, or operated in such a way that people may be harmed, 


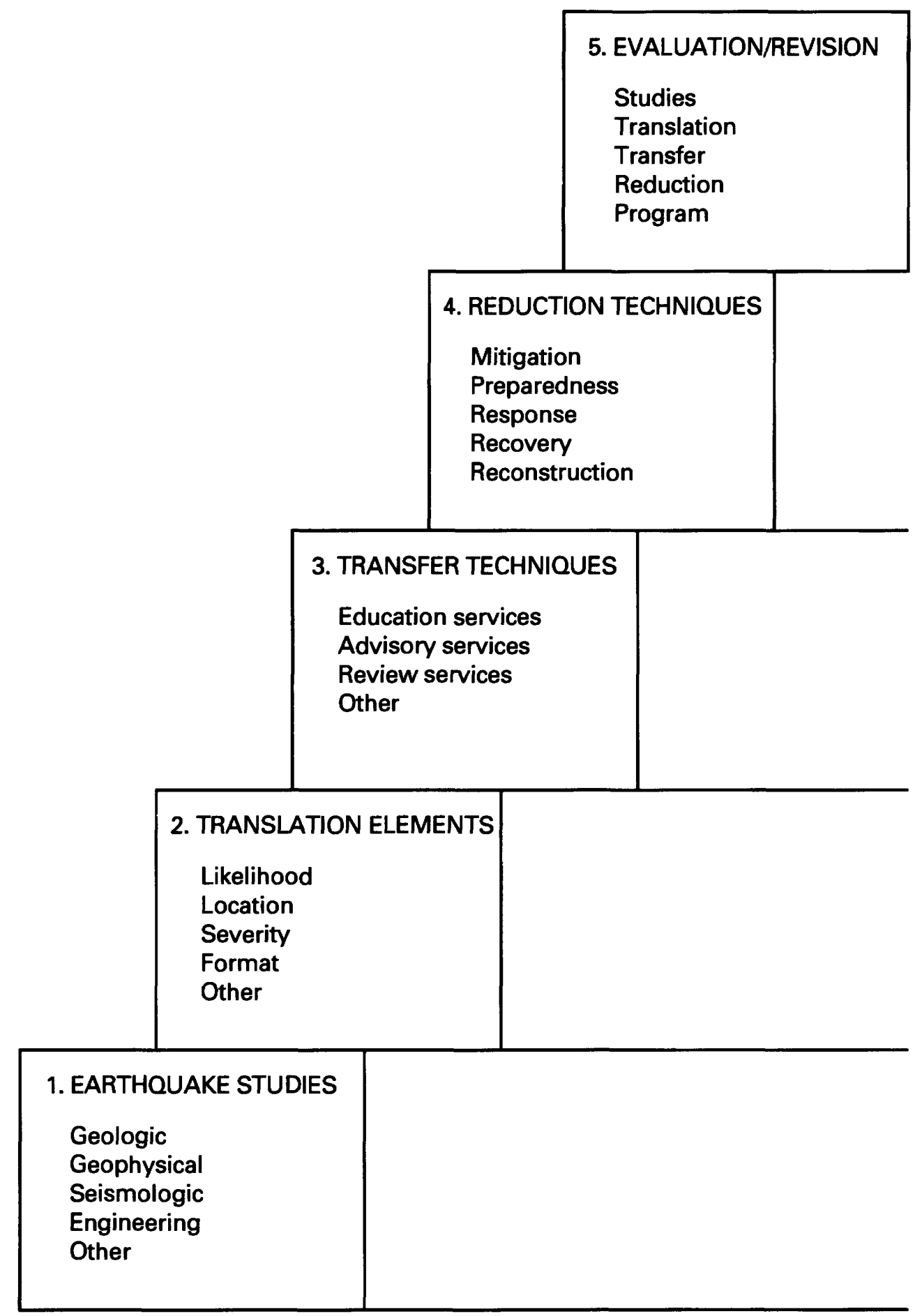

FIGURE 1.-Five components needed for an effective comprehensive earthquake hazard reduction program. The components are depicted as steps or building blocks, each a prerequisite for its successor.

their property damaged, or their socioeconomic systems interrupted.

Numerous geologic, geophysical, seismologic, and engineering studies are necessary to assess potential earthquake hazards in Utah. These studies are con- cerned with the physical process of earthquakes, including source, location, size, likelihood of occurrence, triggering mechanism, path, and severity of effects on a site, man-made structure, or socioeconomic activity. These studies can be divided in several ways. To give the 
nontechnical reader an overview, some of the studies and the knowledge derived are shown in list 1.

A description of many of these studies can be obtained from perusing various scientific and technical reports and texts, such as Richter (1958), Wallace (1974), Borcherdt (1975), Applied Technology Council (1978), Hays (1980), Ziony (1985), Power and others (1986), Evernden and Thomson (1988), and Schwartz (1988). Most of these studies are complex and interconnected, have limitations because of lack of data, and require special technical skills.

Many of these studies were envisioned and are described in the "Regional Earthquake Hazards Assessments" draft work plan for the Wasatch Front. This plan was reproduced in a workshop proceedings edited by Hays and Gori (1984, p. 17-44). The results of those studies may be seen in a two-volume report edited by Gori and Hays (1987).

Such studies are vital because, in the words of former U.S. Geological Survey director Walter C. Mendenhall, "There can be no applied science unless there is science to apply." It has been my experience that it is not prudent for planners to develop land-use regulations, engineers to design structures, and lenders and public works directors to adopt policies reducing earthquake hazards without reliable scientific and engineering assessments. Hanks (1985, p. 3) observes that "implementation plans may not mean much if they are not based on the best scientific knowledge and data available."

\section{HAZARD REDUCTION TECHNIQUES}

Numerous earthquake hazard reduction techniques are available in Utah to engineers, planners, and decisionmakers, both public and private. These techniques are specifically aimed at awareness of, avoidance of, accommodation to, or response to the effect of earthquake phenomena on people, land use, structures, and socioeconomic systems. The general goal of these objectives is to reduce human casualties, property damages, and socioeconomic interruptions.

Many of the reduction techniques are also complex, are interconnected, and require special skills-legal, financial, legislative, design, economic, communicative, educational, political, and engineering. To give the reader an overview, examples of specific reduction techniques are shown in list 2 . These techniques can be divided in other ways, such as the following:

- Mitigation techniques before an event, which may take 1 to $20 \mathrm{yr}$.

- Preparedness measures before an event, which may take 1 to 20 weeks.

- Response during and immediately after an event.
- Recovery operations after an event, which may take 1 to 20 weeks.

- Reconstruction activities after an event, which may take 1 to $20 \mathrm{yr}$.

These estimated time periods vary, depending on the postulated or actual size of the earthquake, the damage, the reduction techniques in place, and the resources available to the State of Utah, its communities, its corporations, and its families.

Many of the hazard reduction techniques identified in this report have been discussed and illustrated by Blair and Spangle (1979), Kockelman and Brabb (1979), Brown and Kockelman (1983), Kockelman (1985, 1986), Jochim and others (1988), Mader and Blair-Tyler (1988), BlairTyler and Gregory (1988), and the United Nations Office of the Disaster Relief Coordinator (Lohman and others, 1988).

\section{UTAH'S DRAFT WORK PLAN}

A collective partnership of Utahans and others in 1983 created a unique State earthquake hazard reduction program. The formulators of the draft work plan for the Wasatch Front not only envisioned the use of scientific and engineering studies to reduce the hazard but also provided for an "implementation" component having three priorities: (1) determining the needs of users, (2) producing translated information that meets the need, and (3) fostering an environment for use of research results by local government. For the purpose of this report, users are defined as those who are interested in or who have responsibility for reducing earthquake hazards.

Examples of specific techniques to reduce hazards (list 2) and potential users of earthquake hazard information (list 3) were compiled. The reduction techniques most appropriate for Utah were to be selected by these users. These techniques and users were included in the draft work plan reproduced by Hays and Gori (1984, p. 37-44). The adopted work plan provides a bench mark for evaluating its accomplishments.

\section{IMPLEMENTATION UNDER WAY}

Descriptions and illustrations of the reduction techniques are beyond the scope of this report. However, many techniques were selected and successfully used or are pending in Utah. Descriptions of some of them may be seen in the volumes edited by Gori and Hays (1987, 1988). A model natural hazards reduction ordinance drafted by the Salt Lake County planning staff (Barnes, 1988a, b) has been adapted and adopted by the city of Washington Terrace. 
List 1. - Examples of scientific and engineering studies necessary to assess earthquake hazards

\begin{tabular}{cc}
\hline Study & Knowledge derived \\
\hline Geologic \\
\hline
\end{tabular}

Detailed geologic mapping

Lithologic investigations

Stratigraphy

Borehole sampling

Trenching

Paleontology

Scarp analysis

Stream offsets

Geomorphologic studies

Structural geology
Fault slip rates, physical properties, fault length, fault age, fault geometry, bedrock strength, zones of deformation, amplification of ground motion, lateral and vertical offsets, earthquake recurrence intervals, earthquake sources, depth to ground water, fault location, bedrock types, deformation patterns, plate tectonics context, driving forces, and other knowledge concerning surface rupture, ground shaking, landsliding, liquefaction, seiches, tsunamis, and subsidence.

\begin{tabular}{lc}
\hline & Geophysical/Geochemical \\
\hline Geodetic leveling and trilateration & Precursor detection, ongoing deformation, fault zone properties, \\
Field monitoring & recurrence intervals, shear wave velocity, stress accumulation, \\
Stress and strain & crustal anatomy, crustal properties, wave attenuation, crustal \\
Tilt and creep & velocity model, ground-motion characteristics, deformation pat- \\
Electrical changes & terns, buried faults or structure locations, and three-dimensional \\
Radon/helium emissions & crustal geometry. \\
Water chemistry changes &
\end{tabular}

Water-well levels

Electromagnetic soundings

Gravity, electrical, and magnetic studies

Seismic refraction and reflection profiling

Radiometric dating

\begin{tabular}{ll}
\hline & \multicolumn{1}{c}{ Seismologic } \\
\hline Historical seismicity & Asperity locations, velocity, severity of shaking, acceleration, \\
Earthquake monitoring & displacement, seismic gaps, source zones, fault mechanism, rup- \\
Strong ground-motion monitoring & ture direction, seismic direction, recurrence interval, epicenters, \\
networks & epicentral intensity, fault type, fault length, fault width, maxi- \\
Ground response & mum probable magnitude, seismic hazard zones, rupture charac- \\
Seismic wave propagation & teristics, seismic moment, stress drop, local amplification, dura- \\
Segmentation analyses & tion of shaking, focal mechanism and depth, and response \\
Wave propagation & spectrum.
\end{tabular}

Rupture process

\section{Engineering}

Structural mechanics

Engineering characteristics

Risk analysis

Monitoring of structures

Damage inventories

Soil-structure interaction

Structural vulnerability

Soil mechanics

Rock mechanics

Soil/rock acoustic impedance

Standard penetration tests

Notes

These are just some of the studies that are necessary to assess earthquake "hazards"; many other types of studies are necessary to evaluate "vulnerable" structures, "secondary" hazards (fires, floods, and toxin spills), people "exposed," and socioeconomic activities "at risk."

The term "studies" is loosely used here to include experiments, measurements, investigations, observations, models, techniques, analyses, mapping, monitoring, or testing. Many of the seismologic studies are a special type of geophysical research.

Robert Brown, geologist, Robert Simpson, geophysicist, Allan Lindh, seismologist, and Mehmet Celebi, structural engineer, U.S. Geological Survey, provided critical comments and valuable suggestions that have refined and improved this list. However, because of its abbreviated form, the author remains responsible for omissions and errors. 


\section{List 2. - Examples of techniques for reducing earthquake hazards in Utah}

\begin{tabular}{|c|}
\hline 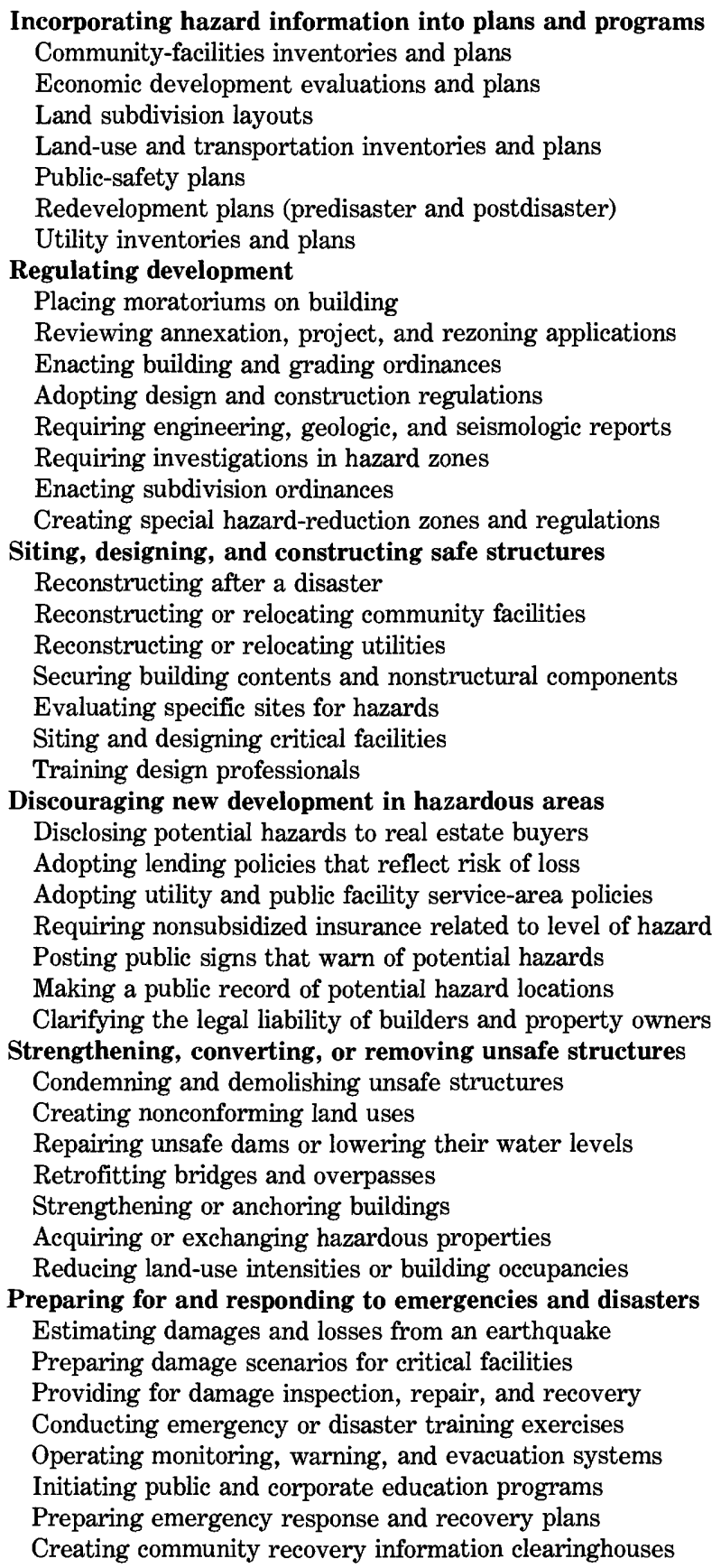 \\
\hline
\end{tabular}

In addition, geologists, engineers, and planners, both public and private, are evaluating the location or design of developments in relation to earthquake hazards, as in these examples: rezonings and annexations by the Utah and Juab Counties geologist R.M. Robison (written commun., 1985, 1986); subdivision layouts, apartment project locations, fire station design, and aqueduct relocation by Salt Lake County geologist C.V. Nelson (1988; written commun., 1985, 1986); and long-range environmental plans, subdivision layouts, and critical facilities, including water tanks, fire stations, jails, and waste disposal by the Weber and Davis Counties geologist Mike Lowe (written commun., 1989).

According to Utah Geological Survey geologist W.F. Case (written commun., 1988), a residential development in Ogden was scrutinized because its proposed location 


\section{List 3. - Examples of potential users of earthquake hazard information in Utah}

City, county, and multicounty government users

City building, engineering, zoning, and safety departments

County building, engineering, zoning, and safety departments

Mayors and city council members

Multicounty planning, development, and preparedness agencies

Municipal engineers, planners, and administrators

City and county offices of emergency services

Planning and zoning officials, commissions, and departments

Police, fire, and sheriff's departments

Public works departments

County tax assessors

School districts

State government users

Department of Community and Economic Development (Community Services Office, Economic and Industrial Development)

Department of Business Regulation (Contracts and Real Estate divisions)

Department of Financial Institutions

Department of Health (Environmental, Health Care Financing)

Department of Insurance

Department of Natural Resources

Department of Public Safety

Department of Social Services

Department of Transportation

Division of Comprehensive Emergency Management

Division of Risk Management

Division of Water Resources

Division of Water Rights

Facilities Construction and Management

Geological and Mineral Survey

Legislative Fiscal Analyst

Legislative Research and General Counsel

Legislature and legislators

National Guard

Office of the Governor

Planning and Budget Office

Public Service Commission

Science Advisor

State Board of Regents

State Fire Marshall

State Tax Commission

State Office of Education

State Planning Coordinator

Private, corporate, and quasi-public users

Civic, religious, and voluntary groups

Concerned citizens

Construction companies

Consulting planners, geologists, architects, and engineers

Extractive, manufacturing, and processing industries

Financial and insuring institutions

Landowners, developers, and real estate salespersons

News media

Professional and scientific societies (including geological, engineering, architecture, and planning societies)

Utility companies

University departments (including geology, civil engineering, structural engineering, architec-

ture, urban and regional planning, and environmental departments)

was in a rockfall hazard area. The developer then hired an engineering firm to determine the extent of the hazard and to reduce it.

Previously adopted techniques to reduce losses from natural hazards can be revised to include the latest earthquake research information. Examples of regulations that can or have been revised include the site development regulations of the Salt Lake City Council (1981), Emigration Canyon master plan adopted by the Salt Lake County Commission (1985), multihazard miti- 
gation plan for Ogden City and Weber County prepared by the Utah Multi Hazards Mitigation Project Administrative Review Committee (1985), and the critical environmental zone created by the Mapleton City Council (1985).

Others include seismic risk reduction recommendations for primary and secondary schools by Taylor and Ward (1979), hillside site development regulations by the Spanish Fork City Council (1980), regulations governing dam safety by Hansen and Morgan (1982), structural seismic resistance regulation by the Ogden City Council (1983), sensitive area overlay zone ordinance by the Ogden City Council (1985), hillside development standards and sensitive lands development ordinance by the Provo Municipal Council (1985), seismic hazard area regulations by the Orem City Council (1986), structural directives of the Headquarters Structural Engineering Staff (1987), development overlay zone by the Washington Terrace City Council (1988), emergency training exercises by the Utah Division of Comprehensive Emergency Management (Tingey and May, 1988), and the emergency recovery plans proposed by the Financial Institution Emergency Preparedness Committee (James Tingey, written commun., 1988).

\section{ACKNOWLEDGMENTS}

Walter Hays, Earl Brabb, Donald Nichols, and Robert Brown, U.S. Geological Survey; Genevieve Atwood, Don Mabey, Doug Sprinkel, and Gary Christenson, Utah Geological Survey; James Tingey, Utah Division of Comprehensive Emergency Management; county geologists Mike Lowe, Robert Robison, and Craig Nelson; and many others read all or part of this report and provided many critical comments and valuable suggestions. However, the author is responsible for all errors of fact or interpretation. Alice Olsen and Ray Eis, U.S. Geological Survey, are especially thanked for processing the words and drawing the figures.

\section{TOWARD THE CONNECTION IN UTAH}

Sometimes planners, engineers, and decisionmakers fail to fully use the research information available. The connection between research (list 1) and the use of research to reduce hazards (list 2) simply is not made. According to several experienced and perceptive observers (McKelvey, 1972; Jacknow, 1985, p. 18; Reilly, 1987; Szanton, 1981, table 3-1, p. 64; Yin and Moore, 1985, p. 18-19; Petak, 1984, p. 456), the reasons vary. They may be simply stated as: not all of the research information is in a language or format understandable to or directly usable by nontechnical users, or it is not effectively transferred to them.

\section{UTAH'S USER NEEDS}

In Utah, nontechnical users such as government officials, corporate planners, land developers, and private citizens have different needs from those in the scientific, engineering, and other technical fields. The nontechnical users in list 3 do not constitute a homogeneous group; rather, they differ widely in the kinds of information needed and in the capability to use that information. Thus, detailed technical information prepared by scientists or engineers often is unsuitable for and unusable by nontechnical users. For example, most professional landuse planners and local officials do not have the training or experience to directly apply earthquake hazard research information (U.S. Office of Science and Technology Policy, 1978, p. 170). Few academic programs train students of planning or public administration to avoid, reduce, or design for natural hazards.

Although many land-use planners and local officials in Utah have some experience with natural hazards, such experience is usually with floods, landslides, or soil problems. Without translating and transferring the earthquake research information, the effective user community is limited to scientists and engineers. At the other extreme, if the users do not become familiar with and proficient in using research information, it is likely to not be used or, worse, misused!

\section{PROBLEM RECOGNIZED}

Both researchers and users of research have recognized the needs of nontechnical users such as decisionmakers (Alexander, 1983, p. 49), State and local governments (Council of State Governments, 1976), nonspecialists (Wenk, 1979), potential user groups (Yin and Moore, 1985), journalists (Peterson, 1986), nontechnical users (White and Haas, 1975), the general public (Petak, 1984), and city, county, and multicounty planners (Kockelman, 1975, 1976b, 1979).

From the beginning of their 5-yr focused effort in 1983, both the Utah Geological Survey (UGS) and the Utah Division of Comprehensive Emergency Management (CEM) were aware of and concerned about the problems of research information being effectively used by nontechnical persons. For instance, during a Utah Governor's conference on geologic hazards held in 1983, most of the 36 working groups identified specific problems or needs of nontechnical users, as in these examples:

- Officials need risk maps.

- Officials lack knowledge concerning expertise available.

- Officials are not aware of the availability of hazards information. 
- Most local governments require technical assistance.

- State and local agencies need a central data bank.

- Some mechanism is needed to transfer information.

- There is a lack of hazard susceptibility maps.

According to UGS deputy director D.A. Sprinkel (written commun., 1986), "most of the research scientists feel the amount of data collected can and should be translated into products for the public and disseminated as soon as possible."

Part of the solution has been widely recognized as simply one of adequate translation for, and effective transfer to, nontechnical users. International agencies (United Nations Educational, Scientific, and Cultural Organization, 1976), Federal agencies and committees (Wallace, 1974; NEHRP Expert Review Committee, 1987), and State agencies (Utah Seismic Safety Advisory Council, 1981; California Seismic Safety Commission, 1986) have all addressed the need for translation and transfer of research information.

Recommendations for translation and transfer have been included in hazard reduction programs for natural hazards other than earthquakes, such as coastal area hazards (White and others, 1976), flood hazards (National Science Foundation, 1980), landslide hazards (U.S. Geological Survey, 1982), and the major natural hazards considered by the Advisory Committee on the International Decade for Natural Hazard Reduction (1987).

\section{UTAH'S WORK PLAN}

Two of the five components (fig. 1) in the work plan adopted by Utahans directly relate to the connection between research and its use. The work plan clearly identifies the need for scientific information to be "translated" before it can be transferred to a user and subsequently used for earthquake hazard reduction. The work plan then specifically addresses those actions likely to improve effective use of scientific information by nonscientists, namely:

- Identify the hazard maps and reports needed for hazard reduction measures and ensure that new information is prepared in detail and at the scales needed by the users.

- Make special efforts to present the information in a format and language suitable for use by engineers, planners, and decisionmakers.

- Design the communications program after an assessment of potential users' needs and capabilities.

- Select the most effective educational, advisory, and review services appropriate to the targeted users.

- Design the communications program so that information can be effectively disseminated (including use of the scientists and investigators to help communicate).
According to Atwood and Mabey (1987, p. S30), achieving this plan "requires communication of translated scientific information to responsible officials and interested parties seeking to reduce losses from the hazards. This is a major challenge to the program because many of the products of scientific research are not directly usable by responsible officials and the public. To accomplish this goal, it is essential to involve the user of the information early in the program."

In their book, In Search of Excellence, management consultants Peters and Waterman (1982, p. 145) observe: "Finally, and most important, is the user connection ... we will simply say that much of the excellent companies' experimentation occurs in conjunction with a lead user." A social scientist (Drabek, 1986, p. 416) remains "convinced that the quality of disaster research will be improved immeasurably if the interaction between practitioners and researchers is increased." A comprehensive review of the use of research (Yin and Moore, 1985, p. 70) includes a conclusion that "the most consistent pattern leading to utilization was the prevalence of rich and direct communication between knowledge producers and users throughout the design and conduct of the research project." Taylor (1979, p. 278) notes that "if users participate in the research process-most especially at the beginning when the problem is defined-then they are likely to identify with the research project and with its outcome."

One way to ascertain nontechnical users' needs is to arrange for a dialogue between researchers and users of hazard information (list 3). In the case of Utahans, this dialogue took place at conferences, workshops, and special sessions, each of which required careful preparation, good-faith effort, and skillful facilitating. Three examples are discussed in more detail in the following subsections.

\section{GOVERNOR'S CONFERENCE}

The Governor's Conference, held August 11 and 12, 1983 , on the campus of the University of Utah, was sponsored by the Utah League of Cities and Towns, Utah Association of Counties, Utah State Legislature, Federal Emergency Management Agency (FEMA), U.S. Geological Survey (USGS), and the University of Utah; it was coordinated by UGS and CEM. The purpose of the conference was to bring together scientists and engineers, elected and appointed officials, leaders of business and private organizations, and private citizens to discuss geologic hazards and to recommend appropriate actions to all levels of government. The first day of the conference was designed to provide information on the principal geologic hazards in Utah. During the second day, 36 working groups met in half-day sessions to 
develop recommendations for actions by all levels of government to reduce the geologic hazards in Utah.

The working groups recommended 171 actions that would reduce the impact of geologic hazards on the lives of Utahans. They concluded that, although much of the information needed to make site-specific decisions has not yet been developed, sufficient information exists on which to base public policy. The working groups determined that the primary support for research on geologic hazards should come from the Federal Government and that the State should take a major role in identifying research priorities and applying research results. The working groups also concluded that information collection and dissemination is the role of State agencies and that local governments should take a more active role in identifying information needs and providing matching assistance. An excerpt from one of the working groups follows:

\section{HAZARDS INFORMATION FOR PLANNERS \\ Chairperson: James P. McCalpin, Geologist, Utah State University \\ Topic c: $\quad$ Interpretation of information \\ Problem: $\quad$ Planners are often unable to interpret available geologic hazards information and therefore can- not use it effectively in land-use planning or regulation. This problem has two related aspects: the data are presented in too technical and specialized a format for planners, or plan- ners have insufficient geologic background. \\ Action: (1) Offer natural hazard information in deriva- tive or interpretive maps .... Such interpretive maps would assess hazards directly with some kind of rating system (e.g., serious, moderate, slight) .... (2) Educate planners via technical workshops ... to train them in hazard interpre- tation from existing geologic maps and forth- coming interpretive maps, or (3) Local govern- ments in critical hazard areas should hire a full- or part-time geologist to identify local haz- ards and to help draft local government ... reg- ulations.}

The results of the conference, including suggestions for action, remarks of the Governor, action items of the working groups, and a summary of the questionnaire, were published by the Utah Geological and Mineral Survey (1983). The dialogue between researchers and the users of geologic hazard information had begun.

\section{EARTHQUAKE HAZARDS WORKSHOPS}

The first of five workshops was held on August 14-16, 1984 , in Salt Lake City. The workshop was sponsored by USGS, FEMA, UGS, CEM, and the University of Utah. The 115 participants, representing the fields of earth science, social science, planning, architecture, engineer- ing, and emergency management, came from various industries, volunteer agencies, academic institutions, local and State governments, the private sector, and the Federal Government.

The two primary objectives of the workshop were to (1) strengthen the capability of the scientific and technical community to compile and synthesize geologic, geophysical, and engineering data needed for evaluating earthquake hazards, and (2) work with public officials in fostering an environment for implementation of research results, creating partnerships, and providing highquality scientific information that can be used by local government to reduce hazards.

Four discussion groups were created, each composed of both researchers and users of hazard information. Two of the groups recommended translation and transfer activities. An excerpt from the "information systems" group moderated by a USGS research geographer reads:

2) An extraordinary effort should be made to communicate. Possible actions include:

b) Devising outreach activities to involve a wide range of groups. These activities could use strategies such as workshops, small group meetings, exchange of technical information, demonstration of products and results of research, neighborhood meetings, and generation of special information packets and audiovisual materials to give them a stake in the process.

An excerpt from the "implementation options" group moderated by a FEMA emergency manager reads:

3) County geologists-Local governments need to attain the capability to take the products (data, maps, reports, etc.) produced ... and apply them to solve problems in their jurisdictions. This application is the only way that the ultimate goal of reducing the loss of life and property from earthquakes will be attained. The Wasatch Front counties ... are the places to start. The county geologists are the key resource. Such a process is needed now.

The results of this innovative workshop and the recommendations of the discussion groups were published in the proceedings edited by Hays and Gori (1984). The results of the 1986 workshop were published in the proceedings edited by Hays and Gori (1987). These workshops resulted in early release of research findings, continued dialogue between researchers and practitioners, and an increased awareness of earthquake hazards by the public.

\section{USER NEEDS SESSION}

A special session was held in the evening (convened and moderated by the Utah State geologist and the USGS earth sciences applications planner) to provide an opportunity for users of earth science information to 
communicate their needs to the UGS, USGS, universities, consultants, and others who produce such information. Invitations to participate in this session were sent to more than 70 city, county, and State officials, planners, engineers, and university researchers and educators. Representatives of the Utah League of Cities and Towns, League of Women Voters, American Planning Association (Utah Chapter), Wasatch Front Regional Council, The Western Planner, and the Southeastern Utah Association of Governments also attended.

Seven speakers experienced in determining or meeting user needs made presentations that were prepared specifically for this session. The speakers' collective experience included conducting studies of user needs, translating scientific information for nontechnical users, communicating information to nontechnical users, or using earth science information to reduce hazards. Briefing materials emphasizing the needs of users were provided to participants.

Six panelists representing important city, county, State, and private planning and decisionmaking agencies were selected on the basis of their experience in the use of earth science information and on their need to have research information translated, transferred, and used. The panelists began the "brainstorming" session by commenting on the usefulness to their organizations of the techniques presented by the speakers. The panelists were asked to list types of information that they felt rated the highest priorities.

The meeting then was thrown open to the nontechnical participants. A "brainstorming" approach was scrupulously followed and resulted in a blackboard filled with items needed. The items listed were organized into five categories: (1) scientific research topics, (2) translation of science for use by nontechnical users, (3) transfer of the information to the users, (4) use of the translated information to reduce hazards, and (5) evaluation of the uses of the information to ensure effectiveness.

After the items were organized, the moderators asked for a weighting of the importance of each need by a simple showing of hands. The users were then asked whether they would actually use the information if it were available. Both information producers and users fully understood that a "no" vote did not mean that the information was not necessary or useful to someone else, but rather that this particular group of users did not think that they would use the information. The spontaneous voting by only the user attendees resulted in a rating on a scale of 1 to 10 , the number 10 indicating that virtually all the users present felt that their organizations needed and would, or should, use a specific type of information. Some of the needs (and weights assigned) follow:
- Site-specific geologic reports that are legally and politically defensible (10).

- Early-warning "red flag" maps, scales 1:9,600 (10).

- Structure types susceptible to failure by shaking (8).

- Location of surface-fault rupture zones (7).

- Maps showing multihazards, scales of 1:2,400 or more detailed (10).

- Maps showing susceptibility to damage or hazard (10).

- Retention of five staff geologists to serve 10 counties (9).

- "Red flag" hazard maps for counties at a scale of $1: 100,000(6)$.

- Maps interpreting research for nontechnical persons (10).

- Education of local planning commissioners (10).

- Increased awareness of hazards (10).

- Educational materials explaining earthquake processes and their effects, meant for adults but that can be understood by sixth graders (5).

- Advisory services (10).

- Training for local government, including planners (10). - Prototypical community training exercises (9).

The names of the session's speakers, panelists, and participants, along with the papers, briefing materials, and the complete results of the "brainstorming," are included in the workshop proceedings edited by Hays and Gori (1984, p. 606-674). This session provided the researchers with the specific translation and transfer needs of the nontechnical users.

\section{RESEARCHERS AND TRANSLATORS}

Various views have been expressed concerning who is responsible for translating and transferring research information to nontechnical users. The following examples concerning the responsibility of researchers and translators are paraphrased from the comments of experienced and perceptive observers:

- Identify user groups, meet their needs, and plan on producing a major product aimed directly at users (Yin and Moore, 1985, p. ix-x).

- Be prepared to make their analyses of earthquake danger comprehensible in common-sense terms by frequent and imaginative use of metaphors and examples from common experience (Turner and others, 1981, pt. 10, p. 96).

- Be willing not only to face the adverse reactions but also to persist in finding truly effective ways of conveying information that is important to societal needs (Peterson, 1986, p. 245).

- See user problems as interesting and worthy of serious intellectual commitment beyond the theoretical implications for other scientists in the field (White and Haas, 1975, p. 152). 
- Seek much greater direct participation by geologists and by planners with better training and understanding of the significance and application of earth science information (Nichols, 1982, p. 290).

In identifying problems and opportunities as experienced by USGS, Bates (1979, p. 29), in his Transferring Earth Science Information to Decisionmakers, concluded that the entire earth science community must mobilize to provide specialized, technical information in a form and language understandable to the intelligent citizen, and to engage in the educational, advisory, and review services necessary to assist the public and its representatives in making effective use of that information. The remarkable efforts made in Utah to translate and transfer research information to nontechnical persons will be seen in subsequent sections of this report.

\section{OTHER ASPECTS}

Translation and transfer activities considered in this paper are only part of the solution to the problem of lack of effective earthquake hazard reduction. Some other aspects that must be considered are the following:

- Perhaps the most telling factor acting against adoption of earthquake-risk reduction measures is that Utah has not experienced a highly destructive earthquake in a heavily populated area (Atwood and Mabey, 1987, p. S19).

- Utah needs trained people to analyze the technical data bases, to extrapolate beyond the limits of the data, and to translate the basic data into maps and other products that can be applied in the community (Hays, 1987, p. R8).

- The research begins with approval of the effort by those top officials who have power to see that results are utilized (White and Haas, 1975, p. 152).

- Lack of leadership due to competing, day-to-day problems, lack of interest or commitment, potential citizen opposition, and inadequate educational programs (Perkins, 1986, p. 3).

- The public lacks knowledge of and underestimates the hazardous quality of the environment; these underestimations reflect busy people occupied with their own life priorities-day-to-day issues of living (Drabek, 1986, p. 320).

Hays (1988b, p. 100-101) emphasizes that the risk management process in every nation depends on seven factors: a perceived need for risk reduction, informed internal advisors, strong external champions, credible products, user-friendly products, balanced political, legal, and economic considerations, and a window of opportunity. Sprinkel (1988), in his review of the earthquake assessment program in Utah, asks, "Will Utah meet the challenge?" and then answers that question in the affirmative by noting the existence of the following key factors: champions, challenge, symbiotic relationship, true believers, strong partnership, key players, early planning, long-time advocates, mutual buy-in, enthusiasm, credibility of the program, excellent media coverage, commitment of funds, translation expedited, talented people, and potential devastating earthquake.

\section{TRANSLATION FOR PRACTITIONERS}

The objective of translating hazard information for practitioners is to: make them aware that a hazard exists which may affect them or their interests; provide them with information that can easily be presented to their superiors, clients, or constituents; and provide materials that can be directly used in a reduction technique (list 2). The Utah work plan is quite specific as to what is expected of translated information:

- Easy access to data in media, scales, and formats that will be most useful.

- Standard base maps and mapping scales.

- Interpreted information derived from basic scientific data.

- Easy for local government, engineers, architects, planners, and emergency responders to use the technical information.

- Information in a format and language suitable for use by engineers, planners, and decisionmakers.

\section{DEFINITION}

Much has been said about the need for and objectives of translation. No clear, concise definition or criterion has been offered, nor are any found in the literature except by inference or by an analysis of what is actually used by practitioners. However, various researchers, translators, and users of earthquake research information are specific about what is needed by nontechnical users: "Knowledge of the distribution of earthquakes in time, location, and size is essential for insurance ratings and underwriting purposes," (Steinbrugge, 1982, p. 13) and "Successful translation of science must (1) show hazard locations on maps at suitable scales, (2) provide some sense of the damage likely to result from occurrence of a hazardous event, and (3) provide some sense of when a hazardous event is likely to occur" (Keaton and others, 1987, p. 73).

My experience with reducing potential natural hazards (primarily atmospheric hazards, floods, unstable soils, landslides, and earthquakes) indicates that hazard information successfully used by nontechnical users has the following three elements in one form or another: 
1. Likelihood of the occurrence of an event that will cause human casualties, property damage, or socioeconomic disruption.

2. Location of the effects of the event on the ground.

3. Estimated severity of the effects on the ground, structure, or equipment.

Engineers, planners, and decisionmakers will usually not be concerned with a potential hazard if the likelihood of occurrence is rare, the location is unknown, or the severity is slight. However, concern varies widely with the individual user, the cost of hazard reduction, and who or what might be affected. For example, a pedestrian might prepare for a 50-percent probability of rainfall tomorrow by carrying an umbrella; a lender might require flood insurance if the mortgaged property is within a flood zone with a 100-yr recurrence interval; and a regulatory agency might curtail construction if a critical facility is being located near a fault that has moved in the last $10,000 \mathrm{yr}$. The reader will note that both location (areal, zonal, or specific) and likelihood of occurrence are conveyed in these three examples. Severity, however, is perceived in a much different way-for example, from personal experience, documented damage, or fear of a disaster and possible liability.

Unfortunately, these three elements come in different forms and with different names, some quantitative and precise, others qualitative and general. In each of the several examples that follow, for a product to be defined as "translated" hazard information, the nontechnical user must be able to perceive likelihood, location, and severity of the hazard so that he or she becomes aware, can convey information to others, and can use the information directly in selecting and adopting a hazard reduction technique.

\section{LIKELIHOOD OF OCCURRENCE}

Likelihood of occurrence can be conveyed for a selected size and location of a damaging earthquake by the use of various concepts - probability, return period, frequency of occurrence, or estimated, average, or composite recurrence interval. Sometimes a specific event is chosen: design earthquake, hypothetical earthquake, characteristic earthquake, or postulated earthquake. Each of these terms has a specific definition that is beyond the scope of this report. In all cases, each event chosen must be credible; that is, it must have some likelihood of occurring.

In some cases, an engineering parameter is used for a specific ground failure: "the probability that the critical acceleration would be exceeded in 100 years" for liquefaction by Anderson and others (1986, p. 39) or for landslides by Keaton and others (1987). Algermissen and others (1982) use a map showing probabilistic bedrock peak horizontal ground acceleration that has a 90 -percent probability or likelihood of not being exceeded in a 50-yr period. In another case, the term "opportunity for liquefaction" was used where "a return period of about $30-50$ $\mathrm{yr}$ is anticipated for ground motions sufficient to exceed the liquefaction threshold at a given susceptible site" (Tinsley and others, 1985, p. 315). The period of 30-50 yr is selected because it embraces the economic or functional life of most buildings.

No matter what term is used, it must convey a likelihood of occurrence that is important to the user. This likelihood varies widely, depending upon its use. For example, the National Research Council $(1986$, p. 5) notes that "various public agencies define an active fault as having had displacements (a) in $10,000 \mathrm{yr}$, (b) in 35,000 $\mathrm{yr}$, (c) in $150,000 \mathrm{yr}$, or (d) twice in 500,000 yr." The interest of an engineer, planner, or decisionmaker in likelihood of occurrence also varies widely. For example,

$\begin{array}{ll}\text { Insuring agent } & \text { Premium period (1 yr) } \\ \text { Elected official } & \text { Term of office }(2-6 \mathrm{yr}) \\ \text { Lending officer } & \text { Amortization schedule }(10-30 \mathrm{yr}) \\ \text { Bridge designer } & \text { Structure's life }(50-100 \mathrm{yr}) \\ \text { Waste manager } & \text { Hazard's life }(1,000-10,000 \mathrm{yr}) \\ \text { Pyramid builder } & \text { Next world }(10,000-10,000,000 \mathrm{yr})\end{array}$

\section{LOCATION AND EXTENT}

Once users are convinced of the likelihood of a damaging event, they want to know if their interests might be affected. This information is conveyed by showing the location and extent of ground effects or geologic materials susceptible to failure. These are usually shown on a planimetric map having sufficient geographic reference information to orient the user to the location and extent of the hazard. Topographic maps showing geographic information, such as streams, highways, railroads, and place names, are very helpful. Some maps show streets; others show property boundaries. The scales of such maps vary widely; examples from Utah range from $1: 36,000$ ( 1 in. equals $3,000 \mathrm{ft}$ ) to $1: 1,200,000$ ( 1 in. equals approximately $3 \mathrm{mi}$ ) (compare figs. 3 and 4 ).

The scale selected depends on the detail and amount of information to be shown, as well as the users' needs. For example, the seismic zone map of the United States adopted by the International Conference of Building Officials (1988, p. 178) and incorporated into the widely used Uniform Building Code is at a scale of 1:30,000,000; it is based on the national map by Algermissen and others (1982), which is at a scale of 1:7,500,000. Some building site hazards have been shown at scales of 1:1,200 ( 1 in. equals $100 \mathrm{ft}$ ) or larger. Most hazard maps are a compromise between scale, detail, reliability, difficulty and cost of preparation, and the purpose for which they 
were designed. There are no "best" scales, only more convenient ones.

\section{ESTIMATED SEVERITY}

After the users recognize the likelihood of an event that may affect their interests, the next concern is how severe the effects will be. In other words, is the hazard something that should be avoided or designed for? Should preparations be made to respond during, and recover, repair, and reconstruct after a damaging event? Severity of anticipated effects is best expressed by use of measurable engineering parameters for the various hazards:

- Vertical and horizontal displacements for surface-fault ruptures.

- Peak acceleration, peak velocity, peak displacement, frequency, and duration for ground shaking.

- Velocity and volume for landslides.

- Extensional and vertical displacement for liquefaction.

- Vertical displacement for tectonic subsidence.

- Run-up height for tsunamis.

Modified Mercalli or Rossi-Forel intensity scales of observed or estimated damage also show severity. These scales are used primarily for ground shaking but can include the effects of surface-fault rupture, landsliding, and liquefaction, as well as some of the observed or anticipated effects on structures, occupants, and contents.

\section{FORMAT}

Likelihood, location, and severity have been combined into various formats, some easy for the nontechnical user, and others requiring additional information or an experienced user to appreciate, adapt, and use in a reduction technique. The format may be a single map containing all elements, or all information may be combined in a report or volume, or outside supplemental information must be obtained. Sometimes one of the elements (likelihood of occurrence) is derived from public knowledge or experience, or elements may only be available or combined for a demonstration area. When adequate research information is available for other areas, additional translation work can be done. Otherwise new research must be undertaken to cover the user's area of jurisdiction or interest.

At other times, the format is a "seismic hazards zone" (sometimes called "seismic zonation") showing the location and severity of all the effects from one postulated event. Qualitative terms are often used to show relative susceptibility (high, moderate, low, and very low) of geologic or other units to landslides or liquefaction, or to show relative severity (very violent, very strong, strong, and weak) of shaking. Examples of some of these formats follow.

Wesson and others (1975) and Ziony and Yerkes (1985) show location of faults that have, or may generate, damaging earthquakes or surface-fault rupture on indexscale maps. Maps at much larger scales $(1: 24,000)$ for surface-fault traces are readily available. Likelihood of occurrence (estimate of recurrence intervals) and severity (maximum surface displacement) are conveyed by discussions, tables, and graphs in the text accompanying the index maps. Both reports are in a volume that illustrates surface faulting as part of the predicted effects of a postulated earthquake (magnitude 6.5 ) for a selected fault.

Algermissen and others (1982) show location and severity of ground shaking (in terms of peak velocity and acceleration) by areas on a map. In the map caption, likelihood of occurrence is conveyed by probability (percent) of not being exceeded for various exposure times $(10,50$, and $250 \mathrm{yr})$.

Rogers and others (1985) show location of a demonstration site and severity (mean amplification factor compared with level of shaking at site on rock) by areas on maps for predicted relative ground response. Individual maps are used to show predicted relative ground response in three period bands having significance to buildings of specific heights $(2-5,5-30$, and 30 or more stories). Likelihood of occurrence is conveyed by other papers in the same volume.

Wieczorek and others (1985) show location and extent (levels of susceptibility) and percentage of area likely to fail on a map for slope stability during earthquakes. Likelihood of occurrence is conveyed by a discussion of a lower bound hypothetical (or "design") earthquake large enough to trigger landslides (Richter magnitude 6 or 7 , depending on location of the earthquake). Severity is conveyed by a discussion on the map by noting that "structures generally cannot withstand more than 10 to $30 \mathrm{~cm}$ of movement without damage ...." and then by selecting $5 \mathrm{~cm}(2 \mathrm{in}$.) as a conservative design threshold.

Tinsley and others (1985) map location and extent (levels of relative susceptibility) of liquefaction. Likelihood of occurrence (return period of liquefaction opportunity) for magnitude 5 or larger earthquakes is shown by contours on a separate map. Severity is partially conveyed by photographs showing liquefaction damage to such critical facilities as a causeway, a juvenile hall, and an earth-filled dam. Their paper is in a volume that illustrates liquefaction-related ground failure as part of the predicted effects of a postulated earthquake for a selected fault; the text also conveys severity.

Agnew and others (1988) use a map to show conditional probability of large earthquakes for selected segments. 
Probabilities are based on expected recurrence times, and calculated for the likelihood of occurrence during the next $30 \mathrm{yr}$. Severity is generally conveyed by the expected magnitude of a major earthquake, which is provided for each segment.

In some cases, lists of damaging events, photographs of damage, or diagrams of effects on ground or buildings for similar events are used to convey severity. Examples include the works of Youd and Hoose (1978) for ground failure, Ziony (1985) and Borcherdt (1975) for earthquake hazards, and Hays (1981) for several geologic and hydrologic hazards.

This type of information is an important part of the researcher's observations, but when used in translated information becomes an effective transfer technique, namely, communicating possible effects-casualties, damage, and socioeconomic interruptions. Sometimes this conveyance can be misleading because of differences in the user's environment and that depicted, in terms of earthquake location and size, ground conditions, structure vulnerability, people exposed, and reduction techniques already implemented.

\section{SUCCESSFUL TRANSLATION}

One of the best ways to confirm that likelihood, location, and severity are needed is to look at information that has been prepared for, and successfully used by, engineers, planners, and decisionmakers to reduce earthquake hazards. Many examples of the use of translated (and of course transferred) earthquake research information for specific reduction techniques can be cited. In other words, the connection between research and its use in hazard reduction techniques is being made. Selected examples follow:

- Shaking intensity maps for major fault systems (Evernden and others, 1981) used for anticipating damage and interruptions to critical facilities and preparing for emergencies by utilities and local, multicounty, and State government agencies (Davis and others, 1982; Steinbrugge and others, 1987).

- Fault-rupture zone maps by various Federal, State, university, and consultant researchers (Brown and Wolfe, 1972; Sarna-Wojcicki and others, 1976) used for statewide legislation, city and county regulations, and real-estate seller disclosures (Hart, 1988).

- Fault-rupture, tsunami, liquefaction, shaking, and landslide hazard information combined by computer and used for county seismic safety plans (Santa Barbara County Planning Department, 1979).

- Maximum credible ground acceleration on bedrock map (Greensfelder, 1972) used to assign priorities and to design for strengthening of highway overpasses by a State transportation agency (Mancarti, 1981).
- Maximum earthquake intensity map (Borcherdt and others, 1975) used for estimating cumulative damage potential for different building types by a multicounty agency (Perkins, 1987).

- Numerous studies of ground-shaking acceleration, losses, and predicted intensities used as a basis for inventorying unreinforced masonry buildings and requiring the strengthening or demolishing of unsafe ones (Los Angeles City Council, 1981).

- Probabilistic intensity (Algermissen and others, 1982) and local site amplification (Hays and others, 1978) maps used to estimate loss and replacement cost for various building types in Salt Lake City (Algermissen and Steinbrugge, 1984, p. 12-22).

- Continuous monitoring and analysis of earthquake precursor information for a specific fault segment used to warn local governments, the public, and the press via a governor's office of emergency services (Bakun and others, 1986).

Discussions and illustrations of some of these and other examples can be found in the works of Blair and Spangle (1979), Kockelman and Brabb (1979), Brown and Kockelman (1983), Kockelman (1985, 1986), Jochim and others (1988), Mader and Blair-Tyler (1988), and Blair-Tyler and Gregory (1988).

\section{COMMENT}

These examples of translation vary as to scale, area covered, format, postulated or probable occurrence, single or multiple hazards, limitations, and supplemental information required. What they all have in common is that they convey the likelihood of the occurrence of a damaging event, show location and extent of the hazard on a map, and provide some indication of severity of effects on the ground.

Some of these examples have gone, or can easily be taken, a step further to show potential response of structures, occupants, and equipment. This next step is actually using translated information in a reduction technique (list 2) such as development regulations, loss estimates, overpass retrofits, preparedness scenarios, and warning systems, as seen in the above examples. This step requires the collection, analysis, and use of new information concerning the type, age, and condition of vulnerable structures; characteristics of exposed populations; sensitivity of equipment; and importance of the socioeconomic systems at risk.

Numerous benefits are derived from translating earthquake hazard research for nontechnical users:

- Reports and maps designed for one common user group-intelligent and interested citizens-provide a common basis for discussion during public meetings. 


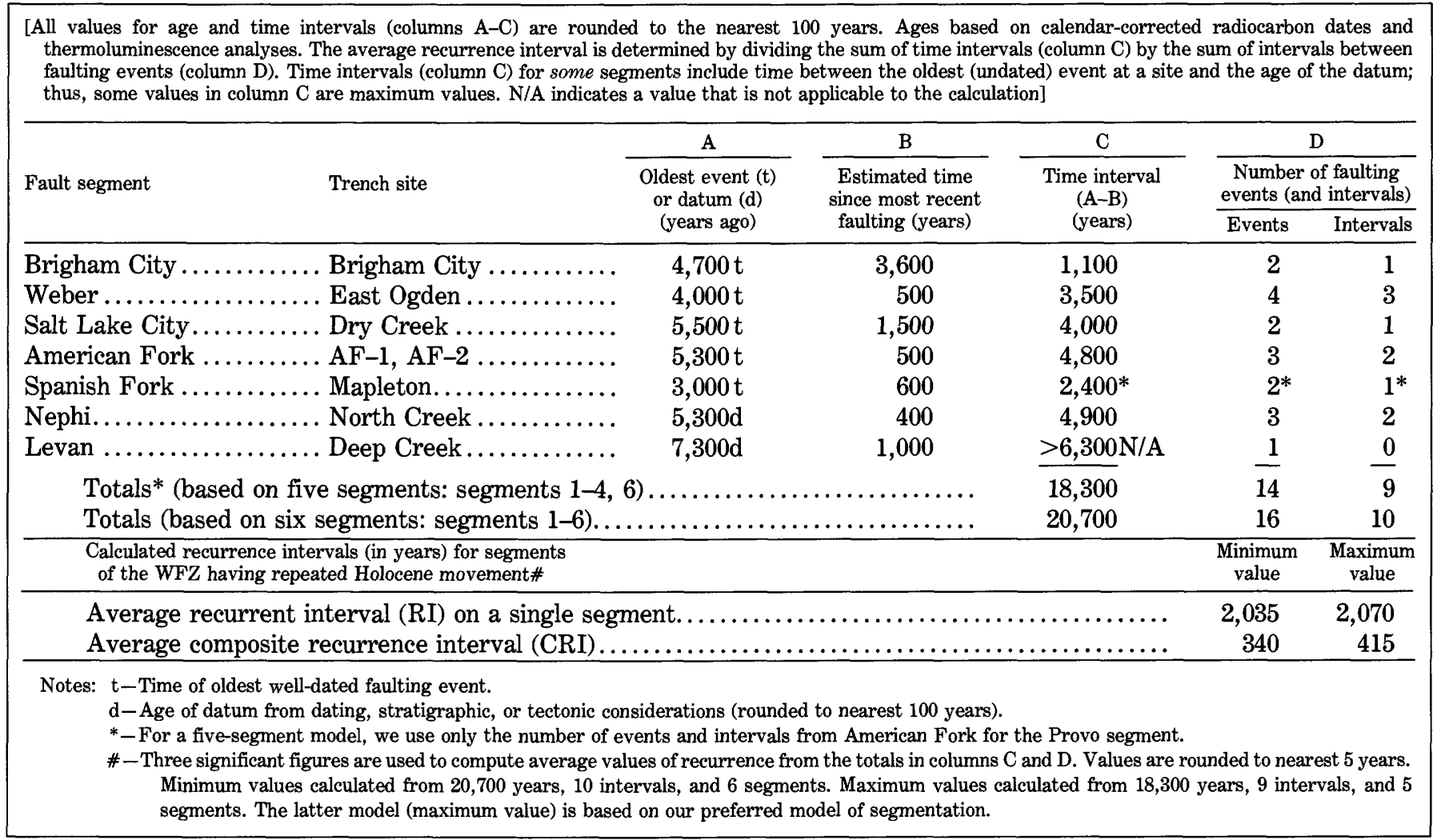

FIGURE 2. - Example of a table showing average recurrence interval on a single segment and average composite recurrence interval for several segments (Machette and others, 1989, table 2).

- Researchers are relieved from repetitive requests for translation.

- Numerous nontechnical transfer agents are available to transfer nontechnical information.

- Transfer and use occur more rapidly, and more correct and appropriate use is made of the research.

- Researchers become more sympathetic to users and their needs, and users become more appreciative and supportive of the researchers.

\section{EXAMPLES OF SUCGESSFUL TRANSLATION IN UTAH}

An unusual effort is being made in Utah to translate earthquake research information for nontechnical users. During 1986, the Utah State geologist convened several meetings to discuss and develop criteria for "translated" research and to identify potential translators. D.A. Sprinkel, UGS Deputy Director (written commun., December 24, 1986), reported that a common understanding was established, a logical progression from the research to its use was identified, and a tentative definition of translation was developed, namely, occurrence, location, and consequences.

Translators in Utah include university, State, and Federal researchers, geotechnical consultants, and county geologists. Hazards being addressed include surface-fault rupture, ground shaking, and failures induced by shaking-liquefaction, landslides, rockfalls, tectonic subsidence, and dam failure. An example and illustration of translated information from Utah for each of these hazards follow.

\section{SURFACE-FAULT RUPTURE}

Machette and others (1989) have prepared a report on surface-fault rupture for the segments in the Wasatch fault zone. The report includes a discussion of recurrence of large earthquakes and a table giving the number of faulting events on seven of the segments, and it introduces the idea of a composite-recurrence interval between 340 and $415 \mathrm{yr}$ (see fig. 2). Personius (1988) shows the location of faults that offset the surficial material on a topographic map (scale 1:50,000). Similar maps are being prepared for the urbanized portion of the Wasatch Front.

In an earlier report, Machette and others (1987) conclude that "recurrence intervals vary widely" on some segments, that some "earthquakes tend to occur in clusters," and that "recurrence intervals within clusters may be as short as 100 years" (revised to $180 \mathrm{yr}$ ). They suggest that the lack of faulting events in the past 
$400-500 \mathrm{yr}$, and the relatively imprecise dating $( \pm 100 \mathrm{yr})$ of the most recent events, may indicate that "a major surface-rupturing earthquake is overdue on one or more of the segments." They include displacement, slip rates for the segments, and length of surface rupture from recent large earthquakes in the northern Basin and Range province.

Machette and others (1987) begin their report by stating that the "heavily urbanized part of the Wasatch Front-between Ogden and Provo-coincides with the part of the fault zone that shows the highest slip rates, shortest recurrence intervals ..., and most recent fault activity" and conclude that major earthquakes have struck the central, heavily urbanized section of the Wasatch fault zone, on average, once every $310 \mathrm{yr}$ (revised to $415 \mathrm{yr}$ ) during the past 4,000-8,000 yr; that a form of temporal clustering of earthquakes has been (and may still be) active; and that lack of movement along the Brigham City segment during the late Holocene (past $3,600 \mathrm{yr}$ ) is somewhat ominous.

Their work on recurrence intervals is applicable to, and frequently provides the likelihood of occurrence element for, the Wasatch Front hazards that are discussed in the following subsections. In addition, McCalpin (1987) has analyzed the geometry of nearsurface ground breakage across some normal faults and defined reasonable setback distances.

The three county geologists serving Davis, Juab, Weber, Salt Lake, and Utah Counties are combining this and other information to show a surface-fault rupture study zone on county maps (see fig. 3). In addition, the geologists are transferring this map information to nontechnical users by use of texts that discuss and illustrate fault characteristics, segments, boundaries, recurrence intervals, and displacement, and they are suggesting use of the maps for hazard reduction. For example, Robison (Surface-fault rupture: A guide for land-use planning, Utah and Juab Counties, Utah, this volume; 1988a) summarizes displacement per event for each of the segments.

\section{GROUND SHAKING}

Youngs and others (1987, fig. 37, p. M88) map the location and severity of ground shaking (peak ground acceleration). Likelihood of occurrence is conveyed in the figure caption by probability (percent) of being exceeded for various exposure times (10, 50, and $250 \mathrm{yr}$ ).

Tinsley (1988) has prepared a map showing increased shaking due to ground conditions in the Salt Lake Valley. Figure 4 is a generalized version of this map at an original scale of 1:200,000. Location of increased ground shaking on unconsolidated deposits is shown by contour lines on the map. Severity is conveyed by use of Modified
Mercalli Intensity (MMI) units, representing an increase in damage intensities that would occur on the underlying bedrock.

The size and location of a credible earthquake can be obtained by referring to Machette and others (1987). A map of MMI on bedrock for such an earthquake is available, and Tinsley's increased intensities can be added to such a map to meet the needs of a nontechnical user.

\section{LIQUEFACTION POTENTIAL}

Anderson and others (1986) have prepared a liquefaction potential map and report for Utah County. The base map used is a USGS 71/2' quadrangle showing topography that has been reduced to a scale of 1:48,000 ( $1 \mathrm{in}$. equals $4,000 \mathrm{ft}$ ) (see fig. 5). They have also prepared similar maps and reports for Davis, Salt Lake, Weber, Cache, Millard, Sanpete, Sevier, and Wasatch Counties and the eastern portions of Box Elder and Juab Counties.

The boundaries of the high, moderate, low, and very low liquefaction-potential areas in figure 5 are based on the probability that a critical acceleration will be exceeded in a 100 -yr period. The critical acceleration for a given location is defined as "the lowest value of the maximum ground surface acceleration required to induce liquefaction." The categories of high, moderate, low, and very low correspond to probabilities of exceeding critical acceleration in the ranges of greater than 50, 10-50, $5-10$, and less than 5 percent, respectively. All of the information for a nontechnical user is shown on the map. The text includes discussions on methods, geotechnical conditions, existing ground failures, and techniques for reducing the susceptibility of site sediments to the liquefaction process.

In addition, Anderson and others (1986) have provided maps showing some information on soils, ground water, geology, and slope that can be used in combination with the liquefaction-potential map (fig. 5) to assess the type of ground failure likely to occur, either loss of bearing capacity, lateral spreading, landslides, flows, or translational landslides. These maps require further translation, which is being done by county geologists.

\section{LANDSLIDE POTENTIAL}

Keaton and others (1987) have prepared an earthquake-induced landslide-potential map and report for the urban corridor of Davis and Salt Lake Counties. The base map used is a USGS $711_{2}^{\prime}$ quadrangle showing topography that has been reduced to a scale of 1:48,000 (1 in. equals 4,000 ft) (see fig. 6). 


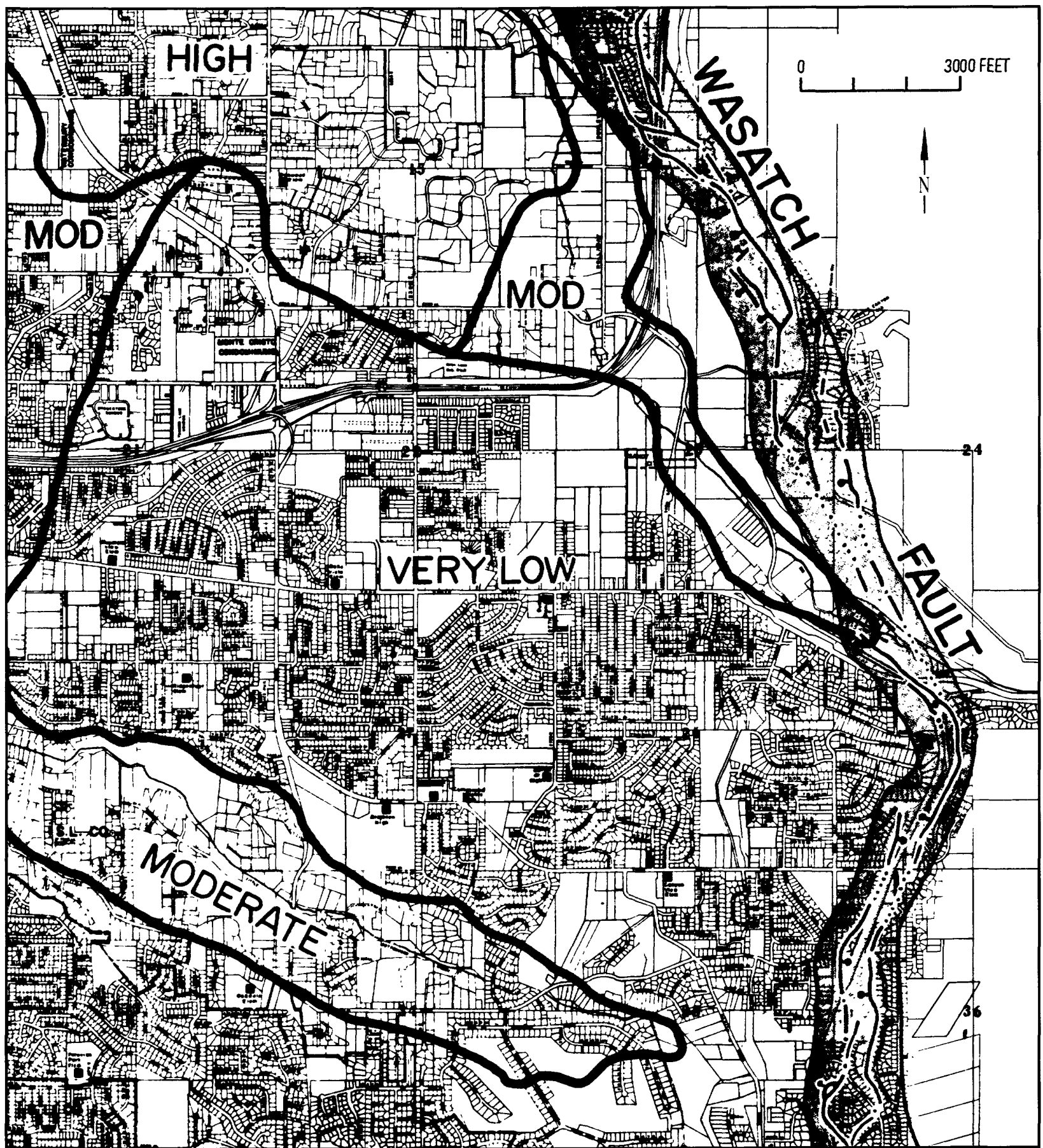

FIGURE 3. - Part of a cadastral map (original scale 1:36,000) of Salt Lake County upon which Nelson (1987) shows a surfacefault rupture zone and the potential liquefaction areas. Fault traces are indicated by a solid line where location is known from scarps or trenching; dashed where approximately located or inferred; dotted where concealed. Bar and ball symbol indicates downthrown side. Shaded area indicates where site-specific studies addressing surface rupture should be performed prior to construction. High, moderate, and very low refer to the areas' potential for liquefaction during an earthquake.
Boundaries of high, moderate, low, and very low landslide-potential zones in figure 6 were assigned on the basis of failure criteria, landslide susceptibilities, and acceleration exceedence probabilities. The text gives the displacement related to these terms, for example, $10 \mathrm{~cm}$ or more in a "moderate" zone during a wet condition, 10 cm or more in a "high" zone during a dry condition. Severity is then described as, "Such ... displacement 


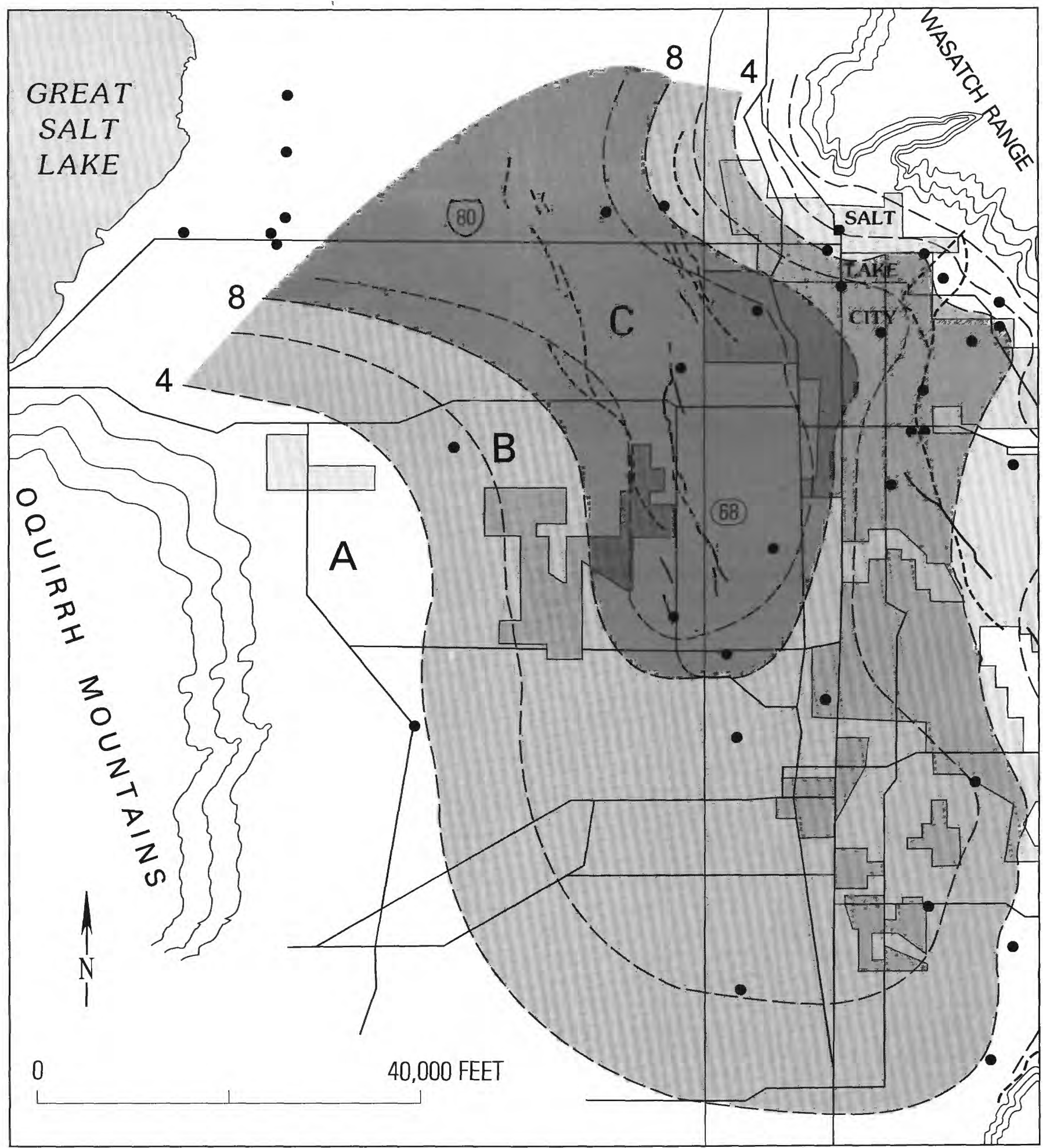

FIGURE 4.-Three levels of ground shaking on alluvium relative to bedrock in the period band $0.2-0.7 \mathrm{sec}$ in the Salt Lake Valley by Tinsley (1988, fig. 1). Contours were drawn on the basis of geology and show alluvium/rock spectral ratios recorded and computed by Kenneth King and Robert Williams. Black dots indicate points of control for the contours and are sites where USGS recorded ground motion. Map is preliminary, and contours may be modified owing to further analysis of the geologic data or after considering other effects including source characteristics, directivity, or geometry of basin margins. Letters indicate an increase in Modified Mercalli Intensity units: $A(+1), B(+2)$, and $C$ (greater than 2 ). 


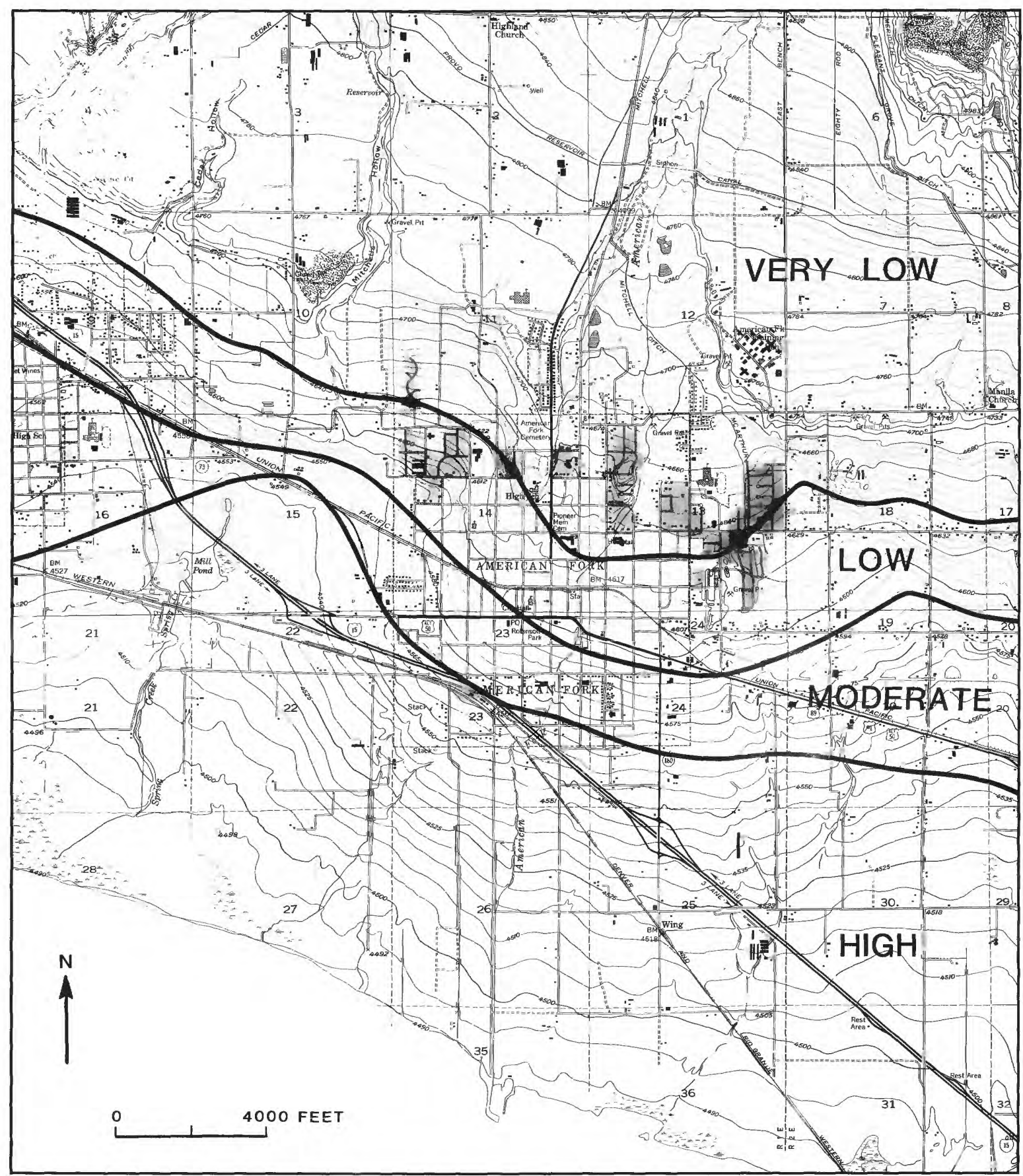

FIGURE 5. - Part of a topographic map (original scale 1:48,000) of Utah County upon which Anderson and others (1986, plate $4 \mathrm{~B})$ show areas with high, moderate, low, and very low potential for liquefaction corresponding to the probability of exceeding a critical acceleration.

would certainly cause substantial damage to structures on ... or utilities buried within a sliding mass" (Keaton and others, 1987, p. 75).

These four zones depend on the probability that a critical acceleration will be exceeded in a 100-yr period. The period of $100 \mathrm{yr}$ is arbitrary but useful for planning, and is the same as that used for liquefaction potential discussed above. The terms high, moderate, low, and very low are functions of the critical acceleration exceedence probabilities and the ground-water conditions similar to those used for liquefaction potential.

All of the information needed by a nontechnical user is shown on the map. The text includes discussion of method, geology, ground water, and ground motion; a 


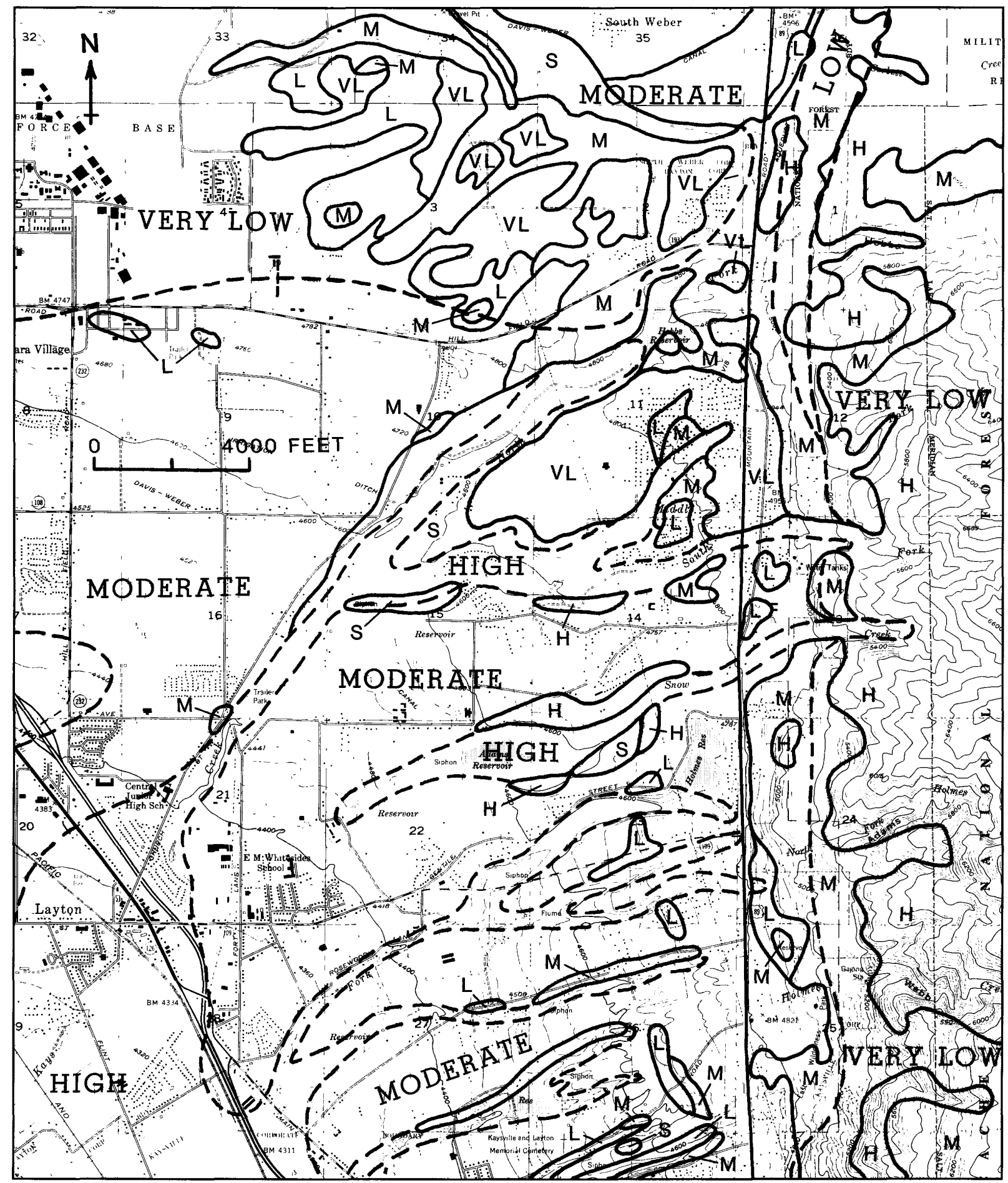

FIGURE 6. - Part of a topographic map (original scale 1:48,000) of Davis County, Utah, upon which Keaton and others (1987, plate $1 \mathrm{~b}$ ) show potential for earthquake-induced landslides and liquefaction. Letters H, M, L, and VL indicate high, moderate, low, and very low potential for landslides. The letter $\mathrm{S}$ indicates existing landslide. The labels, high, moderate, low, and very low, indicate potential for liquefaction. 
list of historical earthquake-induced landslides; and maps showing the historical limit of landsliding due to magnitude 7.5 earthquakes for all segments of the Wasatch fault.

\section{ROCKFALL SUSCEPTIBILITY}

Case (1987, p. V1-V36) has prepared a report and map concerning rockfall hazards in the central Wasatch Front between Layton and Draper (including Magna and Tooele) with particular emphasis on earthquake-induced rockfalls. The base map used is a USGS $712^{\prime}$ quadrangle map showing topography that has been reduced to a scale of 1:100,000 (see fig. 7). Field work was at a scale of $1: 24,000$ and is available from Case. Rockfall source areas are shown, but the maximum downslope extent of the hazardous areas is not. According to C.V. Nelson (oral commun., 1988), three county geologists plan to identify such areas using a computer-simulated model program.

Although frequency of rockfall occurrence is not shown on the map, the text contains a table of historic rockfalls and a conclusion based on a report by Keefer (1984) that reads:

Widespread damage could occur in the Central Wasatch Front area if an earthquake of magnitude 7.0-7.5 should occur. Some of that damage would be due to thousands of rockfalls that would be the result of ground shaking during the event and aftershocks greater than magnitude 4. The Borah Peak and Hebgen Lake earthquakes are examples of such earthquakes that can be reasonably expected in the future somewhere along the Wasatch Front.

W.F. Case (written commun., 1988) makes the frequency of occurrence quite clear:

Ground shaking during an earthquake can produce hundreds to thousands of rockfalls over an area of several thousand square kilometers. They are initiated by nearby earthquakes of magnitudes as low as 4 . Aftershocks of large earthquakes will continue to produce rockfalls after the main shock, particularly if outcrops were loosened by the main shock. A "characteristic" (magnitude 7-7.5) earthquake anywhere in the Wasatch Front will trigger rockfalls throughout the entire Wasatch Front.

Case says the purpose of his mapping project is to "red-flag" hazardous rockfall areas that need site-specific studies. He points out that such studies would require additional translation before use by community planners.

\section{TECTONIC SUBSIDENCE}

Keaton (1987) has prepared a report and map on potential consequences of earthquake-induced regional tectonic subsidence. The area covered includes the Great Salt Lake and vicinity from Salt Lake City to Brigham City along the Wasatch Front, Provo and vicinity, and
Juab Valley north of Nephi. The base maps used are USGS maps (1:100,000 and 1:125,000 scales) showing topography (see fig. 8).

The locations of effects of two earthquake events are shown on the maps: (1) the predicted subsidence that would accompany a "characteristic" Wasatch earthquake of moment magnitude 7.1 and (2) the observed subsidence that accompanied the 1959 Hebgen Lake, Montana, surface wave magnitude 7.5 earthquake. In the report, Keaton (1987, p. 19) restates earthquake occurrence as the "Wasatch fault is ... considered to be capable of generating earthquakes in the range of local magnitude ... 7.5" and "subsidence should be expected to accompany major earthquakes."

Severity is shown on the map by contour lines of subsidence in 5-ft increments, by areas of potential ponding, and by areas of potential lake-margin flooding. In addition, the locations of sewage-treatment plants are shown along with directions and amount of tilt. A relatively slight change in hydraulic gradients at plants, outfalls, or other major drain lines will interrupt gravity flows. Such interruptions may cause ponding of sewage and health hazards.

The text contains general discussions of the effects of subsidence on such critical facilities as transportation, oil refineries, and waste-water treatment plants. Similar critical facilities are likely to be interrupted by the same event, reducing system backup and redundancy.

\section{DAM FAILURE}

McCann and Boissonnade (1985) assessed the impact of shaking on the Pineview Dam and its failure on portions of the city of Ogden. The base map used is a USGS $712^{\prime}$ quadrangle that has been reduced to a scale of 1:48,000. A design earthquake of Richter magnitude 7.5 with an epicenter in downtown Ogden is assumed. Several feet of vertical offset along the $31.5 \mathrm{mi}(50 \mathrm{~km})$ of fault rupture is estimated. Ground acceleration in the range of 50-80 percent of gravity at the dam site is estimated. Since the Pineview Dam is only $6 \mathrm{mi}(10 \mathrm{~km})$ from the fault trace, McCann and Boissonnade (1985, p. 5-1) assume that the ground motion exceeds the design basis of the dam, and failure occurs.

In the event that Pineview Dam fails, the breach of the dam will release the reservoir. The boundaries of the inundated parts of Ogden for a filled reservoir are shown on a map (fig. 9) with peak flood depths. The flood wave is expected to travel with velocities as high as $20 \mathrm{mph}$ (32 $\mathrm{km} / \mathrm{hr}$ ). As part of the study, damage to commercial and residential buildings from the design earthquake and flooding that results from the dam failure is assessed. In addition, casualties from both the earthquake and the dam failure are also estimated. 


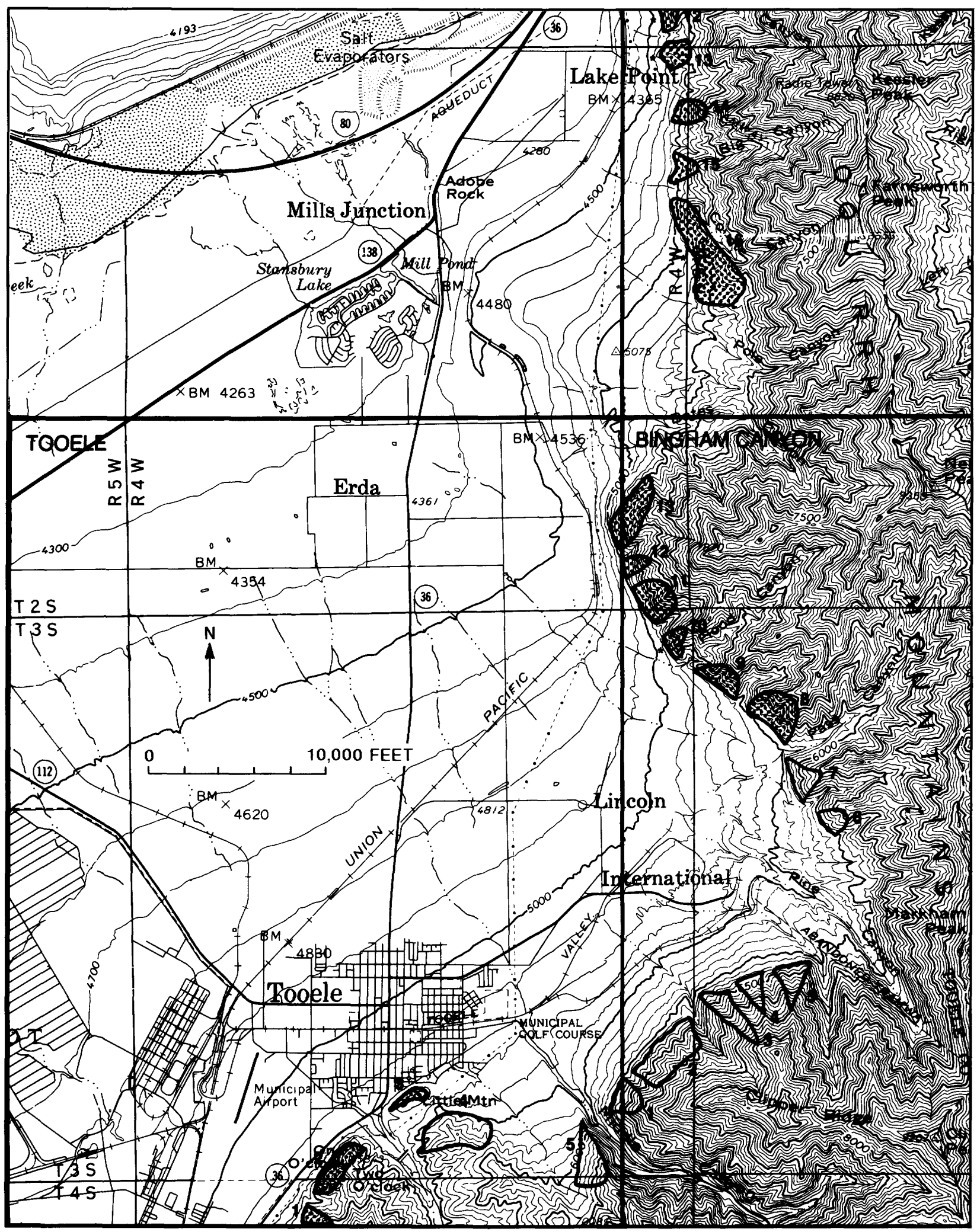

FIGURE 7. - Part of a topographic map (original scale 1:100,000) of Salt Lake and Tooele Counties upon which Case (1987, p. V-11) shows mountain spur areas susceptible to rockfalls. Those areas with a rockfall hazard are stippled. Numbers within each USGS $71_{2}^{\prime}$ quadrangle are referred to in Case's text. 


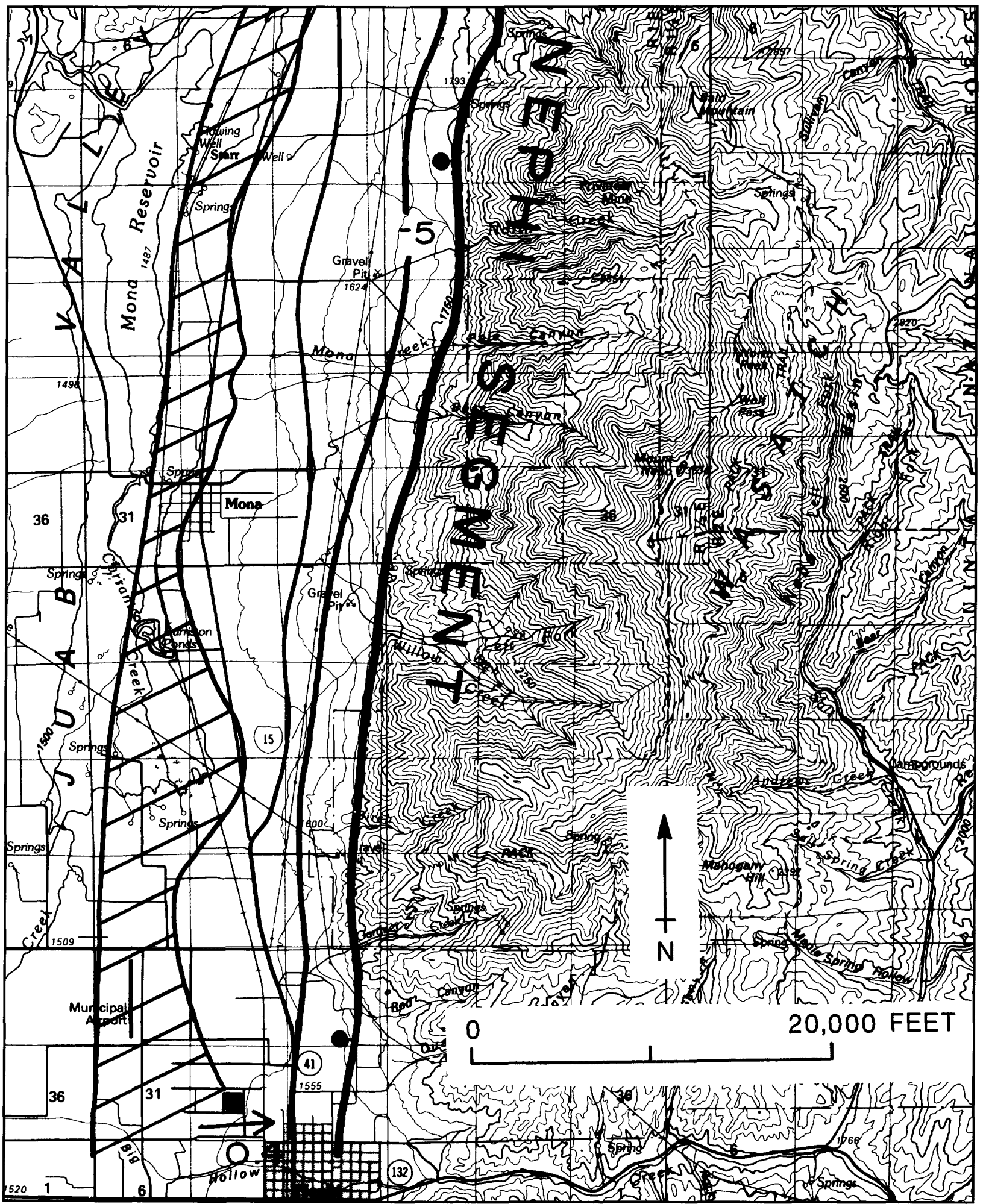

Figure 8.-Part of a topographic map (original scale 1:100,000) of northern Juab Valley, Utah, upon which Keaton (1987, pl. 6) shows potential consequences of tectonic deformation along the Nephi segment of the Wasatch fault. Fault trace is indicated by a heavy line, and contours of subsidence (in feet) by a less heavy line. Cross-hatched area indicates potential ponding of shallow (less than $3 \mathrm{ft}$, or $1 \mathrm{~m}$ ) ground water due to subsidence. Solid square indicates the location of a sewage treatment plant with direction and amount of anticipated tilt (ft/mi) shown. 


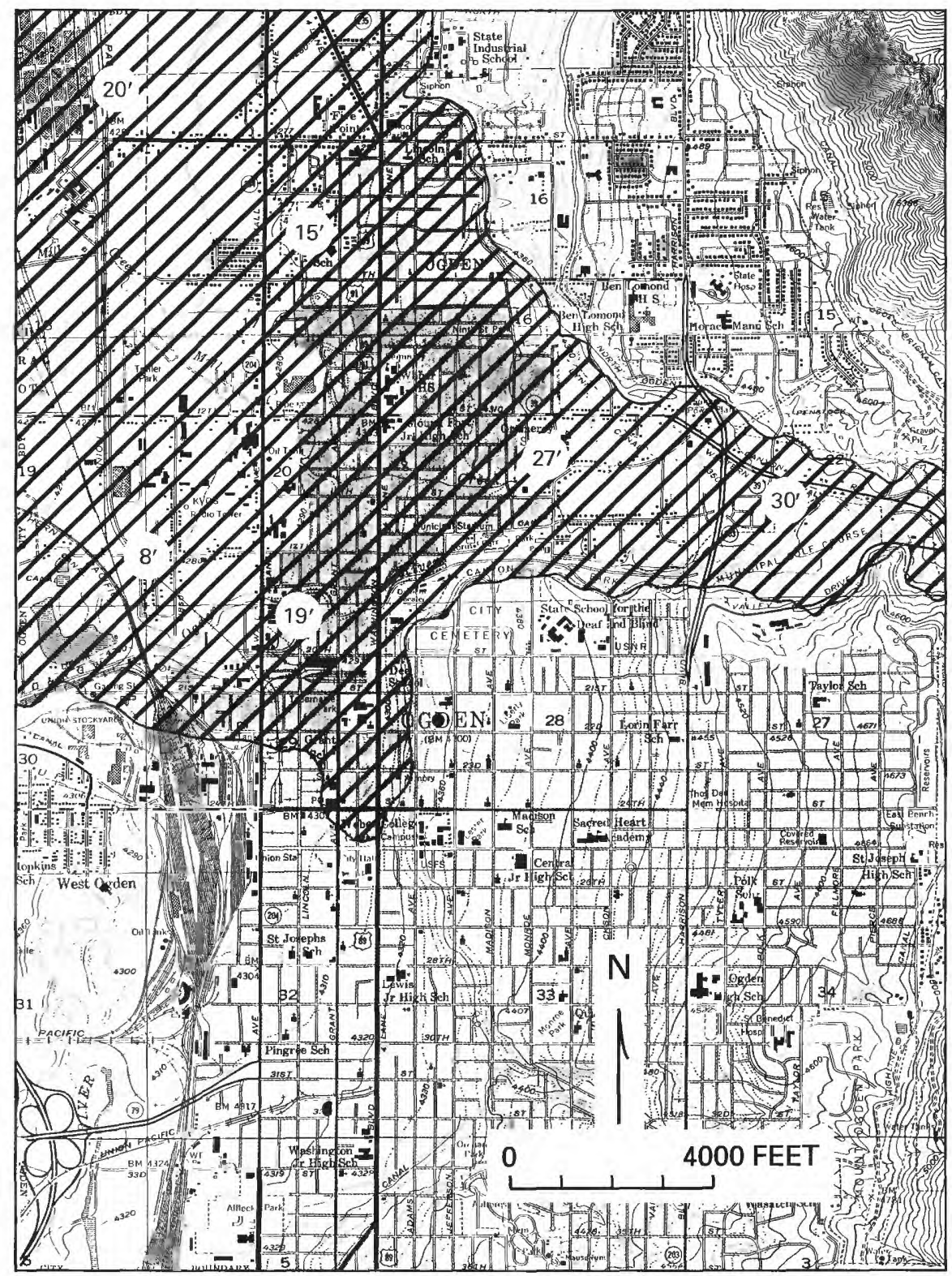

FIGURE 9. - Topographic map (original scale 1:48,000) of Ogden/Pineview, Utah, study area upon which McCann and Boissonnade (1985, fig. 3-4a, pp. 3-27) show inundation area from a failure of Pineview Dam. Numbers indicate peak flood depths in feet.

Even though likelihood, location, and severity are given for the inundation hazard, the example is one of a failure and damage scenario only for the purposes of emergency management planning. McCann and Boissonnade $(1985$, p. $3-2)$ are careful to point out that "no speculation is made concerning the likelihood that the consequences evaluated ... could occur."
This example is one of the uses of translated research for the purpose of assessing the impact of a secondary hazard (dam failure) as well as earthquake shaking. All dams impounding greater than 20 acre-ft $\left(24,660 \mathrm{~m}^{3}\right)$ of water, and all dams for which dam-failure inundation studies have been completed in Utah, have been compiled by Harty and Christenson (1988). 


\section{COMMENT}

In all of these Utah examples, the elements of likelihood, location, and severity are found, although various scales, parameters, and formats are used. Some examples require further translation for the nontechnical user. If these examples are easy to understand and use, then the researchers/translators are meeting major goals of the Utah work plan.

In some cases, the translators have taken the opportunity to include discussions or illustrations of past casualties or damage, and recommendations for using the translated work for hazard reduction. In other cases, county geologists are providing guidelines for use of the translated information for debris flows and liquefaction (Lowe, "Debris-flow hazards: A guide for land-use planning, Davis County, Utah," and "Liquefaction hazards: A guide for land-use planning, Davis County, Utah," this volume), surface-fault rupture and tectonic subsidence (Robison, 1988a, b), landslides (Robison and Lowe, "Landslide hazards: A guide for land-use planning, Davis County, Utah," this volume), rockfalls (Nelson, "Rockfall hazards: A guide for land-use planning, Salt Lake County, Utah," this volume) and other geologic hazards (Lowe and Eagan, 1987).

Often the simplicity of format and ease of use mislead users to believe that the translated products are easy to produce. A familiarity with the references cited in each report will remind the reader that numerous geologic, geophysical, and engineering studies over many years along with many innovative and creative ideas were necessary to produce these examples.

According to C.V. Nelson (oral commun., 1988), the county geologists and others are performing additional studies or compilations that will result in translated information. For example, nonearthquake-induced landslide-potential information will be combined with the earthquake-induced landslide-potential map prepared by Keaton and others (1987) to produce a c.mposite landslide hazards evaluation. A text has also been prepared discussing other hazards such as failure in sensitive clays, seiches, subsidence in granular materials, and hydrologic changes (Lowe, "Hazards from earthquakeinduced ground failure in sensitive clays, vibratory settlement, and flooding due to seiches, surface-drainage disruptions, and increased ground-water discharge, Davis County, Utah," this volume). Emmi ("A mapping of ground-shaking intensities for Salt Lake County, Utah," this volume) has created maps showing the ground-shaking hazard of Salt Lake County using MMI scales.

\section{TRANSFER TO NONTECHNICAL USERS}

The objective of transferring hazard information is to ensure its use in reducing losses from future earth- quakes. Translated hazard information is a prerequisite for transfer to nontechnical users. Its objective has been previously described as making the users aware that a hazard exists; providing information that can easily be presented to superiors, clients, or constituents; and providing materials that can be directly used in a reduction technique (list 2). The Utah work plan is quite specific as to what is expected of transfer activities:

- Foster the creation and implementation of hazardreduction measures.

- Ensure that users will have easy access to data.

- Release information promptly.

- Provide the most effective educational, advisory, and review services appropriate to the targeted users.

- Encourage both the transfer of hazard information and its effective use for hazard reduction.

\section{DEFINITION}

Various terms are used to convey "transfer" of information to users, namely, disseminate, communicate, circulate, promulgate, and distribute. Often these terms are interpreted conservatively, for example, merely issuing a press release on hazards or distributing research information to potential users. This level of activity cannot be expected to result in effective hazard reduction techniques or even to make users aware of the hazard.

According to Slovic (1986), communicators must appreciate the limitations of public understanding, namely that perceptions are often inaccurate, risk information may frighten and frustrate the public, strong beliefs are hard to modify, and naive views are easily manipulated by the format used to present other perspectives. Slovic then suggests that research is needed in the areas of informed consent, information relevance, perceived risk, and the use of the media. Sorensen and Mileti (1987) provide an excellent discussion on the dilemmas of perception, the warning response process, the determinants of senders and receivers, the personalizing of warnings, and the nonbehavioral aspects of response.

No concise definition of, or criteria for, "transfer" has been offered or can be found in the literature except by inference or by analysis of what actually works for those who have developed and adopted reduction techniques. Therefore, I suggest that we use "transfer" to mean the delivery of a translated product in a usable format at a scale appropriate to its use by a specific person or group "interested" in, or responsible for, reducing hazards. To delivery of a product, I would add assistance and encouragement in its use; in other words, an active, ongoing learning experience.

This definition of "transfer" is somewhat analogous to the passing of a football or baton. Assume that the 
football or baton is understandable and in a usable format. Once the hand-off or passing has taken place, the receiver (for various reasons) may not run, win the race, or otherwise act appropriately.

It is the same with a receiver of earthquake hazard information. The information alone without action will not reduce casualties, damages, and interruptions. Obviously, something else is needed. My experience indicates that effective transfer must include not only delivery but assistance and encouragement in the selection and adoption of an appropriate reduction technique. Only then have the researchers, translators, and transfer agents fulfilled their professional obligations.

\section{TRANSFER TECHNIQUES}

Such delivery, assistance, and encouragement can be accomplished through specific transfer techniques, which may be categorized into educational, advisory, and review services (list 4). These services were identified and tested by me during the 1960 's, successfully used by the Southeastern Wisconsin Regional Planning Commission $(1968,1987)$, incorporated into the overall program design for the New Mexico State Planning Office (Kockelman, 1970, p. 34-41), brought to the attention of the USGS (Kockelman, 1976a), and incorporated into the USGS national program of landslide hazard reduction (U.S. Geological Survey, 1982, p. 34, 37-47). In addition, these services are provided by some USGS scientists, engineers, planners, and others as a personal commitment or under various earth science application and public information programs. The remarkable effort in Utah to provide these services can be seen in the following section.

Educational services range from merely announcing the availability of earthquake hazard information, through the publishing and distributing of newsletters and brochures, to sponsoring, conducting, or participating in seminars and workshops for potential users.

Advisory services range from explaining or interpreting earthquake hazard reports and maps, through publishing guidebooks and assisting in the design of regulations based on the information, to giving expert testimony and depositions concerning the information.

Review services include review and comment on policies, procedures, studies, plans, statutes, ordinances, or other regulations that are based on, cite, interpret, or apply earthquake hazard information.

The educational and advisory services should not supplant existing programs or activities of educational institutions, or replace services of private consulting firms or State and local organizations, but should serve as supplements!
The importance of educational and advisory services to accomplish delivery, assistance, and encouragement is obvious. The importance of review services is less obvious. When used in a regulatory technique that affects land use and property values, hazard information is eventually challenged in a courtroom or other public forum. At that time the researcher is requested or subpoenaed to explain (or confirm the proper use of) the research information.

The researcher must have had the opportunity to review the use of the research and to correct any potential misuse, or the regulation will lose validity, the researcher will be embarrassed, and the user chagrined. It is foolish not to review when the effort to review is compared with the time and scarce resources needed to perform the required scientific and engineering studies (list 1), to translate and transfer them, and to prepare, adopt, and enforce a reduction technique (list 2).

Multiple ways of imparting information should be encouraged. A single exposure to new information, especially if the information is complex or differs from a user's previous knowledge, is often insufficient. Repeated exposure in different formats and through different conduits is needed. This strategy is particularly successful when new information is supplied by persons who customarily provide guidance, such as members of the same professional group. The most effective transfer techniques (list 4) should be selected jointly (if possible) by the translator, transfer agent, and user.

Most public hearings or presentations to decisionmakers allow little time, and the transfer agent is competing with numerous other issues. The simplest, most concise translation and transfer techniques are the most successful. A senior scientist at USGS (A.H. Lachenbruch, written commun., 1981), with experience in successfully transferring research information to Congress as well as to local decisionmakers, observed: "Simple maps with a few bright colors are needed ...." Obviously, such maps must be derived from larger scale and more detailed information that, if needed to meet a challenge, are readily available.

\section{TRANSFER AGENTS}

For the purposes of this report, the term "transfer agents" is defined as those who deliver translated research information to potential users and assist and encourage them in selecting and adopting appropriate hazard reduction techniques. In his final report on the County Hazards Geologist Program, Christenson (1988, p. 3) identifies several options for transferring geologic expertise to local governments:

- Permanent, full-time city or county geologist. 


\title{
List 4. - Examples of techniques for transferring hazard information
}

\author{
Educational services
}

Providing serial and other types of publications reporting on hazard research under way, reduction techniques in process, and the adoption and enforcement of reduction techniques.

Assisting and cooperating with universities, university extension divisions, and other schools in the preparation of course outlines, detailed lectures, casebooks, and audio or visual materials.

Contacting speakers and participating as lecturers in State and community education programs related to the use of hazard information.

Sponsoring, conducting, and participating in topical and areal seminars, conferences, workshops, short courses, technology utilization sessions, cluster meetings, innovative transfer meetings, training symposia, and other discussions with user groups.

Releasing information needed to address critical hazards early through oral briefings, newsletters, seminars, map-type "interpretive inventories," open-file reports, reports of cooperative agencies, and "official use only" materials.

Sponsoring or cosponsoring conferences or workshops for planners, engineers, and decisionmakers at which the results of hazard studies are displayed and reported on to users.

Providing speakers to government, civic, corporate, church, and citizen groups, and participating in radio and television programs to explain or report on hazard reduction programs and techniques.

Assisting and cooperating with State and community groups whose intention is to incorporate hazard information into school curricula.

Preparing and exhibiting displays that present hazard information and illustrate their use for hazard reduction.

Guiding field trips to disaster areas, damaged structures, and potentially hazardous sites.

Preparing and distributing brochures, television spots, films, kits, and other visual materials to the news media and other users.

Operating public inquiries offices, sales offices, and clearinghouses.

Advisory services

Preparing annotated and indexed bibliographies of hazard information and providing lists of pertinent reference material to users.

Assisting local, State, and Federal agencies in designing policies, procedures, ordinances, statutes, and regulations that are based on, cite, or make other use of hazard information.

Providing explanations of hazard information and reduction techniques during public hearings.

Assisting local, State, and Federal agencies in the design of hazard information collection and interpretation programs and in work specifications.

Providing expert testimony and depositions concerning hazard research information and its use in reduction techniques.

Assisting in the presentation and adoption of plans and plan implementation devices that are based on hazard information. plans.

Assisting in the incorporation of hazard information into local, State, and Federal studies and

Preparing brief fact sheets or transmittal letters about hazard products to explain their impact on, value to, and most appropriate use by local, State, and Federal planning and development agencies.

Assisting users in the creation, organization, staffing, and formation of local, State, and Federal planning and plan implementation programs to ensure the proper and timely use of hazard information.

Preparing and distributing appropriate guidelines and guidebooks relating to processes, mapping, and reduction techniques for natural hazards.

Preparing models for State safety legislation, regulations, and development policies.

Preparing models for local safety policies, safety plan criteria, and hazard reduction techniques.

Advising on and providing examples of the methods or criteria for hazard identification, vulnerability assessments, hazard reduction, and emergency management.

\section{Review services}

Reviewing proposed programs designed for collecting and interpreting hazard information.

Reviewing local, State, and Federal policies, administrative procedures, and legislative analyses that relate to assessing and reducing hazards.

Reviewing studies and plans that are based on, cite, or otherwise use hazard information.

Reviewing proposed regulations, policies, and procedures that incorporate or cite hazard information. 


\section{List 5. - Potential transfer agents for earthquake hazard information in Utah}

American Planning Association, Utah Chapter

American Society of Civil Engineers, Utah Section

American Society of Public Administrators, Utah Chapter

Association of Engineering Geologists, Utah Section

Bear River Association of Governments

Children's Museum

Church groups, church organizations, and church leaders

Civic and volunteer groups

Consultants (engineers, planners, geologists, and others)

County geologists and extension agents

Educators (university, college, secondary, and elementary)

Governor's Advisory Council on Local Governments

Hansen Planetarium

International Conference of Building Officials, Utah Chapter

League of Women Voters

Local building, engineering, zoning, and safety departments

Local seismic safety advisory groups

Media (journalists, commentators, editors, and feature writers)

Mountainlands Association of Governments

Neighborhood associations

Public information offices

Relief Society, Church of Jesus Christ of Latter-day Saints

Researchers, engineers, and planners (local, State, and Federal)

Society of American Foresters, Wasatch Front Chapter

Southeastern Utah Association of Governments

Speakers' bureaus (State, local, or project area)

Structural Engineering Board, Church of Jesus Christ of Latter-day Saints

University of Utah Seismograph Stations

Utah Association of Counties

Utah Division of Comprehensive Emergency Management

Utah Department of Social Services

Utah Geological Association

Utah Geological Survey

Utah League of Cities and Towns

Utah Museum of Natural History

U.S. Forest Service

U.S. Geological Survey

U.S. Soil Conservation Service

Wasatch Front Regional Council

Western Governors' Policy Office

- Circuit-rider geologist serving several governments contemporarily.

- Geologist employed by an umbrella agency (regional association of governments, State survey) but dedicated to serving local governments.

- Private consulting geologist on retainer or under contract with local government.

It should be noted that consultants under contract with a local government may have the appearance of a "conflict of interest" if they represent other parties within the local government's jurisdiction.

Potential transfer agents of earthquake hazard information in Utah are given in list 5. Many of the users in list 3 will also be transferring such information. Bates $(1979$, p. 11) notes that "although both the use of transfer agents and the education of planners in the earth sciences ... are increasingly important components of the information-transfer system, nothing replaces intensive producer-user interaction ...."

Of course, geologists, seismologists, and other earthquake researchers may be available to provide some of the educational, advisory, and review services, but it is unreasonable to rely solely or heavily on these skilled and scarce resources, as this would divert them from their work of understanding the process, assessing the hazard, and translating their research.

The role of the professional associations of planners, engineers, geographers, and geologists should be emphasized. For example, Petak (1984, p. 457) points out that "hazard and risk assessment must be ... fully supported 
by the efforts of the geotechnical profession." The professions not only can contribute to identifying user needs, translating and transferring complex information, and fostering an environment for use, but they are principal users themselves. The Yin and Andranovich (1987) study on getting research used in the natural hazard field concluded that the role of professional associations "is a diffuse model, in which multiple sources of ideas are mixed with multiple types of users ...." Transfer agents should solicit and use the expertise of those members of the sociological community who are trained and experienced in reducing natural hazards.

Examples of successful transfer agents and their transfer programs follow:

- Circuit rider geologist in the State of Washington (Thorsen, 1981).

- Planning, reviewing, and enforcing by city and county geologists (McCalpin, 1985; Christenson, 1988).

- Advisory services unit of the California Division of Mines and Geology (Amimoto, 1980).

- Educational, advisory, and review services by the Southeastern Wisconsin Regional Planning Commission $(1968,1987)$.

- Earth science information dissemination activities of the U.S. Geological Survey (Information Systems Council's Task Force on Long-range Goals for USGS's Information Dissemination, 1987).

- Earthquake hazard reduction activities of the staff, members, and committees of the California Seismic Safety Commission (1986).

\section{SUCCESSFUL TRANSFER}

One of the best ways to determine which transfer techniques are effective is to look closely at techniques that have been used and that have resulted in the reduction of natural hazards. For more than $25 \mathrm{yr}$, a midwestern multicounty planning commission has transferred geologic, hydrologic, and pedologic hazard information to public and private users. The annual project completion report by the Southeastern Wisconsin Regional Planning Commission (1968) shows that almost every educational, advisory, and review service in list 4 was repeatedly used. Many other examples of the transfer techniques shown in list 4, including their transfer agents, can be cited. Selected examples follow:

- Earthquake hazard reduction series by the Federal Emergency Management Agency (1985-1989).

- Home guide section on how a house withstands an earthquake in the Chicago Tribune by Kerch (1988).

- Guidebook on reducing earthquake risks for planners by Jaffe and others (1981).

- Isoseismal map users guide by the Central United States Earthquake Consortium (1987).
- Canoe trip to view evidence of probable magnitude 8 or 9 earthquake in the Pacific Northwest by Atwater (1988).

- Introduction to geologic and hydrologic hazards in the United States by Hays (1981).

- Using earth science information for earthquake hazard reduction in the Los Angeles region by Kockelman (1985).

- Guidelines for preparing a safety element of the city and county general plan by a governor's office of planning and research (Mintier, 1987, p. 146-153).

- Case studies on strengthening hazardous buildings by the San Francisco Bay Area Regional Earthquake Preparedness Project (1988).

- Guidebook for disaster mitigation for planners, policymakers, and communities by Lohman and others (1988).

- Guidebook on identifying and mitigating seismic hazards in buildings, including a model ordinance for rehabilitating masonry buildings by the California Seismic Safety Commission (1987).

- Guidebook on seismic safety and land use planning by Blair and Spangle (1979).

- Handbook on land-use planning for earthquake hazard mitigation for planners by Bolton and others (1986).

- Analyzing and portraying geologic and cartographic information for land-use planning, emergency response, and decisionmaking in San Mateo County, California, by Brabb (1987).

- Getting ready for a big quake in Sunset Magazine by Lane Publishing Company (1982).

- Landslide hazard mitigation plan for Colorado by Jochim and others (1988).

- Trail signs describing the 1959 Hebgen Lake earthquake-triggered landslides and vertical displacement along the fault in the Gallatin National Forest, Montana, by the U.S. Forest Service.

- Workshop on the evaluation of regional and urban earthquake hazard and risk in Alaska convened by Hays and Gori (1986).

- Periodical on earthquakes and volcanoes (formerly Earthquake Information Bulletin) by the U.S. Geological Survey (Spall, 1975-present).

- Bibliography and index to seismic hazards of western Washington from 1855 to 1988 compiled by Manson (1988).

- Review of State landslide hazard maps by USGS physical scientist W.M. Brown, III (written commun., 1985).

- Peace of mind in earthquake country-How to save your home and life by Yanev (1974).

- Selected annotated bibliography of recent publications concerning natural hazards by Morton (1986). 
- Washington State earthquake hazards by Noson and others (1988).

- Pilot earthquake education projects in Arkansas, Tennessee, Mississippi, Washington, and South Carolina by Bolton and Olson (1987b, app. B).

- Steps to earthquake safety for local governments by Mader and Blair-Tyler (1988).

\section{COMMENT}

Many researchers provide educational, advisory, and review services on a limited and informal basis. Federal, State, and university scientists are frequently called on to assist users. Such services should be formally recognized and included as a work element in any earthquake hazard reduction program, as was done in the Utah work plan.

Many of these services are provided in Utah through cooperative agreements, serial publications, report and map sales offices, geologic inquiries staff, public inquiries offices, professional groups, local and State geologists, municipal planners and engineers, and ordinary day-today contacts with the public by the researchers and translators of earthquake hazard information. Specific examples from Utah are given in the following section.

The reader familiar with the successful transfer agents, programs, and techniques cited here will note that they accomplished the following:

- Delivered the information to those who are interested in using it or required to use it.

- Conveyed the hazard in such a way as to result in the user's awareness.

- Provided the user with a wide selection of reduction techniques.

- Suggested a strategy for using the hazard information in a reduction technique through examples.

It is my experience that educational, advisory, and review services must accompany any successful earthquake research, hazard assessment, translation, and transfer program designed for planners, engineers, and decisionmakers.

Several benefits accrue to the transfer agents and those researchers and translators involved in transfer activities:

- Satisfaction that professional obligations are complete and the "ball is now in another court."

- Sense of accomplishment when community safety is improved.

- Perception of how local, State, and corporate decisions are made.

- Awareness of where and how to make a civic contribution to encourage appropriate decisions.

\section{EXAMPLES OF SUCGESSFUL TRANSFER IN UTAH}

A remarkable effort is being made in Utah to transfer earthquake hazard information to nontechnical users, including real estate salespersons, financial institutions, and church groups. For example, in June 1985 three county geologists began providing educational, advisory, and review services to Weber-Davis, Salt Lake, and Utah-Juab Counties. The geologists were funded by USGS, and other support was provided by the UGS and the five counties. Financial support by local governments for 1989 is an indication of the success of this type of transfer program.

According to Christenson (1988, p. 2), the purpose of the Wasatch Front County Hazards Geologist Program is to

- Compile geologic hazards information and produce maps to delineate hazard areas.

- Review engineering geologic reports.

- Advise planners regarding hazards ordinances.

- Provide geologic expertise as required.

These geologists are a part of the county planning departments under direct supervision of the planning director; the UGS provides technical supervision and other support as needed. The geologists are also available to perform the same services to the cities within their county. Some of the services provided over just a 6-month period may be seen in the excerpt from the report shown in figure 10. A final report on data collection, hazards mapping, ordinance reviews, and many other accomplishments has been prepared by Christenson (1988, p. 5-9; "Wasatch Front county hazards geologist program," this volume).

Much of this work is directed toward reduction techniques (list 2) and therefore is not discussed in this section on transfer techniques. According to county geologist Mike Lowe (unpubl. speech, 1986), examples of such work include site investigation and hazard evaluation for South Weber City, city of Washington Terrace, city of North Salt Lake, Emigration Canyon (Salt Lake County), and the Lake Mountain and Pine Flat areas (Utah County).

Several Federal, State, and county planners, geologists, and emergency managers identified the "provision of education, advisory, and review services" as one of their most significant accomplishments to date (Christenson and others, 1987, p. 84). Examples of some of the transfer techniques used in Utah follow. Each technique can be categorized as an educational, advisory, or review service, or a combination of two or all of the services. In most cases, the transfer agents not only are delivering translated information as defined and illustrated in previous sections of this paper, but also are assisting and encouraging its use for hazard reduction. 
PHASE II (year 2) -- Wasatch Front County Hazards Geologist Program

\author{
Date: June 7, 1987 \\ Grant No. 14-08-0001-G991 \\ Grantee: Utah Geological and Mineral Survey \\ Don Mabey (principal investigator) \\ Title: Wasatch Front County Hazards Geologist Program \\ Grant effective date: February 7, 1985 \\ Grant expiration date: June 7,1988 \\ Period covered by report: December 7, 1986-June 7, 1987
}

This report covers the six-month period from December 7, 1986 to June 7, 1987, completing the second year of this three-year program. Phase I (data collection and compilation) and Phase II (basic data map compilation) are complete or nearly complete, and Phase III (preparation of interpretive or translated maps and text) is about to begin. In February, the UGMS and county geologists met with planning directors and others from each county .... All planning directors indicated firm support for the program and will include the geologists in their budgets for 1988. The principal need now is to convey the importance of the program to the county commissions who must approve the budgets. To do this, special presentations and field trips for commissioners and others are planned for June 1987. Also, the UGMS is planning to devote an issue of its quarterly publication, Survey Notes, to the county geologist program, with copies going to commissioners, mayors, and others involved in the decisionmaking. Final budgets must be approved in December 1987, at which time we will know whether or not the counties have decided to maintain the geologists.

Services provided to cities and counties during this report period include: aid in developing ordinances, reviews of engineering geologic reports, and memos to planners and developers indicating potential hazards at proposed developments requiring geologic investigations. Major special projects have included preparation of: 1) a gravel resource assessment for county property in Davis County, 2) a surface fault rupture hazard study for a proposed Provo City landfill in Utah County, 3) site investigation reports for two water tank sites for the city of North Salt Lake in Davis County, 4) a geologic hazards evaluation of property owned by Payson City proposed for development in Utah County, 5) a review of a proposed county fire station site along the Wasatch fault in Salt Lake County, 6) the engineering geologic section for the Pineview Reservoir Clean Lakes study to control development near the lakeshore to avoid contamination, Weber County, 7) the geologic hazards portion of the master plan for the city of Washington Terrace in Weber County, and 8) an engineering geologic report regarding geologic hazards, slope stability, and potential for ground-water contamination at the North Davis Refuse Dump and new burn plant in Davis County. The county geologists and UGMS have also given talks to various civic groups and governmental organizations, participated in radio talk shows, and been involved in a variety of technical and policy publications ... related to the program.

FIGURE 10. - Part of a final performance report on educational, advisory, and review services over a 6-month period prepared by G.E. Christenson (written commun., 1987). These types of services are identified in list 4. 


\section{WORKSHOPS}

During the period from 1984-1988, six workshops were held in Utah on assessing and reducing earthquake hazards. A field trip followed the 1986 workshop, and preliminary reports for this Professional Paper were released after the 1987 workshop. Each workshop fulfilled a commitment made in 1983 to bring key researchers and users of hazard information together each year for the purpose of providing current information on the earthquake hazard, distributing translated reports and maps, describing how they can be used, and fostering an environment for use of the information for hazard reduction.

Each workshop had various sponsors, including the University of Utah, UGS, CEM, FEMA, and USGS. Five were attended by as many as 130 earth scientists, engineers, planners, and emergency managers. One workshop, attended by more than 400 persons, addressed multihazards and comprehensive hazard reduction (May, 1988). An example of some of the topics addressed may be seen in figure 11. The proceedings of two of the workshops were edited by Hays and Gori $(1984,1987)$ and published as open-file reports to ensure early release and delivery. The UGS compiles examples of interim maps and reports available and uses the workshops as an opportunity to distribute them.

\section{SERIAL PUBLICATIONS}

Several serial reports designed to transfer earthquake hazard information in Utah to nontechnical persons were continued or begun during the past $5 \mathrm{yr}$. The attractive easy-to-read Survey Notes (fig. 12), published quarterly by the UGS (Stringfellow, 1983-present), features excellent articles such as the historic and scientific content of earthquake hazards in Utah by Mabey (1985), UGS information programs (Smith, 1985a), earthquake activity recorded by the University of Utah Seismograph Stations, hiring of county geologists, new publications, and such related activities as ongoing geologic projects, status of applied geology programs, personnel changes, and how UGS responds to disasters (Atwood, 1983).

The Wasatch Front Forum was specially created for the earthquake hazards program and is published and distributed quarterly by the UGS (Hassibe, 1983-1986; Jarva, 1987-present). It features timely articles on neighboring earthquakes (Crone, 1984), prediction in the Wasatch Front (Smith and others, 1985), earthquakeinduced soil liquefaction (Keaton, 1986), disruption of critical facilities (Frank, 1987), and earthquake preparedness projects (Tingey, 1986).

The newsletter also reports on the regional earthquake hazards assessment program (Hays, 1984), accom- plishments of the ground-shaking hazards and loss estimation program (Rogers and others, 1986), Utah County Comprehensive Hazard Mitigation Project (Dewsnup, 1987), progress of geologic, seismologic, and engineering research (Tarr, 1984), earthquake activities recorded by the University of Utah Seismograph Stations, and the results of surveys on the perceptions of risk by residents along the Wasatch Front. Notices of scheduled professional meetings, recent publications, out-of-state workshops of interest, new research programs, and reprints of timely articles such as that by Rogers (1986) are included on a regular basis (see fig. 13).

In addition, the Earthquake Information Bulletin (now Earthquakes and Volcanoes) (Spall, 1975-present), written for nontechnical readers, is published bimonthly by the USGS. It contains feature articles such as "Earthquake Potential of the Wasatch Front" (Spall, 1985), as well as reports on earthquake activity by states and countries. Notices of State, national, and international workshops and conferences on earthquakes and recent publications are also included on a regular basis.

\section{OUTREACH PROGRAMS}

The Utah Museum of Natural History contributes to the geologic education of the general public through exhibits, classes, lecture series, film series, field trips, teaching kits, and teacher workshops. Since the fall of 1985, "Utah Geologic Hazards" has been a popular outreach program.

According to the museum's earthquake safety instructor, Deedee O'Brien (written commun., 1988), the program has reached 3,000 students and adults for each of two school years (1985-86 and 1986-87). During the following year (1987-88), the outreach program was phased down in favor of training teachers to use the materials (fig. 14) and teach the information to their own classes. Three workshops were held in 1988 with instructors from the Museum, CEM, UGS, and the University of Utah. Seventy-nine teachers from five Wasatch Front school districts completed the course. Teachers may check out a teaching kit, which includes a 2-ft square model, cardboard fault blocks, 150 slides with text, and a packet of follow-up earthquake safety activities.

In addition to the geologic hazards curriculum, O'Brien developed an earthquake safety curriculum appropriate for kindergarten through third grade. The program has been tested in approximately 30 classrooms and has been offered to teachers in two in-service workshops entitled "Earthquake Safety in the Elementary Classroom." Forty-eight teachers attended these workshops, cosponsored by CEM. The museum continues to offer earthquake safety in-service courses annually. 


\section{FOREWORD}

Welcoming Remarks at the Workshop on "Earthquake Hazards Along the Wasatch Front": The Honorable Governor Norman H. Bangerter ......

\section{BACKGROUND INFORMATION AND SUMMARY OF THE WORKSHOP}

Background and Summary of the Workshop on "Earthquake Hazards Along the Wasatch Front, Utah"

Walter Hays and Paula Gori

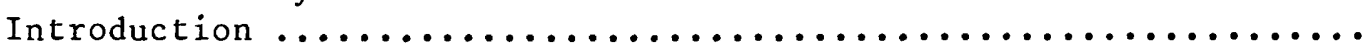
1984 Workshop on "Evaluation of Regional and Urban Earthquake

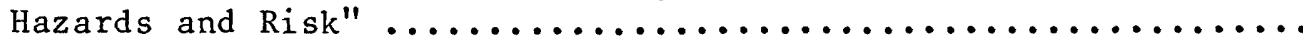

Workshops on "Earthquake and Landslide Hazards" $\ldots \ldots \ldots \ldots \ldots$

The Research-Applications Process ...................... 3

1986 Workshop Sessions ................................ 7

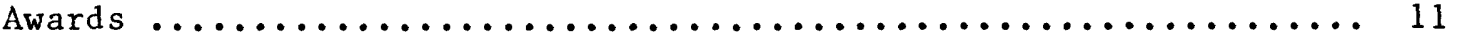

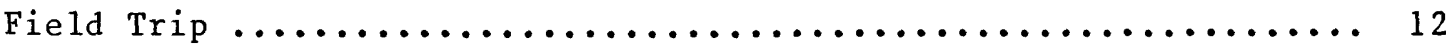

\section{EVALUATION}

Observations on the 1986 Workshop

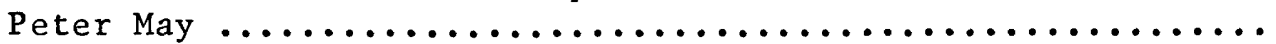

Statement Prepared for Presentation to the House Subcommittee on

Science Research and Technology, March 10, 1987

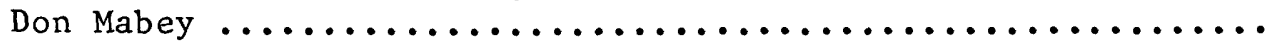

\section{REPORTS OF THE RESEARCH AND IMPLEMENTATION TRIADS}

Tectonic Framework and Earthquake Potential of the Wasatch Front Area and other Parts of Utah

Michael Machette, Bi 11 Lund, and Walter Arabasz ............ The Ground Shaking Hazard and Various Aspects of Loss Estimation in the Wasatch Front Region of Utah

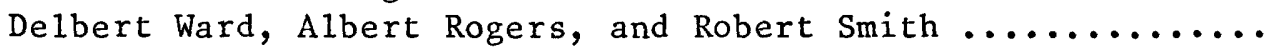

Ground Failure, Rock Falls, and Tectonic Deformation in the

Wasatch Front Area

Loren Anderson, T. Leslie Youd, and Earl Brabb ...........

Collecting, Compiling, Translating, and Disseminating EarthquakeHazards Information for Urban and Regional Planning and Development in the Wasatch Front Area, Utah

Gary Christenson, Jerold Barnes, Joseph Moore, Craig Nelson,

Robert Robison, Mike Lowe, and William Kockelman ...........

Development and Implementation of Loss-Reduction Measures in Utah

Genevieve Atwood, Lorayne Tempest, Gary Johnson and Jerome

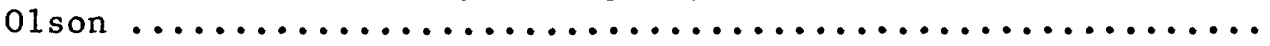

Integrating Scientific and Engineering Information into EarthquakeResistant Design in Utah

Lawrence Reaveley, Delbert Ward, and Walter Hays ..........

FIGURE 11. - Part of a table of contents from a workshop proceedings edited by Hays and Gori (1987). This type of workshop is a good example of a successful transfer technique. 


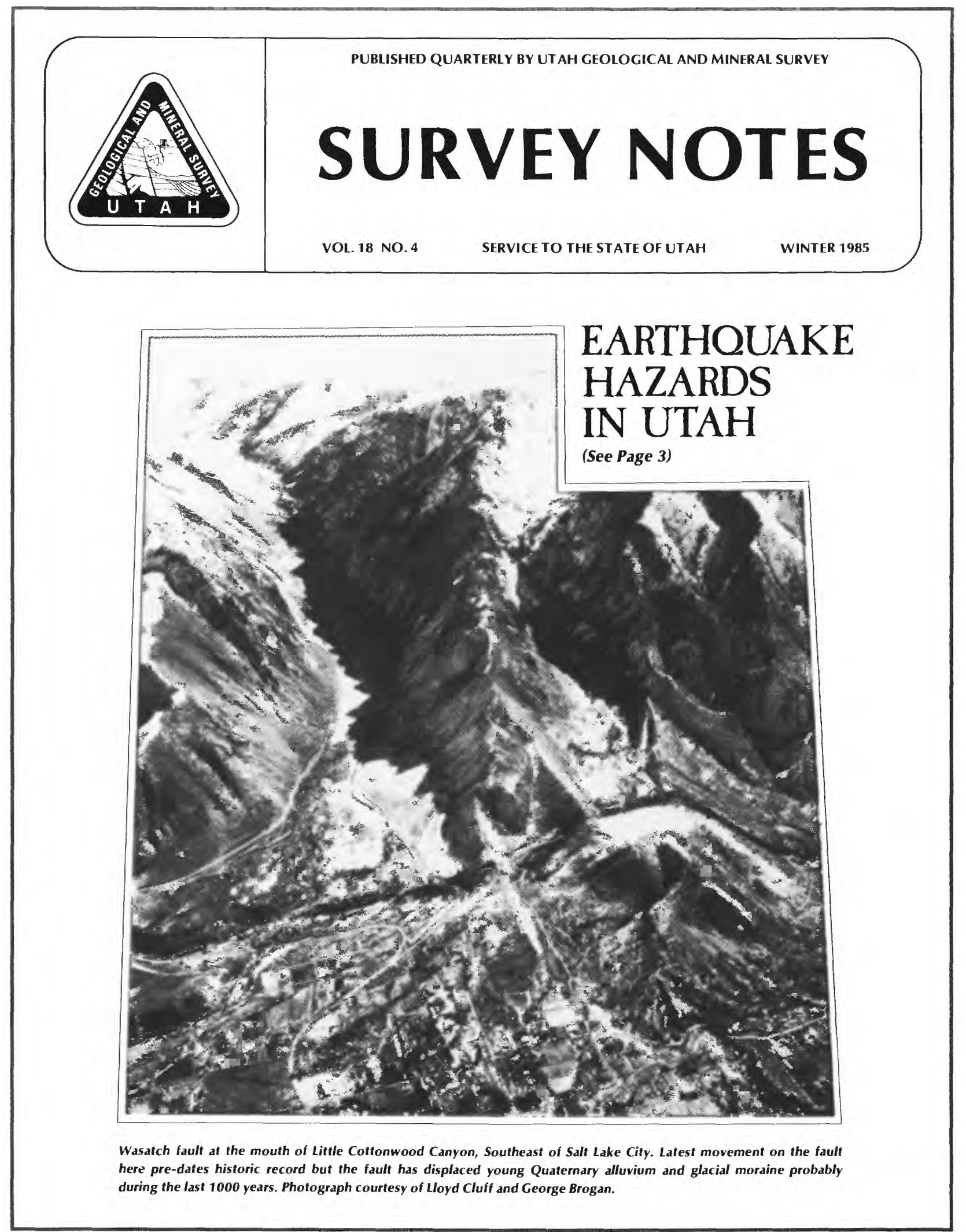

FIGURE 12. - Typical cover of a serial publication that addresses geologic hazard and resource issues. This type of publication is an excellent example of an information transfer technique identified as an educational service in list 4. 
COLLECTING, COMPILING, TRANSLATING, AND

DISSEMINATING EARTHQUAKE-HAZARDS INFORMATION FOR

URBAN AND REGIONAL PLANNING AND DEVELOPMENT IN

THE

WASATCH FRONT AREA, UTAH

By Gary Christenson, Jerold Barnes, Joseph Moore, Craig Nelson, Robert Robison, Mike Lowe, William Kockelman

\section{MOST SIGNIFICANT ACCOMPLISHMENTS}

Much of the work planned under existing programs is in progress but will not be completed for one or two more years. Under the UGMS Wasatch Front County Geologists Program, a series of translated (interpretive) maps $(1: 100,000)$ depicting hazards along the Wasatch Front are planned along with a report describing these hazards. Collecting and indexing hazards information and providing technical assistance to planners are being emphasized under this program. Under the UGMS Applied Geology Program, statewide hazard maps $(1: 750,000)$ are being completed. Other projects emphasize specific hazards mapping, evaluation of reduction techniques, education, and information dissemination.

\section{Some of the most significant accomplishments to date are:}

* Education of planners and decisionmakers in the Wasatch Front area regarding earthquake hazards through meetings, workshops, and placement of geologists on planning staffs in five Wasatch Front counties.

* Creation of county hazard information libraries with ready access to existing hazards information in five county planning department offices.

* Quality control over geotechnical investigations, particularly seismic hazards studies, by providing geological review of reports submitted to local planning agencies.

* Compilation of liquefaction potential maps and reports for three counties.

* Increased communication between earthquake hazards investigators.

* Incorporation of the School Outreach Program into the Museum's overall program, staffing, and budget.

* Provision of educational, advisory, and review services to State and local units of government.

\section{RECOMMENDATIONS AND PRIORITIES FOR THE NEXT TWO YEARS}

Because technical and scientific information is a prerequisite for effective implementation, it is recommended that information collected during the first three years be made available for translation and dissemination. It is further recommended that emphasis during the remaining two years of the program be placed on implementation projects. Many of the projects that have been funded will extend into this period, but priority should be assigned to projects which:

- Continue the building excavation inspection program (UGMS staff)

- Continue the compiling of the statewide hazards bibliography (UGMS staff)

- Provide occurrence intervals and severity of various hazards to give planners and decisionmakers a basis for estimating risk (USGS staff and grantees)
- Provide State and local hazards susceptibility maps and reports (County geologists; UGMS staff)

- Develop guidelines for local governments to use in writing earthquake hazard ordinances (UGMS staff)

- Continue providing educational, advisory, and review services aimed at State and local planners and decisionmakers (UGMS staff; County geologists; CEM staff; Museum staff)

- Incorporate collecting, compiling, translating, and disseminating work into ongoing programs of State and local governments

During the past two years, some additional needs have been identified; the following specific needs should be assigned priority:

- Developing model ordinances, which address earthquake hazards, for local governments

- Collecting examples of reduction techniques for each hazard, and evaluating them for effectiveness

\section{GROUND MOTION ELEMENTS}

(from a presentation by Al Rogers at July 1986 Workshop)

\section{SOURCE}

\section{* SIGNIFICANT ACCOMPLISHMENTS}

$>$ Revised segmentation of the Wasatch Front

$>$ New segmentation slip rates for some segments

$>$ Suggestion that slip rates are related to paleo-lake level

$>$ Discovery that some scarps in the Great Basin may be terminated by detachment faults at shallow depths

$>$ Successful testing of experimental high-frequency reflection techniques for studying Quaternary fault geometry and exploration for Quaternary faults

$>$ Discovery of strike-slip faulting in both the geologic and seismic records for a portion of the Colorado Plateau-Basin and Range Transition Zone

$>$ Borah Peak

Reaffirmation of segmentation

* KNOWLEDGE REQUIRED

$>$ Continued segmentation studies and slip rate estimates

$>$ Continued studies of active fault geometry

$>$ Strong ground motion measurements in the vicinity of Great Basin earthquakes

\section{TRANSMISSION PATH}

\section{* SIGNIFICANT ACCOMPLISHMENTS}

$>$ Revised peak acceleration and velocity curves for western Utah based on regression models and a worldwide strong motion data set

$>$ High and Low $Q$ versions

FIGURE 13. -Typical article reporting on the status of the Utah Earthquake Hazard Reduction Program in the Wasatch Front Forum (vol. 2 , no. 4, p. 5). This type of newsletter is a unique example of a transfer technique in Utah identified as an educational service in list 4. 


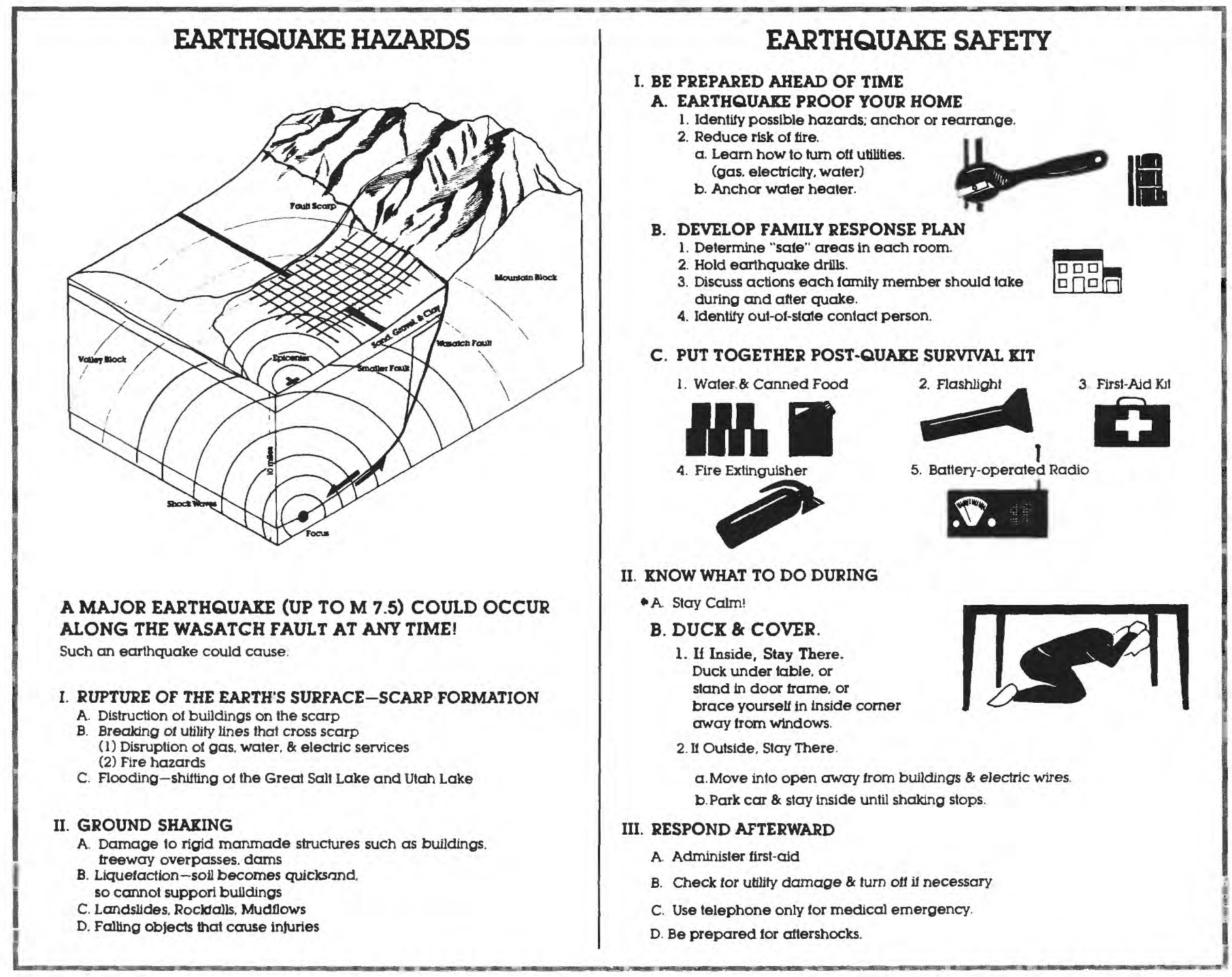

FIGURE 14. - Example of materials provided to students, teachers, and the general public under an outreach program by the Utah Museum of Natural History (1985). This innovative transfer technique is identified as an educational service in list 4 .

Utah's CEM has developed various hazards outreach programs that include educational and advisory services. A good example is an inexpensive booklet by Tingey (1989) that provides both an awareness of the earthquake hazard and suggested preparations to reduce the hazard. According to Tingey and Findlay (1987, p. T11), CEM has made many presentations and, in one year alone, distributed more than 730,000 brochures on earthquakes and hazard reduction. One project completed in 1986 was the production of a television program (video format) that succinctly covered the earthquake hazard, risk, and safety concepts specific to the Wasatch Front. Near the end of the project, the local CBS affiliate, KSL Television, produced an excellent half-hour program ("Not If ... But When"), which was shown twice in response to public reaction, during
January 1987. The program won a regional Emmy Award out of 150 entrants from seven western states. Several copies of the video are being used to make presentations to school, church, business, and other interested groups.

Integrated into the video were results of the latest research on fault-surface expression, segmentation, rupture, and geometry, ground shaking and amplification, liquefaction, and loss estimates for postulated events. Translation of this research was performed by CEM, UGS, scientific and public safety oriented agencies, and the producer of the video program. According to Tingey (1988, p. 102), the producer "had a terrific feel for the material" and was able to distill and translate complex ideas into concepts understandable by the nontechnical audience. 
The Utah State Office of Education (Burningham, 1983) has produced an inexpensive, well-illustrated comprehensive booklet on natural hazards entitled "I can make the difference-Emergency preparedness." One chapter (Burningham, 1983, p. 15-28) addresses earthquake hazards through three personalized scenarios, questions and solutions, a quiz, and a word-hunt game.

The UGS has provided one-page flyers for public use concerning, for example, earthquake hazard situation, safety, and faulting in Utah by Kaliser (1984a-c). These flyers address scientific evidence, historic events, population exposed, past damages, expected magnitude, critical facilities vulnerability, retrofitting, topographic expressions, and other aspects of earthquake hazards and their reduction. Cogent, one-sentence "bullets" are used (see fig. 15).

The county geologists are continually providing educational services. For example, as county employees, they are available to explain earthquake hazards and reduction techniques to various county officials, staffs, and citizens. They have increased community awareness through a slide-lecture program presented to university students, community councils, civic groups, and other local government organizations such as the Ogden City Seismic Committee, citizens groups in Nephi and Provo (Lowe, personal commun., 1986), Salt Lake Board of Realtors, and various community councils in Salt Lake County. The UGS and the Utah County geologist conducted a class and field trip on geologic hazards for the 1988 annual education meeting of the Utah Chapter of the International Conference of Building Officials.

\section{FIELD TRIPS}

Field trips for both small and large groups have been conducted. A particularly comprehensive half-day trip to selected geologic features and buildings in southern Davis and northern Salt Lake Counties sponsored by UGS and USGS was arranged and conducted by Keaton and Reaveley (1986). Their well-illustrated text enhanced the opportunity for the nontechnical attendees to observe key geologic features and buildings in the metropolitan area.

Geologic features seen during the trip included surface evidence of movement along a fault plane, topographic scarps, and lateral spreads caused by earthquakeinduced liquefaction. Vulnerable buildings visited included gravity-frame structures with masonry infill walls, potable water tanks straddling the Wasatch fault, sewage treatment plants subject to subsidence by tectonic deformation, and communications centers with little lateral force resistance. Seismic-resistant structures viewed included Salt Lake County Government Center buildings with concrete shear walls, braced and anchored brick-clad buildings, and the seismically strengthened Veterans Administration Hospital.

The three county geologists have conducted numerous field trips for county commissioners, mayors, and other public officials to see geologic hazards in their respective jurisdictions. The UGS also conducts trips to trench sites for State and local government officials to present research results and to see first-hand evidence.

\section{NEWS MEDIA}

Wide dissemination of information to television viewers, radio listeners, and newspaper readers is one of the most effective ways of delivering information about earthquake hazards to nontechnical users. A typical release by the USGS Public Affairs Office is shown in figure 16. Typical newspaper coverage is shown in figure 17.

According to Sprinkel (1988), UGS, USGS, and CEM targeted the news media as an effective means to inform the public of the positive accomplishments of the earthquake program and to raise public awareness of the potential threat that earthquakes pose to Utahans. The news media are invited to all field trips, and nearly always attend. In addition, county geologists participate in local radio talk shows. The Utah Department of Natural Resources also works to ensure good press coverage. Sprinkel observes that there is an eagerness by the Utah press community to cover most of the earthquake-related stories. The result is an increased level of public understanding and awareness of Utah's susceptibility to earthquake hazards along the Wasatch Front.

\section{INFORMATION SYSTEMS}

At the inception of the Regional Earthquake Hazards Assessment Program in Utah, Tarr and Mabey (1984, p. 148) specified the objectives of the information system as follows:

- To make quality data readily available to meet the needs of researchers and policymakers.

- To create an information system that assures that new data will be available in the form most useful to meeting program objectives.

- To devise a system whereby potential users will have easy access to data in media, scales, and formats that will be most useful.

The authors suggested creating a "clearinghouse" with directories to all information. Much of what they envisioned is now reality (Sprinkel, 1988, p. 94).

During 1985-1988, UGS compiled a comprehensive bibliography of geologic hazards in Utah. References 


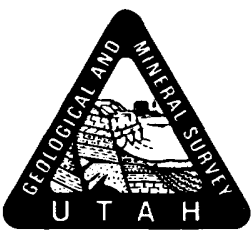

UTAH GEOLOGICAL AND MINERAL SURVEY

606 Black Hawk Way, Salt Lake City, Utah 84108

\section{BUILDING OR BUYING A HOME IN UTAH}

Prepared by Bruce N. Kaliser, Chief Engineering Geologist

BEFORE YOU BUY:

- Most geologic hazards such as landslides, floods, ground settling and aggravated earthquake ground motion can be avoided by proper site selection. Careful examination of sites during initial househunting searches can avoid costly water, wastewater, foundation and terrain stability problems later.

- Whether buying a vacant lot or existing structure, observe the property carefully and thoroughly. Look for: ground cracks - ground holes - disturbed earth - deposits of sediment or debris left by receding flood waters - signs of erosion - steep slopes, including on neighboring parcels - salt efflorescence on ground surface - surface depressions - wet ground - anomalous vegetation - cracked or disturbed foundations, walls, driveways, sidewalks - man-placed fill, engineered and non engineered $\cdot$ water bodies or conveyances (canals, ditches) on or above the property - distribution of bedrock and/or boulders at ground surface.

Interpretation of the significance of each of the above items must be done with caution; if any are present, professional advice should be sought.

Be aware that operations such as landscaping and utility installation may alter the ground surface appearance to resemble or conceal a natural phenomenon.

Modification of terrain in the vicinity of your parcel, either before you buy or after you build, particularly up-slope, may prove critical for you. Examples might include cutting into a slope, filling over a slope, drilling of an uncontrolled flowing well, diverting a spring, or installation of a deeply buried utility line.

Ground surface observation normally is sufficient for the evaluation of a residential property; if there is doubt, one or more holes will need to be dug or drilled and soil samples taken to resolve difficult questions. All examinations for subsurface fluid waste disposal require percolation tests in the soil by Health Authorities.

Ask questions of the realtor, homeowner, neighbors, but MOST IMPORTANT, conduct your own investigation, preferably with competent professional assistance (engineering geologist, geotechnical engineer).

- Consult State and Federal real estate and environmental documents for a broad statement of terrain conditions, but do not confine your examination of a particular parcel to the literature search.

\section{WHEN YOU BUILD:}

- Avoid constructing a home in the vicinity of moving earth, flood paths, fault traces or rock fall zones; do not build over underground openings or in depressions.

- Cost of construction, particularly in rural areas, can be reduced by knowing foundation conditions, depth to bedrock, depth to shallow groundwater, suitability of soils for wastewater disposal leach fields and groundwater depth and quality for primary or secondary water supply purposes.

- Adjust construction to accommodate these potential problems: moisture sensitive soils, high water table (shallow groundwater), low density soils, shallow bedrock or hardpan, severe earthquake ground-shaking zone, poor surface drainage, erosion-susceptible soil, steep or irregular topographic slope, boulders buried at shallow depth, springs or seeps on the property, variability of permeability of soils for fluid waste disposal.

- Maintenance problems can be reduced by prevention of erosion and soil movement under pavement, retaining walls and landscaping. Earth retention structures should all be properly engineered.

- Risk from earthquake to a single-family dwelling can be reduced by proper siting and construction.

Where you choose to build, even within a given parcel of land, can make a considerable difference.

4-8/81 BNK

FIGURE 15. - Example of a general fact sheet widely distributed in Utah that illustrates a common type of transfer technique identified as an educational service in list 4. 


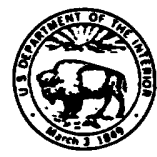

\section{United States \\ Department of the Interior \\ Geological Survey, Western Region Menlo Park, California 94025}

\section{Public Affairs Office \\ Pat Jorgenson \\ For release: UPON RECEIPT (Mailed August 26, 1988) \\ EAST-CENTRAL UTAH AREA HAS UNEXPECTED EARTHQUAKES}

(415) 329-4000

A series of earthquakes that have been shaking east-central Utah and western Colorado for the past two weeks (since Aug. 14, 1988) occurred in a part of Utah where earthquakes have been rare in the past, according to a

\section{U.S. Geological Survey scientist.}

"These quakes happened in a relatively inactive seismic area," said Ernest Anderson of the USGS Office of Engineering Geology and Tectonics in Golden, Colo. The tremors have been centered about $35 \mathrm{miles}$ south of Price, Utah, in a sparsely populated area of Emery County.

Most of Utah's earthquakes have occurred along the Wasatch fault, a north-south fracture in the Earth's crust, generally paralleling the western base of the Wasatch Mountains fust east of the Great Salt Lake. But Dr. Anderson said the Wasatch fault zone, which runs about 220 miles from Malad City, Idaho, south to Gunnison, Utah, about 120 miles south of Salt Lake City, would not have been a factor in the current series of earthquakes.

Carl Stover, a USGS geophysicist in Golden, Colo., who has compiled a series of selsmicity maps for individual states, confirmed that the area of the August earthquakes has "no record of historic seismicity." The seismicity map he prepared of Utah shows only one other recorded earthquake in that area since 1850. It occurred Sept. 7, 1962, and had a magnitude of only 3.3 .

The largest of the current earthquakes occurred Aug. 14 and was recorded at a preliminary magnitude of 5.6 on the Richter scale. The tremor, which occurred at 2:03 p.m. MDT, was preceded by a 3.5 magnitude earthquake at 12:59 p.m. and a 4.3 magnitude 4.3 magnitude tremor at 1:08 p.m. The area has continued to have aftershocks, with the largest (magnitude 3.5) occurring on the morning of Aug. 15.

Although the August earthquakes have caused no injurles and little damage, the 5.6 magnitude earthquake Aug. 14 was the fourth largest recorded earthquake in Utah's history. The only larger ones were a 6.1 magnitude earthquake in a remote area of the Utah-Idaho border in March 1975 and two earthquakes of magnitudes 6.0 and 6.6 in northwestern Utah in March 1934.

$$
\text { * * * USGS * * * }
$$

EARTH SCIENCE IN THE PUBLIC SERVICE

FIGURE 16. - Typical press release by the USGS Public Affairs Office illustrating a common but effective transfer technique. It is identified as an educational service in list 4. 


\section{Salt Lake Tribune 2/18/87 \\ Tests Warn Of S.L. Earthquake}

By Joan O'Brien

Tribune Staff Writer

The trenches tell the story of the past, and sound the warning.

Trenching studies along the Salt Lake section of the Wasatch Fault show that a major earthquake occurs every 2,200 to 2,500 years - and the last one was 2,200 to 2,400 years ago.

"We are right in the window of vulnerability for the next earthquake," said Salt Lake County Geologist Craig V. Nelson.

The Wasatch Front is replete with geologic hazards, but residents can take precautions and mitigate the damage that would occur in a "characteristic" earthquake measuring 7.2 on the Richter Scale, Mr. Nelson said.

For the last year and a half Mr. Nelson has been translating hard geologic data into a language city planners can understand. His maps detailing "red flag" zones will be available to developers and the public within a few months.

Mr. Nelson's federally funded position was created, in part, so the Salt Lake County Planning Commission could take geologic hazards into consideration in development proposals. The United States Geological Survey has also provided funding for similar positions in Weber and Davis counties and Utah and Juab counties.

The Wasatch Fault, stretching from Nephi to Brigham City, is actually a series of fault segments that could produce earthquakes independently of other segments, Mr. Nelson said.

Unlike California's San Andreas Fault, the Wasatch Fault does not creep. "Unfortunately, the Wasatch Fault does not creep and the strain is accumulating," Mr. Nelson said. "What we see in the trenches is that there are 6-foot breaks and then nothing, so it all builds up to a critical point."

When that critical point is reached, scientists expect a "characteristic" earthquake with a magnitude of over 7 on the Richter Scale.
Salt Lake Tribune 8/24/86

County Geologist Advocates LongRange Planning

\author{
Special to The Tribune
}

FARMINGTON-Mike Lowe, Davis County geologist, believes long-range planning is the key to protecting residents from geologic hazards.

Mr. Lowe, speaking to members of the Davis County Council of Governments, summarized his findings after one year as county geologist.

He said recent landslides, flooding, debris flows and the rising Great Salt Lake have created a high degree of public awareness concerning geologic hazards.

As a result of threats and damages by such hazards, Mr. Lowe was hired to collect and translate technical information for use by planners and local government officials in Davis and Weber counties.

Mr. Lowe said, during the Aug. 20 meeting, the county and many cities have adopted ordinances requiring geologic reports in potentially hazardous areas.

"By requiring these reports, hazards and mitigative measures can be identified and assessed," said Mr. Lowe.

"If development is allowed to proceed based on the report's recommendations, with zoning enforcers and building inspectors ensuring that those recommendations are followed, problems related to geologic hazards are less likely to arise," he added.

The geologist said he also has performed recent site evaluations focusing on new water tanks in North Salt Lake and Layton, three sites for a proposed new county jail and several landslide locations in the county.

In addition, the geologist said he did a number of site investigations of Bountiful and Farmington homes experiencing foundation cracks.
Deseret News 9/9/86

Geologist gathering data for hazards ordinance

PROVO - Utah County doesn't have a geological hazards ordinance yet, but by the time Robert Robison finishes a three-year stint as a special consultant for the county, there will be more than enough information to write the ordinance.

Robison is one of three geologists assigned to the Wasatch Front by the federal government.

His work area includes Utah and Juab Counties and he is also available to work with cities in both those counties.

This week Robison told Utah County commissioners he is moving into his second year of work for the county. He said that during the past year he has established a library with 700 maps and articles pertaining to soils and geology in Utah County.

"The purpose of my assignment is to collect information, establish a library, index maps and act as a technical assistant to the county and cities," said Robison.

Jess Mendenhall, Utah County planner, said Robison has provided much valuable information to the county.

"By the time he has finished gathering all the information, the county will be able to design the hazards ordinance and that will be a big help to us," Mendenhall said. "Most of the cities have one, but we haven't had the expertise to draw one up until now."

FigURE 17. - Typical local newspaper coverage of earthquake hazard reduction activities. Permission to publish. These examples are valuable information transfer techniques shown in list 4. 


\begin{tabular}{|c|c|c|c|c|c|c|}
\hline & Text & Weber & Davis & Salt Lake & Utah & Juab \\
\hline $\begin{array}{l}\text { 1. Surface fault rupture } \\
(1: 24,000)\end{array}$ & $\mathrm{F}$ & $\mathrm{F}$ & $\mathrm{F}$ & $\mathrm{F}$ & $\mathrm{D}$ & $\mathrm{D}$ \\
\hline $\begin{array}{l}\text { 2. Ground shaking } \\
(1: 250,000)\end{array}$ & $\mathrm{D}$ & - & - & - & - & - \\
\hline $\begin{array}{l}\text { 3. Liquefaction potential } \\
(1: 48,000)\end{array}$ & $\mathrm{F}$ & \multicolumn{5}{|c|}{ Anderson and others $(1982,1986 a, 1986 b)$} \\
\hline $\begin{array}{l}\text { 4. Seismic slope stability } \\
(1: 48,000)\end{array}$ & F & \multicolumn{5}{|c|}{ Topham and others (1987) } \\
\hline $\begin{array}{l}\text { 5. Tectonic subsidence } \\
(1: 100,000)\end{array}$ & $\mathrm{F}$ & \multicolumn{5}{|c|}{ Keaton (1987) } \\
\hline $\begin{array}{l}\text { 6. Dam failure } \\
\text { (variable scales) }\end{array}$ & $\mathrm{D}$ & \multicolumn{5}{|c|}{ U.S. Bureau of Reclamation } \\
\hline $\begin{array}{l}\text { 7. Landslide hazard } \\
(1: 24,000)\end{array}$ & F & $\mathrm{D}$ & $\mathrm{D}$ & $\mathrm{D}$ & $\mathrm{D}$ & $\mathrm{D}$ \\
\hline $\begin{array}{l}\text { 8. Rock fall hazard } \\
\qquad(1: 24,000)\end{array}$ & $\mathrm{F}$ & $\mathrm{D}$ & $\mathrm{D}$ & $\mathrm{D}$ & $\mathrm{D}$ & $\mathrm{D}$ \\
\hline $\begin{array}{l}\text { 9. Debris flow hazard } \\
(1: 24,000)\end{array}$ & F & $\mathrm{F}$ & $\mathrm{F}$ & $\mathrm{D}$ & $\mathrm{D}$ & $\mathrm{D}$ \\
\hline 10. Lake/stream flooding & F & \multicolumn{5}{|c|}{ NO MAP PLANNED } \\
\hline $\begin{array}{l}\text { 11. Shallow ground water } \\
(1: 48,000)\end{array}$ & - & \multicolumn{5}{|c|}{ Anderson and others $(1982,1986 a, 1986 b)$} \\
\hline $\begin{array}{l}\text { 12. Problem soils } \\
(1: 24,000)\end{array}$ & - & - & - & - & - & - \\
\hline $\begin{array}{l}\text { 13. Other (seiche, sensitive clay, } \\
\text { hydrologic effects) }\end{array}$ & $\mathrm{F}$ & \multicolumn{5}{|c|}{ NO MAP PLANNED } \\
\hline
\end{tabular}

FIGURE 18. - Status of geologic hazard maps and texts being produced by county geologists as of June 1988 (rev. December 1988) from Christenson (1988, table 1, p. 7). Letter F indicates final completed, D indicates draft text or partial mapping completed, and - indicates completion planned for subsequent years. References are given for maps completed by others (see Christenson, 1988, p. 14).

were collected statewide from conventional sources of published information and some unconventional sources. All of the references were keyworded and entered into a computerized data base system for easy manipulation and retrieval. These sources were supplemented by many of the geotechnical engineering firms and government agencies in Utah that permit a review of existing files for more site-specific information.

This compilation was initiated in Octobe $r 1985$ with the goal of not only compiling a computerized hazards bibliography, but also producing generalized hazards maps for the State at a scale of 1:750,000. The nazards bibliography includes a comprehensive listing of all published and unpublished hazards information statewide. Information can be retrieved according to specific hazard, type of information, and geographic locality covered by each entry. When completed, the bibliography can be sorted geographically and printouts made available to various government entities (cities, counties, and multicounty agencies) so that there will be an awareness of what data are available for each jurisdiction.

In conjunction with the bibliography, UGS maintains a file for each USGS $71^{\prime}{ }^{\prime}$ quadrangle in the State that will include site-specific hazards reports (where appropriate), inventory sheets of the contents of each report, and an index map showing the location of each site in the report. Mapping and bibliography compilation proceeded concurrently and were completed in 1989.

The second phase of the UGS hazards compilation project is a cooperative effort with the USGS and five Wasatch Front counties. The three county geologists serving the five counties have collected all pertinent hazards information and developed a hazards library for each county. This information is supplemented with additional field studies, as necessary, to compile hazards maps for each county. Files of site-specific hazards information are being maintained, and index maps showing locations of hazards information are being compiled.

Texts are being prepared to accompany each map to explain the hazard in terms of likelihood, location, and severity. Discussions of possible engineering and site design techniques for mitigation are included, as well as guidelines for the types of information that should be included in site investigation reports. Figure 18 shows the status of these texts and maps as of December 1988.

\section{PUBLIC INQUIRIES}

In addition to compiling and maintaining directories, the UGS maintains a library, public inquiries section, 
and sales office. According to Smith (1985b, p. 4), the library has several thousand items, including materials on earthquake phenomena and hazards. The librarian has access to the computerized "Bibliography of Utah Geology," can make searches by author, location, or type of study, and is adding new titles to keep the list up to date.

The list of UGS publications and maps is now on computer (PUBLIST) indexed by county and kind of study for easy location of specific publications. The data processing section is preparing a new program to keep records of sales and inventories. All except the most recent UGS publications are now available on microfiche, so that no publication is ever out of print.

The sales office fills mail orders for UGS publications (more than 70 percent of its business) and handles over-the-counter sales. Receipts for 1983-84 were $\$ 42,000$, and sales have been increasing annually. In addition, many materials are provided to the public at no charge. The UGS staffs an Applied Geology Program to assist State and local units of government in assessing and reducing geologic hazards. The USGS operates 10 public inquiries offices in the United States, one of which is in Salt Lake City.

\section{ADVISORIES}

Specific advice on reducing earthquake hazards may be in oral or written form. Written information may consist of a general fact sheet that is widely distributed or a letter addressing a specific issue that is requested by a planner or decisionmaker. Figures 15 and 19 illustrate these two types.

The UGS and county geologists provide various advisory services, such as offering explanations and advice along with hazard maps and hazard reduction literature, to prospective real estate buyers, sellers, lenders, and developers. Building officials and planners, both city and county, frequently request advice on specific sites where geotechnical problems are encountered or suspected. The UGS also advises the Utah State Departments of Community and Economic Development and Facilities Construction and Management regarding use of earthquake hazards information in State-funded projects.

The county geologists' advice has been sought by the cities of Salt Lake, Ogden, South Weber, Mapleton, Centerville, Riverdale, and Washington Terrace and the counties of Salt Lake, Utah, and Weber on the content of ordinances regulating the use of hazardous lands.

\section{GUIDELINES}

The Utah Section of the Association of Engineering Geologists $(1986,1987)$ has been preparing guidelines concerning the preparation of engineering geologic reports and the evaluation of various geologic hazards including surface-fault rupture, shaking, liquefaction potential, and landslide potential. Two reports have been published and distributed by the UGS; one is shown in figure 20.

Sometimes a scientist-author includes a transfer technique along with the translated material. A good example is a recommendation included in the earthquakeinduced landslide-potential report by Keaton and others (1987) that accompanies their seismic slope stability map. The recommendations in matrix format for critical facilities and other land uses are shown in figure 21.

\section{GUIDEBOOKS}

Several guidebooks were specially prepared for reducing earthquake hazards in Utah including

- Reducing losses from earthquakes through personal preparedness by Kockelman (1984).

- Suggested approach to geologic-hazard ordinances in Utah by Christenson (1987).

- Utah's geologic hazards-a review for realtors by Christenson and Mabey (1987).

- Planning for natural hazards by the University of Utah Center for Public Affairs and Administration (1988).

The first guidebook introduces the five phases of reduction, namely, pre-event mitigation techniques and preparedness measures, response during the earthquake, and post-event recovery operations and reconstruction activities. Several examples and citations are given for each. Because of the unique effort toward individual and community "self-reliance" in Utah, the guidebook emphasizes the relatively inexpensive actions that can be taken by responsible parents, neighborhoods, and employers, such as inspecting and strengthening the home, organizing the neighborhood, and securing contents and other nonstructural parts of buildings.

The second book encourages prudent land use in areas of geologic hazards, including earthquakes, for the protection of the citizens of those cities and counties enacting ordinances. A concise discussion of hazards and availability of information is followed by a comprehensive survey of city and county geologic hazard ordinances in Utah. An outline of the steps to be included in a hazard reduction ordinance in jurisdictions having geologic hazard maps and those without such maps is shown in figure 22. In addition, the Salt Lake County planning staff drafted an ordinance for natural hazards reduction (Barnes, 1988b) that follows the guidebook recommendations. The ordinance contains a guide to natural hazards reports required for various types of facilities or developments and has been used as a model by other cities and counties (Barnes, 1988a). 


\section{United States Department of the Interior}

GEOLOGICAL SLRVEY

Office of Earthquakes, Volcanoes, and Engineering

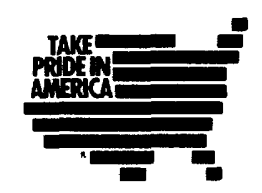

345 Middlefield Road, MS 922

Menlo Park, CA 94025

415/323-8111, x 2312

FTS $467-2312$

EXPRESS MAIL

May 6, 1986

Mr. Jerold H. Barnes, AICP

Salt Lake County Planning Commission

2033 South State Street

Salt Lake City, Utah 84115

Dear Jerry:

In accord with your request yesterday, please find selected materials for use in developing a geologic-hazard-overlay amendment to the county zoning ordinance. These materials include examples of ordinances, discussions of need or use, and the content of geotechnical reports, all of which are paperclipped and highlighted for your convenience:

\section{Ordinances}

Potentially hazardous geologic conditions (Sonoma County, 1974)

Safety geologic (S-G) overlay (San Bernardino County, 1980)

Liquefaction investigation (City of San Diego, 1984)

G-H geologic hazard overlay district (Jefferson County, Colorado, 1983)

Geologic hazard maps (Santa Clara County, 1978)

Model geologic hazard area control (Colorado Geological Survey, 1974)

Resource management zoning district (San Mateo County, 1973)

\section{Discussions}

Site investigations in hazardous areas (Brown and Kockelman, 1983)

Engineering geology at the local government level (McCalpin, 1985)

Landslide hazard zones (Weber, 1980)

Role of geotechnical consultants and reviewers (Leighton, 1975)

Geologic review process (Hart and Williams, 1978)

Hazard avoidance and mitigation (Unknown)

\section{Geotechnical Report Guidelines}

Guidelines to geologic/seismic reports (CDMG, 1973)

General guidelines for geological reports (Ventura County, 1974)

Minimum standards for geotechnical reports (San Mateo County, 1977)

I deliberately selected a wide range of materials to provide you with the greatest flexibility, for example:

FIGURE 19. - This example of a letter addressing a specific issue in Utah illustrates a type of transfer technique identified as an advisory service in list 4.

The third book was prepared to provide Utah's realtors with information that will enable them to place the State's geologic hazards in proper perspective and to communicate this risk to prospective home buyers and business clients. The hazards considered include floods, slope failure, earthquakes, subsidence, and expanding soils. The authors emphasize the need for hazard assessment and then provide general information about the 
o The ordinances range from Sonoma County's one-page regulation requiring a site investigation and recommendations for preventive and corrective measures to San Mateo County's 24-page resource management zoning district that reduces dwelling unit density in soil- and scenic-resource areas as well as fault-rupture and landslide-hazard areas.

- The discussions include a case history on "challenging a geologic-hazard zone," use of a 1:12,000-scale hazard-overlay cadastral map, and land development goals from the viewpoints of the developer, the geologic consultant, and the public agency involved.

- The guidelines range from very general notes to four types of geologic reports requiring detailed data and descriptions, including county certification forms.

According to Jeff Keaton, the Utah Section of the Association of Engineering Geologists is preparing guidelines for engineering geologic reports, including surface-rupture, seismic-shaking, liquefaction, and slope-stability hazards. Genevieve Atwood advised me today that the UGMS is considering publishing these guidelines as UGMS notes.

As we discussed, it would be desirable to keep the geologic-hazard-overlay regulations succinct (as you did with the "hillside protection zone") and to adopt by reference both the official hazards maps and the required geotechnical reports. My experience indicates that such an approach makes it much easier for the public to understand; reduces direct pressure on the local government when references can be made to outside experts (State, Federal, university, consultants, and professional societies); and makes it easier to update them without amending the ordinance.

\section{Caveat}

The enclosed materials are in a raw form directly from my files and, of course, can not be endorsed or recommended by the U.S. Geological Survey. Although many of them have been in effect for several years without successful legal assault, others may have been revised, repealed, or not properly enforced. If a particular example seems promising for your needs, I would be pleased to make one or two inquiries concerning its status and provide you with the administrator's name and number for direct contact.

I hope these materials will be of some help to you, the Commission, and Salt Lake County. Please call me if you have any questions or if I can be of any further assistance.

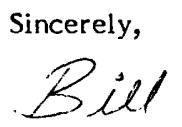

W.J. Kockelman

Enclosures

cc: G. Atwood

J. Keaton

Figure 19.-Continued.

availability of hazard information, status of various hazard-mapping projects, ordinances dealing with hazard warnings or mitigation, and work accomplished by the UGS Applied Geology Program. The report concludes that realtors "have a unique opportunity to inform the property owners of Utah and thus contribute to making Utah safer and more prosperous."

The fourth book offers a guide to the initial steps that may be undertaken at the local level to understand and plan for reduction of potential hazards. The book includes a discussion of local government responsibility and liability, an outline of the planning process, and State and county contacts for information and assistance.

\section{GEOGRAPHIC INFORMATION SYSTEMS}

For the purposes of this report, geographic information systems (GIS's) are defined as the spatial 


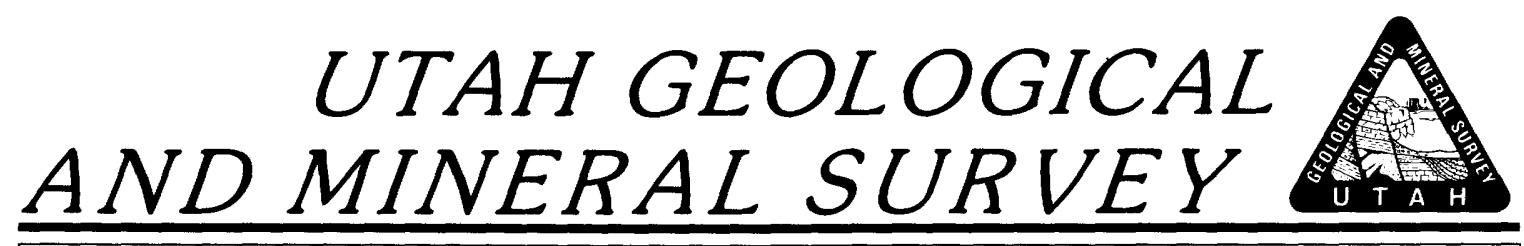

\section{GUIDELINES FOR EVALUATING SURFACE FAULT RUPTURE HAZARDS IN UTAH}

by

The Utah Section of the

Association of Engineering Geologists

These guidelines have been compiled to assist geologists in the investigation of possible hazards due to surface fault rupture and to enable reviewers to evaluate the thoroughness of such investigations. The guidelines were developed by the Guidelines Committee of the Utah Section of the Association of Engineering Geologists, for the purpose of protecting the health, safety, and property of the people of Utah. Previously published guidelines for the State of California (California Division of Mines and Geology, 1975; Slosson, 1984) were used as models. The guidelines do not include systematic descriptions of all available techniques or topics, nor is it suggested that all techniques or topics be utilized on every project. Variations in site conditions and purposes of investigations may require more or permit less effort than is outlined here. All elements of these guidelines should be considered during the preparation and review of engineering geologic reports. Future faulting generally is expected to recur along pre-existing faults (Bonilla, 1970, p. 68); the development of a new fault or reactivation of a pre-Quaternary fault is relatively uncommon and generally need not be a concern in site development for typical facilities. Generally, the more recent the faulting, the greater the probability of future faulting (Allen, 1975 Ziony and others, 1973). Regional and urban earthquake hazards and risk in Utah are reviewed by Hays and Gori (1984).

The evaluation of future fault rupture hazards involves careful application of skills and techniques not commonly used in other engineering geologic investigations (trenching, absolute dating). Many active faults are complex, consisting of multiple breaks which may have originated during different surface-faulting events. To accurately evaluate the potential hazards due to future surface fault rupture, the geologist must determine: I. Fault Locations

This involves locating and accurately mapping all tectonic features at the site, at a scale large enough to be used for site planning ( 1 inch $=200$ feet) II. Nature of Deformation

Surface deformation over active faults may involve single large displace ments, multiple small displacements, monoclinal flexure, backtilting, or a combination of all of these (see Bonilla, 1982). The way in which the surface deforms influences the type and degree of risk posed to various types of structures. III. History of Fault Ruptures

The absolute age of past displacements should be obtained over as long a period of geologic time as possible. Two key measurements are: 1) the age of latest faulting, and 2) the average recurrence interval between surfacerupturing events.

Few structures intended for human occupancy are designed to withstand surface rupture of their foundations without serious damage. If such a structure is sited astride an active fault, the subsequent fault rupture hazard cannot be mitigated unless the structure is relocated. Therefore, the scope of the investigation depends on not only the complexity and economics of the project, but also on the level of risk acceptable for the proposed development. Because of variability in the risk and in the complexity of site geology, not all investigative techniques described here need to be or can be employed in evaluating a single site. The guidelines provide a checklist for preparing complete and well-documented reports.

Regardless of the size of the project (single-family residence vs high-rise building) the conclusions drawn from geologic data must be consistent and unbiased, and must not tie to the design life or perceived economics of the project. Recommendations must be clearly separated from conclusions, since recommendations are not solely dependent on geologic factors.
Suggested Outline for Reports

Evaluating Surface Fault Rupture Hazard

The following subjects should be addressed in any geologic report on faults. Some of the investigative methods listed below should be extended well beyond the site being investigated. Not all of the methods identified will be useful at every site.

A. Purpose and Scope of Investigation

B. Geologic and Seismotectonic Setting

1. Regional Geology

2. Tectonic Setting

a. Location and style of known active faults (see Anderson and Miller, 1979; Nakata and others, 1982).

b. Major earthquakes in historic time (see Arabasz and others, 1979). C. Site Description and Conditions-Include information on depth to ground water, geologic units, graded and filled areas, vegetation, existing structures, and other factors that may affect the choice of investigative methods and the interpretation of data.

D. Office Methods of Investigation

1. Review of published and unpublished literature, maps, or records concerning geologic units, faults, ground-water barriers, and other factors.

2. Stereoscopic interpretation of aerial photographs or other remotely sensed images to detect fault-related topography, soil and vegetation contrasts, and other lineaments of possible fault origin. Low-sunangle photographs are particularly useful for fault scarp recognition (see Cluff and Slemmons, 1971).

3. Personal communication with those who have first-hand knowledge about geologic conditions or pertinent land-use history of the site.

E. Field Methods of Investigation

1. Surface

a. Geologic mapping-distribution, depth, thickness and nature of geologic units, both surficial and bedrock

b. Location and relative ages of tectonic surface features, including fault scarps, sag ponds, aligned springs, offset bedding, disrupted drainage systems, offset ridges, faceted spurs; locations of zones of crushed rock (fault breccia). Relationships with dated alluvial terraces or shorelines (Currey, 1982) may yield indication of age. Surface topographic profiling of fault scarps may permit an age estimate if scarps result from a single rupture event ( $\mathrm{Nash}, 1980$; Hanks and others, 1984) or may show evidence of multiple events (Wallace, 1977).

c. Locations and relative ages of other possibly earthquake-induced features caused by lateral spreading liquefaction, or settlement. Locations of slope failures should be noted, although they may not be conclusively tied to earthquake causes.

\section{surface}

a. Trenching or other excavations across features of suspected tectonic origin. A detailed trench log should be prepared at a scale of i:60 or larger showing geologic units, soil profiles, and all discontinuities (unconformities, fractures, shear zones, fault planes, sand or rubble-filled cracks, burrows). The position of all samples used for absolute dating must appear on the log. Systematic photographs should be taken to document the presence or absence of tectonic features. Because the location of trenches is critical in obtaining

FIGURE 20.-This example of guidelines for evaluating a hazard and preparing reports in Utah is a type of transfer technique from list 4 . When adopted by State or local governments as a requirement, it becomes a reduction technique identified in list 2 
tectonic or stratigraphic data, investigators are encouraged to discuss trench location, orientation, depth, and length with reviewers in advance of excavation. Multiple trenches, if needed, should be excavated concurrently, not sequentially. All critical excavation should be left open for at least 48 hours after logging is completed to allow access by reviewers. Fencing, posting, and shoring of all the trenches is strongly recommended (see Woods, 1976).

b. Absolute dating to determine timing of past surface rupture events. Methods commonly used for Quaternary deposits are reviewed by Colman and Pierce $(1977,1979)$ and McCalpin (1986). Samples should be collected which most tightly bracket the time of faulting e.g., from the youngest parts of faulted units and from the oldest parts of unfaulted units.

c. Borings and test pits to collect data on geologic units, fault-plane geometry, and ground-water elevations. Data points must be sufficient in number and adequately spaced to permit valid correlations and interpretation.

3. Geophysical investigations. These are indirect methods that require knowledge of specific geologic conditions for reliable interpretation. Geophysical methods alone never prove the existence or absence of a fault, nor can they assess the recency of activity. Types of equipment and techiniques used should be described. Methods commonly include seismic refraction, seismic reflection, electrical resistivity, gravity, magnetic intensity, and ground penetrating radar.

4. Other investigations; where special conditions or requirements for critical structures demand more intensive investigation.

a. Aerial reconnaissance overflights.

b. Geodetic and strain measurements.

c. Microseismicity monitoring.

\section{F. Conclusions}

1. Locations of mapped faults; style of associated displacement and age of past surface rupturing events.

2. Anticipated amount and pattern of earth displacements in the next probable surface-faulting event; delineation of areas of high risk.

3. Probability or relative potential for future surface displacements. The likelihood of future faulting may be estimated from the recurrence intervals between past events, plus the age of latest faulting, or from slip rates and amount of anticipated earthquake slip'determined for the specific site or from an identified fault segment which includes the site (for Wasatch Fault segments, see Anderson, in press).

4. Comparison of conclusions developed from site data with previous interpretations on the same fault trace or segment.

5. Degree of confidence in and limitations of data and conclusions.

\section{G. Recommendations}

1. Recommended building restrictions or use limitations within any designated high-risk areas.

a. Setback distances from hazardous faults. Most Utah local governments currently have no laws dictating minimum setback. Therefore, justification must be clearly provided for recommended setback distances (see McCaipin, 1987).

b. Restrictions arising from causes other than discrete surface rupture (e.g., ground tilting, induced mass movements).

2. Risk evaluations relative to the proposed development. Any probabilistic estimates of fault rupture within the design life of the development should be supported with assumptions used and probable error ranges.

3. Need for additional studies.

\section{H. References}

1. Literature and records cited or reviewed

2. Aerial photographs or images interpreted-list type, date, scale, source, and index numbers.

3. Other sources of information, including well records, personal communications, and other data sources.

1. lllustrations-These are essential in understanding the report and reducing the length of the text.

1. Location map-identify site locality, significant faults, geographic features; $1: 24,000$ scale recommended.

2. General geologic map-shows geologic setting of site, geologic units, faults, other geologic structures, geomorphic features, lineaments, springs, epicenters of historic earthquakes of $M \geq 4,1: 24,000$ scale recommended.

3. Site map-combines a detailed, large-scale geologic map of the site with pertinent development-related data (site boundaries, existing and proposed structures, graded areas, streets, exploratory trenches, bor- ing locations, geophysical traverses, and other data). Site geology must correlate with the regional geologic map but should provide refined data on surficial deposits. Recommended scale of 1 inch equals 200 feet or larger $(1: 2,400)$

4. Geologic cross-sections, to extend to the depth of exploratory borings or foundation elements, whichever is greater; same horizontal scale as the site map.

5. Logs of exploratory trenches or borings. Trench logs in particular should show all relevant detail at a scale of 1:60 or larger within zones of suspected deformation; no vertical exaggeration.

6. Geophysical data and its geologic interpretation.

7. Photographs - of scarps, trenches, samples, or other features which enhance understanding of the pertinent site conditions.

J. Appendix-Supporting data not included above (e.g., water well data).

K. Signature of Investigating Geologist-The report must be signed by the engineering geologist who conducted the investigation. The State of Utah currently has no statutory definition of an engineering geologist; however, some local governments do define the minimum qualifications of geologists who can submit reports. Current registration as ageologist in another state may be used in support of demonstrating qualifications.

\section{REFERENCES}

Allen, C.R., 1975, Geologic criteria for evaluating seismicity: Geological Society of America Bulletın, v. 86, p. 1041-1057.

Anderson, L.W., and Miller, D.G., 1979. Quaternary fault map of Utah: Fugro Inc., Long Beach, CA, 35 p., scale 1:500,000.

Anderson, R.E., in press, Regional and local hazards mapping in the eastern Great Basin: National Earthquake Hazards Reduction Program, Summaries of Technical Reports, vol XXIII, U.S. Geological Survey Open-File Report.

Arabasz, W.J., Smith, R. B., and Richins, W.D. (eds.), 1979, Earthquake studies in Utah, 1850 to 1978: Special Publication, University of Utah Seismograph Stations, Salt Lake City, UT, 552 p.

Bonilla, M.G., 1970, Surface faulting and related effects, in Wiegel, R.L. (ed.), Earthquake Engineering: Prentice-Hall Inc., Englewood Cliffs, N.J., p. 47-74.

-1982 , Evaluation of potential surface faulting and other tectonic deformation: U.S. Geological Survey, Open-File Report 82-0732. 91 p.

California Division of Mines and Geology, 1975, Guidelines for evaluating the hazard of surface fault rupture: CDMG Note $49,4 \mathrm{p}$.

Cluff, L.S., and Slemmons, D.B., 1971, Wasatch Fault Zone-features defined by low-sun-angle photography, in Hilpert, L.S. (ed.), Environmental Geology of the Wasatch Front: Utah Geological Association Publication 1, p. H1-H29.

Colman, S.M., and Pierce, K.L., 1977, Summary tabie of Quaternary dating methods: U.S. Geological Survey Map MF-904.

1979. Preliminary map showing Quaternary deposits and their dating potential in the conterminous United States: U.S. Geological Survey Miscellaneous Field Studies Map MF-1052, scale 1:7,500,000.

Currey, D.R., 1982, Lake Bonneville: selected features of relevance to neotectonic analysis: U.S. Geological Survey, Open-File Report 82-1070,30 p., map 1:500,000.

Hanks, T.C., Bucknam, R.C., Lajoie, K.R., and Wallace, R.E., 1984, Modification of wave-cut and faulting-controlled landforms: Journal of Geophysical Research, v. 89 , no. B7, p. $5771-5790$.

Hays, W.W., and Gorı, P.L. (eds.), 1984, Proceedings of Conference XXVI, A Workshop on Evaluation of Regional and Urban Earthquake Hazards and Risk in Utah: U.S. Geological Survey, Open-File Report 84-763, 674 p.

McCalpin, James, 1986, Thermoluminescence dating in seismic hazard evaluations; an example from the Bonneville Basin, Utah in Wood, S.H. (ed.), Proceedings of the 22nd Symposium on Engineering Geology and Soils Engineering: Boise State 22nd Symposium on Engineering

- 1 1987, Recommended setbacks from active normal faults, in McCalpin, James (ed.), Proceedings of the 23rd Annual Symposium on Engineering Geology and Soils Engineering: Utah State University, April 6-8, 1987, p. 35-56.

Nakata, I K. Wentworth, C.M., and Machette, M.N., 1982, Quaternary fault map of the Basin and Range and Rio Grande Rift Provinces, western United States: U.S. Geological Survey, Open-File Report 82-579, scale 1:2,500,000

Nash, D.B., 1980, Morphologic dating of degraded normal fault scarps: Journal of Geology, v. 88 , p. 353-360

Schwartz, D.P. and Coppersmith, K.J., 1984, Fault behavior and characteristic earthquakes: examples from the Wasatch and San Andreas fault zones: Journal of Geophysical Research, v. 89. p. $5681-5698$.

Slosson, J.E., 1984, Genesis and evolution of guidelines for geologic reports: Bulletin of the Association of Engineering Geologists, v. XXI, no. 3, p. 295-316.

Wallace, R.E., 1977, Profiles and ages of young fault scarps, north-central Nevada: Geological Society of America Bulletin, v. 88, p. 1267-1281.

Woods, M.C., 1976. Trench shoring: California Geology, v. 29, no. 8, p. 178-181.

Ziony, J.I., Wentworth, C.M., and Buchanan, J.M., 1973, Recency of faulting; a widely applicable criterion for assessing the activity of faults: Fifth World Conference on Earthquake Engineering, Rome, Italy, p. 1680-1683.

Figure 20. - Continued. 


\begin{tabular}{|c|c|c|c|c|c|c|}
\hline \multirow[t]{2}{*}{ FACILITY CLASS } & \multicolumn{4}{|c|}{$\begin{array}{l}\text { EARTHQUAKE-INDUCED LANDSLIDE } \\
\text { POTENTIAL ZONE }\end{array}$} & \multirow{2}{*}{$\begin{array}{l}\text { EXISTING } \\
\text { LANDSLIDE }\end{array}$} & \multirow{2}{*}{$\begin{array}{l}\text { HIGH } \\
\text { LIQUEFACTION } \\
\text { POTENTIAL }\end{array}$} \\
\hline & HIGH & MODERATE & LOW & VERY LOW & & \\
\hline $\begin{array}{l}\text { CRITICAL } \\
\text { Hospitals, Fire Stations } \\
\text { Police Stations } \\
\text { Other Emergency Facilities }\end{array}$ & YES & YES & YES & YES & YES & YES \\
\hline $\begin{array}{l}\text { LIFELINES } \\
\text { Communications } \\
\text { Transportation, Water Supply } \\
\text { Electric Power, Natural Gas }\end{array}$ & YES & YES & YES & MAYBE & YES & YES \\
\hline $\begin{array}{l}\text { HIGH OCCUPANCY PUBLIC-OWNED } \\
\text { Schools, State Capitol } \\
\text { City Hall, Airports } \\
\text { County Courts, Convention Centers }\end{array}$ & YES & YES & YES & MAYBE & YES & YES \\
\hline $\begin{array}{l}\text { HIGH OCCUPANCY PRIVATE-OWNED } \\
\text { Office Buildings } \\
\text { Apartments, Hotels } \\
\text { Shopping Malls }\end{array}$ & YES & $\begin{array}{l}\text { YES } \\
\text { propriate Di }\end{array}$ & $\begin{array}{l}\text { MAYBE } \\
\text { osure Req }\end{array}$ & NO & YES & YES \\
\hline $\begin{array}{l}\text { INDUSTRIAL-SEVERE CONSEQUENCE } \\
\text { Refineries, Sewage Plants } \\
\text { Hazardous Waste, Explosives }\end{array}$ & YES & $\begin{array}{l}\text { YES } \\
\text { propriate Di }\end{array}$ & $\begin{array}{l}\text { MAYBE } \\
\text { osure Req }\end{array}$ & No & YES & YES \\
\hline $\begin{array}{l}\text { INDUSTRIAL-MINOR CONSEQUENCE } \\
\text { Trucking, Shipping } \\
\text { Light Manufacturing }\end{array}$ & MAYBE & $\begin{array}{l}\text { MAYBE } \\
\text { propriate Di }\end{array}$ & $\begin{array}{l}\text { NO } \\
\text { osure Req }\end{array}$ & & $\begin{array}{c}\text { NO } \\
\text { Appropriate }\end{array}$ & $\begin{array}{c}\text { MAYBE } \\
\text { sure Required }\end{array}$ \\
\hline RESIDENTIAL SUBDIVISION & MAYBE & $\begin{array}{l}\text { MAYBE } \\
\text { propriate Di }\end{array}$ & $\begin{array}{l}\text { NO } \\
\text { osure Req }\end{array}$ & & $\begin{array}{c}\text { NO } \\
\text { Appropriate }\end{array}$ & $\begin{array}{c}\text { YES } \\
\text { sure Required }\end{array}$ \\
\hline RESIDENTIAL SINGLE LOT & NO & $\begin{array}{l}\text { NO } \\
\text { propriate Di }\end{array}$ & $\begin{array}{l}\text { NO } \\
\text { osure Req }\end{array}$ & & $\begin{array}{l}\text { MAYBE } \\
\text { Appropriate }\end{array}$ & $\begin{array}{c}\text { MAYBE } \\
\text { sure Required }\end{array}$ \\
\hline
\end{tabular}

FiguRE 21. - Example of a matrix with recommendations for site-specific stability analysis for critical facilities and other land uses in several hazard zones by Keaton and others (1987, table 4, p. 76). This matrix is a special type of transfer technique in list 4. It was designed by the scientist-authors for nontechnical users. When adopted by State or local governments as a requirement, it becomes a reduction technique identified in list 2.

representation of geologic, hydrologic, topographic, land use, land ownership, and other physical and socioeconomic information that can be readily combined, manipulated, analyzed, and displayed for various purposes by computer technology. The result is a quantifiable analysis of point, line, area, and volume data. The nature and capability of GIS's provide an excellent basis for presenting and combining not only the various earthquake hazards, but critical facilities that might be affected. In addition, an easy-to-use georeference map can be provided for the nontechnical user.

For example, Alexander and others (1987), in demonstrating the use of digital mapping technology, entered surface-fault rupture, liquefaction potential, and landslide potential into a GIS for the Sugar House quadrangle in east-central Salt Lake County. In addition to the hazards maps used in their atlas, other maps were used to illustrate the kinds of information needed to reduce earthquake hazards, namely, political jurisdictions, roads, selected lifelines, and land uses. They then combined hazards with specific land uses, such as lifelines in potential surface-fault rupture zones, schools and resi- dential areas in high liquefaction-potential zones, and schools and residential areas on lands with the lowest stability during earthquakes.

University of Utah Department of Geography professor Phillip Emmi has entered Salt Lake County's lifelines, other critical facilities, and building inventories into a GIS to estimate earthquake loss probabilities. CEM planner Wes Dewsnup entered all information for the Utah County Comprehensive Hazard Mitigation Project into the GIS operated by the Utah State Office of Automated Geographic Referencing. Salt Lake County uses the AUTOCAD system, which, according to C.V. Nelson (written commun., 1989), will greatly increase the transfer of hazard information that has been referenced to land ownership records.

\section{REVIEW SERVICES}

The State and county geologists are sometimes asked to provide the type of review services in list 4. For example, the Salt Lake County geologist has assisted 
A

1) Define boundaries of geologic hazards areas by establishing Geologic Hazards Zones (or equivalent) or officially adopting maps referenced to an ordinance.

2) Require geotechnical reports by qualified engineering geologists and engineers addressing hazards and, if necessary, recommending mitigation measures prior to development in geologic hazard areas.

3) Require review of geotechnical reports by county geologists or other qualified engineering geologists acting on behalf of local government.

4) Submit report and review comments to planning commission for action.

5) Amend geologic hazard area boundaries (zones or adopted maps) if proven necessary by site report.

\section{B}

1) Provide for review of all development proposals by county geologists or other qualified engineering geologists acting on behalf of local government to determine need for geotechnical reports.

2) Require geotechnical reports by qualified engineering geologists and engineers to address potential hazards indicated in review and, if necessary, to recommend mitigation measures. If initial reviews of development proposals are not performed, complete reports may be required for all sites.

3) Require review of geotechnical reports by county geologists or other qualified engineering geologists acting on behalf of local government.

4) Submit report and review comments to planning commission for action.

FiguRE 22. -Suggested topical outline for geologic hazards ordinances in areas with geologic hazards maps (A) and without geologic hazards maps (B) by Christenson (1987, table 1, p. 9). This outline is another type of transfer technique identified as an advisory service in list 4.

West Valley City by providing geologic hazard information to be incorporated into a computerized data bank for land-use planning; the UGS and Utah County geologist provided hazard maps and interpretations for a CEM and county project in the Provo-Orem area to aid emergency response personnel; and the Weber County geologist assisted the city of Washington Terrace in including geologic hazards into its 1987 master plan.

\section{COMMENT}

In all of the examples, delivery of translated information was provided; in many others, assistance and encouragement in the use of information for hazard reduction were provided or offered. The users ranged from practitioners and professional societies to interested citizens, including children. Several of Utah's transfer techniques included suggested reduction techniques. 
Special mention should be made of the unique efforts of the UGS, USGS, university, and consulting researchers to release research findings early to practitioners and other users. This efficiency was accomplished through oral briefings, workshops, workshop proceedings (Hays and Gori, 1984, 1987; Gori and Hays, 1987, 1988), serial publications (Stringfellow, 1983-present), newsletters (Hassibe, 1983-1986; Jarva, 1987-present), and "official use only" materials.

The commitment of the USGS to the transfer of research in Utah and the evaluation of its effectiveness may be seen in a recent award for a proposal by William Spangle and Associates (1989). The summary of their approach follows.

This project is designed to assist local officials in cities and counties of the Wasatch Front region of Utah apply the information provided by the USGS regional assessment of earthquake hazards. The direct experience of the consultants in research, planning practice and information transfer will be shared with Utah officials, especially city planners, on a regular basis during the year. This will be done by participating in up to four meetings throughout the year and being available as needed for direct consultation with local (and State) officials about options for earthquake-hazard reduction. A final report evaluating the effectiveness of the process and opportunities for transfer to other regions will also be prepared.

\section{EVALUATION AND REVISION}

The last component in Utah's comprehensive earthquake hazard reduction program is evaluating the effectiveness of the reduction techniques and revising them if necessary (see fig. 1). Evaluating and revising the entire program, as well as such other components as studies, translation, and transfer, may also be undertaken.

The evaluation component was included as a task in the National Earthquake Hazard Reduction Program (NEHRP) by Wallace (1974) and as recommendations of the California Joint Committee on Seismic Safety (1974) advisory groups. Evaluation has been emphasized in a review of efforts by 10 cities to manage flood plains (Burby and others, 1988, p. 9), in the comprehensive tasks of a national program to reduce landslide hazards (U.S. Geological Survey, 1982, p. 44), and in the recommendations of the NEHRP Expert Review Committee (1987, p. 81-85).

In Utah, evaluation is included in the abbreviated recommendations for earthquake risk reduction by the Utah Seismic Safety Advisory Council (1981), as an active item from a governor's conference on geologic hazards (Utah Geological and Mineral Survey, 1983), and as a task in the Utah work plan.

\section{IMPORTANCE}

The effectiveness of each hazard reduction technique varies with the time, place, and persons involved. There- fore, it is prudent to include a continuing systematic evaluation as part of any program for earthquake hazard reduction. An inventory of uses made of the information, reports of interviews with the users, and an analysis of the results and responses will also result in identifying new users and innovative uses, as well as any problems concerning the research information and its translation, transfer, and use. The evaluation will be helpful, even necessary, to those involved in funding, producing, translating, transferring, and using the research information as well as managing a comprehensive program.

Performing the scientific and engineering studies and then translating and transferring the research information is expensive and difficult because of the limited number of scientists and geotechnicians from national, State, local, university, corporate, and consulting areas, particularly when aligned with the needs of communities throughout the United States. The adoption and enforcement of an appropriate hazard reduction technique is time consuming and requires planning, engineering, legal, and political skills, as well as strong and consistent public support.

Scarce financial and staff resources must be committed; necessarily persistent and difficult actions must be taken to enact a law, adopt a policy, or administer a reduction program over a long period of time. To discover later that the hazard reduction technique selected is ineffective, unenforced, or has greatly disproportionate costs in terms of benefits derived is not only disheartening but may subject those involved to criticism and withdrawal of financial support.

Few systematic evaluations have been made of natural hazards reduction techniques, including those for earthquakes. To my knowledge, no rigorous studies of the ratio of benefits to costs have been conducted. However, a few intensive evaluations have been made for flood, landslide, and other reduction techniques and programs that may be applicable to earthquakes.

The following examples of various evaluations are presented for introductory purposes. The findings and recommendations, although beyond the scope of this report, will be helpful to Utahans in their selection of the most appropriate transfer and reduction techniques.

\section{EVALUATION OF REDUCTION TECHNIQUES}

Several reduction techniques (list 2) have been evaluated, problems identified, and improvements suggested:

- Preparing and implementing local seismic safety elements by the California Seismic Safety Element Review Committee (1985).

- Lending, appraising, and insuring policies of the 12 largest home mortgage lenders in California by Marston (1984). 
- Disclosing surface-fault rupture hazards to real estate buyers in Berkeley and Contra Costa County by Palm (1981).

- School earthquake safety and education project in Seattle and community outreach education centers at Memphis State University and Baptist College in Charleston, South Carolina, by Bolton and Olson (1987b).

- Strengthening, redeveloping, abandoning, or demolishing unreinforced masonry-bearing-wall buildings in the cities of Long Beach, Santa Ana, and Los Angeles by Alesch and Petak (1986).

- Strengthening masonry-bearing-wall buildings in the city of Los Angeles after the 1987 Whittier Narrows earthquake by Deppe (1988).

- Retrofitted highway bridges after the 1986 earthquake in Palm Springs by Mellon (1986).

- Mapping, investigating, and regulating surface-fault rupture zones by Hart (1986).

\section{TRANSLATION AND TRANSFER TECHNIQUES}

Several translation and transfer techniques (list 4) have been evaluated, problems identified, and recommendations made:

- Announcing earthquake prediction and forecast information by Turner and others (1981).

- Disseminating earthquake education material to public and private schools by Bolton and Olson (1987a).

- Disseminating earthquake hazards information to public officials and private sector representatives in Charleston, South Carolina, by Greene and Gori (1982).

- Using earth science information in cities, counties, and selected multicounty agencies in the San Francisco Bay region by Kockelman (1975, 1976b, 1979), Kockelman and Brabb (1979), and Perkins (1986).

- Translating and transferring information in the U.S. Geological Survey by Bates (1979) and O'Kelley and others (1982).

- Conducting a workshop on preparing for and responding to a damaging earthquake in the eastern United States by Tubbesing (1982, p. 57-59).

- Adopting ordinances based on guidelines and model ordinances developed and transferred by the Southeastern Wisconsin Regional Planning Commission (1987, p. 24).

\section{EVALUATION OF PROGRAMS}

Several earthquake hazard reduction programs have been evaluated, problems identified, and revisions suggested:
- Community seismic safety programs before, during, and after the 1983 Coalinga, Calif., earthquake by Tierney (1985).

- Planning and implementing seismic hazard mitigation in Alaska by Selkregg and others (1984).

- Use of earthquake hazard information for enlightenment, decisionmaking, and practice in California, Washington, Utah, South Carolina, Massachusetts, Idaho, Puerto Rico, Kentucky, Alaska, Missouri, U.S. Virgin Islands, and the eastern, western, and central United States by Hays (1988a).

- National Earthquake Hazards Reduction Program in the United States by the NEHRP Expert Review Committee (1987).

- Effectiveness of the geology and planning program in Portola Valley, Calif., by Mader and others (1988, p. 55-61).

- San Francisco Bay Region Environmental and Resources Planning Study by Arthur D. Little, Inc. (1975) and Brown (1975).

- Land use and reconstruction planning after the 1971 San Fernando, 1964 Alaska, and 1969 Santa Rosa earthquakes by Mader and others (1980).

- Seismic safety policies of local governments by Wyner and Mann (1983).

- Structure design and behavior investigation after more than 200 earthquakes by members of the Earthquake Engineering Research Institute (Scholl, 1986).

\section{VARIOUS EVALUATIONS IN UTAH}

Several reduction and transfer techniques and programs in Utah have been evaluated, problems identified, and revisions suggested:

- Awareness and reduction of earthquake hazards by Perkins and Moy (1988, p. 9-19).

- Multihazard mitigation project for Ogden and Weber County by Olson and Olson (1985).

- Hazardous building abatement and sensitive lands development ordinances for Provo by May and Bolton (1986).

- County Hazards Geologist Program by Christenson (1988).

- Earthquake knowledge, risk perception, and mitigation priorities in Salt Lake County by Madsen (1988).

- Adequacy of engineering geologic reports by Nelson and others (1987).

- Perception of earthquake risk and support for regulations by Emmi (1987).

\section{REDUCTION TECHNIQUES FOR OTHER HAZARDS}

Several reduction techniques for other natural hazards have been evaluated, the problems identified, and 
improvements suggested. Their evaluation methods, findings, and recommendations may be applicable to earthquake hazards:

- Disclosing hurricane-flood hazards information to prospective home buyers in Florida by Cross (1985).

- Providing State financial incentives for flood hazard reduction to local governments by Burby and Cigler (1983).

- Subsidizing flood insurance for property owners and their lenders by Miller (1977), Burby and French (1981, p. 294), and Kusler (1982, p. 36, footnote 55).

- Notice, watch, and warning system for a potential 1978 Pillar Mountain landslide in Kodiak by Saarinen and McPherson (1981).

- Warnings for the 1980 Mount St. Helens volcano eruption by Saarinen and Sell (1985).

- Planning and engineering response and recovery to 1982 debris flows at Love Creek (Santa Cruz County) and Inverness (Marin County) by Blair and others (1985).

\section{EVALUATION METHODS}

There are numerous methods for evaluating the effectiveness of an earthquake hazard reduction program and related studies, translation, transfer, and reduction components. The above examples of evaluation indicate that these methods vary widely because of the human and financial resources available, the region involved, and the evaluator's interest, experience, and commitment. A thorough discussion of these methods is beyond the scope of this report; however, the following four illustrations show different levels of rigor:

1. Soliciting comments and suggestions from the producers, translators, transfer agents, and users of the research information.

2. Inventorying the documents where research information is cited and conducting systematic interviews with the users as to the types of information needed and used, the problems identified, and the improvements desired.

3. Comparing losses experienced in several areas having similar hazards and operating under the same type of reduction technique but where different levels of requirements, administration, or enforcement are in effect.

4. Collecting and comparing the benefits and costs, both public and private, of several different reduction techniques before and after a damaging earthquake in a jurisdiction having a uniform geologic and tectonic environment.

The phrase "public and private costs" is used here to mean all direct and indirect costs and losses such as market value declines, road and utility repairs, emer- gency response activities, real property damages, personal property losses, deaths, injuries, tax revenue losses, industrial production losses, commerce interruption, and traffic delays. If it is demonstrated that the cost of a reduction technique is substantially less than the cost of anticipated damage, we may conclude a favorable benefit-cost ratio for the use of the reduction technique.

Several methods that address various topics and have different levels of rigor are introduced here:

- Use of earth science products by city, county, and selected multicounty organizations by Kockelman (1975, p. 20-26; 1976b, p. 16-20; 1979, p. 27-31).

- Appraisal and cost-benefit analysis of plans to reduce natural hazards by Lohman and others (1988, p. 183-201).

- Economics of landslide mitigation strategies by Bernknopf and others (1985).

- Methods of cost-benefit analysis for different building codes and for upgrading existing structures by Paté and Shah (1980).

- Testimony before a State agency on the costs and housing impacts of rehabilitation of unreinforced masonry buildings (Boswell, 1987).

- Benefit-cost ratios for reconstructing more than 1,350 State-owned buildings by H.J. Degenkolb Associates (1981).

\section{COMMENT}

These examples of evaluation vary as to topic, area affected, type of technique, evaluator, and comprehensiveness. What they all have in common is a critical look at the success or failure of a program or of the translation, transfer, or reduction techniques used.

Even if adequate earthquake hazard research information is available, presented in a language understandable by nontechnical users, effectively transferred, and properly used, as is being done in Utah, the lasting effectiveness of each earthquake hazard reduction technique (list 2) depends on many other factors, usually outside the control of the researcher, engineer, planner, or decisionmaker. For example:

- Continued awareness and interest by the public.

- Careful revision (if needed) of enabling legislation by the State legislature.

- Accurate site investigations by qualified geologists and geotechnical engineers.

- Conscientious administration of regulations by plan checkers, inspectors, and other building officials.

- Sustained support of inspection and enforcement officials by political leaders and their constituents.

- Consistent enforcement by government inspectors and attorneys. 


\begin{tabular}{|c|c|c|c|c|c|c|c|c|c|c|c|c|}
\hline \multicolumn{13}{|c|}{ Problem Seriousness Scores in the Six Sites } \\
\hline & \multicolumn{2}{|c|}{$\mathrm{CA}$} & \multicolumn{2}{|c|}{ LA } & \multicolumn{2}{|c|}{ MA } & \multicolumn{2}{|c|}{ BOSTON } & \multicolumn{2}{|c|}{ UTAH } & \multicolumn{2}{|c|}{ SLC } \\
\hline & $\overline{\mathbf{x}}$ & RANK & $\overline{\mathrm{x}}$ & RANK & $\overline{\mathbf{x}}$ & RANK & $\overline{\mathrm{x}}$ & RANK & $\overline{\mathrm{x}}$ & RANK & $\overline{\mathbf{x}}$ & RANK \\
\hline INFLATION & 7.6 & 1 & 6.6 & 4 & 7.5 & 4 & 7.1 & 5 & 7.2 & 1 & 7.5 & 1 \\
\hline POLLUTION & 7.2 & 2 & 7.5 & 1 & 6.0 & 8 & 4.4 & 13 & 5.7 & 3 & 6.7 & 2 \\
\hline UNEMPLOYMENT & 7.0 & 3 & 7.0 & 3 & 8.6 & 1 & 7.6 & 2 & 4.2 & 8 & 4.5 & 9 \\
\hline CRIME & 6.9 & 4 & 5.9 & 8 & 7.3 & 5 & 7.3 & 4 & 5.5 & 4 & 5.6 & 3 \\
\hline WELFARE & 6.9 & 5 & 7.1 & 2 & 8.2 & 2 & 7.4 & 3 & 5.9 & 2 & 5.0 & 6 \\
\hline EDUCATION & 6.2 & 6 & 6.3 & 5 & 5.4 & 11 & 7.0 & 6 & 4.1 & 9 & 4.3 & 11 \\
\hline DRUGS & 6.0 & 7 & 6.0 & 7 & 6.1 & 7 & 6.6 & 8 & 5.1 & 5 & 4.9 & 7 \\
\hline TRAFFIC & 5.7 & 8 & 6.2 & 6 & 5.1 & 12 & 6.5 & 9 & 3.8 & 10 & 4.7 & 8 \\
\hline HOUSING & 5.5 & 9 & 5.7 & 9 & 6.4 & 6 & 6.4 & 10 & 4.8 & 7 & 5.5 & 4 \\
\hline FIRES & 5.3 & 10 & 4.2 & 14 & 6.0 & 9 & 5.9 & 11 & 3.4 & 12 & 3.7 & 12 \\
\hline TOO LITTLE GROWTH & 5.0 & 11 & 5.0 & 12 & 7.8 & 3 & 7.7 & 1 & 3.7 & 11 & 3.3 & 14 \\
\hline RACE & 4.7 & 12 & 4.4 & 13 & 5.4 & 10 & 6.9 & 7 & 2.6 & 16 & 3.4 & 13 \\
\hline QUAKES & 4.6 & 13 & 5.5 & 10 & 1.2 & 18 & 1.3 & 18 & 3.2 & 15 & 1.2 & 16 \\
\hline PORNOGRAPHY & 4.1 & 14 & 5.3 & 11 & 4.0 & 14 & 5.4 & 12 & 5.0 & 6 & 5.1 & 5 \\
\hline FLOODS & 3.3 & 15 & 2.8 & 15 & 4.5 & 13 & 2.2 & 15 & 3.3 & 13 & 4.5 & 10 \\
\hline TOO MUCH GROWTH & 2.5 & 16 & 1.6 & 16 & 1.3 & 17 & 1.3 & 16 & 3.3 & 14 & 3.0 & 15 \\
\hline HURRICANES & 1.3 & 17 & 1.0 & 17 & 3.1 & 15 & 2.3 & 14 & 1.0 & 17 & 1.2 & 17 \\
\hline TORNADOES & 1.1 & 18 & 1.0 & 18 & 1.5 & 16 & 1.3 & 17 & 1.0 & 18 & 1.0 & 18 \\
\hline$\overline{\mathbf{x}}=$ & 5.05 & & 4.95 & & 5.30 & & 5.26 & & 4.04 & & 4.17 & \\
\hline
\end{tabular}

FIGURE 23. - Rankings by key public and private decisionmakers as to the relative seriousness of 18 State and local issues for three States and three cities (Atkisson and Petak, 1981, table I9, p. I40).

- Judicious adjustment of regulations by administrative appeal bodies.

- Skillful advocacy by public regulators and plaintiffs, and proper interpretation by the courts.

- Genuine concern for individual, family, and community safety by real estate buyers, developers, insurers, and lenders.

A consultant and expert witness who is a former State geologist and former president of a State board of registration for geologists and geophysicists reports in the work by Slosson and Havens (1985) on his experience during the past $25 \mathrm{yr}$ :

... many of the problems and losses related to damage from earthquakes ... are directly or indirectly attributable to government's (local, State, and/or Federal) inability and/or failure to enforce existing policies, codes, or regulations.

The benefits of evaluation and revision cannot be restated often enough, namely, to avoid an unconscionable waste of taxpayers' money and a usually irreparable loss of program managers' credibility.

\section{CONCLUSION}

The reduction of casualties, damages, and interruptions in Utah requires that appropriate earthquake research be conducted and used by planners, engineers, and decisionmakers. A major part of any effective earthquake hazard reduction program must be dedicated to the translation and transfer of research information to nontechnical users, as is being done in Utah.

The selection of earthquake areas or processes for study and the performance of the necessary scientific and engineering studies are only the first steps in any earthquake hazard reduction program. If the information prepared is inadequate, inappropriate, not translated, not transferred, or not used, earthquake losses will increase, public and private monies will be wasted, and demands will be made on Federal, State, and local government agencies for disaster relief and costly reconstruction.

Usually, public planners, engineers, and decisionmakers give most of their attention and resources to problems that are perceived to be serious or pressing. A 1977 study of six sites of varying political environments and attitudes toward seismic safety was conducted by Atkisson and Petak (1981, p. I39). They found at that time that the "seriousness attributed to earthquakes ... was consistently low in all sites" (see fig. 23). With the exception of floods (tenth in Salt Lake City) and earthquakes (tenth in Los Angeles), natural hazards at all sites were considered least serious, ranking 13 to 18 on the list of serious problems.

Recently, Perkins and Moy (1988, rept. 3, table 4, p. $15)$ asked 15 city managers and county administrators in Utah to indicate what earthquake hazard reduction techniques had been adopted in the past $5 \mathrm{yr}$. According to J.B. Perkins (verbal commun., 1989), of the 13 respondents, all had adopted at least one technique, 9 had adopted a technique primarily for reasons of earthquake safety, and 4 of the 9 had adopted 4 or more techniques. Obviously, Utahans are not only more aware of the earthquake hazard but are continuing to take appropriate actions.

The effective use of research information in Utah depends on (1) the users' interest, capabilities, and 
experience in hazard-related activities, (2) legislation authorizing State and local hazard reduction activities, (3) adequate detailed information in a readily usable and understandable form, and (4) the use of effective transfer techniques. These four elements exist in Utah. All that remains is for Utahans to continue to adopt appropriate reduction techniques and enforce them over many years.

\section{REFERENCES}

Advisory Committee on the International Decade for Natural Hazard Reduction, 1987, Confronting natural disasters-An international decade for natural hazard reduction: Washington, D.C., National Academy Press, $60 \mathrm{p}$.

Agnew, D.C., Allen, C.R., Cluff, L.S., Dieterich, J.H., Ellsworth, W.L., Keeney, R.L., Lindh, A.G., Nishenko, S.P., Schwartz, D.P., Sieh, K.E., Thatcher, W.R., and Wesson, R.L., 1988, Probabilities of large earthquakes occurring in California on the San Andreas fault: U.S. Geological Survey Open-File Report 88-398, $62 \mathrm{p}$.

Alesch, D.J., and Petak, W.J., 1986, The polities and economies of earthquake hazard mitigation-Unreinforced masonry buildings in southern California: Boulder, University of Colorado, Institute of Behavioral Science, Program on Environment and Behavior, Monograph 4, $276 \mathrm{p}$.

Alexander, R.H., 1983, Land resource information needs of county government-A case study in Larimer County, Colorado: U.S. Geological Survey Open-File Report 83-103, 80 p.

Alexander, R.H., Crane, M.P., Di Nardo, T.P., Firestone, L.M., Jessen, Eldon, Mladinich, C.S., and Rich, C.L., 1987, Sugar House quadrangle atlas-Applying digital cartographic and geographic information systems technology and products to the National Earthquake Hazards Reduction Program, in Hays, W.W., and Gori, P.L., eds., A workshop on "Earthquake hazards along the Wasatch Front, Utah," Proceedings of conference XXXVIII, May 16, 1986, Salt Lake City: U.S. Geological Survey Open-File Report 87-154, p. 100-146.

Algermissen, S.T., Perkins, D.M., Thenhaus, P.C., Hanson, S.L., and Bender, B.L., 1982, Probabilistic estimates of maximum acceleration and velocity in rock in the contiguous United States: U.S. Geological Survey Open-File Report 82-1033, 99 p.

Algermissen, S.T., and Steinbrugge, K.V., 1984, Seismic hazard and risk assessment-Some case studies, Proceedings of the first meeting of the international working group on natural disasters and insurance: Geneva, United Nations Disaster Relief Organization, The Geneva Papers on Risk and Insurance, v. 9, no. 30, p. 8-26.

Amimoto, Perry Y., 1980, Advisory services: Sacramento, California Division of Mines and Geology, California Geology, May 1980, p. $99-100$.

Anderson, L.R., Keaton, J.R., and Bischoff, J.E., 1986, Liquefaction potential map for Utah County, Utah: Logan, Utah University, Department of Civil and Environmental Engineering, and Salt Lake City, Dames and Moore, 46 p., 16 pls.

Applied Technology Council, 1978, Tentative provisions for the development of seismic regulations for buildings - A cooperative effort with the design professions, building code interests, and the research community: Washington, D.C., U.S. Government Printing Office, Publication ATC 3-06, 505 p., 2 pls.

Arthur D. Little, Inc., 1975, An evaluation of the San Francisco Bay region environment and resources planning study-Report to the
U.S. Department of Housing and Urban Development, Office of Policy Development and Research: San Francisco, Calif., 93 p.

Atkisson, A.A., and Petak, W.J., 1981, Seismic safety policies and practices in U.S. metropolitan areas-A three city case study: Redondo Beach, Calif., J.H. Wiggins Co., Technical Report 80-1373-2, Contract EMW-C-0043, 289 p.

Atwater, B.F., 1988, Probable local precedent for earthquakes of magnitude 8 or 9 in the Pacific Northwest, in Hays, W.W., ed., A workshop on "Evaluation of earthquake hazards and risk in Puget Sound and Portland areas," Proceedings of conference XLII: U.S. Geological Survey Open-File Report 88-541, p. 62-68.

Atwood, Genevieve, 1983, UGMS responds to disasters: Salt Lake City, Utah Geological and Mineral Survey, Survey Notes, v. 17, no. 2, p. 2 .

Atwood, Genevieve, and Mabey, D.R., 1987, Reducing earthquake risk in Utah-Past trends and future opportunities, in Gori, P.L., and Hays, W.W., eds., Assessment of regional earthquake hazards and risk along the Wasatch Front, Utah: U.S. Geological Survey Open-File Report 87-585, v. 2, p. S1-S38.

Bakun, W.H., Bredehoeft, J.D., Burford, R.O., Ellsworth, W.L., Johnston, M.J.S., Jones, L.M., Lindh, A.G., Mortensen, C.E., Roeloffs, E.A., Schulz, Sandra, Segall, Paul, and Thatcher, W.R., 1986, Parkfield earthquake scenarios and response plans: U.S. Geological Survey Open-File Report 86-365, 46 p.

Barnes, J.H., 1988a, Utilization of hazard maps in Salt Lake County, in Hays, W.W., ed., A review of "Earthquake research applications in the National Earthquake Hazards Reduction Program, 1977-1987," Proceedings of conference XLI: U.S. Geological Survey Open-File Report 88-13A, p. 362-376. 1988b, Natural hazards ordinance: Salt Lake City, Salt Lake County Public Works Planning Division, Draft no. 4, chap. 19.75, 16 p., 8 maps.

Bates, T.F., 1979, Transferring earth science information to decisionmakers-Problems and opportunities as experienced by the U.S. Geological Survey: U.S. Geological Survey Circular 813, 30 p.

Bernknopf, R.L., Brookshire, D.S., Campbell, R.H., Shapiro, C.D., and Fleming, R.W., 1985, The economics of landslide mitigation strategies in Cincinnati, Ohio-A methodology for benefit-cost analysis, in Campbell, R.H., ed, Feasibility of a nationwide program for the identification and delineation of hazards from mud flows and other landslides: U.S. Geological Survey Open-File Report 85-276, p. D1-D16.

Blair, M.L., and Spangle, W.E., 1979, Seismic safety and land-use planning-Selected examples from the San Francisco Bay region, California: U.S. Geological Survey Professional Paper 941-B, 82 p.

Blair, M.L., Vlasic, T.C., Cotton, W.R., and Fowler, William, 1985, When the ground fails-Planning and engineering response to debris flows: Boulder, University of Colorado, Institute of Behavioral Science, Program on Environment and Behavior, Monograph $40,117 \mathrm{p}$

Blair-Tyler, M.L., and Gregory, P.A., 1988, Putting seismic safety policies to work: Portola Valley, Calif., William Spangle and Associates, Inc., $40 \mathrm{p}$.

Bolton, P.A., Heikkala, S.G., Greene, M.M., and May, P.J., 1986, Land use planning for earthquake hazard mitigation-A handbook for planners: Boulder, University of Colorado, Institute of Behavioral Science, Natural Hazards Research and Applications Information Center, Special Publication 14, 123 p.

Bolton, P.A., and Olson, Jon, 1987a, An assessment of dissemination activities of the California earthquake education project: Seattle, Battelle Human Affairs Research Centers, Contract SSC-6009, $43 \mathrm{p}$.

-1987b, Final report on the evaluation of three earthquake education projects: Seattle, Battelle Human Affairs Research Centers, Report BHARC 800-88-027, 153 p. 
Borcherdt, R.D., ed., 1975, Studies for seismic zonation of the San Francisco Bay region-Basis for reduction of earthquake hazards, San Francisco Bay region, California: U.S. Geological Survey Professional Paper 941-A, 102 p.

Borcherdt, R.D., Gibbs, J.F., and Lajoie, K.R., 1975, Maps showing maximum earthquake intensity predicted in the southern San Francisco Bay region, California, for large earthquakes on the San Andreas and Hayward faults: U.S. Geological Survey Miscellaneous Field Studies Map MF-709, sheet 2, scale 1:125,000.

Boswell, Brenda, ed., 1987, Costs and housing impacts of unreinforced masonry building rehabilitation: Sacramento, California Seismic Safety Commission, $90 \mathrm{p}$.

Brabb, E.E., 1987, Analyzing and portraying geologic and cartographic information for land-use planning, emergency response, and decisionmaking in San Mateo County, California, in GIS '87-San Francisco "... into the hands of the decisionmaker," Second annual international conference, exhibits, and workshops on geographic information systems, October 26-30: Falls Church, Va., American Society for Photogrammetry and Remote Sensing and the American Congress on Surveying and Mapping, p. 362-374.

Brown, R.D., Jr., 1975, Project management-San Francisco Bay region environment and resources planning study, Unpublished report: Menlo Park, Calif., U.S. Geological Survey, 41 p.

Brown, R.D., Jr., and Kockelman, W.J., 1983, Geologic principles for prudent land use-A decisionmaker's guide for the San Francisco Bay region: U.S. Geological Survey Professional Paper 946, $97 \mathrm{p}$.

Brown, R.D., Jr., and Wolfe, E.W., 1972, Map showing recently active breaks along the San Andreas fault between Point Delgada and Bolinas Bay, California: U.S. Geological Survey Miscellaneous Geologic Investigations Map I-692, scale 1:24,000.

Burby, R.J., Bollens, S.A., Holloway, J.M., Kaiser, E.J., Mullan, David, and Sheaffer, J.R., 1988, Cities under water-A comparative evaluation of ten cities' efforts to manage floodplain land use: Boulder, University of Colorado, Program on Environment and Behavior, Monograph 47, $250 \mathrm{p}$.

Burby, R.J., and Cigler, B.A., 1983, Flood hazard managementEffectiveness of State assistance programs for flood hazard mitigation: Chapel Hill, University of North Carolina, Center for Urban and Regional Studies, $29 \mathrm{p}$.

Burby, R.J., and French, S.P., 1981, Coping with floods-The land use management paradox: Journal of the American Planning Association, v. 47 , no. 3 , p. $289-300$.

Burningham, G.L., 1983 (rev.), I can make (a) the difference-Emergency preparedness: Salt Lake City, Utah State Office of Education, $83 \mathrm{p}$.

California Joint Committee on Seismic Safety, 1974, Meeting the earthquake challenge-Final report to the legislature: Sacramento, California Division of Mines and Geology Special Publication $45,223 \mathrm{p}$.

California Seismic Safety Commission, 1986, California at riskReducing earthquake hazards, 1987 to 1992: Sacramento, California Seismic Safety Commission, $92 \mathrm{p}$.

-1987, Appendix to the guidebook to identify and mitigate seismic hazards in buildings: Sacramento, California Seismic Safety Commission Report SSC 87-03, 96 p.

California Seismic Safety Element Review Committee (Mader, G.G., $\mathrm{chm}$. ), 1985, A review of the seismic safety element requirement in California-A report to the California Seismic Safety Commission: Sacramento, California Seismic Safety Commission Report SSC $85-05,26 \mathrm{p}$.

Case, W.F., 1987, Rockfall hazard susceptibility due to earthquakes, central Wasatch Front, Utah, in Gori, P.L., and Hays, W.W., eds., Assessment of regional earthquake hazards and risk along the Wasatch Front, Utah: U.S. Geological Survey Open-File Report 87-585, v. 2, p. V1-V36.
Central United States Earthquake Consortium, 1987, Map users guide: Memphis, Tenn., 4 p.

Christenson, G.E., 1987, Suggested approach to geologic hazards ordinances in Utah: Salt Lake City, Utah Geological and Mineral Survey Circular 79, 16 p.

-1988, Final technical report-Wasatch Front county hazards geologist program: Salt Lake City, Utah Geological and Mineral Survey, USGS Grant 14-08-0001-G991, 14 p.

Christenson, G.E., Barnes, J.H., Moore, Joseph, Nelson, C.V., Robison, R.M., Lowe, Mike, and Kockelman, W.J., 1987, Collecting, compiling, translating, and disseminating earthquake hazards information for urban and regional planning and development in the Wasatch Front area, Utah, in Hays, W.W., and Gori, P.L., eds., A workshop on "Earthquake hazards along the Wasatch Front, Utah," Proceedings of conference XXXVIII, Salt Lake City, May 14-18, 1986: U.S. Geological Survey Open-File Report $87-154$, p. $80-86$.

Christenson, G.E., and Mabey, D.R., 1987, Utah's geologic hazards-A review for realtors: Salt Lake City, Utah Geological and Mineral Survey Open-File Report 109, 5 p.

Council of State Governments, 1976, Natural resource data needs recommendations: Lexington, Ky., Council of State Governments, $25 \mathrm{p}$.

Crone, A.J., 1984, The Borah Peak, Idaho, earthquake-An analog of future Wasatch Front earthquakes?: Salt Lake City, Utah Geological and Mineral Survey, Wasatch Front Forum, v. I, no. 3, p. 3.

Cross, J.A., 1985, Flood hazard information disclosure by realtors: Boulder, University of Colorado, Institute of Behavior Sciences, Natural Hazard Research, Working Paper 52, 44 p.

Davis, J.F., Bennett, J.H., Borchardt, G.A., Kahle, J.E., Rice, S.J., and Silva, M.A., 1982, Earthquake planning scenario for a magnitude 8.3 earthquake on the San Andreas fault in southern California: California Division of Mines and Geology Special Publication $60,128 \mathrm{p}$.

Degenkolb, H.J., Associates, 1981, Seismic hazard survey-State of California buildings: Sacramento, California Seismic Safety Commission Report SSC-604, 83 p.

Deppe, Karl, 1988, The Whittier Narrows, California, earthquake of October 1, 1987-Evaluation of strengthened and unstrengthened unreinforced masonry in Los Angeles City: El Cerrito, Earthquake Engineering Research Institute, Earthquake Spectra, v. 4, no. 1 , p. 157-180.

Dewsnup, Wes, 1987, The Utah County comprehensive hazard mitigation project: Salt Lake City, Utah Geological and Mineral Survey, Wasatch Front Forum, v. 3, no. 3-4, p. 8-9.

Drabek, T.E., 1986, Human system responses to disaster-An inventory of sociological findings: New York, Springer-Verlag, $509 \mathrm{p}$.

Emmi, P.C., 1987, Utahans nervous about earthquake risk-Survey shows support for regulations: Salt Lake City, Utah Geological and Mineral Survey, Wasatch Front Forum, v. 3, no. 3-4, p. 4-5.

Evernden, J.F., Kohler, W.M., and Clow, G.D., 1981, Seismic intensities of earthquakes of conterminous United States-Their prediction and interpretation: U.S. Geological Survey Professional Paper 1223, $56 \mathrm{p}$.

Evernden, J.F., and Thomson, J.M., 1988, Predictive model for important ground motion parameters associated with large and great earthquakes: U.S. Geological Survey Bulletin 1838, 27 p.

Federal Emergency Management Agency, 1985-1989 (various titles relating to seismic safety): Washington, D.C., Hazards Reduction Series, nos. 1-52.

Frank, Lorayne, 1987, Energy systems and disruption: Salt Lake City, Utah Geological and Mineral Survey, Wasatch Front Forum, v. 3, no. $3-4$, p. $9-10$. 
Gori, P.L., and Hays, W.W., eds., 1987, Assessment of regional earthquake hazards and risk along the Wasatch Front, Utah: U.S. Geological Survey Open-File Report 87-585, 2 vols.

1988, Assessment of regional earthquake hazards and risk along the Wasatch Front, Utah: U.S. Geological Survey Open-File Report 88-680, v. 3, $160 \mathrm{p}$.

Greene, M.R., and Gori, P.L., 1982, Earthquake hazards information dissemination-A study of Charleston, South Carolina: U.S. Geological Survey Open-File Report 82-233, 57 p.

Greensfelder, R.W., 1972, Maximum credible bedrock acceleration from earthquakes in California: Sacramento, California Division of Mines and Geology Map Sheet 23, scale 1:2,000,000. (Revised August 1974, modified by California State Department of Transportation Office of Structures, October 1974.)

Hanks, T.C., 1985, The National Earthquake Hazards Reduction Program-Scientific status: U.S. Geological Survey Bulletin 1659, $40 \mathrm{p}$.

Hansen, D.C., and Morgan, R.L., 1982, Rules and regulations governing dam safety in Utah: Salt Lake City, Utah Department of Natural Resources and Energy, Division of Water Rights, $17 \mathrm{p}$.

Hart, E.W., 1986, Zoning for surface-faulting hazards in southern California, in Brown, W.M., III, Kockelman, W.J., and Ziony, J.I, eds., A workshop on "Future directions in evaluating earthquake hazards of southern California," Proceedings of conference XXXII, Nov. 12-13, 1985, Los Angeles: U.S. Geological Survey Open-File Report 86-401, p. 74-83.

1988, Fault-rupture hazard zones in California: Sacramento, California Division of Mines and Geology Special Publication 42, $24 \mathrm{p}$.

Harty, K.M., and Christenson, G.E., 1988, Flood hazard from lakes and failure of dams in Utah: Salt Lake City, Utah Geological and Mineral Survey Map 111, 8 p., scale 1:750,000.

Hassibe, W.R., ed., 1983-1986, Wasatch Front Forum (quarterly): Salt Lake City, Utah Geological and Mineral Survey.

Hays, W.W., 1980, Procedures for estimating earthquake ground motions: U.S. Geological Survey Professional Paper 1114, 77 p.

1981, Facing geologic and hydrologic hazards-Earth-science considerations: U.S. Geological Survey Professional Paper 1240B, $109 \mathrm{p}$.

1984, Regional earthquake hazards assessment program: Salt Lake City, Utah Geological and Mineral Survey, Wasatch Front Forum, v. 1, no. 3, p. 2.

1987, Making the implementation process of the National Earthquake Hazards Reduction Program work in Utah, in Gori, P.L., and Hays, W.W., eds., Assessment of regional earthquake hazards and risk along the Wasatch Front, Utah: U.S. Geological Survey Open-File Report 87-585, p. R1-R44.

, ed., 1988a, A review of earthquake research applications in the National Earthquake Hazards Reduction Program, 1977-1987, Proceedings of conference XLI: U.S. Geological Survey Open-File Report 88-13-A, $597 \mathrm{p}$.

1988b, The knowledge utilization process, in Williams, M.E. and Hays, W.W., eds., Proceedings of the executive briefing on strategic planning to reduce economic impacts of earthquake hazards throughout the world, Washington, D.C., March 8-9, 1988: U.S. Geological Survey Open-File Report 88-361, p. 99-103.

Hays, W.W., Algermissen, S.T., Miller, R.D., and King, K.W., 1978, Preliminary ground response maps for the Salt Lake City, Utah, area: Proceedings of the second international conference on microzonation for safer construction-Research and application, San Francisco, Nov. 26-Dec. 1, 1978: Seattle, University of Washington, v. 1, p. 497-507.

Hays, W.W., and Gori, P.L., eds., 1984, A workshop on "Evaluation of regional and urban earthquake hazards and risk in Utah," Proceed- ings of conference XXVI, Salt Lake City, Aug. 14-16, 1984: U.S. Geological Survey Open-File Report 84-763, 687 p.

-1986, A workshop on "Evaluation of regional and urban earthquake hazards and risk in Alaska," Proceedings of conference XXXI, Anchorage, Alaska, Sept. 5-7, 1985: U.S. Geological Survey Open-File Report 86-79, $450 \mathrm{p}$.

1987, A workshop on "Earthquake hazards along the Wasatch Front, Utah," Proceedings of conference XXXVIII, May 14-18, 1986, Salt Lake City: U.S. Geological Survey Open-File Report 87-154, 164 p.

Headquarters Structural Engineering Staff, 1987 (rev.), Structural directives (including seismic safety): Salt Lake City, Church of Jesus Christ and Latter-day Saints, 9 p.

Information Systems Council's Task Force on Long-Range Goals for USGS's Information Dissemination, 1987, Review of current and developing U.S. Geological Survey earth-science information dissemination activities (summary version): Reston, Va., U.S. Geological Survey, update of May 1985 report, $6 \mathrm{p}$.

International Conference of Building Officials, 1988, Uniform building code: Whittier, Calif., $926 \mathrm{p}$.

Jacknow, Joel, 1985, Technology transfer-An entrepreneurial approach to Federal research: Government Executive, v. 17, no. 4, p. 18-19.

Jaffe, Martin, Butler, JoAnne, and Thurow, Charles, 1981, Reducing earthquake risks-A planner's guide: Chicago, American Planning Association Advisory Services Report 364, 82 p.

Jarva, J.L., ed., 1987-present, Wasatch Front Forum (quarterly): Salt Lake City, Utah Geological and Mineral Survey.

Jochim, C.L., Rogers, W.P., Truby, J.O., Wold, R.L., Jr., Weber, George, and Brown, S.P., 1988, Colorado landslide hazard mitigation plan: Denver, Colorado Geological Survey Bulletin 48, 149 p.

Kaliser, B.N, 1984a, Earthquake hazard situation in Utah (rev.): Salt Lake City, Utah Geological and Mineral Survey, 1 p.

-1984b, Earthquake safety in Utah (rev.): Salt Lake City, Utah Geological and Mineral Survey, 1 p.

1984c, Earthquake faulting in Utah (rev.): Salt Lake City, Utah Geological and Mineral Survey, 1 p.

Keaton, J.R., 1986, Earthquake-induced soil liquefaction: Salt Lake City, Utah Geological and Mineral Survey, Wasatch Front Forum, v. 2 , no. 3, p. 2-4.

1987, Potential consequences of earthquake-induced regional tectonic deformation along the Wasatch Front, north-central Utah: Logan, Utah State University, Department of Civil and Environmental Engineering, 23 p., 6 pls. (Text also in McCalpin, James, compiler and ed., Proceedings of the 23rd symposium on engineering geology and soils engineering: Boise, Idaho Department of Transportation, p. 19-34.)

Keaton, J.R., Anderson, L.R., Topham, Dale, and Rathbun, D.J., 1987, Earthquake-induced landslide potential in and development of a seismic slope stability map of the urban corridor of Davis and Salt Lake Counties Utah: Logan, Utah State University, Department of Civil and Environmental Engineering, 47 p., 4 pls. (Text also in McCalpin, James, compiler and ed., Proceedings of the 23rd symposium on engineering geology and soils engineering: Boise, Idaho Department of Transportation, p. 57-80.)

Keaton, J.R., and Reaveley, L.D., 1986, Field guide to selected geologic features and buildings in southern Davis and northern Salt Lake Counties, Utah, July 18, 1986: Salt Lake City, Utah Geological and Mineral Survey, $22 \mathrm{p}$.

Keefer, D.K., 1984, Landslides caused by earthquakes: Geological Society of America Bulletin, v. 95, p. 406-421.

Kerch, Steve, 1988, In quakes, many homes shake, rattle-not roll: Chicago, Ill., Chicago Tribune, Home Guide section, February 27, 2 p. 
Kockelman, W.J., 1970, Overall program design for the State Planning Office: Santa Fe, New Mexico State Planning Office, 124 p., 16 app.

1975, Use of U.S. Geological Survey earth-science products by city planning agencies in the San Francisco Bay region, California: U.S. Geological Survey Open-File Report 75-276, 110 p.

1976a, Educational, advisory, and review services: Menlo Park, Calif., U.S. Geological Survey administrative report, $25 \mathrm{p}$.

$-1976 \mathrm{~b}$, Use of U.S. Geological Survey earth-science products by county planning agencies in the San Francisco Bay region, California: U.S. Geological Survey Open-File Report 76-547, 185 p.

-1979 , Use of U.S. Geological Survey earth-science products by selected regional agencies in the San Francisco Bay region, California: U.S. Geological Survey Open-File Report 79-221, $173 \mathrm{p}$.

1984, Reducing losses from earthquakes through personal preparedness: U.S. Geological Survey Open-File Report 84-765, 13 p. -1985, Using earth-science information for earthquake hazard reduction, in Ziony, J.I., ed., Evaluating earthquake hazards in the Los Angeles region-An earth-science perspective: U.S. Geological Survey Professional Paper 1360, p. 443-469.

-1986, Some techniques for reducing landslide hazards: College Station, Tex., Association of Engineering Geologists Bulletin, v. 23 , no. 1 , p. 29-52.

Kockelman, W.J., and Brabb, E.E., 1979, Examples of seismic zonation in the San Francisco Bay region, in Brabb, E.E., ed., Progress on seismic zonation in the San Francisco Bay region: U.S. Geological Survey Circular 807, p. 73-84.

Kusler, J.A., 1982, Regulation of flood hazard areas to reduce flood losses: Washington, D.C., U.S. Government Printing Office, U.S. Water Resources Council, v. 3, 357 p.

Lane Publishing Company, 1982, Getting ready for a big quake: Menlo Park, Calif., Sunset Magazine, p. 104-111.

Lohman, Ernst, Vrolijks, Luc, and Roos, Jaap, 1988, Disaster mitigation-A manual for planners, policymakers, and communities, Final draft: Geneva, United Nations Office of the Disaster Relief Coordinator, $489 \mathrm{p}$.

Los Angeles City Council, 1981, Ordinance no. 154,807 relating to earthquake hazard reduction in existing buildings: Los Angeles Municipal Code, chap. IX, art. 1, div. 68, sec. 91.6801 and following.

Lowe, Mike, and Eagan, Keith, 1987, Geology and geologic hazards of the Brigham City area, Box Elder County, Utah, with recommendations for land-use planning, Unpublished report: Farmington, Utah, $49 \mathrm{p}$.

Mabey, D.R., 1985, Earthquake hazards in Utah: Salt Lake City, Utah Geological and Mineral Survey, Survey Notes, v. 18, no. 4, p. 3-4, $6-11$.

Machette, M.N., Personius, S.F., and Nelson, A.R., 1987 (rev. 1988), Quaternary geology along the Wasatch fault zone-Segmentation, recent investigations, and preliminary conclusions, in Gori, P.L., and Hays, W.W., eds., Assessment of regional earthquake hazards and risk along the Wasatch Front, Utah: U.S. Geological Survey Open-File Report 87-585, v. 1, p. A1-A72.

Machette, M.N., Personius, S.F., Nelson, A.R., Schwartz, D.P., and Lund, W.R., 1989, Segmentation models and Holocene movement history of the Wasatch fault zone, Utah, in Schwartz, D.P., and Sibson, R.H., eds., Workshop on "Fault segmentation and controls of rupture initiation and termination," Proceedings of conference XLV: U.S. Geological Survey Open-File Report 89-315, p. 229-245.

Mader, G.G., and Blair-Tyler, M.L., 1988, California at risk-Steps to earthquake safety for local government: Sacramento, California Seismic Safety Commission Report SSC-88-01, 55 p.
Mader, G.G., Spangle, W.E., Blair, M.L., Meehan, R.L., Bilodeau, S.W., Degenkolb, H.J., Duggar, G.S., and Williams, Norman, Jr., 1980, Land-use planning after earthquakes: Portola Valley, Calif., William Spangle and Associates, Inc., $158 \mathrm{p}$.

Mader, G.G., Vlasic, T.C., and Gregory, P.A., 1988, Geology and planning-The Portola Valley experience: Portola Valley, Calif., William Spangle and Associates, Inc., 67 p., 2 app.

Madsen, G.E., 1988, Earthquake knowledge, perceptions of risk, and mitigation priorities of planners and building officials in Salt Lake County: Salt Lake City, Utah Geological and Mineral Survey, Wasatch Front Forum, v. 5, no. 1, p. 5-6.

Mancarti, G.D., 1981, New concepts in earthquake retrofitting of highway bridges-Paper presented at Northwest Bridge engineers conference, Boise, Idaho, 1981: Sacramento, California Department of Transportation, $22 \mathrm{p}$.

Manson, C.J., 1988, Seismic hazards of western Washington and selected adjacent areas-Bibliography and index, 1855-June 1988: Olympia, Washington Division of Geology and Earth Resources, Open-File Report 88-4, 1,039 p.

Mapleton City Council, 1985, Ordinance no. 85-2, Creating a critical environment zone: Mapleton, Utah, Zoning ordinance sec. 7-6-12, $12 \mathrm{p}$.

Marston, S.A., 1984, A political economy approach to hazards-A case study of California lenders and the earthquake threat: Boulder, University of Colorado Institute of Behavioral Science, Natural Hazards Research Working Paper 49, 31 p.

May, Fred, 1988, Governor's conference on comprehensive hazards reduction: Salt Lake City, Utah Geological and Mineral Survey, Wasatch Front Forum, v. 4, no. 3-4, p. 15-16.

May, P.J., and Bolton, P.A., 1986, Reassessing earthquake hazard reduction measures: American Planning Association Journal, v. 52 , no. 4, p. 443-451.

McCalpin, James, 1985, Engineering geology at the local government level-Planning, review, and enforcement: Association of Engineering Geologists Bulletin, v. 22, no. 3, p. 315-327.

1987, Recommended setbacks from active normal faults, in McCalpin, James, ed., Proceedings of the 23rd symposium on engineering geology and soils engineering: Logan, Utah State University, p. 35-56.

McCann, M.W., Jr., and Boissonnade, A.C., 1985, An assessment of earthquake and dam failure consequences in the Ogden/Pineview, Utah, area: Salt Lake City, Utah Division of Comprehensive Emergency Management, and Mountain View, Calif., Jack R. Benjamin and Associates, Inc., Report JBA 210-030, 110 p.

McKelvey, V.E., 1972, Concluding remarks at the American Association of Petroleum Geologists meeting: Denver, Colo., April 17, 1972.

Mellon, Steve, 1986, Highway bridge damage-Palm Springs earthquake July 8, 1986-Seismic report, post-earthquake investigation team (intra-agency document): Sacramento, California Department of Transportation, Office of Structures Design, $40 \mathrm{p}$.

Miller, H.C., 1977, Coastal flood hazards and the national flood insurance program: Washington, D.C., Federal Emergency Management Agency FIA-9, March 1981, 50 p.

Mintier, J.L., 1987 (rev.), State of California general plan guidelines: Sacramento, Calif., Governor's Office of Planning and Research, $368 \mathrm{p}$.

Morton, D.R., ed., 1986, A selected annotated bibliography of recent (1985-1986) hazards publications: Boulder, University of Colorado Natural Hazards Research and Applications Information Center, $146 \mathrm{p}$.

National Research Council, 1986, Active tectonics-Studies in geophysics: Washington, D.C., National Academy Press, 266 p.

National Science Foundation, 1980, A report on flood hazard mitigation: Washington, D.C., National Science Foundation, 253 p. 
NEHRP Expert Review Committee, 1987, The National Earthquake Hazards Reduction Program-Commentary and recommendations of the expert review committee: Washington, D.C., Federal Emergency Management Agency, $85 \mathrm{p}$.

Nelson, C.V., 1987, Surface fault rupture and liquefaction hazard areas map, Salt Lake County: Salt Lake City, Salt Lake County Planning Division, scale (approximately) 1:36,000.

1988, Geoseismic evaluation, Granite Fire Station, Salt Lake County, Utah: Salt Lake City, Utah Geological and Mineral Survey Report of Investigations 218, p. 99-128.

Nelson, C.V., Christenson, G.E., Lowe, Mike, and Robison, R.M., 1987, The review process and adequacy of engineering geologic reports, Wasatch Front, Utah, in McCalpin, James, ed., Proceedings of the 23rd annual symposium on engineering geology and soils engineering-Utah State University, April 6-8, 1987: Logan, Utah State University, p. 83-85.

Nichols, D.R., 1982, Application of earth sciences to land-use problems in the United States with emphasis on the role of the U.S. Geological Survey, in Resources for the twenty-first centuryProceedings of the international centennial symposium of the U.S. Geological Survey: U.S. Geological Survey Professional Paper 1193 , p. 283-291.

Noson, L.L., Qamar, Anthony, and Thorsen, G.W., 1988, Washington State earthquake hazards: Olympia, Washington Division of Geology and Earth Resources Information Circular 85, $77 \mathrm{p}$.

Ogden City Council, 1983, Ordinance no. 8-83 creating seismic requirements for buildings: Ogden, Utah, Municipal code sec. 16.04.090, p. $1-4$.

-1985, Ordinance no. $27-85$ creating a sensitive area overlay zone: Ogden, Utah, Municipal code chap. 27, sec. 19-27-1 and following.

O’Kelley, J.T., Jr., Fleisig, Susan, Shapiro, Carl, Kugel, T.L., DuBose, Lorraine, Gordon, Leonard, and Pittman, Russell, 1982, Program evaluation of USGS information translation and transference activities, Unpublished report: Reston, Va., U.S. Geological Survey, $90 \mathrm{p}$.

Olson, R.S., and Olson, R.A., 1985, The Utah multi-hazard mitigation project-An evaluation, Unpublished report: Sacramento, Calif., VSP Associates, Inc., $44 \mathrm{p}$.

Orem City Council, 1986, Ordinance no. 579 relating to seismic areas: Orem, Utah, City code, chap. 23, Subdivision ordinance sec. 23-7-3, p. 31 .

Palm, Risa, 1981, Real estate agents and special studies zones disclosure-The response of California home buyers to earthquake hazards information: Boulder, University of $\mathrm{C}$ l lorado Institute of Behavioral Science Program on technology, environment, and man, Monograph 32, $147 \mathrm{p}$.

Paté, M.E., and Shah, H.C., 1980, Public policy i :es-Earthquake engineering: Seismological Society of America Bulletin, v. 70, no. 5, p. $1955-1968$.

Perkins, J.B., 1986, Results of a survey of local governments-Use of earthquake information: Oakland, Calif., Association of Bay Area Governments, $14 \mathrm{p}$.

1987, On shaky ground: Oakland, Calif., Association of Bay Area Governments, $32 \mathrm{p}$.

Perkins, J.B., and Moy, Kenneth, 1988, Liability of local governments for earthquake hazards and losses-Background research reports: Oakland, Calif., Association of Bay Area Governments, 3 repts., $295 \mathrm{p}$.

Personius, S.F., 1988, Preliminary surficial geologic map of the Brigham City segment and adjacent parts of the Weber and Collinston segments, Wasatch fault zone, Box Elder and Weber Counties, Utah: U.S. Geological Survey Miscellaneous Field Studies Map MF-2042, scale 1:50,000.
Petak, W.J., 1984, Geologic hazard reduction-The professional's responsibility: College Station, Tex., Association of Engineering Geologists Bulletin, v. 21, no. 4, p. 449-458.

Peters, T.J., and Waterman, R.H., Jr., 1982, In search of excellenceLessons from America's best-run companies: New York, Harper and Row, $360 \mathrm{p}$.

Peterson, D.W., 1986, Volcanoes-Tectonic setting and impact on society, in Active tectonics-Studies in geophysics: Washington, D.C., National Academy Press, p. 231-246.

Power, M.S., Chang, C.-Y., Idriss, I.M., and Kennedy, R.P., 1986, Engineering characterization of ground motion-Task II, Summary report: Washington, D.C., U.S. Nuclear Regulatory Commission, Report NUREG/CR-3805, v. 5, 131 p., 1 app.

Provo Municipal Council, 1985, Sensitive lands development ordinance: Provo, Utah, City ordinances, chap. 15.08, p. 287-293.

Reilly, W.K., 1987, Foreword, in Davies, J.C., Covello, V.T., and Allen, F.W., eds., Risk communication: Washington, D.C., The Conservation Foundation, $143 \mathrm{p}$.

Richter, C.F., 1958, Elementary seismology: San Francisco, W.H. Freeman and Company, $768 \mathrm{p}$.

Robison, R.M., 1988a, Text to accompany surface fault rupture hazard maps for Utah and Juab Counties, Utah: Provo, Utah County Planning Department, $19 \mathrm{p}$.

1988b, Text to accompany tectonic subsidence hazard maps for Utah and Juab Counties, Utah: Provo, Utah County Planning Department, $19 \mathrm{p}$.

Rogers, A.M., 1986, Living with the earthquake risk: Salt Lake City, Utah Geological and Mineral Survey, Wasatch Front Forum, v. 3, no. 2, p. 2-4.

Rogers, A.M., Smith, Robert, and Ward, D.B., 1986, The groundshaking hazard and various aspects of loss estimation in the Wasatch Front area of Utah: Salt Lake City, Utah Geological and Mineral Survey, Wasatch Front Forum, v. 2, no. 4, p. 4.

Rogers, A.M., Tinsley, J.C., and Borcherdt, R.D., 1985, Predicting relative ground response, in Ziony, J.I., ed., Evaluating earthquake hazards in the Los Angeles region-An earth-science perspective: U.S. Geological Survey Professional Paper 1360, p. 221-247.

Saarinen, T.F., and McPherson, H.J., 1981, Notices, watches, and warnings-An appraisal of the USGS warning system with a case study from Kodiak, Alaska: Boulder, University of Colorado, Institute of Behavioral Science, Natural Hazard Research Working Paper 42, $88 \mathrm{p}$.

Saarinen, T.F., and Sell, J.L., 1985, Warning and response to the Mount St. Helens eruption: Albany, State University of New York Press, $240 \mathrm{p}$.

Salt Lake City Council, 1981, Site development regulations: Salt Lake City, Utah, Revised ordinances, title 47, chaps. 1-7, 138 p.

Salt Lake County Commission, 1985, Salt Lake County master plan program-Emigration Canyon master plan: Salt Lake City, Utah, $19 \mathrm{p}$.

San Francisco Bay Area Regional Earthquake Preparedness Project, 1988, Hazardous buildings-Case studies: Oakland, Calif., 4 studies, glossary.

Santa Barbara County Planning Department, 1979, Seismic safety and safety element: Santa Barbara, Calif., $207 \mathrm{p}$.

Sarna-Wojcicki, A.M., Williams, K.M., and Yerkes, R.F., 1976, Geology of the Ventura fault, Ventura County, California: U.S. Geological Survey Miscellaneous Field Studies Map MF-781, scale 1:6,000.

Scholl, R.E., mgr., 1986, Reducing earthquake hazards-Lessons learned from earthquakes: Oakland, Calif., Earthquake Engineering Research Institute, 208 p. 
Schwartz, D.P., 1988, Geologic characterization of seismic sourcesMoving into the 1990s, Reprint: Park City, Utah, Earthquake Engineering and Soil Dynamics II Proceedings, GT Division/ASCE, $42 \mathrm{p}$.

Selkregg, L.L., Ender, R.L., Johnson, S.F., Kim, J.C.K., Gorski, S.E., Preuss, Jane, and Kelso, Duncan, 1984, Earthquake hazard mitigation-Planning and policy implementation-The Alaska case: Washington, D.C., National Science Foundation Grant CEE 8112632.

Slosson, J.E., and Havens, G.W., 1985, Government appears to be failing in enforcement, Unpublished paper: Van Nuys, Calif., Slosson and Associates, $5 \mathrm{p}$.

Slovic, Paul, 1986, Informing and educating the public about risk: Journal of the Society for Risk Analysis, v. 6, no. 4, p. 403-415.

Smith, M.R., 1985a, Information program at the UGMS: Salt Lake City, Utah Geological and Mineral Survey, Survey Notes, v. 19, no. 4 , p. 3-5.

1985b, Utah Geological and Mineral Survey annual report, 1983-84: Salt Lake City, Utah Geological and Mineral Survey Circular 78, $10 \mathrm{p}$.

Smith, R.B., Arabasz, W.J., Pechmann, J.C., and Richins, W.D., 1985, Integrated studies of earthquake source zone characteristics, hazards, and prediction in the Wasatch Front urban corridor and adjacent intermountain seismic belt: Salt Lake City, Utah Geological and Mineral Survey, Wasatch Front Forum, v. 2, no. 2, p. 3-6.

Sorenson, J.H., and Mileti, Dennis, 1987, Public warning needs, in Gori, P.L., and Hays, W.W., eds., A workshop on "The U.S. Geological Survey's role in hazards warnings," Feb. 2-3, 1987, Proceedings of conference XL, Denver, Colo.: U.S. Geological Survey Open-File Report 87-269, p. 9-75.

Southeastern Wisconsin Regional Planning Commission, 1968, Project completion report, urban planning grant project no. Wis. P-53Educational, advisory, and review service programs: Waukesha, Wisc., $32 \mathrm{p}$.

-1987, Twenty-five years of regional planning in southeastern Wisconsin-1960-1985: Waukesha, Wisc., 49 p.

Spall, Henry, ed., 1975-present, Earthquakes and volcanoes (bimonthly) (formerly Earthquake Information Bulletin): Reston, Va., U.S. Geological Survey.

-1985, Earthquake potential of the Wasatch fault in Utah: U.S. Geological Survey Earthquake Information Bulletin, v. 17, no. 6, p. 218-225.

Spanish Fork City Council, 1980 (rev.), Subdivisions-Hillside site development: Spanish Fork, Utah, title 16, sec. 12, 2 p.

Sprinkel, D.A., 1988, A review of the regional earthquake hazards assessment program for the Wasatch Front area, Utah-Will Utah meet the challenge?, in Hays, W.W., ed., A review of "Earthquake research applications in the National Earthquake Hazards Reduction Program, 1977-1987"-Proceedings of conference XLI, 1987: U.S. Geological Survey Open-File Report 88-13-A, p. 88-99.

Steinbrugge, K.V., 1982, Earthquakes, volcanoes, and tsunamis-An anatomy of hazards: New York, Skandia America Group, $392 \mathrm{p}$.

Steinbrugge, K.V., Bennett, J.H., Lagorio, H.J., Davis, J.F., Borchardt, Glenn, and Toppozada, T.R., 1987, Earthquake planning scenario for a magnitude 7.5 earthquake on the Hayward fault in the San Francisco Bay area: California Division of Mines and Geology Special Publication 78, 229 p., 4 app., 23 map sheets.

Stringfellow, J.R., ed., 1983-present, Survey Notes (quarterly): Salt Lake City, Utah Geological and Mineral Survey.

Szanton, Peter, 1981, Not well advised: New York, Russell Sage Foundation and the Ford Foundation, $173 \mathrm{p}$.

Tarr, A.C., 1984, Progress reports: Salt Lake City, Utah Geological and Mineral Survey, Wasatch Front Forum, v. 1, no. 3, p. 5-6.

Tarr, A.C., and Mabey, D.R., 1984, Wasatch Front hazards information system, in Hays, W.W., and Gori, P.L., eds., A workshop on
"Evaluation of regional and urban earthquake hazards and risk in Utah," Proceedings of conference XXVI, Salt Lake City, August 14-16, 1984: U.S. Geological Survey Open-File Report 84-763, p. $148-150$.

Taylor, A.J., 1979, Directions for social research in disaster prevention, mitigation and relief: Disasters, The International Journal of Disaster Studies and Practice, v. 3, no. 3, p. 275-281.

Taylor, C.E., and Ward, D.B., 1979, Seismic risk assessment of Utah primary and secondary schools and recommendations for risk reduction: Salt Lake City, Utah Seismic Safety Advisory Council, Contract 79-5037, $91 \mathrm{p}$.

Thorsen, G.W., 1981, The circuit rider geologist, Final report: U.S. Geological Survey Agreement 7020-086-79, Project 9-7020-26001, $29 \mathrm{p}$.

Tierney, K.J., 1985, Report on the Coalinga earthquake of May 2, 1983: Sacramento, California Seismic Safety Commission Report SSC-85-01, $90 \mathrm{p}$.

Tingey, James, 1986, Utah earthquake preparedness project: Salt Lake City, Utah Geological and Mineral Survey, Wasatch Front Forum, v. 3 , no. 1 , p. $2-4$.

1988, Research applications and the Utah earthquake preparedness program, in Hays, W.W., ed., A review of "Earthquake research applications in the National Earthquake Hazards Reduction Program, 1977-1987"-Proceedings of conference XLI: U.S. Geological Survey Open-File Report 88-13-A, p. 100-105.

1989, Utah's earthquake hazard-Awareness and preparedness: Salt Lake City, Utah Division of Comprehensive Emergency Management, $15 \mathrm{p}$.

Tingey, James, and May, Fred, 1988, CEM alert report summary of August 14, 1988-Earthquake in Emery County: Salt Lake City, Utah Geological and Mineral Survey, Survey Notes, v. 22, no. 1-2, p. 20-21.

Tingey, J.L., and Findlay, R.F, 1987, Emergency management in Utah for earthquakes, in Gori, P.L., and Hays, W.W., eds., Assessment of regional earthquake hazards and risk along the Wasatch Front, Utah: U.S. Geological Survey Open-File Report 87-585, v. 2, p. T1-T19.

Tinsley, J.C., 1988, Quaternary framework for earthquake studies, Los Angeles, California: U.S. Geological Survey Open-File Report 88-434, p. 528-532.

Tinsley, J.C., Youd, T.L., Perkins, D.M., and Chen, A.T.F., 1985, Evaluating liquefaction potential, in Ziony, J.I., ed., Evaluating earthquake hazards in the Los Angeles region-An earth-science perspective: U.S. Geological Survey Professional Paper 1360, p. 263-315.

Tubbesing, Susan, 1982, Highlights of the workshop on preparing for and responding to a damaging earthquake in the eastern United States (including evaluations by workshop participants), in Hays, W.W., ed., A workshop on "Preparing for and responding to a damaging earthquake in the eastern United States," Proceedings of conference XV: U.S. Geological Survey Open-File Report 82-220, p. 37-59.

Turner, R.H., Nigg, J.M., Paz, D.H., and Young, B.S., 1981, Community response to earthquake threat in southern California: Los Angeles, University of Southern California, Institute for Social Science Research, 10 pts.

United Nations Educational, Scientific, and Cultural Organization, 1976, Intergovernmental conference on the assessment and mitigation of earthquake risk, Final report: Paris, $50 \mathrm{p}$.

University of Utah Center for Public Affairs and Administration, 1988, Planning for natural hazards-A technical manual for Utah communities: Salt Lake City, University of Utah, $36 \mathrm{p}$.

U.S. Geological Survey, 1982, Goals and tasks of the landslide part of a ground-failure hazards reduction program: U.S. Geological Survey Circular 880,48 p. 
U.S. Office of Science and Technology Policy, 1978, Earthquake hazards reduction-Issues for an implementation plan: Washington, D.C., Executive Office of the President, Working Group on Earthquake Hazards Reduction, $231 \mathrm{p}$.

Utah Geological and Mineral Survey, 1983, Governor's conference on geologic hazards: Salt Lake City, Utah Geological and Mineral Survey Circular 74, 99 p.

Utah Multi Hazards Mitigation Project Administrative Review Committee, 1985, Ogden City and Weber County multi hazards mitigation plan: Ogden, Utah, $32 \mathrm{p}$.

Utah Museum of Natural History, 1985, Utah geologic hazards: Salt Lake City, $4 \mathrm{p}$.

Utah Section of the Association of Engineering Geologists, 1986, Guidelines for preparing engineering geologic reports in Utah: Salt Lake City, Utah Geological and Mineral Survey Miscellaneous Publication M, 2 p.

1987, Guidelines for evaluating surface-fault rupture hazards in Utah: Salt Lake City, Utah Geological and Mineral Survey Miscellaneous Publication N, 2 p.

Utah Seismic Safety Advisory Council, 1981, A brief summary of earthquake safety in Utah and abbreviated recommendations for risk reduction: Salt Lake City, $13 \mathrm{p}$.

Wallace, R.E., 1974, Goals, strategy, and tasks of the earthquake hazard reduction program: U.S. Geological Survey Circular 701, $27 \mathrm{p}$.

Washington Terrace City Council, 1988, Ordinance no. 16-88 providing for a development overlay zone: Washington Terrace, Utah, revised ordinances, chap. 28, sec. 28-15-1 and following.

Wenk, Edward, Jr., 1979, Scientists, engineers, and citizens, excerpt from Margins for survival: Science, v. 206, no. 4420 (editorial), p. 144-147.

Wesson, R.L., Helley, E.J., Lajoie, K.R., and Wentworth, C.M., 1975, Faults and future earthquakes, in Borcherdt, R.D., ed., Studies for seismic zonation of the San Francisco Bay region: U.S. Geological Survey Professional Paper 941-A, p. 5-30.

White, G.F., Baker, E.J., Baumann, D.D., Chow, W.T., Downing, T.E., Lord, W.B., Marts, M.E., Mitchell, J.K., Platt, R.H., Sorenson, J.H., Tubbesing, S.K., and Waterstone, Marvin, 1976, Natural hazard management in coastal areas: Washington, D.C., U.S. Office of Coastal Zone Management, 294 p.
White, G.F., and Haas, J.E., 1975, Assessment of research on natural hazards: Cambridge, Mass., MIT Press, $487 \mathrm{p}$.

Wieczorek, G.F., Wilson, R.C., and Harp, E.L., 1985, Map showing slope stability during earthquakes in San Mateo County, California: U.S. Geological Survey Miscellaneous Investigations Series Map I-1257-E, scale 1:62,500.

William Spangle and Associates, 1989, Proposal for rendering assistance in implementing seismic safety programs in the Wasatch region, Utah: Portola Valley, Calif., U.S. Geological Survey Grant 14-08-0001-G1681.

Wyner, A.J., and Mann, D.E., 1983, Seismic safety policy in California-Local governments and earthquakes: Santa Barbara, University of California, Department of Political Science, National Science Foundation Grant ENV77-03688, $350 \mathrm{p}$.

Yanev, Peter, 1974, Peace of mind in earthquake country: San Francisco, Chronicle Books, $304 \mathrm{p}$.

Yin, R.K., and Andranovich, G.D., 1987, Getting research used in the natural hazards field-The role of professional associations: Washington, D.C., Cosmos Corporation, 205 p.

Yin, R.K., and Moore, G.B., 1985, The utilization of research-Lessons from the natural hazards field: Washington, D.C., Cosmos Corporation, $101 \mathrm{p}$.

Youd, T.L., and Hoose, S.N., 1978, Historic ground failures in northern California triggered by earthquakes: U.S. Geological Survey Professional Paper 993, 177 p., 5 pl.

Youngs, R.R., Swan, F.H., Power, M.S., Schwartz, D.P., and Green, R.K., 1987, Probabilistic analysis of earthquake ground-shaking hazard along the Wasatch Front, Utah, in Gori, P.L., and Hays, W.W., eds., Assessment of regional earthquake hazards and risk along the Wasatch Front, Utah: U.S. Geological Survey Open-File Report 87-585, v. 2, p. M1-M110.

Ziony, J.I., ed., 1985, Evaluating earthquake hazards in the Los Angeles region-An earth-science perspective: U.S. Geological Survey Professional Paper 1360, 505 p.

Ziony, J.I., and Yerkes, R.F., 1985, Evaluating earthquake and surface-faulting potential, in Ziony, J.I., ed., Evaluating earthquake hazards in the Los Angeles region-An earth-science perspective: U.S. Geological Survey Professional Paper 1360, p. $43-91$. 


\title{
PUBLIC PERCEPTIONS OF THE IMPLEMENTATION OF EARTHQUAKE MITIGATION POLICIES ALONG THE WASATCH FRONT IN UTAH
}

\author{
By Gary E. Madsen, ${ }^{3}$ Loren R. Anderson, ${ }^{4}$ Jerold H. Barnes, ${ }^{5}$ and Genevieve Atwood, ${ }^{6}$
}

\begin{abstract}
The earthquake hazard potential along the Wasatch Front in Utah has been well defined by a number of scientific and engineering studies. Translated earthquake hazard maps have also been developed to identify areas that are particularly vulnerable to various causes of damage such as ground shaking, surface rupturing, and liquefaction. The implementation of earthquake hazard reduction plans are now under way in various communities in Utah. The results of a survey presented in this paper indicate that technical public officials (planners and building officials) have an understanding of the earthquake hazards and how to mitigate the risks. Although the survey shows that the general public has a slightly lower concern about the potential for economic losses, they recognize the potential problems and can support a number of earthquake mitigation measures. The study suggests that many community groups along the Wasatch Front, including volunteer groups, business groups, and elected and appointed officials, are ready for action-oriented educational programs. These programs could lead to a significant reduction in the risks associated with earthquake hazards.
\end{abstract}

\section{INTRODUCTION}

Earthquakes can cause loss of life and costly property damage, and therefore, in areas of high seismic activity, earthquake hazard mitigation is an important consideration in intelligent land-use planning and in the establishment and implementation of local ordinances and building codes. Damage during earthquakes can result from surface faulting, ground shaking, ground failure, generation of large waves (tsunamis and seiches) in bodies of water, and tectonic deformation. All of these causes of damage need to be considered in reducing the potential for economic and human losses during earthquakes.

The occurrence of earthquakes along the Wasatch Front in Utah has been documented since the arrival of the early pioneers about 1850 (Arabasz and others, 1979), and recent scientific work has documented the seriousness of the earthquake hazard problem (see Gori and

\footnotetext{
3 Department of Sociology, Utah State University, Logan, Utah.

4 Department of Civil Engineering, Utah State University, Logan, Utah.

5 Salt Lake County Planning Division, Salt Lake City, Utah.

${ }^{6}$ Utah Geological Survey, Salt Lake City, Utah.
}

Hays, 1987). In addition to earthquakes, a number of other geologic hazards exist along the Wasatch Front that should be considered in land-use planning. For example, during approximately 3 months in the spring of 1983 , the State of Utah, with a population of some 1.6 million people, sustained direct damages from landslides, debris and mud flows, and flooding in excess of $\$ 400$ million. These disastrous events were so extensive that 22 of the 29 counties in the state were declared natural disaster areas (Anderson and others, 1984). U.S. Geological Survey (USGS)-sponsored workshops on earthquake hazards in Utah from 1985 to the present have broadened earthquake hazard awareness beyond the scientific community. These well-organized workshops have summarized the research efforts of seismologists, geologists, and engineers and have heightened the awareness of planners and the staffs of local government agencies. However, much work must be done to bring the urgency of the earthquake hazard problem to the general public so that they will understand the work of scientists, engineers, and planners and then embrace the implementation of ordinances, building codes, and other actions aimed at mitigating earthquakes and other natural hazards.

Kockelman (1990, p. AA-22) has identified five components that are needed in the development of any earthquake hazard reduction program:

1. Conducting scientific and engineering studies of the physical processes of earthquake phenomena that may be hazardous, e.g., source, location, size, likelihood of occurrence, severity, triggering mechanism, path, ground response, structure response, and equipment response.

2. Translating the results of such studies into reports and onto maps at an appropriate scale so that the nature and extent of the hazards and their effects are understood by nontechnical users.

3. Transferring this translated information to those who will or are required to use it, and assisting them in its use through educational, advisory, and review services.

4. Selecting and using appropriate hazard reduction techniques such as legislation, regulations, design criteria, education, incentives, public plans, and corporate policies. 
5. Evaluating the effectiveness of the hazard reduction techniques after they have been in use for a period of time and revising them if necessary. Evaluation and revision of the entire program as well as the other components-studies, translation, and transfer-may also be undertaken.

Research activities sponsored by the USGS Earthquake Hazard Reduction Program during the past several years have produced a number of translated research findings that identify the seriousness of earthquake hazards along the Wasatch Front. Maps specifically for Salt Lake County have been completed that identify the potential for fault rupture, ground shaking, ground failure (by liquefaction and earthquake-induced landslides), and tectonic deformation. Thus components 1 and 2 above have already received a great deal of attention. Much more effort needs to be directed toward meeting objectives 3 through 5 .

Before implementation activities can be successful, the public must have an awareness and an understanding of the hazards, and, at the same time, engineers, planners, and public policy officials must be aware of the level of hazard reduction activities that the public will accept. Much can be done by the engineering community and the public to significantly reduce earthquake hazards at little additional cost, provided that the problems are identified and mitigated early.

Recent projects (Madsen and others, 1988, 1990) have been aimed at implementing an earthquake hazard reduction plan for Salt Lake County, the most populous county in the State of Utah. The overall goal was directed toward earthquake preparedness rather than toward programs dealing with emergency response and recovery during or after earthquakes. The major objective was to develop a program of preparedness in Salt Lake County involving public officials, community groups, and the general public. The program was designed to create heightened awareness of earthquake problems, create a public acceptance of earthquake hazard reduction programs, and to develop and implement an earthquake hazard reduction plan for the county. The first step was to assess the earthquake hazard awareness and understanding of both public officials (those working in a technical capacity) and the general public, and to determine types of mitigation measures that each will support.

This paper presents the results of a survey of technical public officials (planners and building officials) and the general public. It assesses concerns of these two groups regarding the potential for widespread and damaging earthquakes in the Salt Lake County area of Utah and assesses the support they give to various mitigation strategies.

\section{ACKNOWLEDGMENTS}

This project was supported by the U.S. Geological Survey under award 14-08-0001-G1531. However, the contents do not necessarily represent the policy of that agency, and endorsement by the Federal Government should not be assumed.

Jeffrey R. Keaton, Larry Reaveley, and Craig Nelsen have been part of the project team. The work of these individuals is much appreciated. We have also received significant input from Gary Christenson and William Case of the Utah Geological Survey and from James Tingey of the Division of Comprehensive Emergency Management.

\section{METHODOLOGY}

Salt Lake County contains 12 municipalities, 10 of which have at least one planning or building official. Unincorporated areas are served by personnel of Salt Lake County government. Two surveys were conducted to determine levels of awareness of earthquake problems and support for various mitigation strategies. The first consisted of 28 planners and building officials. In the largest government units, the highest level administrative personnel were identified. Each individual was interviewed in person during May and June of 1988. The completion rate was 100 percent. The second survey consisted of 409 male and female adults who resided in Salt Lake County. They were randomly drawn from Salt Lake County telephone listings and were interviewed by telephone during September of 1988. The response represents a 70 percent completion rate from the sampling frame. The interviews were conducted by the Survey Research Center at the University of Utah and pertained to the assessment of three factors: earthquake hazard knowledge, perceptions of earthquake risks, and priorities for earthquake risk reduction.

\section{RESULTS OF THE SURVEYS}

The planners and building officials were asked to rank seven causes of damage from potential earthquakes in Salt Lake County (Salt Lake Valley), assigning the number 1 to the item with the highest potential for damage and the number 7 to the item with the lowest potential, and individually ranking the items between the extremes. The results, presented in table 1 , indicate a high correspondence between rankings by local officials and by the scientific community (see Christenson, 1987). For example, based on scientific investigations, the problem of ground shaking is considered to be the 
TABLE 1.-Rankings by local government planners and building officials as to potential damage from earthquake hazards in Salt Lake Valley

\begin{tabular}{|c|c|c|}
\hline \multirow{2}{*}{ Causes of damage } & \multicolumn{2}{|c|}{ Rank* } \\
\hline & $\bar{x}$ & S.D. \\
\hline Ground shaking $\ldots \ldots \ldots \ldots \ldots \ldots \ldots \ldots \ldots$ & 1.52 & 0.75 \\
\hline Ground failure induced by liquefaction ......... & 2.26 & 1.13 \\
\hline Fault rupture $\ldots \ldots \ldots \ldots \ldots \ldots \ldots \ldots \ldots \ldots \ldots$ & 3.63 & 1.55 \\
\hline Landslides and rockfalls.............. & 4.04 & 1.29 \\
\hline Tectonic deformation...$\ldots \ldots \ldots \ldots \ldots \ldots \ldots$ & 4.82 & 1.39 \\
\hline Dam failure $\ldots \ldots \ldots \ldots \ldots \ldots \ldots \ldots \ldots \ldots$ & 5.22 & .94 \\
\hline Water waves............................ & 6.52 & 1.37 \\
\hline
\end{tabular}

greatest potential hazard. Those surveyed in the general public were not asked to make this ranking because of its highly technical content.

The next item surveyed was how local planners and building officials (technical officials) and the public perceive earthquake risks. Both sample groups were asked to indicate the likelihood of an earthquake that would cause widespread, severe damage in the Salt Lake Valley within the next 100 , the next 50 , and the next 10 yrs. The possible responses included very high (point value of 5), high, moderate, low, and very low (point value of 1 ). The results, presented in table 2 , indicate that there is a great deal of concern about the likelihood of a future earthquake damaging the Salt Lake Valley. In the $100-\mathrm{yr}$ period the technical officials' mean $(\bar{x})$ of 4.64 approaches the ranking of very high, whereas the public sample mean of 3.97 is associated with the ranking of high. For each time period, the mean of the technical officials is higher than that of the public. However, even the public's rating for the 10 -yr time period $(\bar{x}=2.80)$ approaches the ranking of moderate. There is also greater variability among the public than among the technical officials, as indicated by the standard deviations (S.D.). The technical officials constituted a population, but since the public sample was randomly drawn from a larger population, a standard error (S.E.) was calculated for each public sample mean. For example, the 95 percent confidence interval for the $100-\mathrm{yr}$ period is $\bar{x}=3.97+0.1$, which is a small range of variability from sample to sample drawn from the same population. Data from the public sample comparing men and women are also presented in table 2 . A $t$-test between means yields a statistically significant difference at the 0.05 level for the 10-yr period only. Thus, in general, men and women appear to have similar views about the likelihood of future damage from earthquakes in the Salt Lake Valley.

Respondents to the public survey were also asked about concerns for personal safety and damage to their residences if a serious earthquake were to occur in the Salt Lake Valley. The questions were taken from a survey by Rossi and others (1982, p. 318), and the wording was modified to refer to earthquakes rather than to natural disasters in general. Data pertaining to these questions are presented in table 3 . Respondents were asked whether they were very concerned, somewhat concerned, or not at all concerned that (1) the building in which they live would suffer serious damage, (2) the contents of their residence would be seriously damaged, and (3) they or someone in their family would be seriously injured.

The results indicate that approximately 85 to 90 percent of the respondents were either somewhat or very concerned about their residence, its contents, and the likelihood of personal injury. The category most often identified for both building damage and contents damage was "somewhat concerned," with 49.8 and 54.6 percent,

TABLE 2.-Perceptions of the likelihood of a future damaging earthquake in the Salt Lake Valley: Comparison of local technical officials (planners and building officials) and public residents

\begin{tabular}{|c|c|c|c|c|c|c|c|c|c|c|c|c|c|c|}
\hline \multirow{3}{*}{ Earthquake risk time period } & \multicolumn{3}{|c|}{ Technical officials* } & \multicolumn{4}{|c|}{ Public residents* } & \multicolumn{6}{|c|}{ Public residents by gender* } & \multirow{3}{*}{$t$-ratio } \\
\hline & \multirow[b]{2}{*}{$N$} & \multirow[b]{2}{*}{$\bar{x}$} & \multirow[b]{2}{*}{ S.D. } & \multirow[b]{2}{*}{$N$} & \multirow[b]{2}{*}{$\bar{x}$} & \multirow[b]{2}{*}{ S.D. } & \multirow[b]{2}{*}{ S.E. } & \multicolumn{3}{|c|}{ Men } & \multicolumn{3}{|c|}{ Women } & \\
\hline & & & & & & & & $N$ & $\bar{x}$ & S.D. & $N$ & $\bar{x}$ & S.D. & \\
\hline $\begin{array}{l}\text { Likelihood of earthquake causing } \\
\text { widespread and severe damage } \\
\text { in the Salt Lake Valley within } \\
\text { the next } 100 \text { years? }\end{array}$ & 28 & 4.64 & 0.62 & 394 & 3.97 & 1.02 & 0.05 & 179 & 3.98 & 1.05 & 212 & 3.94 & 1.00 & 0.38 \\
\hline $\begin{array}{l}\text { Likelihood of earthquake causing } \\
\text { widespread and severe damage } \\
\text { in the Salt Lake Valley within } \\
\text { the next } 50 \text { years? }\end{array}$ & 28 & 4.18 & .77 & 385 & 3.56 & 1.08 & .06 & 172 & 3.48 & 1.07 & 210 & 3.65 & 1.07 & 1.55 \\
\hline $\begin{array}{l}\text { Likelihood of earthquake causing } \\
\text { widespread and severe damage } \\
\text { in the Salt Lake Valley within } \\
\text { the next } 10 \text { years? }\end{array}$ & 28 & 3.14 & .71 & 385 & 2.80 & 1.10 & .06 & 171 & 2.68 & 1.03 & 211 & 2.91 & 1.15 & 2.05 \\
\hline
\end{tabular}

* The response alternative of very high was assigned a point value of 5 , high 4 , moderate 3 , low 2 , and very low 1 . No probability statistics were calculated for the technical officials, since they were a population, not a sample drawn from a population, as was the case for the public respondents. Gender was not determined for three public residents. S.E. = standard error 
TABLE 3.-Concern of public residents about a future serious earthquake occurring in Salt Lake Valley

\begin{tabular}{|c|c|c|c|c|c|c|c|c|c|c|c|c|c|c|c|c|c|c|c|c|c|c|}
\hline \multirow{4}{*}{ Area of concern } & \multicolumn{7}{|c|}{ Concern levels of public residents } & \multicolumn{14}{|c|}{ Concern levels of public residents by gender* } & \multirow{4}{*}{$\begin{array}{c}\text { Chi- } \\
\text { square } \\
p\end{array}$} \\
\hline & & & & & & & & \multicolumn{7}{|c|}{ Men } & \multicolumn{7}{|c|}{ Women } & \\
\hline & \multicolumn{2}{|c|}{ Not at all } & \multicolumn{2}{|c|}{ Somewhat } & \multicolumn{2}{|c|}{ Very } & \multirow{2}{*}{$\begin{array}{c}\text { Total } \\
N\end{array}$} & & at all & Som & what & & ery & Total. & Not & at all & Som & lewhat & & ery & Total & \\
\hline & $N$ & $\%$ & $N$ & $\%$ & $N$ & $\%$ & & $N$ & $\%$ & $N$ & $\%$ & $N$ & $\%$ & $N$ & $N$ & $\%$ & $N$ & $\%$ & $N$ & $\%$ & $N$ & \\
\hline $\begin{array}{l}\text { The building in } \\
\text { which you live } \\
\text { would suffer } \\
\text { serious damage. }\end{array}$ & 42 & 10.3 & 202 & 49.8 & 162 & 39.9 & 406 & 27 & 14.6 & 92 & 49.7 & 66 & 35.7 & 185 & 15 & 6.9 & 108 & 49.5 & 95 & 43.6 & 218 & 0.026 \\
\hline $\begin{array}{l}\text { The contents of } \\
\text { your residence } \\
\text { (furniture, car- } \\
\text { pets, appliances) } \\
\text { would be seriously } \\
\text { damaged. }\end{array}$ & 62 & 15.3 & 221 & 54.6 & 122 & 30.1 & 405 & 41 & 22.1 & 100 & 54.1 & 44 & 23.8 & 185 & 21 & 9.7 & 118 & 54.4 & 78 & 35.9 & 217 & .0006 \\
\hline $\begin{array}{l}\text { You or someone } \\
\text { in your family } \\
\text { would be seriously } \\
\text { injured. }\end{array}$ & 44 & 10.8 & 134 & 33.0 & 228 & 56.2 & 406 & 27 & 14.5 & 66 & 35.5 & 93 & 50.0 & 186 & 17 & 7.8 & 66 & 30.4 & 134 & 61.8 & 217 & .025 \\
\hline
\end{tabular}

* Gender was not determined for three public residents.

respectively. The mode for the personal injury question was "very concerned," with 56.2 percent of the total. These findings are consistent with the findings of Rossi and others (1982, p. 114-115). In their survey of California residents, they found that, with respect to natural disasters, people were more concerned about personal injuries than about building or content damage.

Gender was also found to be an important variable with respect to feelings of concern. A chi-square test to compare the responses of men and women yielded statistically significant differences for all three questions, with women indicating higher overall levels of concern. The percentages of men and women identifying themselves as somewhat concerned are very similar for the three questions. However, the percentages of women in the not at all concerned category were consistently about half the percentages for the men, and the responses of women were about 8-12 percentage points above the men in the very concerned category.

Higher levels of earthquake concern among women than men are supported by other related studies. In a review of the literature concerning responses to public disaster warnings, Sorenson and Mileti (1987) documented that women are more likely than men to hear warnings, to believe such warnings, and to engage in protective warning responses. Turner and others (1986) also found gender differences in levels of fear and concern about an earth uplift in the Palmdale, Calif., area. This uplift was identified as a possible precursor to an earthquake. Women reported higher levels of fear and concern than men, and taking warnings seriously was also related to fear and concern.

It is important to know if local technical officials are knowledgeable about earthquake hazards and consider a serious earthquake to be likely. It is also important to determine whether the public perceives similar risks and is concerned about them. However, are these attributes of knowledge and concern related to support for policies to decrease earthquake risks in the Salt Lake Valley? To identify mitigation policies, the technical officials were also asked open-ended questions followed by fixedalternative questions regarding actions they felt should be taken to reduce the risks from earthquakes in the Salt Lake Valley. Several fixed-alternative items were derived from Kockelman (1986), and those receiving the highest overall ranks using both methods were then presented to the public sample for their evaluations. The data comparing the two groups are presented in table 4 . The response alternatives to the policy items were as follows: very high importance (point value of 5), high importance, moderate importance, low importance, and not at all important (value of 1 ).

The averages of the technical officials for 10 of the 11 policy items were higher than those of the public sample. However, with the exception of "requiring disclosure of earthquake hazards to real estate buyers," which the public rated 3.61, no item fell below a mean of 4.0 (corresponding to high importance) among the public resident sample. In general, the standard deviations indicated greater variability among the public respondents than among the technical officials. The standard errors for each public sample mean when multiplied by 1.96 produce 95 percent confidence intervals of slightly less than one-tenth to slightly more than one-tenth of a point.

Gender comparisons are also identified in table 4 . The data reveal that the averages on all 11 policy items are higher for women than for men. These mean differences 
TABLE 4.-Policies to reduce earthquake risks in the Salt Lake Valley: Comparison of local technical officials (planners and business officials) and public residents

\begin{tabular}{|c|c|c|c|c|c|c|c|c|c|c|c|c|c|c|}
\hline \multirow{3}{*}{ Mitigation policy } & \multicolumn{3}{|c|}{ Technical officials $^{\mathrm{a}}$} & \multicolumn{4}{|c|}{ Public residents $^{\mathrm{a}}$} & \multicolumn{6}{|c|}{ Public residents by gender ${ }^{a}$} & \multirow{3}{*}{$\begin{array}{l}t- \\
\text { ratio }\end{array}$} \\
\hline & \multirow[b]{2}{*}{$N$} & \multirow[b]{2}{*}{$\bar{x}$} & \multirow[b]{2}{*}{ S.D. } & \multirow[b]{2}{*}{$N$} & \multirow[b]{2}{*}{$\bar{x}$} & \multirow[b]{2}{*}{ S.D. } & \multirow[b]{2}{*}{ S.E. } & \multicolumn{3}{|c|}{ Men } & \multicolumn{3}{|c|}{ Women } & \\
\hline & & & & & & & & $N$ & $\bar{x}$ & S.D. & $N$ & $\bar{x}$ & S.D. & \\
\hline $\begin{array}{l}\text { Controlling the location } \\
\text { and specific design } \\
\text { requirement of new } \\
\text { schools, police facili- } \\
\text { ties, and fire stations }\end{array}$ & 28 & $4.68^{\mathrm{b}}$ & $0.54^{\mathrm{b}}$ & 407 & 4.45 & 0.82 & 0.04 & 186 & 4.35 & .88 & 218 & 4.54 & 0.76 & 2.28 \\
\hline $\begin{array}{l}\text { Strengthening existing } \\
\text { hospitals, schools, } \\
\text { police facilities, and } \\
\text { fire stations }\end{array}$ & 28 & $4.58^{\mathrm{b}}$ & $.67^{\mathrm{b}}$ & 406 & 4.15 & .95 & .05 & 185 & 3.92 & 1.02 & 218 & 4.34 & .85 & 4.46 \\
\hline $\begin{array}{l}\text { Informing and educat- } \\
\text { ing the public about } \\
\text { earthquake hazards } \\
\text { and earthquake pre- } \\
\text { paredness }\end{array}$ & 28 & 4.75 & .44 & 408 & 4.29 & .86 & .04 & 186 & 4.12 & .93 & 219 & 4.43 & .77 & 3.67 \\
\hline $\begin{array}{l}\text { Providing public offi- } \\
\text { cials with earthquake } \\
\text { hazard information }\end{array}$ & 28 & 4.64 & .56 & 405 & 4.22 & .91 & .05 & 186 & 4.10 & .93 & 216 & 4.32 & .89 & 2.50 \\
\hline $\begin{array}{l}\text { Providing public offi- } \\
\text { cials with professional } \\
\text { technical assistance }\end{array}$ & $\ldots^{c}$ & $\ldots$ & $\ldots$ & 406 & 4.13 & .94 & .05 & 185 & 3.99 & .94 & 218 & 4.25 & .94 & 2.76 \\
\hline $\begin{array}{l}\text { Promoting land-use } \\
\text { planning that consid- } \\
\text { ers earthquake hazard } \\
\text { areas }\end{array}$ & 28 & 4.54 & .74 & 402 & 4.11 & .99 & .05 & 185 & 4.03 & 1.03 & 214 & 4.20 & .91 & 1.75 \\
\hline $\begin{array}{l}\text { Adhering to existing } \\
\text { earthquake-related } \\
\text { building codes, zoning } \\
\text { ordinances, and build- } \\
\text { ing inspections }\end{array}$ & 28 & 4.58 & .88 & 400 & 4.31 & .87 & .04 & 183 & 4.19 & .92 & 214 & 4.43 & .75 & 2.79 \\
\hline $\begin{array}{l}\text { Establishing more } \\
\text { stringent earthquake- } \\
\text { related building } \\
\text { codes, zoning ordi- } \\
\text { nances, and building } \\
\text { inspections }\end{array}$ & 28 & $3.86^{\mathrm{d}}$ & 1.08 & 395 & 4.06 & .97 & .05 & 180 & 3.89 & 1.01 & 212 & 4.22 & .87 & 3.45 \\
\hline $\begin{array}{l}\text { Adopting uniform } \\
\text { earthquake-related } \\
\text { building codes, zoning } \\
\text { ordinances, and build- } \\
\text { ing inspections }\end{array}$ & $\ldots{ }^{\mathrm{c}}$ & $\ldots$ & $\ldots$ & 401 & 4.02 & 1.03 & .05 & 183 & 3.91 & 1.00 & 215 & 4.13 & .98 & 2.14 \\
\hline $\begin{array}{l}\text { Requiring disclosure of } \\
\text { earthquake hazards to } \\
\text { real estate buyers }\end{array}$ & 28 & 4.32 & 1.02 & 397 & 3.61 & 1.15 & .06 & 179 & 3.37 & 1.21 & 215 & 3.84 & 1.04 & 4.10 \\
\hline $\begin{array}{l}\text { Encouraging public } \\
\text { agency programs that } \\
\text { improve emergency } \\
\text { responses }\end{array}$ & 28 & 4.21 & .79 & 405 & 4.03 & 1.08 & .05 & 185 & 3.94 & 1.15 & 217 & 4.14 & .96 & 1.97 \\
\hline
\end{tabular}

\footnotetext{
a The response alternatives for the items (except the two indicated) were as follows: very high importance was assigned a point value of 5 , high importance 4 , moderate importance 3 , low importance 2 , and not at all important 1 . No statistical tests were calculated for the technical officials, since they were a population, not a sample drawn from a population, as was the case for the public respondents. Gender was not determined for three public residents.

b These first two policy items were originally presented to the technical officials as eight separate items. Each type of facility was presented separately. The means and standard deviations for the technical officials in the table are the averages of the mean and S.D. for each item. The actual figures for controlling the location of new hospitals were $\bar{x}=4.96$, S.D. 0.19 ; schools 4.82 and 0.39 , police facilities 4.39 and 0.79 , and fire stations 4.54 and 0.79 . Corresponding figures for strengthening hospitals were $\bar{x}=4.82$, S.D. $=0.39$; schools 4.75 and 0.52 , police facilities 4.29 and 0.90 , and fire stations 4.46 and 0.88 .

$\mathfrak{c}^{\mathfrak{c}}$ Two items were identified by the technical officials in open-ended questions that solicited policy items without the prompting one gets from fixed alternative items. These two items were not ranked in the same way as the fixed alternatives but were included because they were identified more often than others as being important policies.

$\mathrm{d}$ This item fell below all others ranked by the technical officials. It was in the public survey because the mean of the planners was 4.29 , while that for the building officials was 3.18 . This difference between the two subgroups was greater than for any of the original 49 policy items that were ranked.
} 
are statistically significant at the 0.05 level or greater ( $t$-ratios of 1.96 or larger) for all policy items except "promoting land-use planning that considers earthquake hazard areas." Not only are women more concerned than men about future earthquakes, they are also more supportive of mitigation policies to reduce earthquake risks.

\section{APPLICATION OF RESEARCH FINDINGS TO IMPLEMENTATION OF EARTHQUAKE HAZARD REDUCTION ON THE WASATCH FRONT}

Kockelman (1990), in his analysis of the success of the Wasatch Front Earthquake Hazard Reduction Program, identifies the importance of targeting specific audiences with specific messages tailored to the needs of each. Sorenson and Mileti (1987) provide a stepwise model that puts this observation in context: individuals must hear, understand, believe, and personalize a message before they will take action.

How do these observations apply to the Wasatch Front? First, the Salt Lake County survey results indicate a high degree of opinion congruence between technical officials and the general public. It follows that the elected and appointed officials who enact public policy also need to know that there is broad-based support for hazard mitigation. The importance of public support in the mitigation process has been identified by Selkregg and others (1984, p. 167), who stated:

This relationship between public awareness, support, and implementation is an important one. It suggests that the political and technical leaders are less likely to achieve policy goals related to risk reduction in the absence of public support.

Concerning the importance of educational programs, Selkregg and others (1984, p. 166) have further suggested:

\begin{abstract}
Scientists and planners need to build communication skills to inform the public and the policy makers of their findings. Consideration of seismic risk in land use planning, building structures, site planning, critical facilities, and other areas will gain greater prominence only if scientists and researchers promote understanding of their work, learn how to communicate and evaluate their needs and the needs of planners and policy makers, and design their products and recommendations to be of optimum use. This broadening scientific responsibility would enhance public understanding and support of research needed to assist policy makers in setting guidelines for public safety. Elected officials, planners, professionals, and scientists need to assume the role of public education.
\end{abstract}

The results of the Salt Lake County surveys suggest that educational programs concerning earthquake hazards and earthquake preparedness can be directed toward receptive audiences. These data indicate that many community groups along the Wasatch Front, including volunteer groups, business groups, and elected and appointed officials, are ready for action-oriented educational programs. These programs could lead to a significant reduction in the risks associated with earthquake hazards.

The gender differences identified among the public sample suggest that women in the general public are likely to be a readily identifiable group of individuals who believe in the earthquake hazards and are likely to take action. This raises the possibility that the National Earthquake Hazards Reduction Program (NEHRP) could target this group and tailor information to be readily understood and personalized. To our knowledge, this "targeting" has not been done on the basis of gender.

One implication of this study is the need to better understand this gender difference among the general public. An application of this study might be to develop information specifically targeted for the perceived needs of some of the more visible women's groups or those in which women are highly active, such as local chapters of the League of Women Voters, Parent Teacher Associations (PTA), and the Church of Jesus Christ of Latterday Saints (LDS) Relief Society. Each of these group's differing missions contains elements that could be related to NEHRP. For instance, the League of Women Voters has supported land-use planning along the Wasatch Front that incorporates geologic hazards such as earthquakes. Local PTA organizations have advocated earthquake hazard preparedness in the schools. The LDS Relief Society plays a key role in the preparation of food supplies in case of emergency. Can earthquake information be "translated" in terms specifically designed for these groups as well as others? Can the information be personalized for various memberships so that it leads to a commitment to personal preparedness? Can an education program be developed that leads not only to personal preparedness but also to active support for changes in public policy? We feel these challenges are worth pursuing.

Utah needs to prepare for a major damaging earthquake along the Wasatch Front. The scientific evidence for the hazard is overwhelming, even though it has not been experienced in historic time. The challenge in Utah is to take policy actions before the devastating earthquake. The results of this research strongly suggest a window of opportunity that should not be missed.

\section{REFERENCES}

Anderson, L.R., Keaton, J.R., Saarinen, T.F., and Wells, W.G., 1984, The Utah landslides, debris flows, and flood of May and June 1983: Washington, D.C., National Academy Press. 
Arabasz, W.J., Smith, R.B., and Richins, W.D., eds., 1979, Earthquake studies in Utah, 1850-1978: Salt Lake City, University of Utah Seismograph Station, Special Publication.

Christenson, G.E., 1987, Suggested approach to geologic hazards ordinances in Utah: Utah Geological and Mineral Survey, Circular 79.

Gori, P.L., and Hays, W.W., eds., 1987, Assessment of regional earthquake hazards and risk along the Wasatch Front, Utah: U.S. Geological Open-File Report 87-585, 2 vols.

Kockelman, W.J., 1986, Some techniques for reducing landslide hazards: Bulletin of the Association of Engineering Geologists, v. 23, no. 1 , p. 29-52.

1990, Reducing earthquake hazards in Utah, The crucial connection between researchers and practitioners: USGS Open-File Report 90-225, p. AA1-AA153.

Madsen, G., Barnes, J., and Anderson, L.R., 1988, The implementation of an earthquake hazard mitigation program in Salt Lake County, Utah: U.S. Geological Survey, Grant 14-08-0001-G1531.
1990, The implementation of an earthquake hazard mitigation program in Salt Lake County, Utah: U.S. Geological Survey, Grant 14-08-001-G1797.

Rossi, P.H., Wright, J.D., and Weber-Burdin, E. 1982, Natural hazards and public choice: The state and local politics of hazards mitigation, New York, Academic Press.

Selkregg, L.L., Preuss, J., Ender, R.L., Johnson, S.F., Kim, J.C.K., Gorski, S.E., and Kelso, D., 1984, Earthquake hazard mitigation, Planning and policy implementation, The Alaska case: Anchorage, University of Alaska, and Seattle, Urban Regional Research.

Sorenson, J.H., and Mileti, D., 1987, Public warning needs, in Gori, P.L., and Hays, W.W., eds., A workshop on "The U.S. Geological Survey's role in hazards warnings," Proceedings of conference XL: U.S. Geological Survey Open-File Report 87-269, p. 9-75.

Turner, R.H., Nigg, J.M., and Heller Paz, D., 1986, Waiting for disaster, Earthquake watch in Califorma: Berkeley, University of California Press. 


\title{
A DATA BASE DESIGNED FOR URBAN SEISMIC HAZARDS STUDIES
}

\author{
By Arthur C. TARr
}

\begin{abstract}
A computerized data base has been designed for use in urban seismic hazards studies conducted by the U.S. Geological Survey. The design includes file structures for 16 linked data sets, which contain geological, geophysical, and seismological data used in preparing relative ground response maps of large urban areas. The data base is organized along relational data base principles. A prototype urban hazards data base has been created for evaluation in two urban areas currently under investigation: the Wasatch Front region of Utah and the Puget Sound area of Washington. The initial implementation of the urban hazards data base was accomplished on a microcomputer using dBASE III Plus software and transferred to minicomputers and a work station.
\end{abstract}

\section{INTRODUCTION}

For more than a decade, the U.S. Geological Survey (USGS) has been studying seismic hazards in earthquake-prone urban areas of the United States. Part of the process of seismic risk assessment is the evaluation of site response of soils and underlying geological units (relative to nearby bedrock) to earthquake motions. Site response (also called relative ground response) is a complex function of many geological and geophysical variables (Rogers and others, 1985). Spatial variations of intensity in a localized area are due principally to site response.

Determining which combination of geological and geophysical factors is most significant in affecting site response is the subject of ongoing research. Once those significant factors are determined, one exceedingly important task is organizing a (frequently) large body of data so that site response may be correlated with geotechnical variables and with Modified Mercalli (MM) intensities, when they are available. This report describes a computerized data base designed for use in urban seismic hazards assessment.

\section{ACKNOWLEDGMENTS}

The design and implementation of the urban hazards data base evolved as a result of many long discussions with Stanley Brockman, David Carver, Edward Cran- swick, Kenneth King, John Tinsley, David Trumm, and Robert Williams; their assistance is gratefully acknowledged.

\section{SUMMARY OF METHODS}

Previous theoretical and empirical studies have indicated that seismic site response may be influenced by the thickness and degree of consolidation of sediments at the site, by the seismic shear velocity and mean void ratio of the sediment layers, and by degree of saturation and depth to water table. Figure 24 schematically illustrates these general characteristics. In general, greater thicknesses of soft, low-velocity sediments beneath a site yield higher overall levels of relative ground response (fig. 24, site 1) relative to a bedrock reference site (Borcherdt, 1975; Ohta and others, 1978; Kagami and others, 1982, 1986; Rogers and others, 1985). In addition, narrowbandwidth amplification is frequently observed at sites where thin layers of low-velocity sediments overlay hard rock (fig. 24, site 2); the amplification is due to resonance in the thin low-velocity layers (Rogers and others, 1985).

Site effects, due to whatever causes, are commonly invoked to explain substantial variations, within rather localized areas, of observed earthquake intensity patterns and instrumentally recorded ground motions. For example, severe but localized damage to medium-rise structures in Mexico City has been explained by resonance amplification (due to deposits of young, soft, lakebed sediments) of seismic ground vibrations from the September 19, 1985, Mexico earthquake (Cluff, 1985).

Relative ground response can be determined without relying on strong earthquake ground motions. Studies conducted in the San Francisco Bay region of California (Borcherdt and others, 1975), in the Los Angeles, Calif., area (Rogers and others, 1985), and in the Wasatch Front region of Utah (Hays and King, 1982) have relied on nuclear explosions as seismic sources. Similar studies using microtremors (small-amplitude vibrations) as seismic sources have been conducted in Japan and the San Fernando Valley of southern California (Ohta and others, 1978; Kagami and others, 1982, 1986). Relative 
ground response values determined from small ground motions have been shown to be comparable to response values determined from recordings of strong ground motions (Rogers and others, 1985).

The results of the Los Angeles study are illustrative. Fourier spectra of seismograms recorded at sites in the Los Angeles urban area were compared with spectra recorded at a single reference site (Rogers and others, 1985). The recordings were of nuclear explosions at the Nevada Test Site (NTS). Seismic stations were widely distributed across the Los Angeles area and installed on diverse geologic materials; the reference site was located on hard rock.

Spectral ratios were computed for each seismic event by dividing smoothed Fourier spectra of the various site records by the smoothed Fourier spectrum of the reference site record. Mean spectral ratios for each recording site and seismic event were computed for three period bands: short period $(0.2-0.5 \mathrm{~s} ; 5-2 \mathrm{~Hz})$, intermediate period $(0.5-3.3 \mathrm{~s} ; 2-0.3 \mathrm{~Hz}$ ), and long period (3.3-10 s; $0.3-0.1 \mathrm{~Hz}$ ). Geological and geotechnical data were gathered from logs of nearby water wells and from boreholes drilled for soil-engineering studies. The geographical variation in relative ground response was evaluated in terms of the underlying geotechnical conditions at each recording site by means of cluster and discriminant analyses.

In the Los Angeles area, Rogers and others (1985) found that ground motions were enhanced at sites underlain by Holocene and Pleistocene sediments, with the overall response generally increasing with the thickness of Quaternary deposits and depth to bedrock. The chief factors controlling short-period relative ground response in the Los Angeles study were mean void ratio in near-surface layers, thickness of unconsolidated (principally Holocene) sediment, and depth to bedrock. Intermediate- and long-period responses were controlled principally by depth to bedrock and by thickness of Quaternary alluvium.

Similar studies have been completed by the USGS in Utah along the Wasatch Front urban corridor (Hays and King, 1982) and the Puget Sound area of Washington (King and others, 1990). Preliminary results in Utah indicate correlations of relative ground response with geotechnical parameters similar to the Los Angeles study. More than 50 boreholes were drilled and logged for the Wasatch Front study (J. Tinsley, written commun., 1989).

Once the critical geotechnical factors affecting site response have been identified, a theoretical ground response model is constructed, and maps displaying the model are produced. The theoretical ground response model is employed in the construction of probabilistic

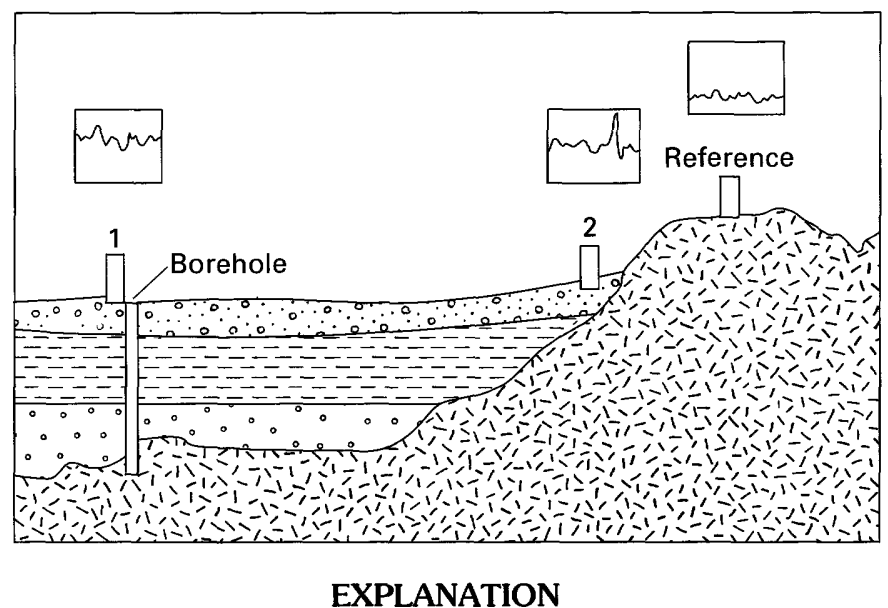

$\because \because 0 \%$ Unconsolidated sediments of Holocene age

Semiconsolidated sediments of Quaternary age

\begin{tabular}{|l|l|}
\hline$\because 0$ & 0 \\
0 & 0
\end{tabular} Sedimentary rock

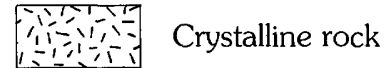

FIGURE 24.-Cross section of hypothetical seismic ground response study area. Three representative response sites are designated Reference, 1, and 2; the small rectangle at each site designates a seismic station. The small rectangular diagram above each site represents a Fourier amplitude spectrum (Fourier amplitude versus frequency) of a typical seismogram recorded at each site. Spectrum examples show that overall spectral level is elevated slightly at site 2 and more so at site 1; high frequency resonance peak is shown in the spectrum at site 2 .

acceleration maps, which are necessary for a variety of applications, such as loss estimation.

\section{DATA BASE MANAGEMENT SYSTEM}

Producing a site response map of a large urban area at risk from strong ground shaking requires many relative ground response values to establish response zones on the map. These values are derived from a clustering analysis of measured ground response utilizing variables that have been demonstrated to be significant factors in affecting ground response. Measured values of these significant factors can be quite numerous. Therefore, it should be clear that a large urban seismic hazards study involves an extensive data collection, data organization, and data analysis effort; this effort is facilitated by a utilitarian data base design and computerized data base management system (DBMS). 


\section{BENEFITS AND COSTS OF A DATA BASE MANAGEMENT SYSTEM}

The benefits derived from organization of a voluminous amount of data with a good DBMS are

- Orderliness. A good data base design assures that logically associated data will be related by the DBMS.

- Efficiency. Data entry, editing, and retrieval operations are fast in comparison with manual recordkeeping systems.

- Flexibility. A good DBMS allows restructuring of data file design as necessary (without additional or redundant data entry) and permits establishing complex relationships among data contained within several files.

- Security. Once data have been entered into a data base, edited, and proofed, they are part of a permanent record and are less susceptible to accidental loss or alteration.

- Transportability. Data that are organized with a good DBMS on one computer system can be easily moved to another computer system.

The costs associated with the organization of large data sets in a DBMS are

- Software cost. DBMS software is sometimes expensive to purchase, depending on the host computer used and the application.

- Hardware cost. Hardware cost is minimal if an existing computer is used, more expensive (sometimes prohibitively so) if a new computer system is to be dedicated to the DBMS software.

- Labor cost. Manual data entry is labor intensive (and hence costly) for large data sets. Data base maintenance (updating, verification, backup, archiving) is usually less labor intensive after initial data entry. In-house programming costs are largely up-front and may be high (one of the trade-offs if DBMS software is written in-house).

A manual records system is entirely adequate for small numbers of observations of only a few geotechnical factors; one can keep the data close at hand and in mind, and the cost of organizing the data is insignificant. However, a manual records system becomes more unwieldy as the number of response observations and geotechnical factors increases. Further, as the geotechnical analysis becomes more complex, relating data items from numerous sources (data sheets, tables, notebooks, etc.) and graphing data become tedious, and the opportunities for error increase. Computerization of the data is inevitable if applications software is used to analyze the data. If several data formats are required for different applications software packages, incompatibilities may arise, and duplicate keyboarding may be required.
In summary, a good DBMS and standard data structures can minimize problems when data sets are large, when several applications software packages are used to analyze the data, and when analytical techniques become complex.

\section{DESIGN OBJECTIVES}

The preceding discussion has indicated the complex relationship of geological, physical, and geotechnical factors in determining a theoretical relative ground response model. Relative ground response maps derived from the model are the principal end products of seismic hazards research. The maps traditionally have been constructed by overlaying transparent sheets on which the various data sets have been plotted and by manually drafting the final map. Recently, Geographic Information System (GIS) technology has been employed to construct the maps by extracting the ground response data and associated geotechnical data from a data base and then electronically combining these data layers. Thus, three major considerations influence data base design: how the data are acquired, how the data are analyzed, and how the data are to be used.

\section{DATA BASE DESIGN CONSIDERATIONS}

Three sets of data base terminology are often used interchangeably, to describe similar entities and similar characteristics of the data base (Martin, 1977). The sets of terms differ because of differences in viewpoint of the data user, the data manager, and the applications programmer toward the form of the data and toward the organization of data:

1. The form of the data is tangible and physical for the user. The data user (and frequently the data gatherer) probably has a manual system for recording and organizing the data: notebook pages or sheets of paper upon which are written specific data values, often in tabular form; graphs upon which data values are plotted; and index cards, such as bibliographic citations, which can be sorted.

2. The form of the data is symbolic for the data manager. The data manager views the data as organized into generalized lists or tables of data items and seldom thinks in terms of the actual values the data items may assume.

3. The applications programmer visualizes the data both symbolically and physically. To the programmer, the symbolic lists and tables of the data manager become arrays of variables (containing data values) that will be manipulated within a program and that will be physically stored in computer memory or in a disk file. 

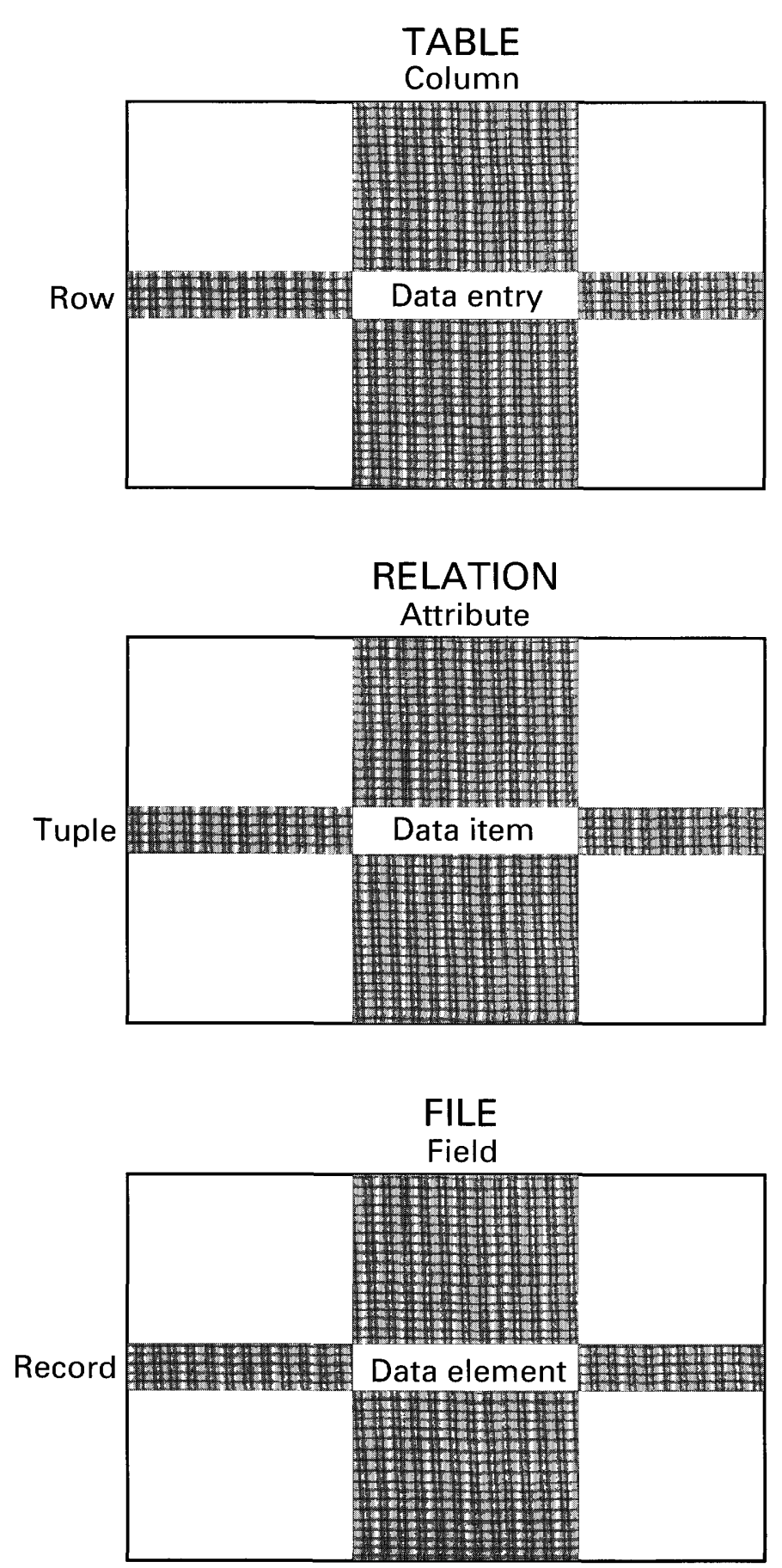

FIGURE 25. - Relationships of terms used in three different representations of data in a data base.

Figure 25 compares the three sets of terms as they apply to a data table, a relation, and a data file. In the following discussion, square brackets enclose alternate terms to help the reader as the perspective shifts among the three viewpoints.

The provisional design for the urban hazards data base is relational in organization, consisting of several large

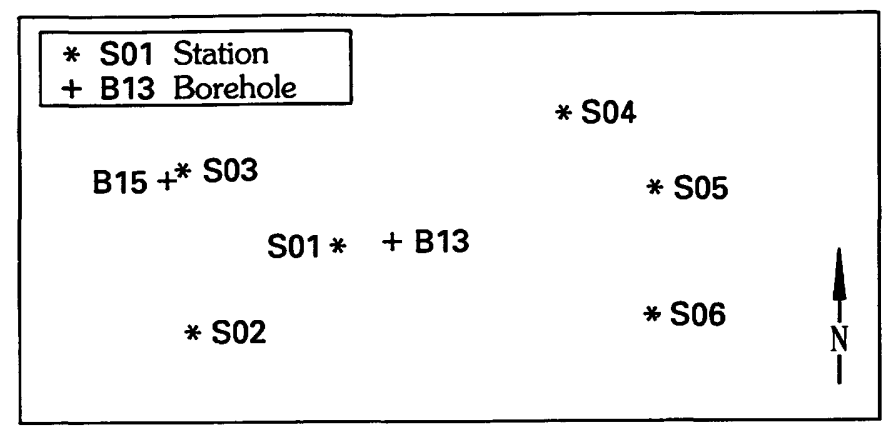

FIGURE 26. - Seismic stations (asterisks) and boreholes (crosses) in a hypothetical area where seismic response studies are conducted.

tables [relations, arrays, files] of data. The data are arranged in the table in rows and columns, each row representing a unique entity, such as a seismic station, a borehole site, or a rock unit. Each column [attribute] represents one property or characteristic of the entities listed in the table; latitude and borehole depth are examples of attributes. Each row of attribute values is called a tuple or record, and the part of a record containing an attribute value is called a field. The entire collection of records is called a data set, data file, or flat file. A group of related data sets or data files is called a data base in all three terminologies.

\section{EXAMPLE OF RELATIONAL ORGANIZATION}

Suppose that we have completed an experiment at six locations where seismic instruments have recorded seismograms of seismic events; seismic response ratios will be computed from the seismograms. Further, suppose that at two of the sites (fig. 26) boreholes were drilled for determination of vertical profiles of seismic velocity and geological properties. Say that we desire a list that will comprehensively and completely summarize in one place the properties of the six response sites. In a manual records system, we would probably construct a table and list each of the site locations on a separate line, identifying each site by a number, a code, an address, or a comment. Each line would contain other information such as coordinates, elevation, site geology, and, if a borehole had been drilled at that site, the borehole depth. The information in the table constitutes a compact and usable data set.

If we computerize these data using a relational organization scheme, we conceptually transform the physical table into a relation or a flat file. The data describing seismic stations and associated boreholes would be stored in a file; in this example, the file is called STATION (fig. 27). Each record in the file contains data 


STATION
Ident. Latitude Longitude
\begin{tabular}{|c|c|c|c|c|c|}
\hline S01 & 37.068 & -117.987 & $\ldots$ & \multicolumn{3}{c|}{$\begin{array}{c}\text { Bore- } \\
\text { hole ID Depth }\end{array}$} \\
\hline S02 & 37.113 & -118.007 & $\ldots$ & B 13 & 87.9 \\
\hline S03 & 37.990 & -117.803 & $\ldots$ & B15 & 72.0 \\
\hline S04 & 38.012 & -118.122 & $\ldots$ & & \\
\hline S05 & 38.245 & -118.098 & $\ldots$ & & \\
\hline S06 & 37.112 & -117.889 & $\ldots$ & & \\
\hline
\end{tabular}

STATION

\begin{tabular}{|c|c|c|c|c|c|c|}
\hline \multicolumn{3}{|c|}{ Ident. Latitude Longitude } & $\cdots$ & \multirow{2}{*}{\multicolumn{3}{|c|}{$\begin{array}{c}\text { Bore- } \\
\text { Ident. hole ID Depth }\end{array}$}} \\
\hline S01 & 37.068 & \multirow[t]{2}{*}{-117.987} & $\cdots$ & & & \\
\hline \multirow{2}{*}{ S02 } & \multirow{2}{*}{37.113} & & & - S01 & B13 & 87.9 \\
\hline & & -118.007 & 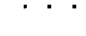 & \multirow{2}{*}{$\mathrm{S} 03$} & \multirow{2}{*}{ B15 } & \multirow{2}{*}{72.0} \\
\hline S03 & 37.990 & -117.803 & $\cdots$ & & & \\
\hline S04 & 38.012 & -118.122 & $\cdots$ & & & \\
\hline S05 & 38.245 & -118.098 & $\cdots$ & EXPI & ANA & IION \\
\hline S06 & 37.112 & -117.889 & & & INTEF & \\
\hline
\end{tabular}

FIGURE 27.-Station and borehole data collected in a table [relation, file] called STATION (top) and two tables [relations, files] called STATION and BORE. Arrows designate pointers that link related borehole data to a station. Note that the combined physical size of the two lower tables [relations, files] is smaller than the upper table [relation, file] because of elimination of null data despite the need to duplicate the station identifiers in BORE.

describing a specific (and unique) seismic station and (optional) borehole. ${ }^{7}$

The fields in each record contain data values such as the station's latitude, longitude, and elevation, a brief description of the site geology, the borehole identifier, and the borehole depth. One field, the station's unique identifier, is also called the primary key field; other fields (such as the borehole identifier), which may or may not be unique, are called secondary key fields. (Key fields are used for data retrieval operations in the data base; however, it is not necessary that a file have keys.)

\footnotetext{
7 This example is somewhat contrived to illustrate the point about null data elements. Because boreholes are seldom located precisely at a station location, borehole data (including latitude, longitude, and elevation) should be kept in a separate file.
}

Some attributes (such as borehole depth) may not contain data values in all records, perhaps because the data do not exist (in the example, boreholes were not drilled at all sites) or the data are not known; such empty data elements are called null data elements.

One principle employed in relational data base design is to eliminate duplication of identical attributes [columns] in different files wherever possible. Strict application of this principle eliminates the possibility of inconsistent data values for the same attribute in different files and reduces the amount of computer storage required for each record. Another design principle is to minimize the number of null data elements in the file. This is accomplished by eliminating attributes that have few occurrences of data compared with the number of null data elements. These data (which, although sparse, are often important) may be stored in a smaller, auxiliary file. This auxiliary file contains a field value that links the data in a record in the smaller file to an associated record in the larger file (fig. 27). The field that permits the linking of records in different files is called a pointer field.

In the STATION example, say that the borehole data are removed from STATION and stored in a small file named BORE. The link between the two files is established in the BORE file by the pointer field containing a value that is identical to a value in a field in STATION. The station identifier, since it is unique, would be a good choice for a pointer to associate records in STATION and BORE. A record may contain multiple pointers; the principal data base design requirement for pointers is that they must not cause confusion during retrieval operations. For example, a pointer in one file should not point to multiple records in another file because retrievals attempted at various times might retrieve a different record each time. However, the same pointer value in several records pointing to just one record in another file is permissible because no ambiguity exists. Thus, for unique retrievals, one-to-one and many-to-one pointers are permissible, but one-to-many pointers are not (fig. 28).

The many-to-one case is illustrated by the RESPONSE data file. There are two fields in RESPONSE (station_id and event_id) whose values are pointers to unique records in the STATION and EVENT files, respectively. In the RESPONSE file, each measurement of the average spectral ratio across the band is entered as a separate record; consequently, the values for station_id and the values for event_id are identical for each of the RESPONSE records of that station and event combination. Thus, the station_id pointers in many RESPONSE records point to one STATION record, and the event_id pointers in the same records point to one EVENT record. 

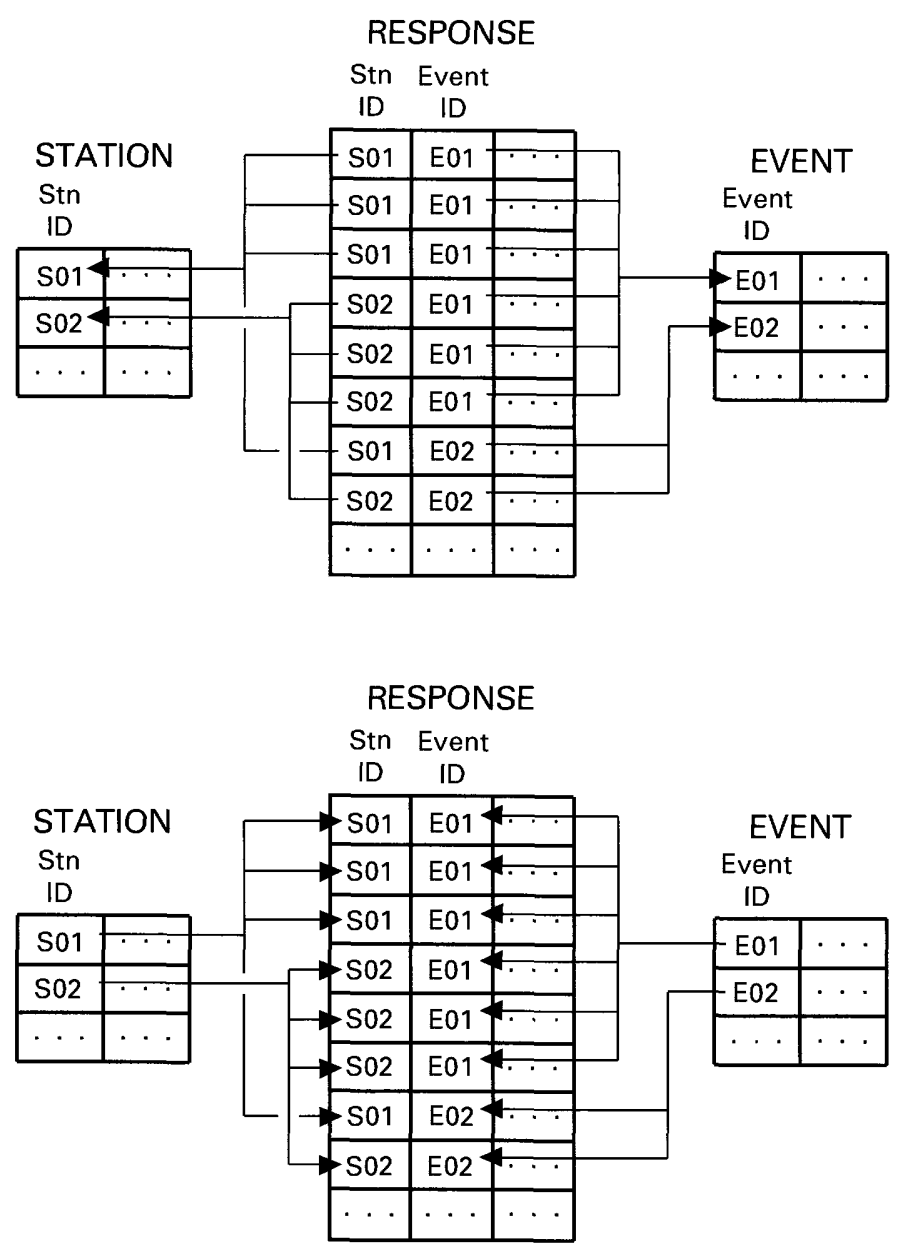

FIGURE 28. - Examples of many-to-one (upper diagram) and one-tomany (lower diagram) pointer relationships among records in hypothetical STATION, RESPONSE, and EVENT relations. One-tomany pointers cause confusion in data retrieval operations of response records from station and event data because of the lack of uniqueness in the relationships; one-to-many pointers should be avoided in data base management.

Why could not the station identification, event identification, and a fixed number of mean spectral ratio fields be stored in a single RESPONSE record? There are two reasons that this suggestion is not feasible in the RESPONSE example: the need for flexibility and the need to eliminate null data elements. Establishing a fixed number of spectral ratio fields, one each for a predetermined frequency band, would preclude any band that did not fit the format. Further, the number of spectral ratio fields would have to be the largest number of fields to be expected, not just the number needed to describe the ratio spectrum; the larger the number of fields, the greater the likelihood of null data elements. In the preferred structure of RESPONSE, any bandwidth may be specified, and there are only as many records as needed to describe the ratio spectrum.

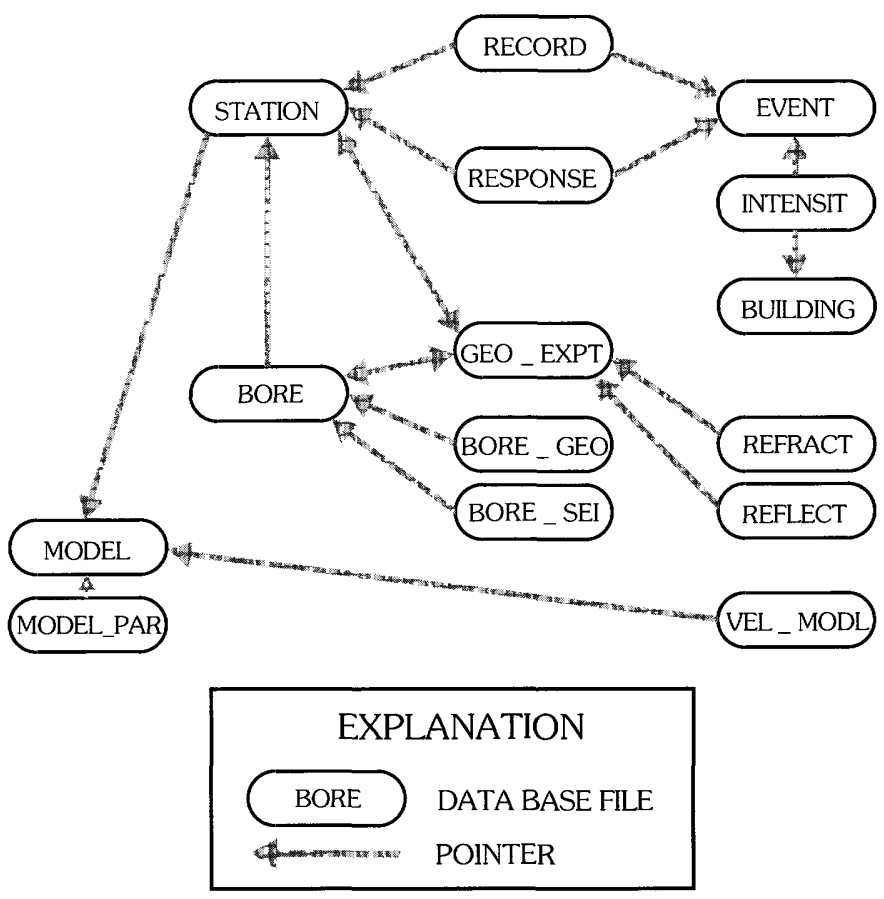

FIgURE 29. - Relationships of data files (boxes) in the geotechnical data base. Names of files within boxes are described in the text. Arrows designate pointers that link records within data files.

\section{DATA FILES IN THE DATA BASE}

The data files and data structures that are used in the data base design are listed in Appendix A; figure 29 shows how the data are linked by pointers.

Data files STATION and BORE are similar: they contain data characteristic of the site, such as the location and general geological description. Each record in the RESPONSE file contains a response measurement at one station from one event over one frequency band. Each record in EVENT contains location and origin time and other data regarding seismic sources such as explosions and earthquakes. BORE_GEO contains geological data from a specific depth interval in the borehole, and BORE_SEI contains seismic data (such as velocity and density) from a specific depth interval in the borehole. In the same way that a station identification field and an event identification field in each RESPONSE record point to associated records in STATION and EVENT, respectively, borehole identification fields in BORE_GEO and BORE_SEI point to associated records in $B O \bar{R} E$. A field in BORE containing the identifier of the nearest seismic station points to a record in STATION. A pointer expt_id in REFLECT and REFRACT links seismic reflection and seismic refraction experiment data to GEO_EXP, in which records describe the location and geology of the experiment site. 
The design of the RESPONSE, BORE_GEO, and BORE_SEI data files is flexible enough to allow documentation of single, multiple, and reduced measurements at a specific seismic response site or borehole site. For example, the response in a given frequency band for a particular station and event is usually a single measurement, but in some instances it may be a simple mean, weighted mean, or smoothed value of several measurements. Similarly, the design of INTENSIT allows for multiple observations of MM intensity to be documented for a specific site.

\section{IMPLEMENTATION OF THE DATA BASE}

A prototype urban hazards data base (UHDB) utilizing the relational data base principles described in this report has been implemented to manage the seismic hazards data for two urban areas currently under investigation: the Wasatch Front in Utah and Puget Sound in Washington. The Wasatch Front hazards assessment has entered the final stages, and thus most of the seismic hazards data have been acquired. Entry of these data into the files of the UHDB has permitted evaluation of the degree of soundness and appropriateness of the initial data structures. In addition, a user interface called GEOTEK was programmed using the dBASE III Plus language.

The UHDB is currently implemented on a number of computer systems: a USGS PRIME 9955 minicomputer located in Lakewood, Colo.; five systems located in Golden, Colo. (a USGS VAX 11/750 minicomputer, a SUN Microsystems 3/60 work station, and three microcomputers); and microcomputers in California and Nevada.

There are significant advantages to implementation on multiple computer systems. The microcomputers are used principally in the data acquisition and data analysis phases of projects, both in the field an ! in the office. After newly acquired data are edited and proofed, the data sets are transferred to one microcomputer, where the master data base is maintained. Copies of the master data base are installed on the two minicomputers and the work station in Golden and distributed to other users as needed. Thus, the data are available for use by GIS and other applications software installed on those systems. In addition, the data files are accessible to many additional USGS personnel and to a large number of analysis programs not available on a microcomputer.

Since the dBASE III Plus software is installed on several field microcomputers, data entry, data editing, and data retrieval are possible in the field as data are being acquired. Program and data design development are much easier using a software package such as dBASE III Plus; once the data base design has been settled on, implementation on the VAX 11/750 (which requires FORTRAN programming because data base management software is unavailable in the present VAX installation) should be simplified.

Multiple site implementation is feasible because it is possible to transfer data files easily between the various user sites, electronically by using either a modem or one of several existing computer networks or physically by transporting a diskette or magnetic tape containing the data. No data file conversion is required between similar systems (microcomputer-to-microcomputer). Between dissimilar systems, a dBASE III Plus conversion utility, a communications software package, and hardware connection (or modem) are required.

\section{REFERENCES}

Borcherdt, R.D., Joyner, W.B., Warrick, R.E., and Gibbs, J.F., 1975, Response of local geologic units to ground shaking, in Studies for seismic zonation of the San Francisco Bay region: U.S. Geological Survey Professional Paper 941-A, p. A52-A67.

Cluff, L.S., 1985, Firsthand experience of the $M_{\mathrm{S}} 8.1$ earthquake that struck Mexico City on 19 September 1985: Bulletin of the Seismological Society of America, v. 75, p. 1843-1846.

Hays, W.W. and King, K.W., 1982, Zoning of the earthquake groundshaking hazard, in Proceedings, Third international earthquake microzonation conference: Seattle, Wash., p. 145-156.

Kagami, H., Duke, C.M., Liang, G.C., and Ohta, Y., 1982, Observation of 1 - to 5 -second microtremors and their application to earthquake engineering-Part II, Evaluation of site effect upon seismic wave amplification due to extremely deep soil deposits: Bulletin of the Seismological Society of America, v. 72, no. 3, p. $987-998$.

Kagami, H., Okada, S., Shiono, K., Oner, M., Dravinski, M., and Mal, A.K., 1986, Observation of 1- to 5-second microtremors and their application to earthquake engineering-Part III, A twodimensional study of site effects in the San Fernando Valley: Bulletin of the Seismological Society of America, v. 76, no. 6, p. 1801-1812.

King, K.W., Tarr, A.C., Carver, D.L., Williams, R.A., and Worley, D.M., 1990, Seismic ground-response studies in Olympia, Washington, and vicinity: Bulletin of the Seismological Society of America, v. 80 , no. 5, p. 1057-1078.

Martin, James, 1977, Computer database organization (2nd ed.): Englewood Cliffs, N.J., Prentice-Hall, 713 p.

Ohta, Y., Kagami, H., Goto, N., and Kudo, K., 1978, Observation of 1to 5 -second microtremors and their application to earthquake engineering-Part I, Comparison with long-period accelerations at the Tokachi-Oki earthquake of 1968: Bulletin of the Seismological Society of America, v. 68, no. 3, pp. 767-779.

Rogers, A.M., Tinsley, J.C., and Borcherdt, R.D., 1985, Predicting relative ground response in earthquake hazards in the Los Angeles region: U.S. Geological Survey Professional Paper 1360, p. 221-248. 


\section{APPENDIX A. URBAN HAZARDS DATA BASE FILE STRUCTURES}

There are currently 16 data files in the urban hazards data base:

BORE [Borehole data]

BORE_GEO [Borehole geology data]

BORE_LOG [Borehole log data]

BORE_SEI [Borehole seismology data]

BUILDING [Building data]

EVENT [Seismic event data]

GEO_EXPT [Geophysical experiment data]

INTENSIT [Seismic intensity data]

MODEL [Model structure]

MODL_PAR [Model parameters]

RECORD [Seismic record]

REFLECT [Seismic reflection data]

REFRACT [Seismic refraction data]

RESPONSE [Seismic response data]

STATION [Seismic station data]

VEL_MODL [Velocity model]

The files and fields in the data base are:

BORE [Borehole data]

Borehole identification

Alternate borehole identification

Owner

Borehole location description

Borehole latitude

Borehole longitude

Borehole elevation

Quadrangle name

Section/township/range description

Logged by whom

Casing

Date(s) drilled

Date closed

Borehole (well) depth

Depth to cementation

Depth to water table

Depth to bedrock (basement)

Thickness Holocene sediments

Thickness Quaternary sediments

Total thickness sediments

Preferred station (pointer to STATION)

Distance to preferred station

Preferred geophysical experiment (pointer to GEO_EXPT)

Remarks

Reference

BORE_GEO [Borehole geology data]

Borehole identification (pointer to BORE)

Minimum interval depth

Maximum interval depth

Percent silt and clay

Percent sand

Percent gravel

Description of interval

Texture

Soil classification

Age

Grain size

Liquid limit

Plastic limit
Plastic index

Moisture content

Density solids

Dry density

Void ratio

Remarks

Reference

BORE_LOG [Borehole log data]

Borehole identification (pointer to BORE)

Minimum interval depth

Maximum interval depth

Color

Field description

Unit name

Remarks

BORE_SEI [Borehole seismology data]

Borehole identification (pointer to BORE)

Minimum interval depth

Maximum interval depth

P-velocity

S-velocity

Remarks

Reference

BUILDING [Building data]

Building identification

Building location (name, address)

Building latitude

Building longitude

Building elevation

Building description

Number of stories

Remarks

Reference

EVENT [Seismic event data]

Event identification

Event type (earthquake, nuclear shot, HE shot)

Event date

Event time

Event latitude

Event longitude

Event elevation (focal depth, burial depth)

Event size (magnitude, pounds or tons TNT)

Remarks

Reference

GEO_EXPT [Geophysical experiment data]

Experiment identification

Alternate experiment identification

Experiment type (reflection, refraction)

Experiment date

Experiment location description

Experiment latitude

Experiment longitude

Experiment elevation

Experiment description

Preferred station (pointer to STATION)

Preferred borehole (pointer to BORE)

Remarks

INTENSIT [Seismic intensity data]

Event identification (pointer to EVENT)

Building identification (pointer to BUILDING)

MM intensity value

Number of observations

Remarks

Reference 
MODEL [Model structure]

Model identifier

Model latitude

Model longitude

Model elevation

Remarks

MODL_PAR [Model parameters]

Model identifier [pointer to MODEL]

Minimum interval depth

Maximum interval depth

P-velocity

S-velocity

Dip

Density

Shear modulus

Bulk modulus

Poisson's ratio

Remarks

RECORD [Seismic record]

Record identification

Event identification (pointer to EVENT)

Station identification (pointer to STATION)

Event type

Event extension

VAX directory

REFLECT [Seismic reflection data]

Reflection experiment identification (pointer to GEO_EXPT)

Geometry description

Length

Azimuth

CDPfold

Source type

Source spacing

Source offset

Source arrays

Shots per shotpoint

Geophone type

Geophone frequency

Geophone spacing

Geophone arrays

Recorder type

Recording medium

Recording format

Sampling interval

Record length

Filters

Number of files

Remarks

REFRACT [Seismic refraction data]

Refraction experiment identification (pointer to GEO_EXPT)
Geometry description

Length

Azimuth

Source type

Shots per shotpoint

Geophone type

Geophone frequency

Geophone spacing

Recorder type

Recording medium

Recording format

Sampling interval

Record length

Filters

Number of files

Remarks

RESPONSE [Seismic response data]

Station identification (pointer to STATION)

Event identification (pointer to EVENT)

Minimum frequency of band

Maximum frequency of band

Relative response

Number of measurements

Standard deviation (for multiple measurements)

Remarks

Reference

STATION [Seismic station data]

Station identification

Alternate station identification

Station location description

Station latitude

Station longitude

Station elevation

Quadrangle abbreviation

Section/township/range description

Surface geology of station (generalized)

Preferred borehole (pointer to BORE)

Distance to preferred borehole

Nearest geophysical experiment (pointer to GEO_EXPT)

Preferred model (pointer to MODEL)

Remarks

VEL_MODL [Velocity model]

Velocity model identification

Depth to top of layer

Depth to bottom of layer

P-wave velocity

S-wave velocity

$\mathrm{Vp} /$ Vs ratio

Two-way travel time $\mathrm{P}$-wave

Two-way travel time S-wave 


\title{
A MAPPING OF GROUND-SHAKING INTENSITIES FOR SALT LAKE COUNTY, UTAH
}

\author{
By Philip C. EMмI
}

\begin{abstract}
This paper documents the development of maps showing a probabilistic assessment of the earthquake of ground-shaking hazard for zones within an area of Salt Lake County, Utah, suitable for contiguous urban development. Measures of ground shaking are considered, and a preference for the Modified Mercalli Intensity (MMI) scale is established. Data and relationships relevant to a microzonation of MMI are reviewed. Alternative methods for estimating spatial variation in MMI are described and compared. The findings include the following: MMI with a 10 percent chance of being exceeded in a 10-yr period range from $\mathrm{V}$ on bedrock above benches of Pleistocene Lake Bonneville to VIII + on fine clays and silts of the Quaternary flood plain and delta complex south of the Great Salt Lake and along the margins of the Jordan River at the valley's center. MMI with a 10 percent chance of being exceeded in a 50-yr period range from VII at the valley's edge to X at the valley's center. MMI with a 10 percent chance of being exceeded in a $250-\mathrm{yr}$ period range from VIII at the valley's edge to XI at the valley's center. These results are specific to the ground-shaking hazard and do not consider related hazards such as liquefaction, near-field directivity effects, rock fall, debris flow, fault rupture, seiches, and tectonic subsidence. These results are summarized in a set of maps developed with the use of a geographic information system.
\end{abstract}

\section{INTRODUCTION}

The purpose of this paper is to explain the development and use of ground-shaking intensity maps for an area of Salt Lake County, Utah, suitable for contiguous urban development. These maps show the degree of ground shaking to which this area is considered subject over a 10-, a 50-, and a 250-yr period of exposure. The maps are developed on a geographic information system (GIS) and are photographic reductions of computergenerated maps otherwise available at the 1:100,000 scale. Use of a GIS facilitates an integration of data on bedrock motion, relative site amplification, and surficial geologic units. The integration of combined data permits a mapping of the ground-shaking hazard at a degree of spatial resolution that begins to approach the detail needed for seismically attentive land-use planning.

\footnotetext{
${ }^{8}$ Department of Geography, University of Utah, Salt Lake City.
}

Ground-shaking intensity maps use the Modified Mercalli Intensity (MMI) scale to represent different degrees of shaking (Wood and Neumann, 1931). At each MMI level, a description of associated perceptions of ground motion and degrees of damage to common elements of the built environment are noted. (See Appendix A for an abbreviated description of the MMI scale.) Maps of ground-shaking intensity have many potential uses, such as estimating seismically related losses for insurance planning, designing seismic retrofit programs for vulnerable structures, siting and designing critical facilities and lifelines, and planning for earthquake emergencies.

This paper has four functions: enumerate viable approaches to assess ground-shaking hazards, develop alternative estimates of the local ground-shaking hazard, evaluate the alternative estimates, and present the preferred methodology together with the associated groundshaking hazard maps. The paper is divided into five additional sections that serve to review measures of ground shaking, describe a model for the assessment of ground shaking, review prior studies and detail available data, describe and compare alternative computational methods, and present research findings.

\section{ACKNOWLEDGMENTS}

The author wishes to acknowledge the help of Drs. Maurice Powers, Jeffrey Keaton, John Tinsley, and Kenneth King for assistance with issues of method and technique.

\section{MEASUREMENT OF GROUND SHAKING}

In general, ground shaking increases with the magnitude of a seismic event and decreases with distance from its epicenter. However, significant variations from this generality are caused by sensitive soil conditions, topological conditions, and stratigraphic geometry. The study of ground shaking and its spatial variation requires measurement of ground-shaking intensity. Measures of 
ground shaking are divided into two classes: instrumental measures and observational measures.

\section{INSTRUMENTAL MEASURES OF GROUND SHAKING}

Instrumental measures are most commonly taken from seismograph readings called accelerograms. An accelerogram measures lower frequency horizontal and vertical components of site acceleration during an earthquake. Velocity and displacement seismograms are developed from the data recorded on an accelerogram (Trifunac, 1970). Thus, the measures available from a seismograph reading include ground-motion duration, displacement, velocity, and acceleration at low frequencies (fig. 30). Other measures available from seismograph readings, including earthquake magnitude, are discussed by Hays (1980, p. 25-28).

The duration of shaking above some standard threshold of perceptibility is an earthquake's measured duration. Up to a point, duration increases with epicentral distance. Duration is longer on soft soils than on nearby rock sites. When allowance is made for other parameters of ground motion, longer duration implies greater damage. Greater durations also trigger liquefaction. Duration on soft soil of a Richter magnitude 7.0 earthquake has a mean and standard variation of from $13 \mathrm{~s} \pm 8 \mathrm{~s}$ at 25 $\mathrm{km}$ epicentral distance (Krinitzsky and others, 1987).

The maximal movement of soil particles from rest is a measure of displacement. Because of its relative insensitivity to geologic variations, ground displacement propagates more coherently than either velocity or acceleration. Displacement at the fault of a great earthquake probably does not exceed $200-400 \mathrm{~cm}$, while displacement at a 3- to 5-km distance probably does not exceed 20-40 cm (Trifunac and Brady, 1975).

The maximum speed attained by a seismically oscillating soil particle is its peak velocity. Peak velocity is measured in both horizontal and vertical directions. Oscillation causes a stretching and compressing of the soil and is noted as shear strain. The degree of shear strain to which the site is subject is proportional to the velocity of ground motion and inversely proportional to the shear wave velocity of its composite materials. Soft soils have a lower shear wave velocity than rock and are, therefore, subject to greater shear strain than are nearby rock sites. Richter magnitude 7.0 earthquakes induce a peak horizontal velocity (PHV) measured on soft soil at $25 \mathrm{~km}$ epicentral distance of $22-74 \mathrm{~cm} / \mathrm{s}$ (Krinitzsky and others, 1987).

An oscillating soil particle has a measurable acceleration. Peak acceleration occurs midway between oscillations. The peak horizontal accelerations (PHA) for Richter magnitude 7.0 earthquakes range from 110-510 $\mathrm{cm} / \mathrm{s} / \mathrm{s}$ at $25 \mathrm{~km}$ epicentral distance, i.e., from $0.11-0.52$ units of gravity $(g)$ (Krinitzsky and others, 1987). Peak vertical acceleration is usually about two-thirds peak horizontal acceleration (Werner and Ts'ao, 1975). Peak horizontal acceleration is widely used by structural engineers as a measure of the lateral forces on taller buildings.

PHA is also used to define earthquake magnitude on the Richter scale (Richter, 1935). Richter magnitude $\left(M_{L}\right)$ is defined as the logarithm of the maximum trace amplitude recorded on an accelerogram of a WoodAnderson seismograph at an epicentral distance of 100 $\mathrm{km}$. Adjustments are made for observations at distances other than $100 \mathrm{~km}$ (Hays, 1980).

Instrumental measures of ground-shaking intensity are important to assessing the risk of damage to structures. Each structure responds to ground shaking like an oscillating system with its own fundamental natural frequency. Buildings in excess of seven stories usually have a natural frequency less than $0.6 \mathrm{~Hz}$. Buildings from three to seven stories resonate at $0.6-2.5 \mathrm{~Hz}$. One- to two-story buildings resonate at $2.5 \mathrm{~Hz}$ or more (Borcherdt, 1985, fig. 3.2). Larger earthquakes are known to have a greater proportion of their energy concentrated in lower frequency ranges and are, thus, relatively more hazardous to taller buildings. Also, since lower frequency seismic energy is known to attenuate less rapidly with distance, taller buildings are subject to relatively more risk over a larger area than are shorter buildings. Yet the frequency-dependent effects of magnitude and distance are often secondary to the frequencydependent effects of local site conditions. This is particularly the case when considering buildings located on deep lake sediments as are found in the Salt Lake Valley. To better assess the risk of damage to structures, it helps to know at which frequencies a ground-motion parameter will peak when given certain assumptions about magnitude, distance, and local site conditions. It is also useful to know which classes of buildings resonate with the frequency ranges containing parameter peaks.

A transformation of ground-motion time histories can be used to generate a series of harmonic functions in the frequency domain. These define the maximum amplitude of harmonic oscillator response to a given ground-motion history. The many response maxima defined across a wide frequency range are called an earthquake response spectrum.

For ground-shaking studies, pseudo-relative velocity (PSRV) response spectra are perhaps the most important of the several different kinds of response spectra used in seismology. At a given frequency, the PSRV response spectra measure the velocity of the center of mass of a simple resonant structure relative to the velocity of its base. PSRV is often used to assess the amplification of bedrock motion by a resonant column of unconsolidated soil deposits. Thus, like other response 

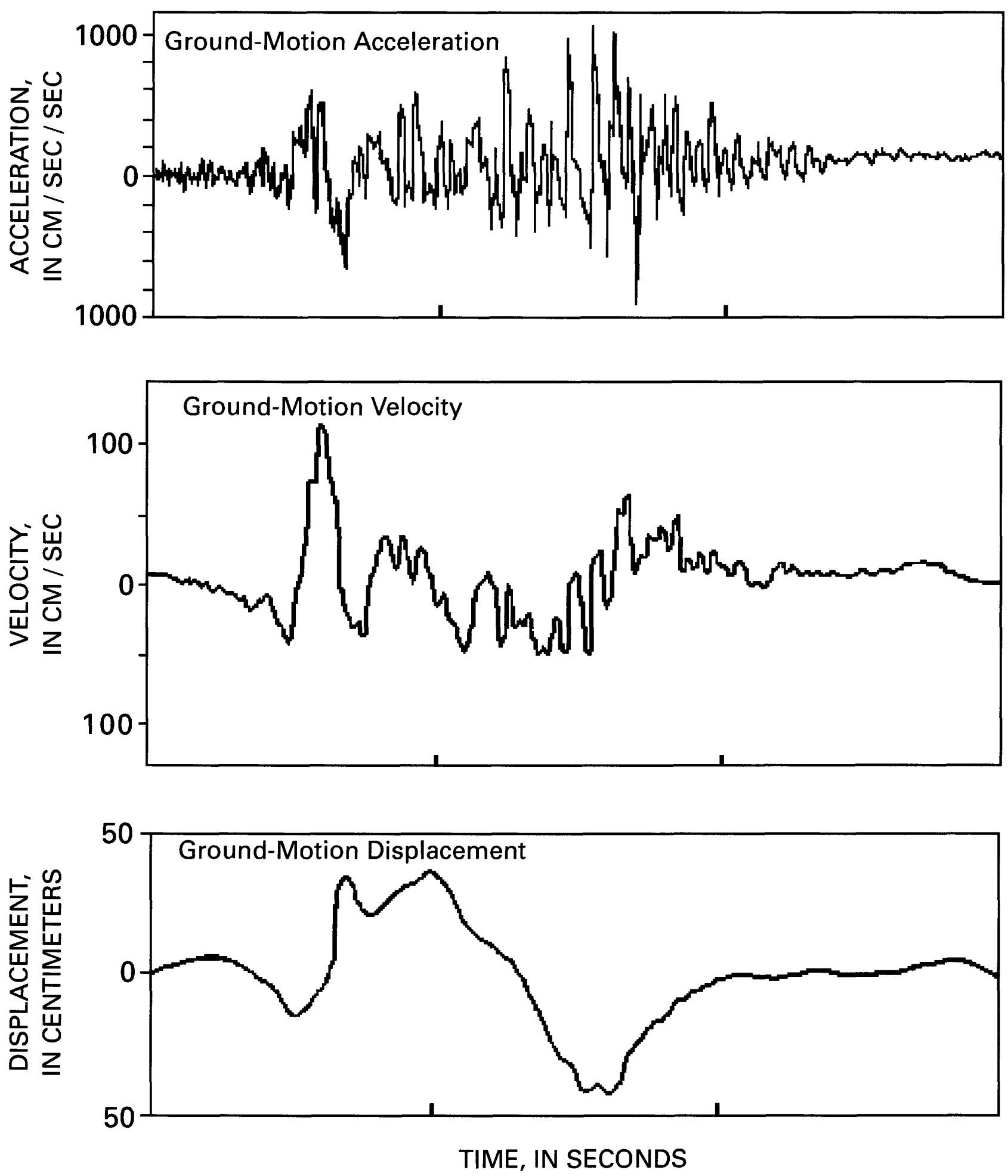

FIGURE 30. - The $\mathrm{S} 16^{\circ} \mathrm{E}$ component horizontal accelerogram recorded at Pacoima Dam and the velocity and displacement seismograms derived from it; 1971 San Fernando, Calif., earthquake (adopted from Hays, 1980, p. 28).

spectra, the PSRV response spectrum often shows a maximal value at a specific frequency that is several times larger than the maximal value shown by a corresponding low-frequency seismogram (fig. 31).
Pseudo-absolute acceleration, pseudo-relative velocity, and relative displacement are often graphed together against the frequency of vibration as pseudo-response spectra. Pseudo-absolute acceleration is graphed over a 
VELOCITY SEISMOGRAM

(Step 1)

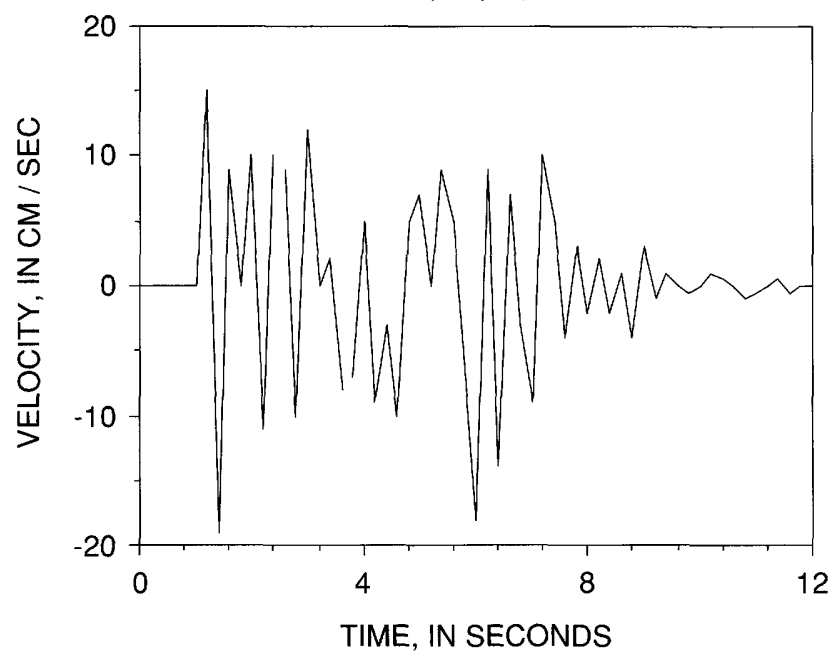

HARMONIC OSCILLATOR RESPONSE

$\mathrm{FOR} \mathrm{Hz}=2.0$

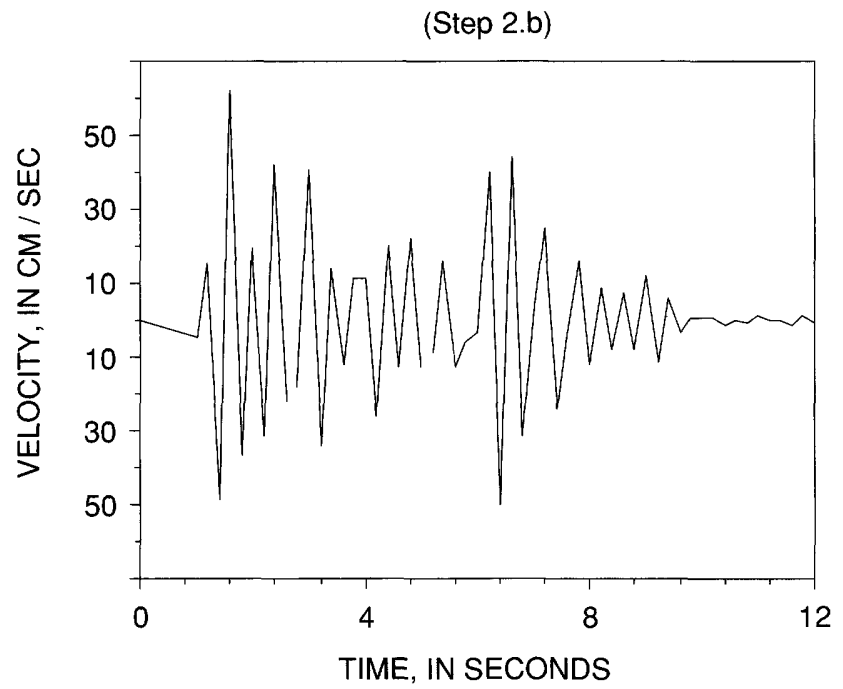

HARMONIC OSCILLATOR RESPONSE

FOR $\mathrm{Hz}=0.33$

(Step 2.a)

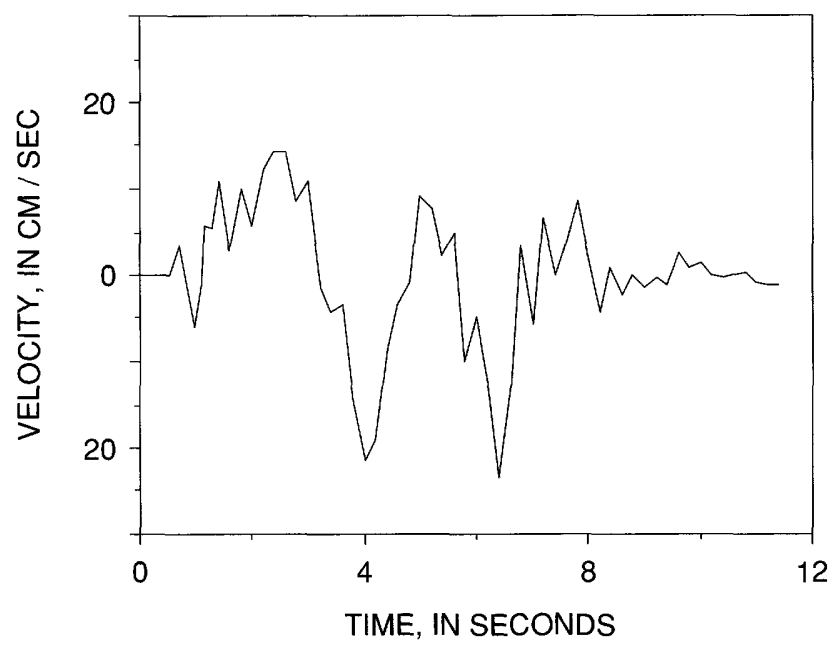

PSEUDO-RELATIVE VELOCITY 5 PERCENT DAMPED

(Step 3)

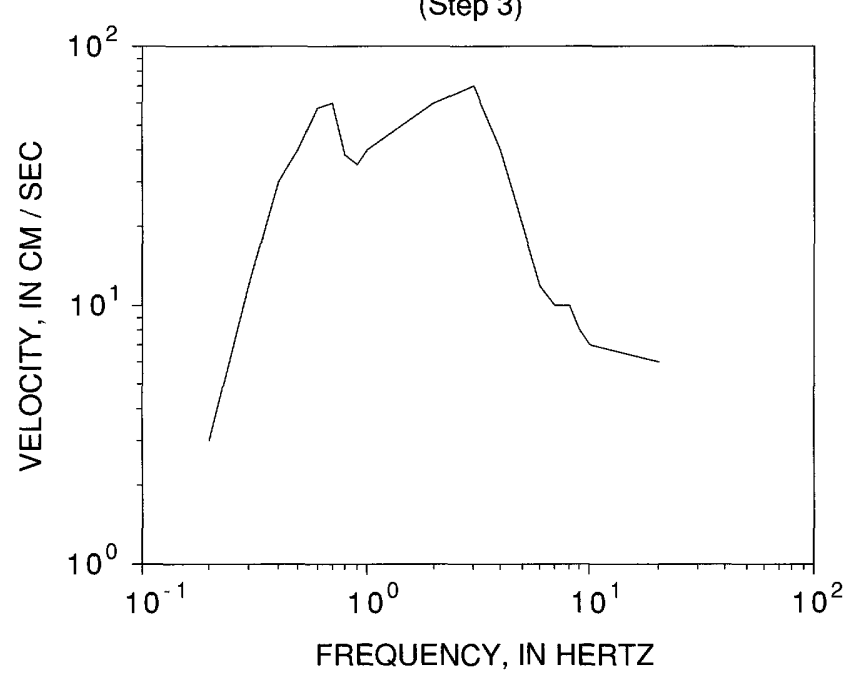

F1GURE 31. - Derivation of the harmonic oscillator response at $0.33-\mathrm{Hz}$ and $2.0-\mathrm{Hz}$ frequency from a velocity seismogram and the role in the construction of a pseudo-relative velocity response spectrum (adopted from Hays, 1980, p. 38).

high-frequency range (from $2.5-33 \mathrm{~Hz}$ ) and is used when considering the response of shorter buildings (roughly one to five stories high). PSRV is graphed over an intermediate-frequency range (of $0.25-2.5 \mathrm{~Hz}$ ) and is used when considering the response of buildings of intermediate height (roughly 5-16 stories high). Relative displacement is graphed over a low-frequency range (from $0-0.25 \mathrm{~Hz}$ ) and is used when considering the response of taller buildings. Thus response spectra are used in conjunction with data on local site conditions to estimate the frequency-specific effects of earthquakes of hypothesized magnitude and distance. Effects within given frequency ranges can then be related to the design of structures with known resonant frequencies.

\section{OBSERVATIONAL MEASURES OF GROUND SHAKING}

Observational measures of ground-shaking intensity rely on human perception and observation. At each intensity level on an observational scale, there is a description of associated human perceptions of ground motion (felt by a few persons, felt by nearly everyone), a 
description of associated physical events (suspended objects may swing, unstable objects overturn, great damage to poorly built structures), and, at the higher intensity levels, descriptions of associated geophysical events (sand boils, surface faulting, liquefaction, rock falls, seiches, and tsunamis).

There are several observational scales of groundshaking intensity in use around the world today. They provide useful judgnients about ground-shaking intensity in areas without permanently installed seismographs. They are useful in providing information about historic events for which there were no instrumental readings. Finally, most studies of the relationship between ground shaking and damage, loss, or injury use observational measures of ground shaking rather than instrumental measures. Researchers wishing to assess seismic loss potentials are bound by this fact to work with observational intensity measures. In this study, we use the MMI scale.

In spite of the distinction between instrumental and observational measures of ground-shaking intensity, it is necessary to work with both classes of measures. However, since there are real differences between instrumental and observational measures, caution must be used when converting from one class of measure to the other. First, since MMI, PHA, PHV, and displacement all have different rates of attenuation from epicentral distance, it is difficult to transform estimates of PHA to PHV and then to MMI without compounding errors. Second, observational measures will sometimes fail to perceive the differences in dominant frequencies among seismic events and their effects on observable damage or geophysical disturbance. This situation contributes to a partial tautology in the definition of seismic intensity based on subjective observations. Often intensity is deemed to be high (or low) because damage is great (or slight) and not because the dominant frequencies happened to resonate (or not resonate) with a large proportion of local structures. Third, the response spectra corresponding to two site intensities thought to be identical on the MMI scale can vary considerably in shape and in peak frequencies. Thus, two sites might be thought to be equally hazardous on the basis of past observations when, in fact, their seismic responses are quite different: the sites could be used safely if the structures to be located there were designed with instrumental data about their different response spectra in mind.

\section{GENERAL MODEL FOR THE ASSESSMENT OF GROUND-SHAKING HAZARDS}

A general model for the probabilistic assessment of regional ground-shaking hazard involves four steps. The first is to identify and characterize likely seismic sources.
The source region needs to be larger than the subject region because earthquakes outside the subject region can do considerable damage within the subject region. Along the Wasatch Front, any source capable of a large earthquake that is within at least $120 \mathrm{~km}$ of the subject area should be included in the source region. Seismic sources need to be characterized by the range of event magnitudes of which they are capable and the frequencies with which events of each magnitude are likely.

The second step is to construct a multiple-source-tomultiple-site geometry. This step requires measuring the distances from each source to various locations within the subject region. Typically, the subject region is divided into a grid, and the distance from each source to the center of each grid cell is measured and recorded. This procedure is repeated for all likely sources.

The third step is to attenuate ground motion from source to site. Each source is characterized by a distribution of event magnitudes (typically $M_{S}$ or $M_{L}$ ). Each magnitude is characterized by a distribution of event frequencies. At each source, each event magnitude (weighted by its probability of occurrence during a specified exposure period) is converted to a measure of ground motion (typically PHA), and that measure is attenuated by distance from source to subject site.

Since there are several measures of ground-shaking intensity, there are several approaches to the problem of source-to-site attenuation. Again, the most important division among approaches is between the direct attenuation of MMI and the attenuation of either PHA or PHV with conversion to MMI at site. The attenuation problem is exacerbated in the present case by the limited availability of regional data with which to construct regionally specific attenuation curves for either MMI, PHA, or PHV. Recent studies by Hooper (1988) and by Algermissen and others (1988) correct this situation in part with their study and deployment of a regional MMI attenuation function.

The final step is to estimate the effects of site characteristics on ground motion (see Hays, 1983). Here the problem is principally one of adjusting for the possibility of ground-motion amplification because of seismically sensitive soils and soil stratigraphies (fig. 32). Again, there are several approaches used to address groundmotion amplification. One option is to use attenuation functions specific to soil types. These typically distinguish between "hard" and "soft" soils but make no further distinction among soil conditions. Another option is to attenuate MMI directly from source to site and then use intensity increments to adjust for the presence of amplifying soil conditions. (This method typically distinguishes between three or four different soil types.) A third option is to use site-response functions empirically calibrated within the study area. With this option, por- 


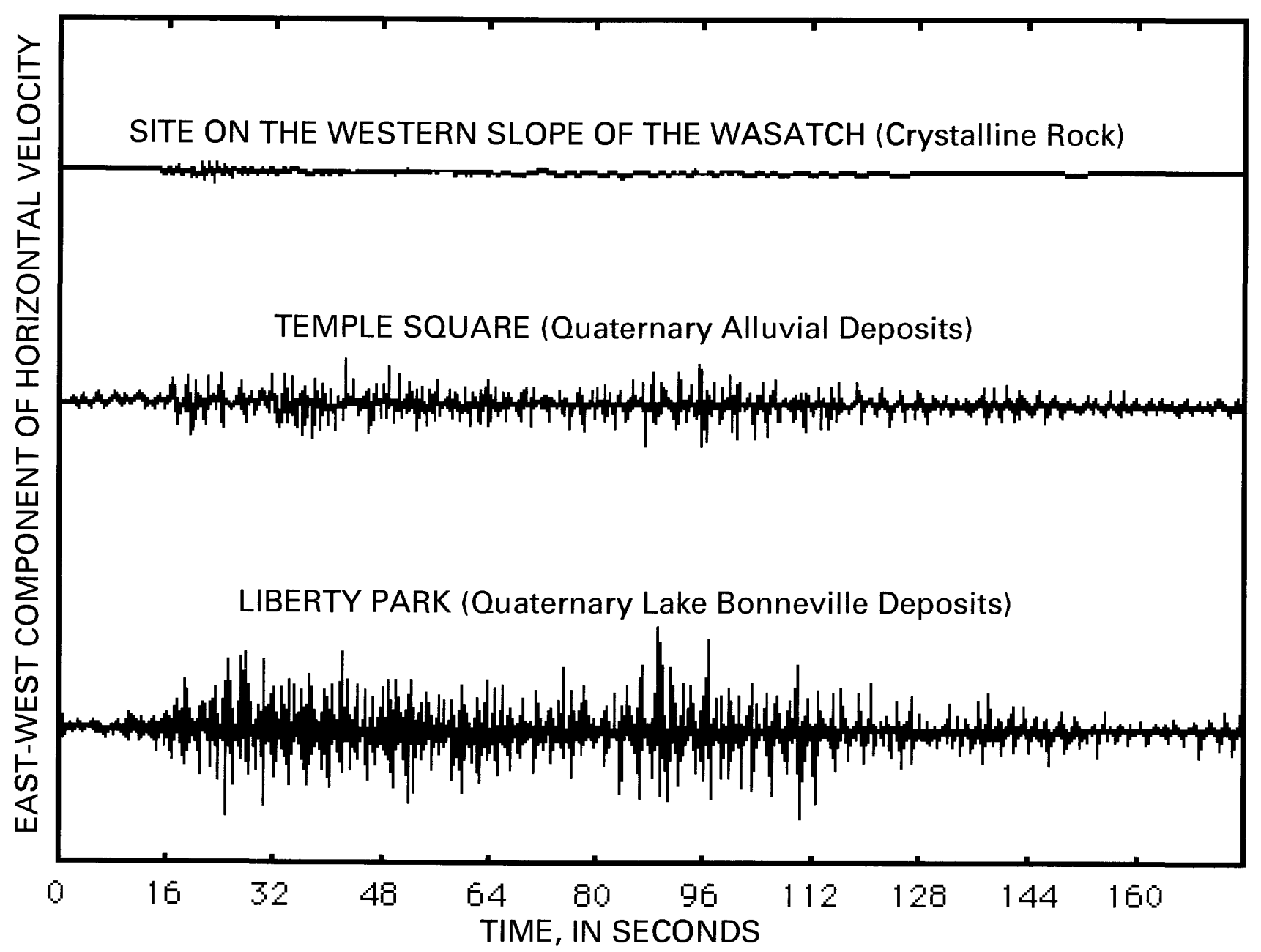

FIGURE 32. - Velocity seismograms for three Salt Lake City locations exemplifying site amplification during low-amplitude ground motions initiated by a low-strain event that induced linearly elastic relative site responses (adopted from Hays, 1987, p. K-8).

table seismometers are deployed at numerous sites, and measurements are taken during seismic aftershocks or during nuclear or mining explosions. Ground-motion parameters are measured on different soils, and ratios of ground-motion parameters, usually the ratios of PSRV, are found relative to a reference rock site. These ratios are then used as site-specific ground-motion amplification factors. A variation on this third option is to correlate site-response functions to geological and geotechnical variables, so findings can be generalized beyond areas where seismographic readings were originally taken.

There is yet another site characteristic of potential importance. It has to do with subbasin geometry and the possibility of directivity (or focusing) effects (Benz and Smith, 1989). Directivity effects would be important to Salt Lake County in the event of a fault-rupturing earthquake on the Salt Lake segment of the Wasatch fault. Directivity refers to the effect that the great impedance contrast between high-density rocks to the east of the Wasatch fault plane and the low-density sediments to the west of the fault plane is likely to have on directing seismic energy originating on that plane up the surface of the plane and on concentrating strong ground motion along the surface expression of the fault. Thus, in addition to the ground-motion amplification effects concentrated in the center of the Jordan River Valley, one could also have near-field directivity effects focused on areas adjacent to the surface expression of the Salt Lake segment of the Wasatch fault. The implications of the directivity effect for levels of risk in Salt Lake County are interpreted in a related paper (Emmi, 1989).

\section{POINTS OF DEPARTURE-DATA AND RELATIONSHIPS}

Data and relationships relevant to a mapping of MMI for Salt Lake County are reviewed in terms of source characteristics, ground-shaking, and ground-motion intensities at site. 


\section{SOURCE CHARACTERISTICS AND RECURRENCE INTERVALS}

Studies of source characteristics for the Wasatch fault zone are numerous and ongoing. Early compilations were done by Williams and Tapper (1953) and again by Rogers and others (1976). Recent studies of recurrence relationships based on observational data and covering the complete range of seismic magnitudes are reviewed by Arabasz and others (1987). Paleoseismologic investigations documented by Machette and others (1987) add to the instrumental record. Estimates of the composite return interval for fault-rupturing events located along the entire length of the Wasatch fault zone appear to be converging upon a consensus. Summarizing paleoseismic studies, Schwartz and Coppersmith (1984) report a return interval of 400-600 yr, with a preferred estimate of $444 \mathrm{yr}$. Updating Schwartz and Coppersmith with a review of subsequent paleoseismic studies, Lund (1987) reports a preferred interval of 310-350 yr. Using the University of Utah earthquake catalog of instrumental recordings (July 1962-December 1985), Arabasz and others (1987) report a recurrence interval for $M_{L} 7.0$ events of 120-630 years, with a preferred estimate of 270 yr. Young and others (1987) report a similar interval of $330 \pm 90$ years.

\section{GROUND-SHAKING HAZARD}

The Wasatch Front ground-shaking hazard study by Rogers and others (1976) identified sources, estimated recurrence intervals, and estimated the attenuation of intensities from sources to sites using three soil-specific attenuation curves based on a preliminary study of soil response factors. These curves accommodate soil amplification by the addition of intensity increments of 1.9 and 2.6 MMI units over bedrock. Hypothetical earthquakes of magnitude 7.5 at selected epicentral locations are posited. In all cases, MMI in Salt Lake County ranges from level VI to level IX-a range of three intensity units.

The study by Rogers and others (1976) illustrates the impact that site response has on spatial variation in ground-shaking intensities. Hays and others (1978) used a more extensive array of seismographs and measured site responses on soil and rock during nuclear explosions at the Nevada Test Site. They computed transfer functions (also called spectral ratios, site-response factors, and spectral amplification factors) in both the $0.1-0.2-\mathrm{s}$ and the $0.2-0.7-\mathrm{s}$ period bands. They found site amplification factors ranging from 1.5 to more than 10.0. (These correspond to MMI increments of up to three intensity units.) They presented their findings as point observations and generalized these observations to create iso- pleth maps showing contours within which they would expect to find similar spectral ratios.

Algermissen and others (1982) contributed a study of map contours showing probabilistic estimates of PHA and PHV in rock for the contiguous United States. The maps show values that have a 10 percent chance of being exceeded over 10-, 50-, and 250-yr periods. (These values correspond to expected return periods of 95,475 , and $2373 \mathrm{yr}$, respectively.) The area along the Wasatch Front containing Salt Lake County has a 10-yr, 10 percent exceedence value for peak horizontal acceleration of 98 $\mathrm{cm} / \mathrm{s}^{2}$ or 10 percent of gravity $(0.10 \mathrm{~g})$. The $50-\mathrm{yr}, 10$ percent exceedence value is $274 \mathrm{~cm} / \mathrm{s}^{2}$, or $0.28 \mathrm{~g}$. The $250-\mathrm{yr}, 10$ percent exceedence value is $686 \mathrm{~cm} / \mathrm{s}^{2}$, or 0.70 g. (See Appendix B for an explanation of such risk statements.)

Algermissen and Steinbrugge (1984) used these estimates together with spectral ratios for the $0.2-0.7$-s band from Hays and others (1978) to generate a map for Salt Lake City of expected MMI levels for a hypothesized $M_{S}=7.5$ earthquake. The areas of the city where spectral ratios are less than 1.5 have an estimated MMI level of VII, while areas where spectral ratios are greater than 10.0 have an estimated MMI level of X. Intensities are larger by one unit over those shown by Rogers and others (1976). The low- to high-intensity range is the same: three intensity units. The low- to high-intensity range of two to three intensity units is confirmed by Oaks (1987) in a study of intensities from historic damaging earthquakes in Salt Lake City and across the Jordan River Valley.

Soil properties such as soil void ratios, densities, and shear wave velocities correlate well with spectral amplification ratios (Rogers and others, 1983). These properties can be captured reasonably well by surficial geologic units. Rogers and others (1984) offered correlations between three broadly defined surficial geologic units and the spectral amplification ratios published by Hays and others (1978). Silts and clays have a mean amplification factor of 6.2, sands and gravel a factor of 3.7, and rubble a factor of 2.7. With these correlations, one can more readily estimate site effects in areas on the Wasatch Front where specific site response studies have not been conducted but where soil types are known. Use of correlations with surficial geologic units permits a generalization and extension of analytical results. However, because of the limited number of soil classifications and the different and sometimes weak correlations, the findings reported by Rogers and others (1984) must be used with particular caution.

The study of seismic risk to State Government property, fuel lines, and water lines by Taylor and others (1986) begins with a reassessment of the ground-shaking hazard. They identify and characterize likely seismo- 
genic sources and then attenuate PHV in rock from each of several sources to sites in four Wasatch Front counties using a velocity attenuation curve published by Campbell (1984). They compute PHV in soil using the three surficial geologic units identified by Rogers and others (1984) and convert to MMI using a function developed by Wiggins and Taylor (1981). They find that MMI in Salt Lake County for a hypothetical $M_{L}=7.3$ earthquake on the Salt Lake segment of the Wasatch fault ranges from below VII at the valley edge to X or more in the valley center, again a range of three intensity units.

Advances in paleoseismic investigations, plus innovations in probabilistic assessments of seismic hazards, prompted further investigation by Young and others (1987), whose study is regarded as among the most complete and sophisticated assessments of groundshaking hazard yet done for any region. It includes an inventory of seismic sources with ten segments of the Wasatch fault, five segments of the Oquirrh Mountains fault, two segments each of the East Cache Valley fault, the Hansel Valley fault, and the East Bear Lake fault, the West Valley fault, and a generalized background source. The study focuses on PHA in soil and on pseudoabsolute acceleration as preferred measures of groundshaking intensity. Local site effects are addressed by using attenuation functions and spectral amplification functions for rock and soil conditions calibrated on California data. The authors note (Young and others, 1987, p. M-57-58), "The applicability of these relationships to areas of [Bonneville] lake clays and silts is questionable, but alternative relationships are not available at present. The relationships used in the analysis may underestimate response spectra of longer-period motions in areas of soft lake deposits." Despite this conservative bias, estimates of PHA by Young and others (1987) for Salt Lake County are generally greater than earlier estimates by Algermissen and others (1982). Their estimate of PHA on rock with a 10 percent chance of being exceeded over a 10 -yr period is $86 \mathrm{~cm} / \mathrm{s}^{2}$, or $0.09 \mathrm{~g}$, for a 50 -yr period is 353 $\mathrm{cm} / \mathrm{s}^{2}$, or $0.36 \mathrm{~g}$, and for a $250-\mathrm{yr}$ period is $823 \mathrm{~cm} / \mathrm{s}^{2}$, or $0.84 \mathrm{~g}$.

\section{CONVERTING ACCELERATION TO INTENSITY AT SITE}

Lacking a functional relationship with which to compute the direct attenuation of seismic intensities from source to site while simultaneously addressing site characteristics, we face the alternative problem of converting smaller scale estimates of PHA on rock to larger scale estimates of MMI on soil sites with varying seismic sensitivities. Young and others (1987) provide the most accurate and spatially detailed estimates of PHA exceedence values. However, their findings introduce a further complication-the need to account more accurately for site characteristics than was possible with hard and soft soil attenuation functions. This need is met by converting PHA on hypothetical rock sites to MMI on hypothetical rock sites and then accounting for the alteration of MMI on rock by various site characteristics. There are several ways to convert from PHA to MMI values, and there are several ways to account for site characteristics. These problems are discussed next, along with combinations of approaches that promise reasonable results.

The two methods used to link PHA to MMI are (1) a continuing effort to define a direct and reliable relationship between acceleration and MMI (see the references cited in fig. 33) and (2) linking acceleration indirectly to MMI by way of ground-motion velocity as an intermediate variable. The second path must be considered for two reasons: velocity is thought to be more sensitive to site characteristics than acceleration, and site-specific spectral amplifications of PSRV should be applied to regional estimates of PHV (not PHA) when using spectral amplification factors to estimate spatial variation in MMI (C.E. Taylor, private commun., 1988).

A search of the literature yields ten functional relationships between PHA and MMI (figs. $33 A$ and $33 B$ ) and seven relationships between PHV and MMI (fig. 34). The parameters in some of these relationships are adjustable, depending on hypotheses concerning magnitude and distance. Other relationships are, in fact, suites of relationships controlled for variation in distance or soil-versusrock conditions. The relationships are converted to an identical functional form, so their slope and intercept coefficients can be readily compared. Outlying relationships are discarded. A suite of relationships by Krinitzsky and Chang (1987) was chosen for use in converting acceleration to intensity. A function by Wiggins and Taylor (1981) was retained for use in converting velocity to intensity. When needed, a relationship provided by Donovan (1983) was used to convert PHA to PHV given appropriate values for soil-versus-rock conditions, expected magnitude, and epicentral distance.

Given data and relationships currently available for this region, three general methodologies can be discerned with which to address local variation in site conditions. One way is to start with PHA on rock, convert either directly or indirectly to MMI on rock, and then, following Borcherdt and others (1979), add intensity increments associated with the relative siteresponse contours provided by Tinsley (1988). This procedure yields a localized estimate of MMI. This option will be referred to as the intensity increment option.

Borcherdt and others (1979) define a relationship between shear wave velocity and intensity increments measured on the San Francisco intensity scale. They also define a relationship between shear wave velocity and ground-motion amplification. Implied, with proper conversion among intensity scales, is a relationship between 
A

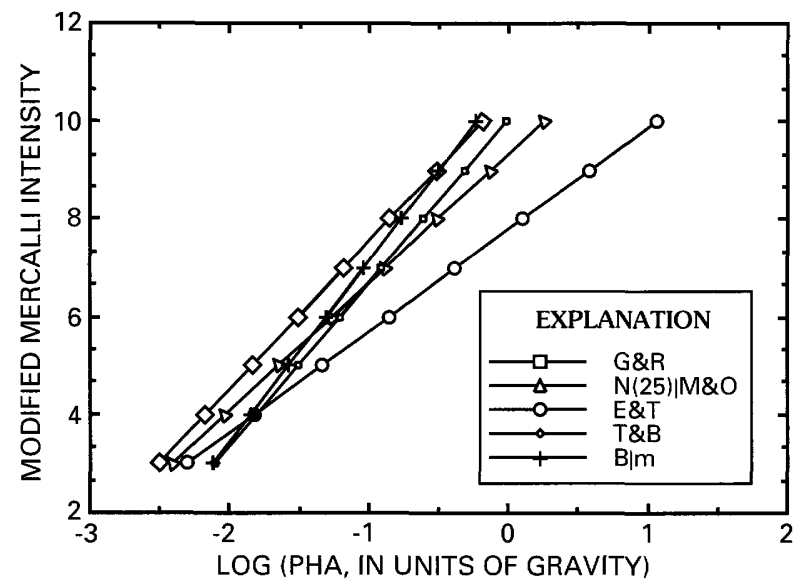

Sources:

G\&R: $\log (P H A)=-3.49+0.33 \mathrm{MMI}$, from Gutenberg and Richter (1956). $\mathrm{N}(25) \mid \mathrm{M} \& O: \log (\mathrm{PHA})=-3.55+0.38 \mathrm{MMI}$, for $\mathrm{R}=25 \mathrm{~km}$ from Neumann (1954) as modified by Murphy and O'Brien (1977).

$E \& T: \log (P H A)=-3.74+0.48 \mathrm{MMI}$, from Evernden and Thompson (1985). T\&B: $\log (\mathrm{PHA})=-3.01+0.30 \mathrm{MMI}$, from Trifunac and Brady (1975). $\mathrm{B} \mid \mathrm{m}: \log (\mathrm{PHA})=-2.93+0.27 \mathrm{MMI}$, for $\mathrm{M}=6.5$ from Bernreuter (1981).

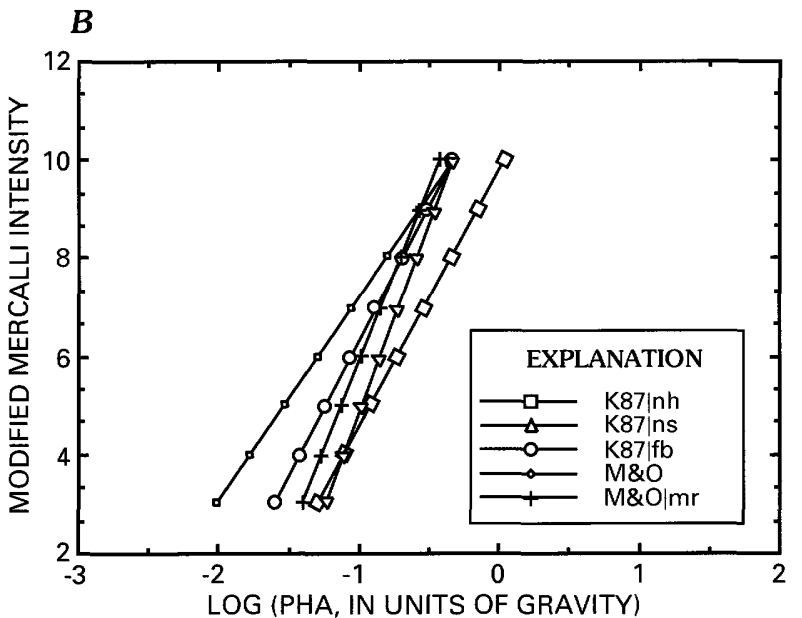

Sources:

From Krinitzsky and Chang (1987):

K87!nh: $\log (\mathrm{PHA})=-1.86+0.19 \mathrm{MMI}$, for near field, hard soil conditions K87|ns: $\log (\mathrm{PHA})=-1.63+0.13 \mathrm{MMI}$, for near field, soft soil conditions. $\mathrm{K} 87 \mid \mathrm{fb}: \log (\mathrm{PHA})=-2.15+0.18 \mathrm{MMI}$, for far field, both soil conditions.

From Murphy and O'Brien (1977):

$\mathrm{M} \& O: \log (\mathrm{PHA})=-2.74+0.24 \mathrm{MMl}$.

$M \& O: \log (P H A)=-1.83+0.14 \mathrm{MMl}$, for $R=24 \mathrm{~km}$ and $M=6.25$

FIGURES $33 A$ and B.-Functional relationships suggested by various authors between MMI and the logarithm of peak horizontal acceleration measured in units of gravity.

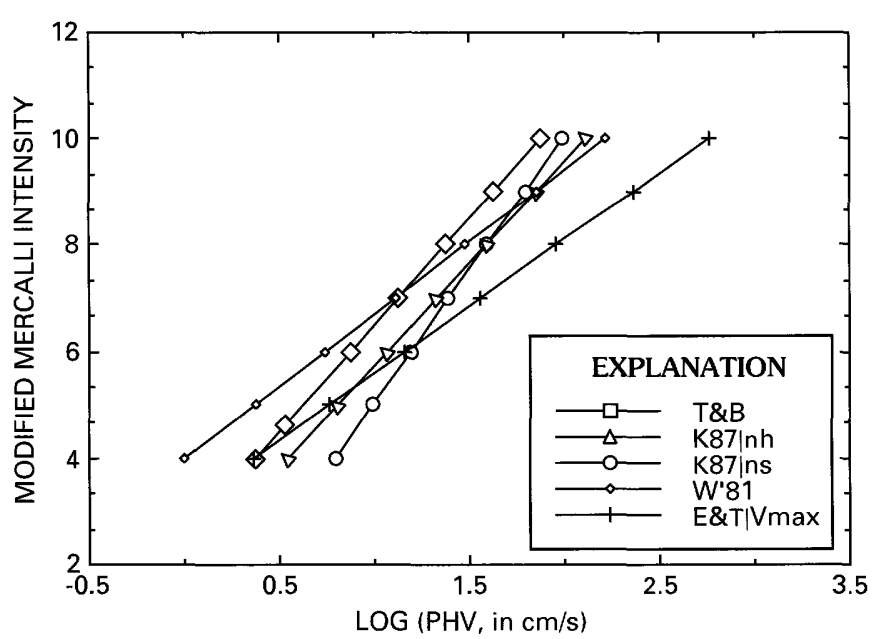

Sources:

T\&B: $\log (P H V)=-0.63+0.25 \mathrm{MMI}$, from Trifunic and Brady (1975). From Krinitzsky and Chang (1987): K87|nh: $\log (P H V)=-0.49+0.26 \mathrm{MMI}$, for near field, hard soils. K87|ns: $\log (P H V)=-0.01+0.20 \mathrm{MMI}$, for near field, soft soils. $W^{\prime} 81: \log (\mathrm{PHV})=-1.48+0.37 \mathrm{MMI}$, from Wiggins and Taylor (1981). E\&T Vmax: $\log (\mathrm{MaxHV})=-1.24+0.40 \mathrm{MMI}$, from Evernden and Thompson (1985).

FIGURE 34.-Functional relationships suggested by various authors between MMI and the logarithm of peak horizontal velocity measured in centimeters per second. ground-motion amplification and MMI increments (fig. 35). This relationship is more consistent with historical observations and instrumental measurements than the comparable equation given earlier by Borcherdt and others (1975) (fig. 36).

Evernden and others (1981) invert this procedure. They start with PHA on alluvial soil, convert to MMI on soil, and apply MMI decrements for stiffer geologic units. This approach will not serve the present situation, since alluvial deposits are not the most seismically sensitive soils in Salt Lake Valley.

A second option is to convert from PHA on rock to PHV on rock, apply amplification factors (Rogers and others, 1984; Tinsley, 1988), and then compute MMI values using Wiggins and Taylor's (1981) equation. Since this is a variation of the method used by Taylor and others (1986), this option will be referred to as the Taylor variation.

A third option is a variation on a method employed by Krinitzsky (1988). It uses two starting points, two soilspecific conversion equations, and interpolates values in between. First, PHA on soil for the valley center is converted to MMI on soil using an equation specific to soft soils. Next, PHA on rock for the valley edge is converted to MMI on rock using an equation specific to hard soils. The next step is to interpolate between these 


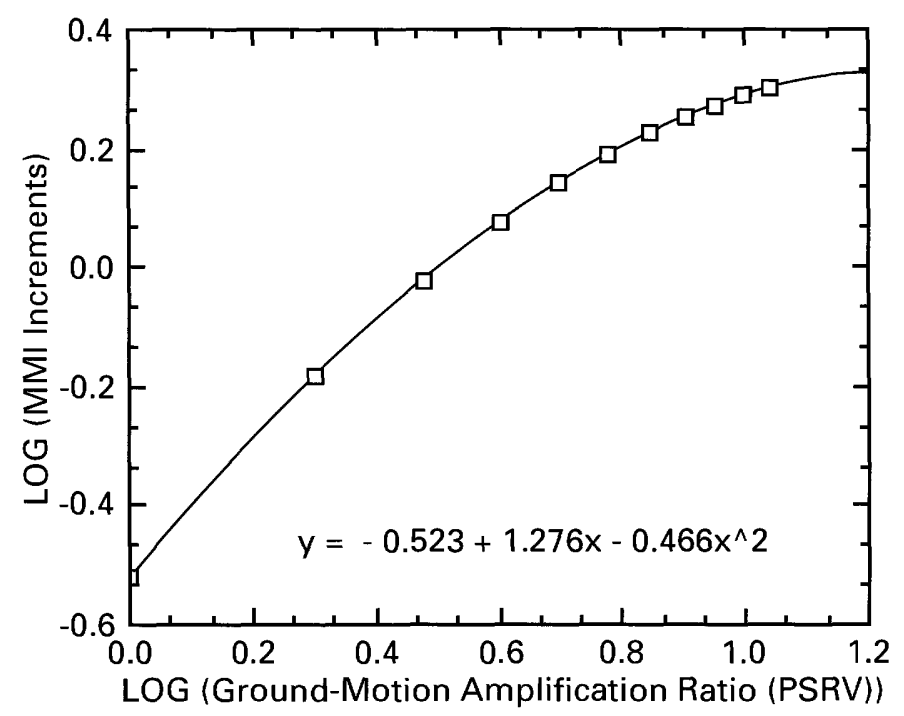

FIgURE 35. -A functional relationship between ground-motion amplification ratios (relative to a reference rock site) and intensity increments for nearby soil sites that can be added to estimates of MMI at the reference rock site to obtain MMI estimates for soil sites (based on relationships by Borcherdt and others, 1979).

extreme values for site-specific MMI values. This method is referred to as the Krinitzsky option.

These options are explored below. In addition to the issues raised here, challenges remain to clarify the relationship between soil properties and site amplification (see Tinsley, 1988), to apply response spectral attenuation relationships that control for detailed geotechnical properties (Joyner and Fumal, 1985), to develop and apply regionally specific MMI attenuation equations (see Algermissen and others, 1988), to specify basin geometric and directivity effects on relative ground motion (Benz and Smith, 1989), and to merge results to further refine localized estimations of MMI.

\section{COMPARISON OF ALTERNATIVE METHODS}

\section{ALTERNATIVE METHODS}

Different methods for converting acceleration to intensity are detailed below, and results are discussed and compared (table 5 and fig. 37). Different methods are explored to better understand the range of likely results and to better control for spurious results. The comparison also helps clarify the logic of each approach.

The intensity increment option is used to develop methods 1 and 2 . For method 1, we begin with estimates of PHA on rock that have a 10 percent chance of being exceeded over 10-, 50-, and 250-yr periods (Young and others, 1987). We then use appropriate equations from Krinitzsky and Chang (1987) to convert to MMI on rock. We note the relative ground-shaking factors in the $\partial I(79)$ is derived from Borcherdt and others (1979) $\partial \mathrm{I}(75)$ is from Borcherdt and others (1975)

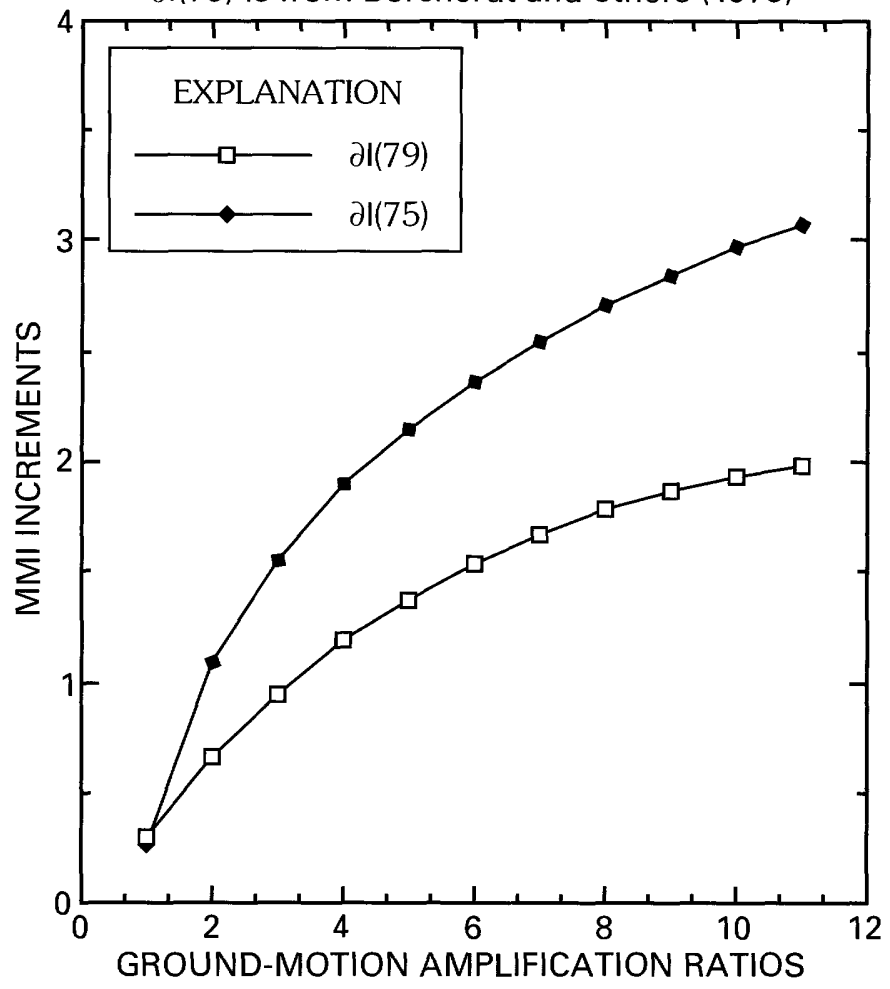

FIGURE 36. - A comparison of curves defining the relationship between ground-motion amplification ratios and rock-site intensity increments (measured on the MMI scale) from material presented by Borcherdt and others $(1975,1979)$.

0.2-0.7-s period band (Tinsley, 1988), truncate at factors above eight (because of a possible nonlinear response above a factor of eight), and then apply the corresponding intensity increments given in figure 35 . This procedure yields, for the intermediate $(50-\mathrm{yr})$ time horizon, MMI values of VII for rock at the valley edge and MMI values of $\mathrm{X}$ for soft clays at the valley center.

For method 2, we begin with estimates of PHA on rock (Young and others, 1987), convert to PHV on rock (Donovan, 1983), estimate MMI on rock (Krinitzsky and Chang, 1987), note appropriate relative ground-shaking factors, and apply the corresponding intensity increments given in figure 35 . This procedure yields MMI values for rock at the valley edge and for soft clays at the valley center of VI+ and IX+, respectively, for the intermediate (50-yr) time horizon.

The Taylor variation is used to develop methods 3 and 4. For method 3, we begin with estimates of PHA on rock (Young and others, 1987) and convert to PHV on rock (Donovan, 1983). We then apply Tinsley's (1988) relative ground-shaking factors to find velocities at site and convert to MMI estimates using an equation provided by Wiggins and Taylor (1981). This procedure yields MMI 
TABLE 5.-Estimates of Modified Mercalli Intensity for the edge and center of the Jordan River Valley, Utah, using the six different methods of estimation discussed in this study

[The valley edge Iocation assumes a crystalline rock site, while the valley center location assumes a site with silt and clay Quaternary flood plain and deltaic deposits.]

\begin{tabular}{|c|c|c|c|c|c|c|c|}
\hline \multirow{2}{*}{$\begin{array}{l}\text { Time } \\
\text { horizon, } \\
\text { yr }\end{array}$} & \multirow{2}{*}{ Location } & \multicolumn{6}{|c|}{ Method number } \\
\hline & & 1 & 2 & 3 & 4 & 5 & 6 \\
\hline \multirow[t]{2}{*}{$10 \ldots \ldots$} & Edge & 6.1 & 5. & 6.0 & 6.0 & 5.4 & 5.1 \\
\hline & Center & 8.9 & 8. & 8.7 & 8.4 & 5.9 & 6.4 \\
\hline \multirow[t]{2}{*}{$50 \ldots \ldots$} & Edge & 7.0 & 6.7 & 7.4 & 7.4 & 7.3 & 6.9 \\
\hline & Center & 10.1 & 9.6 & 10.2 & 10.0 & 8.7 & 7.8 \\
\hline \multirow[t]{2}{*}{$250 \ldots \ldots$} & Edge & 8.6 & 8.0 & 8.3 & 8.3 & 9.0 & 8.3 \\
\hline & Center & 11.7 & 10.8 & 11.1 & 10.8 & 11.4 & 9.5 \\
\hline
\end{tabular}

values for rock at the valley edge and for soft clays at the valley center of $\mathrm{VII}+$ and $\mathrm{X}$, for the 50 -yr time horizon.

For method 4, we proceed as above except we replace Tinsley's relative ground-shaking factors with those provided by Rogers and others (1984) for surficial geologic units. Results derived by this method are about the same as in method 3.

The Krinitzsky option is used to develop methods 5 and 6. For method 5, we begin with estimates of PHA on rock and PHA on soil and convert to MMI on rock and to MMI on soil using functions from Krinitzsky and Chang (1987). Intensities on sites with surficial deposits having densities somewhere between hard rock and soft soil can be estimated by interpolation between these two points. Rock and soft soil MMI values derived by this method are VII+ and VIII+, respectively, over the 50-yr time horizon.

For method 6, we begin with PHA on rock and PHA on soil, convert to velocities, and then convert from PHV to MMI on rock and soil using Krinitzsky and Chang (1987). Rock and soft soil values derived by this method are VII and VIII, respectively over the 50-yr time horizon.

Results for the 10-, 50-, and 250-yr time horizons by generalized Salt Lake Valley location are given in figure 37 . Note that the valley edge location refers to bedrock sites with a site amplification ratio of 1.0 , while valley center locations refer to sensitive soil sites with the highest site amplification ratio possible under each method.

\section{EVALUATION OF ALTERNATIVE METHODS}

Results from methods 1 through 4 have similar ranges. The range of results from methods 5 and 6 is notably narrower. In view of historical observations (Oaks, 1987) and instrumental measurements on various soils in the Jordan River Valley, methods 5 and 6 must be regarded as offering an unacceptably narrow range of results by location. Apparently, the use of simple PHA-to-MMI and PHV-to-MMI functions for rock and soft soils fails to

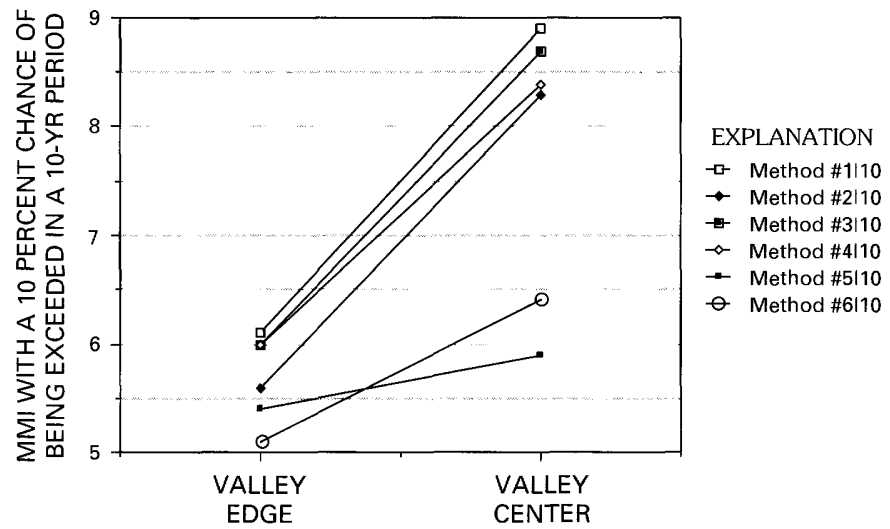

SALT LAKE VALLEY LOCATION

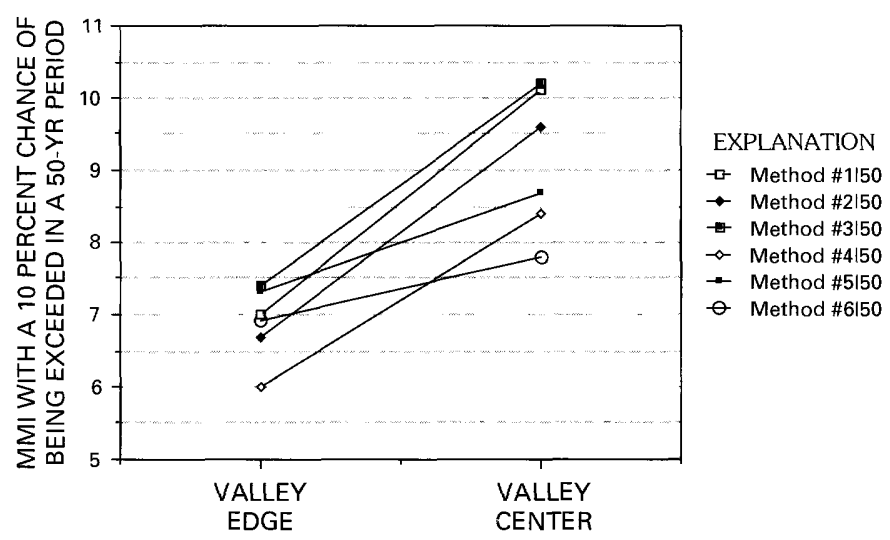

SALT LAKE VALLEY LOCATION

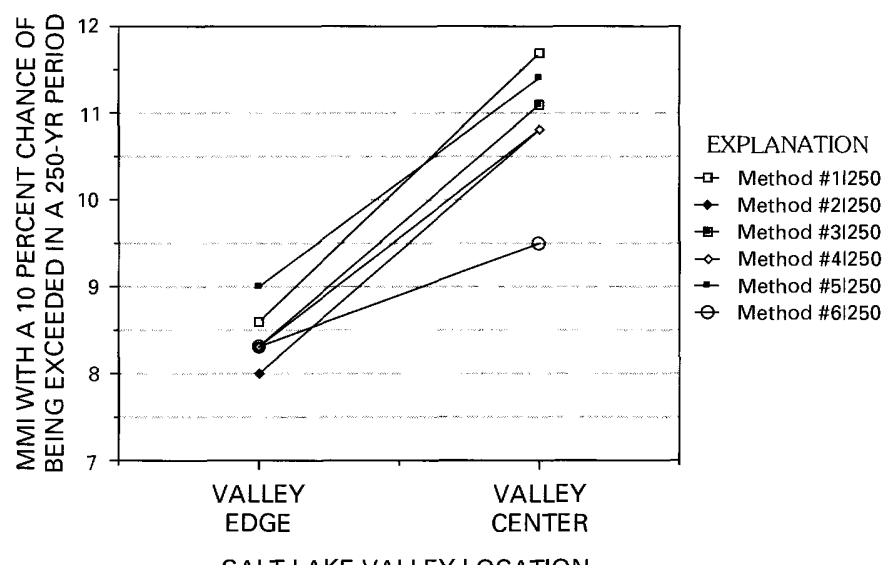

SALT LAKE VALLEY LOCATION

FIgURE 37. - A comparison of estimates of MMI with a 10 percent chance of being exceeded over a 10-, a 50-, and a 250-yr exposure period by valley location within Salt Lake County, Utah.

fully account for the range of site characteristics found locally. By averaging a broad range of ground-motion responses to two points on a broad spectrum of response and referring to each point respectively as "a rock response" and "a soil response," one destroys information and ignores differences that are notable at the geographic scale of this analysis. For these reasons, methods 5 and 6 are excluded from further consideration. 
Method 1 employs a direct conversion of acceleration to intensity. It has the simplest logic and, thus, appears least likely to propagate errors through extended chain models. However, method 1 relies on an estimate of the relationship between grouıd-motion amplification and MMI increments from Borcherdt and others (1979). Because of numerous intensity scale conversions (San Francisco to Rossi-Forell to MMI), this relationship is of questionable reliability.

Methods 2, 3, and 4 convert from velocity to MMI, and this procedure is preferred on theoretical grounds. However, method 2 yields uniformly lower estimates of intensities, while method 4 yields a somewhat smaller range of intensities by location. The choice is narrowed to methods 1 and 3. Results from method 1 tend to be higher, the method relies on a theoretically less preferred conversion from acceleration on rock directly to MMI on rock, and it uses a relationship between spectral amplification ratios and MMI increments that is of uncertain reliability. For these reasons, method 3 is preferred over method 1.

\section{A VARIATION ON THE PREFERRED METHOD}

Method 3 uses Tinsley's (1988) map of relative groundshaking factors. One difficulty in using the map is the manner in which the isopleth contours ignore differences in surficial geologic units known to influence site response. (Work in progress by Tinsley will correct this feature.) Rogers and others (1984) sought to address this issue by correlating three different surficial geologic units with site-response factors, although there is a loss both in range and in spatial resolution due to the small number of geologic units considered.

To resolve this problem, a schedule of six surficial geologic units is collapsed from a larger number of units represented on Davis's (1983) map compilation. Each of the six geologic units is assigned a spectral amplification factor (table 6). The reasonableness of the assigned amplification factors is confirmed through review of the literature, correlation with standard cone penetrometer test scores, and corroboration with geologists familiar with the problem (G. Christensen, D.R. Currey, and K.W. King, personal communs., 1988).

We then digitize these six units, digitize Tinsley's relative ground-shaking factors map, and use a geographic information system to create a composite map from the two underlying digital map planes, so that the polygons in the composite map have site-response scores that equal the square root of the product of the polygon scores from the two underlying map layers. This procedure results in a modified site-response surface that combines with equal weight the amplification factors associated with both Tinsley's isopleth contours and
Davis's surficial geologic units. The resulting map, which constructively combines information in the underlying map planes and offers a finer grained representation of site characteristics is used in method 3 in place of Tinsley's isopleth contours. The range and magnitude of results are the same, but the degree of spatial resolution is improved. (Methodological details are discussed in Appendix C.)

\section{A MAPPING OF GROUND-SHAKING INTENSITIES}

The central objective of this study is to create maps showing spatial variation in the ground-shaking intensities that have a 10 percent chance of being exceeded over a 10-, a 50-, and a 250-yr exposure period. The two digital map planes and the set of relationships used as inputs are maps of PHA by Young and others (1987), the composite site-response surface described above, and the relationships among PHA, PHV, site amplification, and MMI used in method 3. For each exposure period, we define a digital map plane in which MMI is a logarithmic function of the product of two input digital map planes, one defining spatial variation in PHA and the other defining spatial variation in relative site response. The result is a set of maps depicting spatial variation in MMI exceedence values for each of three time horizons (figs. $38 A-C$ ).

Figure $38 A$ shows MMI's that have a 10 percent chance of being exceeded in a 10-yr period. Refer to this map when addressing concerns about the internal contents of structures. Figure $38 B$ shows the same informa-

TABLE 6. A cross classification of surficial geologic units used by Davis (1983) and in this study with site amplification factors assigned by the author to each unit

\begin{tabular}{|c|c|}
\hline Surficial geologic units & \multirow{2}{*}{$\begin{array}{l}\text { Amplification } \\
\text { factor } \\
\text { assigned to } \\
\text { each unit }\end{array}$} \\
\hline Davis (1983) & \\
\hline $\begin{array}{l}\text { Quaternary flood-plain and } \\
\text { delta complex ........... Fine clays and silts }\end{array}$ & 8.0 \\
\hline $\begin{array}{l}\text { Quaternary Lake Bonneville } \\
\text { plus Jordan River flood- } \\
\text { plain deposits........... Coarse clays and silts }\end{array}$ & 5.6 \\
\hline $\begin{array}{l}\text { Quaternary alluvium plus } \\
\text { active and abandoned } \\
\text { flood-plain deposits on }\end{array}$ & \\
\hline Jordan River tributaries... Fine sand and gravel & 4.2 \\
\hline Quaternary Bonneville and & \\
\hline Provo shore facies plus & \\
\hline $\begin{array}{l}\text { Quaternary Bonneville } \\
\text { and Alpine complex ....... Coarse sand and gravel }\end{array}$ & 3.2 \\
\hline $\begin{array}{l}\text { Quaternary morraines and } \\
\text { talis .................. Rubble }\end{array}$ & 2.0 \\
\hline $\begin{array}{l}\text { Quaternary Hawkers } \\
\text { fanglomerate plus older } \\
\text { rocks } \ldots \ldots \ldots \ldots \ldots \ldots \text {. Rock }\end{array}$ & 1.0 \\
\hline
\end{tabular}




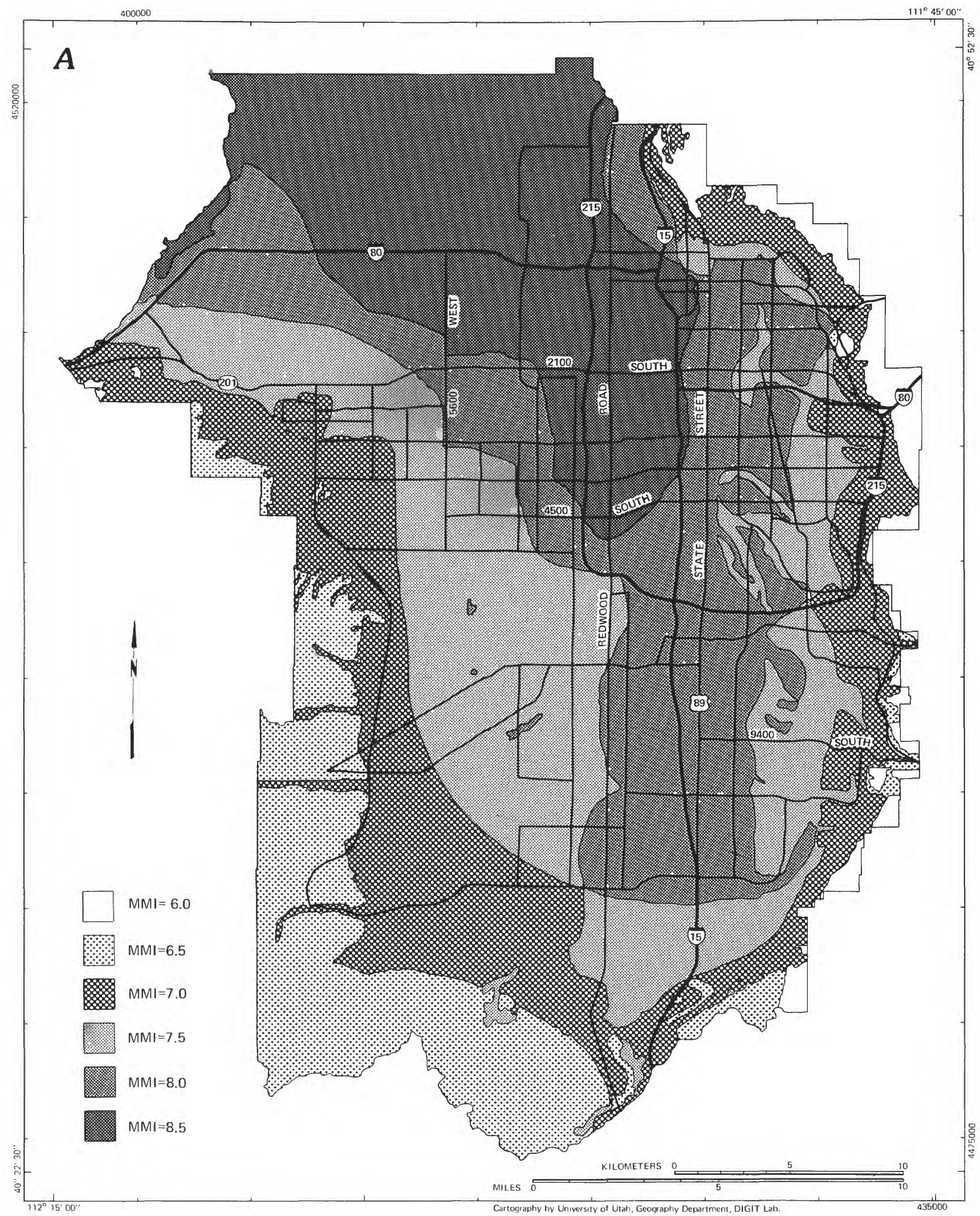

FIGURE 38A. - A microzonation of MMI with a 10 percent chance of being exceeded over a 10-yr exposure period for the urbanizable area of Salt Lake County, Utah. These maps (figs. $38 \mathrm{~A}-\mathrm{C}$ ) do not account for the effects of ground failure (liquefaction, slumps, slides, falls, flows, and fault rupture) or the focusing effects expected of a near-field event on the Salt Lake segment of the Wasatch fault. 


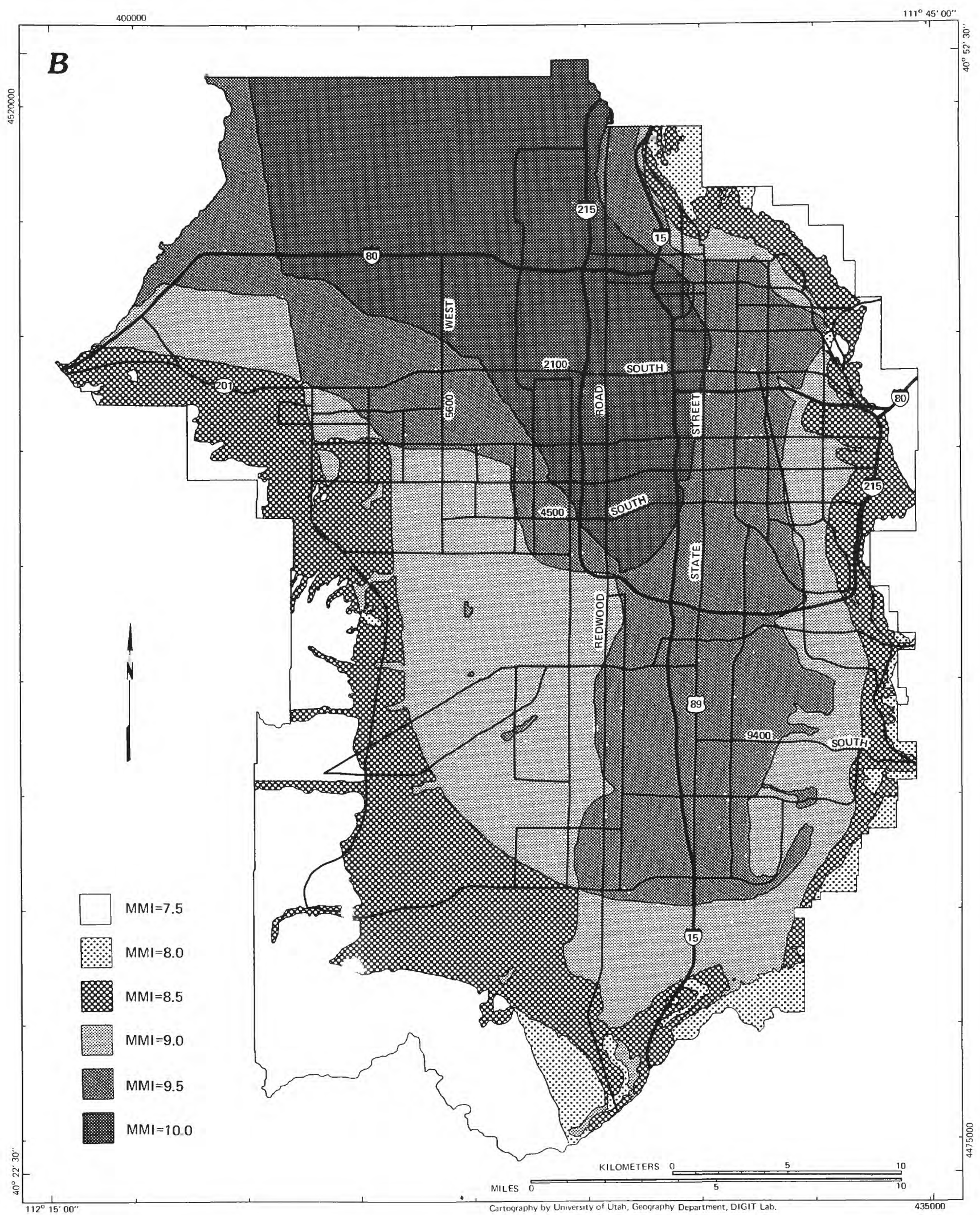

FIGURE 38B. -A microzonation of MMI with a 10 percent chance of being exceeded over a 50 -yr exposure period for the urbanizable area of Salt Lake County, Utah. 


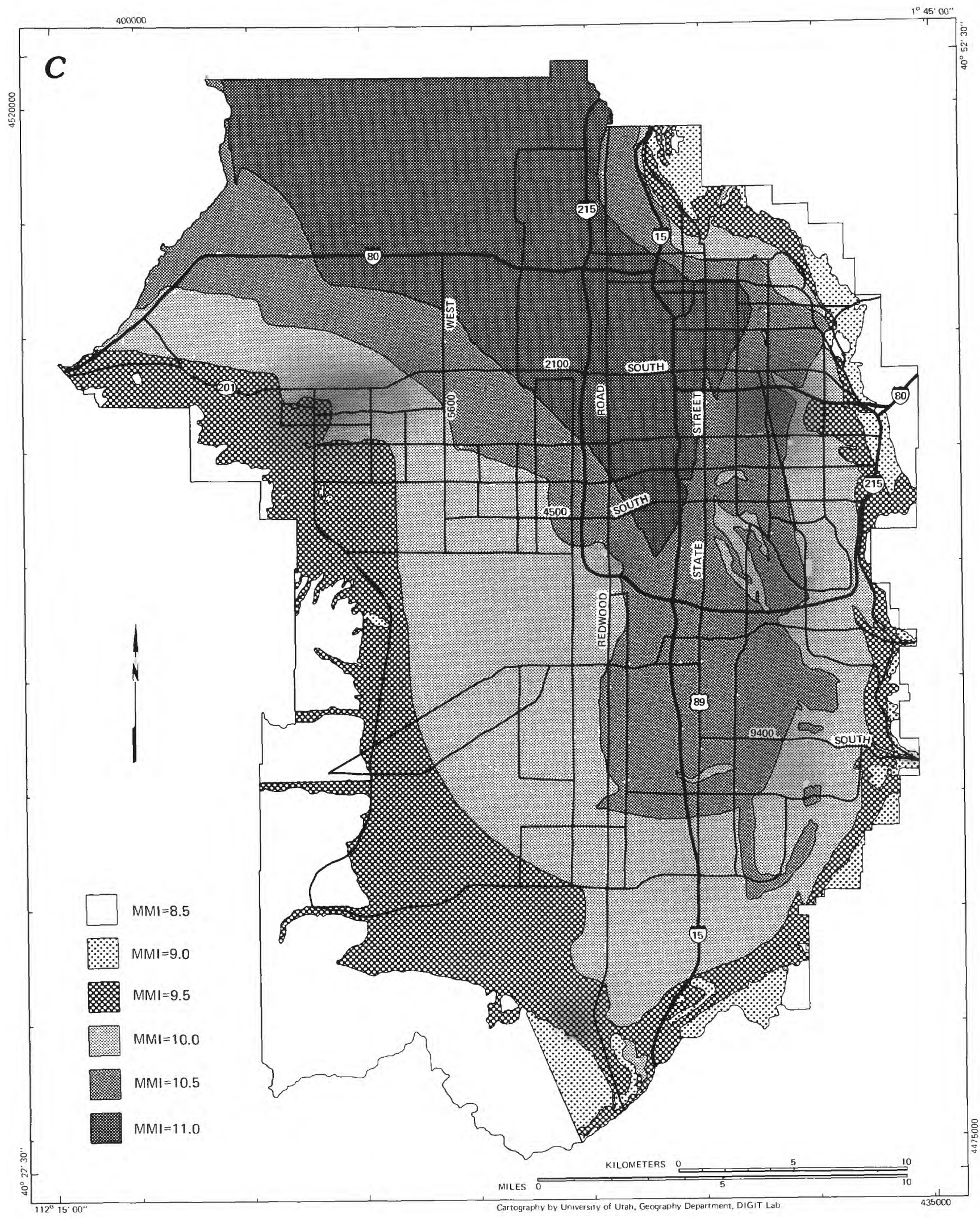

FIGURE 38C. -A microzonation of MMI with a 10 percent chance of being exceeded over a 250 -yr exposure period for the urbanizable area of Salt Lake County, Utah. 
tion for a 50-yr period. Refer to this map when addressing concerns about the structural integrity of ordinary buildings. Figure $38 \mathrm{C}$ shows the same information for a 250 -yr period. This is the reference map for addressing concerns about the structural integrity of lifelines, critical facilities, and structures containing hazardous materials.

Specific reservations must be noted about the use and interpretation of these maps. They refer only to the ground-shaking hazard as understood through an analysis of ground-motion amplification. They do not consider the near-field directivity effects recently noted by Benz and Smith (1989). They do not consider the induced effects of ground failures such as liquefaction, slumps, slides, flows, falls, and subsidence (Anderson and others, 1986; Keaton, 1986; Case, 1987). They do not include the effects of fault rupture and surface displacement (McCalpin, 1987). The polygon boundaries drawn on these maps should be regarded as having a range of uncertainty extending over a few hundred meters.

In spite of these reservations, the maps do have useful applications. They can be used for regional loss estimations, regional calculation of insurance premiums, and in the overall design of earthquake emergency response systems. They can be used to help frame discussion of seismic retrofit policies and generalized land-use policies. They can be used to guide the general siting and design of lifelines, critical facilities, and large-capacity structures. They serve as a basis for the study of related geologic hazards activated by various intensities of ground shaking.

To improve this line of inquiry, further research needs to be done on several topics. Results need to be compared with those produced through the direct attenuation of intensity from source to site. Correlations of PSRV with the physical characteristics of surface and subsurface geology need to be detailed. Further study of directivity effects in the near field are needed to clarify the nature of this hazard. Critical intensities triggering liquefaction and other ground failure hazards in differentially sensitive soils need to be mapped. Also needed are loss estimations specific to building use and frame type based on a large-scale mapping of ground-shaking intensities and related ground-failure hazards (Emmi and Horton, 1991). The current study can serve, in part, as a basis from which to address these research and application needs.

\section{REFERENCES}

Algermissen, S.T., Arnold, E.P., Steinbrugge, K.V., Hooper, M.G. and Powers, M.S., 1988, Earthquake losses in central Utah, in Gori, P.L., and Hays, W.W., eds., Assessment of regional earthquake hazards and risk along the Wasatch Front, Utah: U.S. Geological Survey Open-File Report 88-680, v. 3, p. X-1-62.
Algermissen, S.T., Perkins, D.M., Thenhaus, P.C., Hanson, S.L., and Bende, B.L., 1982, Probabilistic estimates of maximum acceleration and velocity in rock in the contiguous United States: U.S. Geological Survey Open-File Report 82-1033, 99 p.

Algermissen, S.T., and Steinbrugge, K.V., 1984, Seismic hazard and risk assessment, Some case studies: Geneva Papers on Risk and Insurance, v. 9, p. 8-26.

Anderson, L.R., Keaton, K.R., Spitzley, J.E., and Allen, A.C., 1986, Liquefaction potential map for Salt Lake County, Utah: Department of Civil and Environmental Engineering, Utah State University, Logan, and Dames and Moore, Salt Lake City, Utah, 48 p.

Arabasz, W.J., Pechmann, J.C., and Brown, E.D., 1987, Observational seismology and the evaluation of earthquake hazards and risk in the Wasatch Front area, Utah, in Gori, P.L., and Hays, W.W., eds., Assessment of regional earthquake hazards and risk along the Wasatch Front, Utah: U.S. Geological Survey Open-File Report 87-585, v. 1, p. D-1-39.

Benz, H.M., and Smith, R.B., 1989, Elastic wave propagation and site amplification in the Salt Lake Valley, Utah, from simulated normal faulting earthquakes: Bulletin of the Seismological Society of America, in press.

Bernreuter, D.L., 1981, Seismic hazard analysis, Application of methodology, results, and sensitivity studies: Washington, D.C., U.S. Nuclear Regulatory Commission Report MUREG/CR-3756.

Borcherdt, R.D., 1985, Predicting earthquake ground motion, An introduction, in Ziony, J.I., ed., Evaluating earthquake hazards in the Los Angeles region: U.S. Geological Survey Professional Paper 1360, p. 93-99.

Borcherdt, R.D., Gibbs, J.F., and Fumal, T.E., 1979, Progress on ground-motion predictions for the San Francisco Bay region, in Brabb, E.E., ed., Progress on seismic zonation in the San Francisco Bay region: U.S. Geological Survey Circular 807.

Borcherdt, R.D. Joyner, R.E., Warrick, R.E., and Gibbs, J.F., 1975, Response of local geologic units to ground shaking, in Borcherdt, R.D., ed., Studies for seismic zonation of San Francisco Bay region: U.S. Geological Survey Professional Paper 941-A, p. $52-67$.

Campbell, K.W., 1984, Near-source attenuation of strong ground motion for moderate to large earthquakes-An update and suggested application to the Wasatch fault zone on north-central Utah, in Hays, W.W., and Gori, P.L., eds., A workshop on "Evaluation of regional and urban earthquake hazard and risk in Utah": U.S. Geological Survey Open-File Report 84-763, p. $483-499$.

1986, An empirical estimate of near-source ground motion for a major $m_{b}=6.8$ earthquake in the eastern United States: Bulletin of the Seismological Society of America, v. 76, p. 1-17.

1987, Predicting strong ground motion in Utah, in Gori, P.L., and Hays, W.W., eds., Assessment of regional earthquake hazards and risk along the Wasatch Front, Utah: U.S. Geological Survey Open-File Report 87-585, v. 2., p. L-1-90.

Case, W.F., 1987, Rock fall hazard susceptibility due to earthquakes, central Wasatch Front, Utah, in Gori, P.L. and Hays, W.W., eds., Assessment of regional earthquake hazards and risk along the Wasatch Front, Utah: U.S. Geological Survey Open-File Report $87-585$, v. 2, p. V-1-36.

Davis, F., 1983, Geologic map of the central Wasatch Front: Salt Lake City, Utah Geologic and Mineral Survey, Map no. 54-A.

Donovan, N., 1983, A practitioner's view of site effects on strong ground motion, in Hays, W.W., ed., A workshop on "Site effects of soil and rock on ground motion and the implications for earthquake-resistant design": U.S. Geological Survey Open-File Report 83-845, p. 68-79. 
Emmi, P.C., 1989, An interpretation of recent findings on the directivity effects of a surface-faulting earthquake on the Salt Lake Segment of the Wasatch Fault: Salt Lake City, Department of Geography, University of Utah.

Emmi, P.C., and Horton, C.A., 1991, An assessment of casualty risk due to earthquake ground shaking: Salt Lake County, Utah, Proceedings of the Eleventh Annual ESRI Users Conference, Palm Springs, v. 2, p. 309-320.

Evernden, J.F., and Thomson, J.M., 1985, Predicting seismic intensities, in Ziony, J.I., ed., Evaluating earthquake hazards in the Los Angeles Region: U.S. Geological Survey Professional Paper 1360, p. 151-202.

Evernden, J.F., Kohler, W.M., and Clow, G.D., 1981, Seismic intensities of earthquakes of conterminous United States -Their prediction and interpretation: U.S. Geological Survey Professional Paper 1223, $56 \mathrm{p}$.

Gutenberg, B., and Richter, C.F., 1956, Earthquake magnitude, intensity, energy, and acceleration, Seismological Society of America Bulletin, v. 32, p. 163-191.

Hays, W.W., 1980, Procedures for estimating earthquake ground motion: U.S. Geological Survey Professional Paper 1114, 77 p.

ed., 1983, A workshop on "Site effects of soil and rock on ground motion and the implications for earthquake-resistant design": U.S. Geological Survey Open-File Report 83-845, 357 p.

1987, Site amplification in the Salt Lake City-Ogden-Provo urban corridor and the implications for earthquake-resistant design, in Gori, P.L., and Hays, W.W., eds., Assessment of regional earthquake hazards and risk along the Wasatch Front, Utah: U.S. Geological Survey Open-File Report 87-585, v. 2, p. K-1-69

Hays, W.W., Algermissen, S.T., Miller, R.D., and King, K.W., 1978, Preliminary ground response maps for the Salt Lake City area: Proceedings of the 2nd International Conference on Microzonation, San Francisco, v. 2. p. 487-508.

Hooper, M.G., 1988, Isoseismals of some historical earthquakes affecting the Wasatch Front area, Utah, in Gori, P.L., and Hays, W.W., eds., Assessment of regional earthquake hazards and risk along the Wasatch Front, Utah: U.S. Geological Survey Open-File Report 88-680, v. 3, p. Y-1-28.

Joyner, W.B., and Fumal, T.E., 1985, Predictive mapping of earthquake ground motion, in Ziony, J.I., ed., Evaluating earthquake hazards in the Los Angeles region: U.S. Geological Survey Professional Paper 1360, p. 203-220.

Keaton, J.R., 1986, Evaluation of potential consequences of earthquake induced tectonic subsidence along the Wasatch Front, northcentral, Utah: Salt Lake City, Utah, Dames and Moore, p. 52.

King, K.W., Williams, R.A., and Carver, D.L., 1987, Relative ground response in Salt Lake City and areas of Springville-Spanish Fork, Utah, in Gori, P.L., and Hays, W.W., eds., Assessment of regional earthquake hazards and risk along the Wasatch Front, Utah: U.S. Geological Survey Open-File Report 87-585, v. 2., p. N-1-48.

Krinitzsky, E.L., 1988, Empirical earthquake ground motions for an engineering site with fault sources-Tooele Army depot, Utah: Vicksburg, Miss., Waterways Experiment Station, U.S. Army Corps of Engineers, $79 \mathrm{p}$.

Krinitzsky, E.L., and Chang, F.K., 1987, State-of-the-art for assessing earthquake hazards in the United States, Report 25, Parameters for specifying intensity-related earthquake ground motions: Vicksburg, Miss., Geotechnical Laboratory, U.S. Army Corps of Engineers, Waterways Experiment Station Miscellaneous Paper S-73-1, 43 p.

Krinitzsky, E.L., Chang, F.K., and Nuttli, O.W., 1987, State-of-theart for assessing earthquake hazards in the United States, Report 26, Parameters for specifying magnitude-related earthquake ground motions: Vicksburg, Miss., Geotechnical Laboratory, U.S. Army Corps of Engineers, Waterways Experiment Station Miscellaneous Paper S-73-1.

Lund, W.R., 1987, 1986-1987 Paleoseismic trenching program summary: Wasatch Front Forum, v. 4, no. 1-2, p. 1-7.

Machette, M.N., Personius, S.F., and Nelson, A.R., 1987, Quaternary geology along the Wasatch fault zone, Segmentation, recent investigations, and preliminary conclusions, in Gori, P.L., and Hays, W.W., eds., Assessment of regional earthquake hazards and risk along the Wasatch Front, Utah: U.S. Geological Survey Open-File Report 87-585, v. 1, p. A-1-72.

McCalpin, J., 1987, Recommended setbacks from active normal faults: Proceedings of the 23rd Symposium on Engineering Geology and Soils Engineering, Logan, Utah, April 6-8, p. 35-56.

Murphy, J.R., and O'Brien, L.J., 1978, The correlation of peak ground acceleration amplitude with seismic intensity and other physical parameters: Bulletin of the Seismological Society of America, v. 66, p. $915-935$.

Neumann, F. 1954, Earthquake intensity and related ground motion: Seattle, Washington University Press, $40 \mathrm{p}$.

Oaks, S.D., 1987, Effects of six damaging earthquakes in Salt Lake City, Utah, in Gori, P.L., and Hays, W.W., eds., Assessment of regional earthquake hazards and risk along the Wasatch Front, Utah: U.S. Geological Survey Open-File Report 87-585, v. 2, p. P-1-95.

Richter, C.F., 1935, An instrumental earthquake magnitude scale: Seismological Society of American Bulletin, v. 25, p. 1-32.

Rogers, A.M., Algermissen, S.T., Hays, W.W., and Perkins, D.M. (geologic portions), Van Strien, D.O., Hughes, H.C., Hughes, R.C., Lagorio, H.J., and Steinbrugge, K.V. (engmeering analysis), 1976, A study of earthquake losses in the Salt Lake City, Utah, area: U.S. Geological Survey Open-File Report 76-89, $357 \mathrm{p}$.

Rogers, A.M., Carver, D.L., Hays, W.W., King, K.W., and Miller, R.D., 1984, Preliminary estimates of geographic variation in relative ground shaking in the Wasatch Front urban corridor, in Hays, W.W., and Gori, P.L., eds., A workshop on "Evaluation of regional and urban earthquake hazard and risk in Utah": U.S. Geological Survey Open-File Report 84-763, p. 547-556.

Rogers, A.M., Tinsley, J.C., and Hays, W.W., 1983, The issues surrounding the effects of geologic conditions on the intensity of ground shaking, in Hays, W.W., ed., A workshop on "Site effects of soil and rock on ground motion and the implications for earthquake-resistant design": U.S. Geological Survey Open-File Report 83-845, p. 32-67.

Rojahn, R.L., 1985, Earthquake damage evaluation data for California: Redwood City, Calif., Applied Technology Council Report ATC-13, $492 \mathrm{p}$.

Schwartz, D.P., and Coppersmith, K.J., 1984, Fault behavior and characteristic earthquakes from the Wasatch and San Andreas faults: Journal of Geophysical Research, v. 89, no. B7, p. 5681-5698.

Taylor, C.E., Wiggins, J.H., Haber, J.M., and Ward, D.B., 1986, A systems approach to Wasatch Front seismic risk problems: Redondo Beach, Calif., NTS Engineering Report to the U.S. Geological Survey.

Tinsley, J.C., 1988, Quaternary framework for earthquake studies, in Jacobson, M.L., ed., National Earthquake Hazards Reduction Program, Summaries of technical reports: U.S. Geological Survey Open-File Report 88-434, v. 26, p. 528-532.

Trifunac, M.D., 1970, Low frequency digitization errors and a new method for zero baseline corrections of strong ground-motion accelerograms: Pasadena, Calif., California Institute of Technology, Earthquake Engmeering Research Lab. Report EERL $70-07,30 \mathrm{p}$. 
Trifunac, M.D., and Brady, A.G., 1975, On the correlation of seismic intensity scales with the peaks of recorded strong ground motion: Bulletin of the Seismological Society of America, v. 65, p. 139-162.

Werner, S.D., and Ts'ao, H.S., 1975, Investigation of vertical groundmotion characteristics for nuclear plant design: Agbabian Association report to Reactor Research and Development Division, Energy Research and Development Administration, SAN/ 1011-107, $29 \mathrm{p}$.

Wiggins, J.H., and Taylor, C.E., 1981, Earthquake hazards and risk mitigation-Identification and evaluation methods: Redondo Beach, Calif., J.H. Wiggins Co. Report to FEMA, 3 vols.
Williams, J.S., and Tapper, M.L., 1953, Earthquake history of Utah, 1850-1949: Seismological Society of America Bulletin, v. 43, p. $191-218$.

Wood, H.O., and Neumann, F., 1931, Modified Mercalli intensity scale of 1931: Seismological Society of America Bulletin, v. 21, p. $277-283$.

Young, R.R., Swan, F.H., Powers, M.S., Schwartz, D.P., and Green, R.K., 1987, Probabilistic analysis of earthquake ground-shaking hazard along the Wasatch Front, Utah, in Gori, P.L., and Hays, W.W., eds., Assessment of regional earthquake hazards and risk along the Wasatch Front, Utah: U.S. Geological Survey Open-File Report 87-585, v. 2, p. M-1-110. 


\section{APPENDIX A. ABBREVIATED DESCRIPTION OF THE MODIFIED MERCALLI INTENSITY SCALE}

I. Not felt but by a very few under especially favorable conditions.

II. Only felt by a few persons at rest, especially on upper floors of buildings.

III. Felt noticeably by persons indoors, especially on upper floors of buildings. Many people do not recognize it as an earthquake. Standing cars may rock slightly. Vibration similar to the passing of a truck. Duration can be estimated.

IV. Felt indoors by many and outdoors by a few. At night, some are awakened. Dishes, windows, and doors are disturbed. Walls make cracking sound. Standings cars rock noticeably.

V. Felt indoors by practically all. Many are awakened. A few run outdoors. Some dishes are broken. Small or unstable objects overturn.

VI. Felt by all, indoors and out. Many are frightened, many run outdoors. Persons made to move unsteadily. Dishes and glassware are broken in considerable quantity. Some heavy furniture is moved. Some plaster may fall.

VII. All are frightened and run outdoors. Many find it difficult to stand. Sand and gravel stream beds cave in. Damage negligible in buildings of good design and construction; slight to moderate in well-built ordinary structures; considerable in poorly built or badly designed structures. Some chimneys are broken. Fall of plaster is considerable to large amounts. Loose brickwork and tiles are shaken down. Weak chimneys are broken at the roof line. Cornices fall. Heavy furniture is overturned and damaged.

VIII. General fright. Alarm approaches panic. Sand and mud are ejected in small amounts. Damage slight in specially designed structures; considerable damage in ordinary substantial buildings, with partial collapse. Panel walls are thrown out in frame structures. Damage is great in poorly built structures. Chimneys, factory stacks, columns, monuments, and walls twist and fall. Very heavy furniture is moved and overturned.

IX. General panic. Ground cracks conspicuously. Damage considerable in masonry structures; welldesigned frame structures are thrown out of plumb. Damage is great in substantial buildings, which may partially collapse. Frame buildings are shifted off their foundations. Underground pipes are broken. Reservoirs are compromised.

$\mathrm{X}$. Cracked ground, especially when loose and wet: yard-wide fissures run parallel to canal and stream banks. Landslides are considerable. Sands and mud shift horizontally on flat land. Some well-built wooden structures are destroyed. Most masonry and frame structures are destroyed as well as their foundations. Buried pipelines are torn apart or crushed end-wise. Open cracks and wavy folds in cement pavement and asphalt roads.

XI. Ground disturbances are many and widespread, including fissures, slumps, and slides. Water charged with sand and mud is ejected in large amounts. Seiches and tsunamis of significant magnitude occur. Damage is great to dams, dikes, and embankments, and to wood frame structures. Few if any masonry structures remain standing. Bridges are destroyed by the wrecking of supporting piers and pillars. Rails are bent greatly. Buried pipelines are put completely out of service.

XII. Damage is practically total. Moving waves are actually seen on the ground surface. Objects are thrown into the air.

Figures 39 and 40 depict expected damage to common structures as a function of MMI. These figures are based on data from the Applied Technology Council (Rojahn, 1985). 

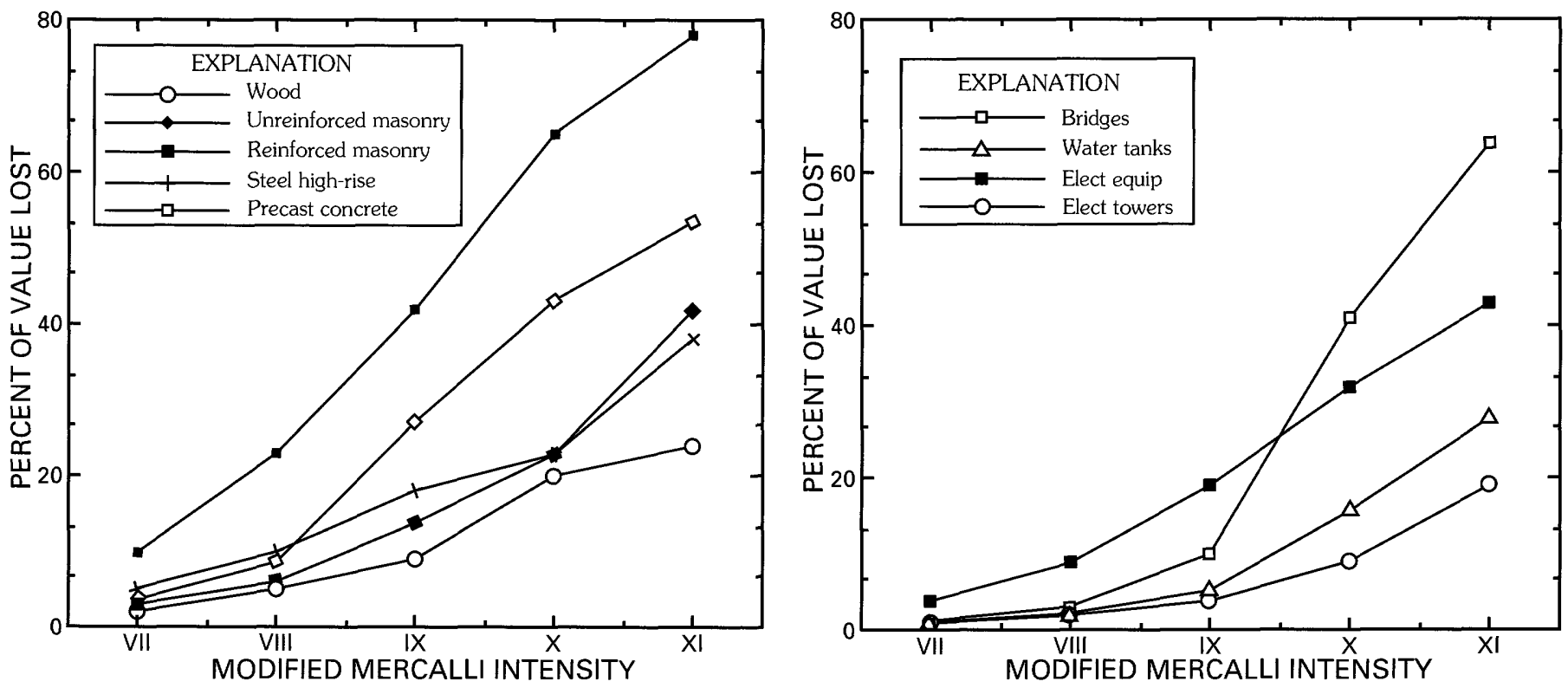

FIGURE 39.-Estimated loss to selected structures as a function of FIGURE 40.-Estimated loss to selected lifelines as a function of MMI MMI based on relationships given by Rojahn (1985). based on relationships given by Rojahn (1985). 


\section{APPENDIX B. THE INTERPRETATION OF TEGHNICAL STATEMENTS OF RISK}

Risk is defined as the chance of injury, damage, or loss. Technical statements of risk try to specify the degree of risk per unit of time. Risky events that are dichotomous (either happen or not) are easy to quantify by simply stating the probability of their occurrence during some relevant time period. However, most risky events vary in severity or intensity and, therefore, efforts to quantify such risk must deal simultaneously with three aspects of risk-probability, exposure time, and intensity.

First is a measure of the intensity with which a hazardous event can occur. In the present context, a measure of ground-shaking intensity, the MMI is used. Second is a time horizon over which exposure is considered. Here, three time horizons, a 10-yr, a 50-yr, and a 250 -yr time period, are used. Third is a critical probability at which one wants to know, for each exposure period, the intensity of hazardous events to expect. Here the 10 percent probability level is used as the critical level. In this way, a specific degree of danger can be taken into account for certain kinds of design and siting decisions. For example, knowing that there is a 10 percent chance of MMI $>$ VIII+ over a 250 -yr period would have important design implications were the University of Utah to propose installing a class IV biological laboratory capable of producing pathological organisms for which no cure is known.

For purposes of exposition, we try to reduce statements of risk to simple numbers. Clearly, hazardous events that vary in intensity are not adequately described by a single number. A curve or a functional equation needs to be used to specify the degree of risk. In fact, representing the risk of hazardous events requires a family of curves or functional equations.

Figure 41 presents this concept graphically. Earthquake ground shaking is classified into ranges of low, medium, and high intensity. The risk of low-intensity ground shaking is described by a curve that shows high probabilities of this low-intensity level being exceeded over various exposure periods. The curve intersects a horizontal line marking the 10 percent exceedence probability at the 10-yr time horizon and indicates, thereby, a 10 percent chance of a low-intensity of ground shaking being exceeded over any 10-yr exposure period. But the curve for low-intensity ground shaking arcs upward rapidly to define higher exceedence probabilities over longer exposure periods. For example, it shows a very high (92 percent) chance of a low level of ground-shaking intensity being exceeded over a 250 -yr exposure time.

The curve for medium-intensity ground shaking intersects the 10 percent exceedence probability line at the 50-yr exposure period. It, too, ares upward, though less

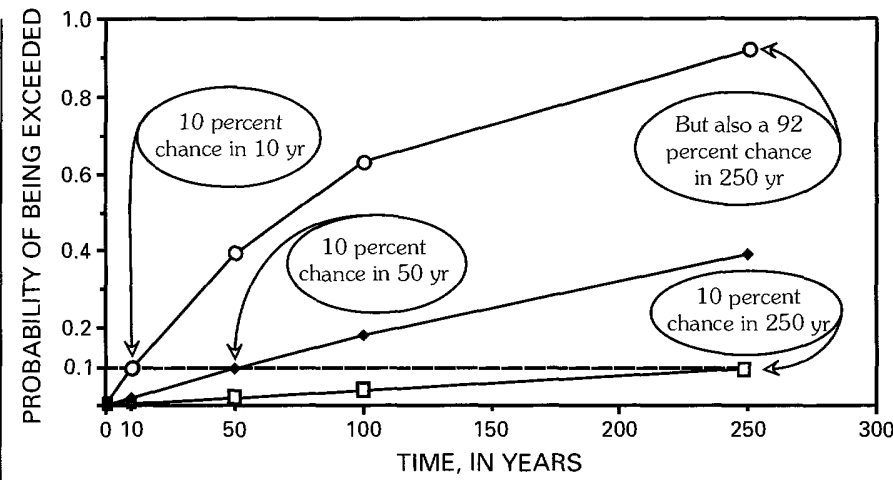

EXPLANATION

$\rightarrow-$ Low-Probability, High-Intensity Events

$\rightarrow$ Medium-Probability, Medium-Intensity Events

-o- High-Probability, Low-Intensity Events

FIGURE 41.-Functions describing the probabilities with which events of different intensity might occur over various exposure periods.

rapidly, to define higher exceedence probabilities over longer exposure periods. Someone concerned with the design of a structure expected to last $100 \mathrm{yr}$ could determine from this curve that the structure has about a 1 in 5 chance of being subject to at least an intermediate level of ground shaking. If, with standard design, the structure could not withstand such an event, then earthquake insurance over the useful life of the structure should cost at least one-fifth the structure's value. If, with proper design and limited expense, the structure can be made to withstand such an event, one would then be advised to adopt such designs in lieu of bearing the risk or carrying earthquake insurance.

The curve for high-intensity ground shaking intersects the 10 percent probability line at the 250 -yr time horizon. The probability of high-intensity ground shaking over a 100 -yr time horizon is about 4 percent. Thus, only one out of every twenty-five 100-yr time periods is likely to have high-intensity ground shaking. The possibility should be kept in mind only when considering a limited class of important or hazardous structures.

Making comprehensible statements about seismic risk in the Salt Lake County, Utah, is made even more difficult because of the wide range of ground-shaking intensities to which the county is exposed during each of the three exposure periods. Figures $38 A-C$ indicate that the ground-shaking intensities included in the three intensity classes broadly overlap. Structures on seismically sensitive soils can be subject to high intensities of ground shaking with intermediate levels of probability and subject to intermediate levels of ground shaking with high probability. In addition to severity, time horizon, and exceedence probability, the further aspect of site conditions, which vary considerably by location, must also be considered. 


\section{APPENDIX C. USE OF COMPUTER MAPPING AND GIS METHODOLOGIES}

All GIS operations are done on a PC/AT compatible with a raster-based software package by Earth Resources Data Analysis System (ERDAS). Tabular data input is through tape and floppy disk drives, while mapped data input is through an E-size digitizing table. Mapped output is through a color dot-matrix printer or through photographs of a VGA standard color monitor.

A base map is digitized from a USGS intermediatescale $(1: 100,000)$ topographic map of Salt Lake County, Utah, with both Universal Transverse Mercador zone 12 and Utah State plane coordinate ticks. The study area includes the central valley of Salt Lake County suitable for contiguous urbanization. This area is bounded on the north by the Davis County boundary, on the east by the Wasatch National Forest boundary, on the south by the Utah County boundary, and on the west by the boundaries of census tracts that intersect the increasingly steep slopes approximately marked by the 6,000-ft topographic contour. Freeways, highways, and major surface roads are added to provide informal locational reference. In digital form, the base map contains more than 260,000 picture elements (pixels). Each pixel represents approximately 80 by $100 \mathrm{~m}$, or about half of an acre.

Maps published by Young and others (1987) with PHA values having a 10 percent chance of being exceeded over a 10-yr, a 50-yr, and a 250-yr period are photographically enlarged, transferred to the base map using a reflecting projector, and digitized. Full 1:100,000 scale spectral amplification maps from Tinsley (1988) are digitized at scale, as are the relevant geologic units interpreted from Davis's (1983) map compilation.

In digital form, Tinsley's spectral amplification ratios are used as our first digital map plane. Amplification ratios assigned to selected surficial geologic units from Davis's compilation are used as our second digital map plane. These two map planes are combined to create a composite site-response surface. A program written in Pascal language reads the first pixel from the first digital map plane and the first pixel from the second digital map plane and computes a value for the first pixel of a third digital map plane as the square root of the product of the prior two pixel values. The program writes the new value as the first pixel of a composite site-response map and then repeats the cycle for all successive pixels. In this manner, a composite site-response surface is built up as an algebraic function of the two underlying map planes (fig. 42).

The composite site-response surface is then used in conjunction with each of three digital maps on PHA on rock. PHA on rock with a 10 percent chance of being exceeded in a 10-yr period is used as the first map plane. The composite site-response surface is used as the second map plane. Functional relationships between PHA on rock, site amplification, and MMI as specified in the previous description of method 3 are collapsed into a single functional equation. This equation has PHA on rock and composite amplification ratios as independent variables and MMI as the dependent variable. A second Pascal language program uses this equation to compute MMI values with a 10 percent chance of being exceeded over a 10-yr period for each pixel on a third map plane. The process is repeated to create maps showing MMI values with a 10 percent chance of being exceeded over a 50 -yr and a 250-yr period.

Maps of MMI exceedence values are put out to a color dot-matrix printer at 1:100,000 scale. Maps shown in figures $38 A-C$ are reductions prepared from these larger scale maps by cartographer Steven Thomas of the University of Utah, Department of Geography, DIGIT Lab. 


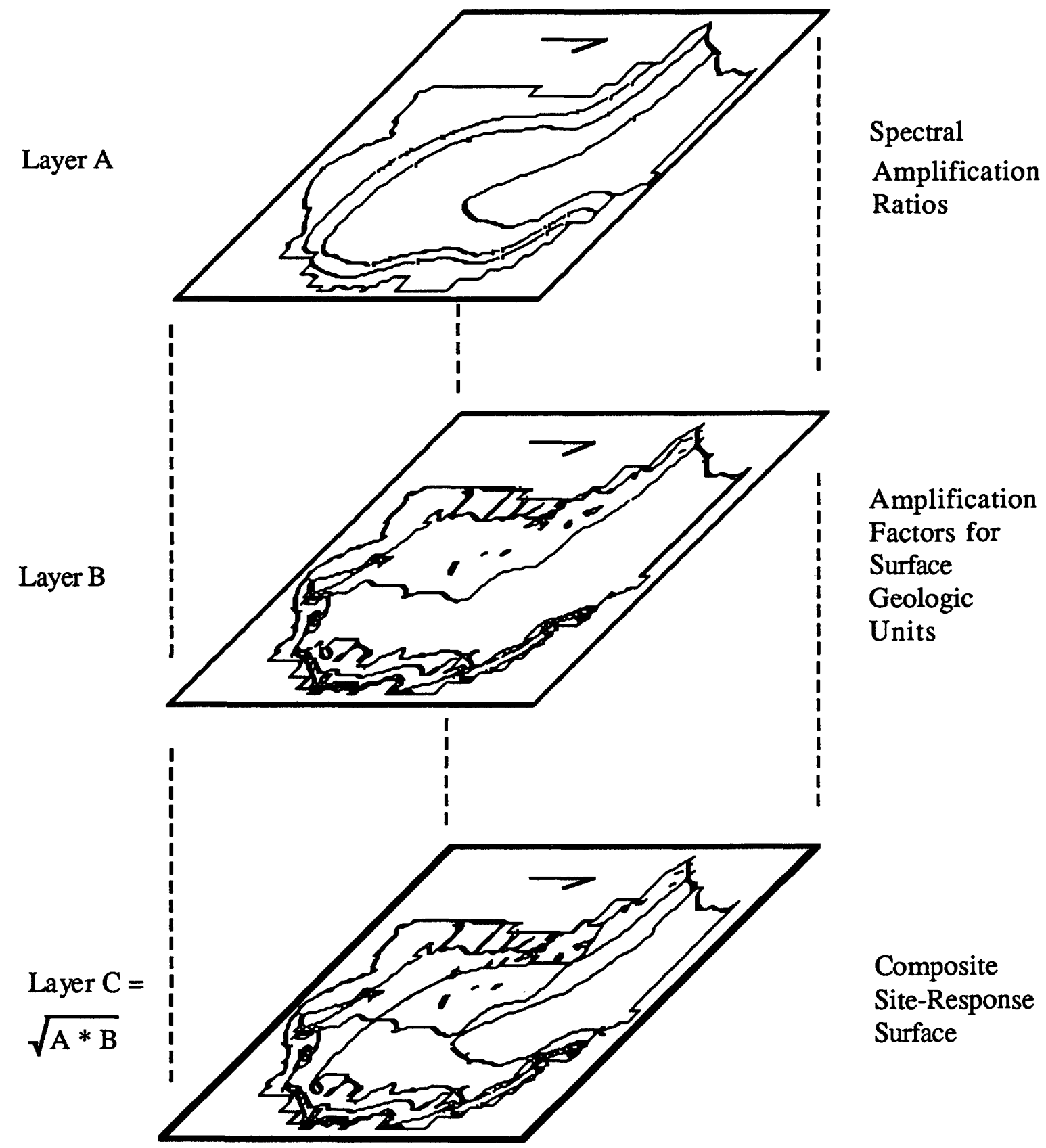

FIGURE 42. - An illustration of a graphic overlay technique using a geographic information system to combine Tinsley's (1988) spectral amplification ratios (layer A) with the spectral amplification ratios assigned by the author to surficial geologic units from Davis's (1983) map compilation (layer B) to create a composite site-response surface (layer C) as the square root of the product of the scores from layers A and B. 


\title{
WASATCH FRONT COUNTY HAZARDS GEOLOGIST PROGRAM
}

\author{
By Gary E. Christenson ${ }^{9}$
}

\begin{abstract}
The Wasatch Front County Hazards Geologist Program was initiated and conducted by the Utah Geological Survey (UGS) with funding from the U.S. Geological Survey under the National Earthquake Hazards Reduction Program (NEHRP). The purpose of the program was to reduce hazards by aiding in the use of geologic information, particularly earthquake hazards information produced under the NEHRP. The rationale behind the program was that local governments have the responsibility to regulate land use and that geologic information and expertise would be most effective in reducing hazards if provided at the city and county level. Three geologists were placed in five Wasatch Front counties (Weber-Davis, Salt Lake, and Utah-Juab Counties) for a term of 3 years beginning in June 1985. The geologists were a part of the county's planning department staff but were available to other departments and to cities for educational, advisory, and review services.

The principal duties of the geologists were to (1) produce geologic hazards maps, (2) assist in writing geologic hazards ordinances, (3) review engineering geologic reports, and (4) provide other technical services as needed. Hazards maps were produced for inclusion in ordinances that require site investigations prior to development in hazard areas. Site investigation reports are reviewed and approved by the county geologist prior to issuance of building permits. The work of the geologists was coordinated by the UGS, which also provided support and technical supervision. At the end of the program in June 1988, counties were in various stages of completing mapping and adopting ordinances; all three of the county geologists were retained and funded by the counties. The program has demonstrated the value of a staff geologist in populated, highly developed counties in highhazard areas such as the Wasatch Front.
\end{abstract}

\section{INTRODUGTION}

Geologic hazards play a significant role in life along the Wasatch Front and have caused hundreds of millions of dollars in property damage and at least one fatality since 1982. The Wasatch Front is particularly vulnerable because of the variety of hazards and the concentration of population in the area. Although a number of techniques are available to reduce geologic hazards, one of the most effective is proper long-range land-use planning based on an assessment of the hazards and their potential impacts. However, planning with respect to geologic hazards

\footnotetext{
${ }^{9}$ Utah Geological Survey, Salt Lake City, Utah.
}

along the Wasatch Front has been difficult because of a lack of hazards information, particularly in the form of translated hazards maps at suitable scales, and lack of an effective way to aid planners in incorporating this information into the planning process.

Because of the general lack of necessary hazards information and maps on which to base planning decisions, land use has progressed in may areas without proper consideration of hazards and the risks they present. Some of the damage incurred in wet years in the early 1980's, for example, could have been avoided through proper land use with respect to the rise of Great Salt Lake, stream flooding, debris flows, and landslides. Although damage was extensive, that which will result from a large earthquake along the Wasatch Front is much greater and can be significantly reduced by wise land-use practices.

The Utah Geological Survey (UGS) has long advocated the consideration of geologic hazards in planning. It has been available to local governments to provide hazards information and review engineering geologic reports, but these services have not been fully used. The UGS has no regulatory authority to implement recommendations made in report reviews. Therefore, effective influence on land use can best be accomplished by geologists in local governments, where decisions are made and enforced.

Geologists at the local level can become involved in projects early on and can follow the process further. The purpose of the Wasatch Front County Hazards Geologist Program was to provide geologic expertise at the local government level in order to better use geologic hazards information to reduce casualties and damage. The scope of work of the county geologists was to (1) compile geologic hazards information and produce maps to delineate hazards areas, (2) advise planners regarding hazards ordinances, (3) review engineering geologic reports, and (4) provide geologic expertise as required, including performing site investigations for critical public facilities and investigating hazardous geologic events. Emphasis of the program was on geologic hazards, and the geologists did not perform other services typically provided by 
a county geologist, such as resource evaluations or waste disposal siting, except when specifically requested.

\section{ACKNOWLEDGMENTS}

The idea that county geologists would be one of the most effective ways to implement geologic hazards information and loss reduction along the Wasatch Front was first proposed by William R. Lund (UGS). Genevieve Atwood (former Director, UGS) and Don R. Mabey (former Deputy Director, UGS) solicited support from the counties and provided for the administration of the program. Planning department directors Graham Shirra (Weber County), Rick Mayfield (Davis County), Jerold Barnes (Salt Lake County), and Jeff Mendenhall (Utah County) and Juab County Commissioner Thomas Fowkes ensured that the program worked and convinced their planning commissions and county commissions to support it. Particular thanks go to Graham Shirra and Jeff Mendenhall for taking key responsibility for payroll and administration for geologists serving Davis and Juab Counties, respectively. Principal credit for the success of the program goes to the county geologists-Mike Lowe, Craig V. Nelson, and Robert M. Robison-whose diligence and dedication demonstrated to the counties the value of a staff geologist and the need to consider geologic hazards in development.

Walter W. Hays and William J. Kockelman of the U.S. Geological Survey (USGS) provided information and reviewed work products. Michael Machette, Alan Nelson, and Steve Personius (USGS) provided advance copies of fault maps and, along with David P. Schwartz (USGS), have lent support in report reviews and trench investigations. During data collection phases of the project, information was obtained from State and Federal agencies and private consultants too numerous to list. Don Mabey, Mike Lowe, Craig Nelson, Robert Robison, and Bill Kockelman all reviewed this paper.

\section{DESCRIPTION OF THE PROGRAM}

To provide geologic expertise to local governments, several options are available (1) a permanent, full-time city or county geologist, (2) a circuit-rider geologist serving several governments simultaneously (Thorsen, 1981), (3) a geologist employed by an umbrella agency (regional association of governments, State survey) but dedicated to serve local governments, or (4) a private consulting geologist on retainer or otherwise under contract with local government. Any one option may be appropriate, depending on population served, development pressure, extent of hazards, and other needs for geologic expertise. Option 1 is most appropriate where a need exists for a full-time geologist, as is the case for some counties in the Wasatch Front area.

The UGS received USGS funding under the National Earthquake Hazards Reduction Program (NEHRP) to place three geologists in Wasatch Front counties for a 3 -yr pilot program. To set up the program, UGS met with the county commissioners and planning department directors of the most populous counties and solicited support and advice from regional associations of governments (Wasatch Front Regional Council) and county councils of governments (composed of all mayors of cities in the county and representatives of the county commission). Based on these discussions, it was decided that the three geologists should cover five Wasatch Front counties (Weber, Davis, Salt Lake, Utah, and Juab) (fig. 43).

These geologists were to be placed in one of the county planning departments under the direct supervision of the planning director; the UGS would provide technical supervision and other support, as needed. One geologist (Mike Lowe) covered both Weber and Davis Counties, maintaining an office in each county and dividing his time evenly. Another geologist (Robert M. Robison) covered both Utah and eastern Juab Counties, maintaining a permanent office in Utah County and making periodic visits to Juab County, as needed. The third geologist (Craig V. Nelson) covered Salt Lake County. The geologists were hired through the county personnel departments. The UGS assisted in evaluating resumes and participated in interviewing and selecting candidates. The three geologists selected had similar backgrounds, consisting of bachelor's degrees in geology and master's degrees or work experience in engineering geology. Because the positions were temporary, geologists were hired as contractors rather than merit employees, although they received the county fringe benefits.

The program was broken into three 1-yr phases. The first year consisted chiefly of data collection and literature research, as in-house geologic libraries were established in each county. During the second year, this information was compiled to produce basic data maps needed to derive hazard maps. During the third year, hazard map compilation was begun, and explanatory "translated" texts were developed that clearly explained the hazards and gave recommendations on how to address each of them in planning.

Technical supervision by the UGS included monthly or semimonthly meetings to discuss issues, encourage cooperative efforts, and provide a uniform approach. All reports, report reviews, and other products prepared by the county geologists were reviewed by the UGS. The county geologists were included in UGS activities, and information was freely exchanged. Quarterly meetings were also held between Davis and Weber Counties regarding the work of the geologist that they shared. 

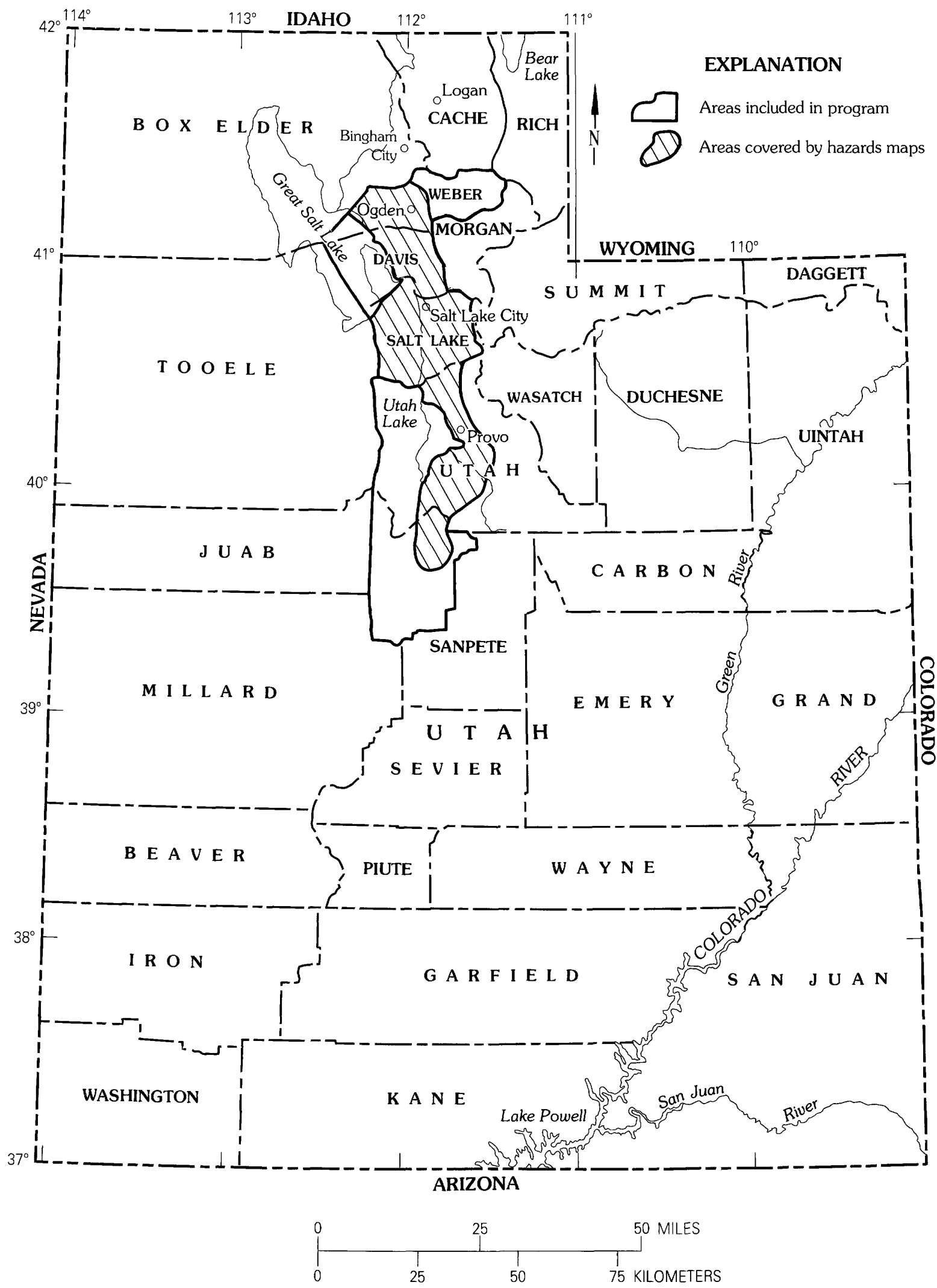

FIGURE 43.-Location map. 
The UGS provided a geologist for technical supervision on the program; many other staff members also contributed.

\section{ACCOMPLISHMENTS}

\section{DATA COLLECTION}

A principal goal during initial work was to identify and, if possible, collect library copies of all existing engineering geologic information. Published literature was relatively easily identified and collected, but unpublished literature in the files of government agencies and private consultants was not. All agencies and companies likely to possess information were contacted; information was collected to the extent possible, and, where not possible, its existence was noted for future reference. All references were indexed into a subject card catalog and organized into an easily accessible library in each county planning department.

A series of index maps showing locations of studies was compiled. For site investigations, locations were plotted on 1:24,000 scale topographic quadrangles. More regional studies were plotted on four smaller scale countywide maps at scales of 1:100,000 or larger, showing general geology, soil, landslide, and earthquake references. This information will be incorporated into the UGS statewide computerized hazards bibliography.

\section{HAZARDS MAPPING}

The principal goal of the final two phases of the program was to produce countywide hazards maps for use in planning. These maps, at 1:24,000 scale, covered the urbanizing parts of the counties in valley floors and extended up to the crest of the Wasatch Range (fig. 43). Thus, eastern Weber County (Ogden Valley), Cedar Valley, eastern Utah County, and western Juab County were not included in the mapping.

The county geologists prepared surface-fault-rupture, landslide, debris-flow, and rock-fall hazards maps. Some of the needed maps had already been prepared under the NEHRP, and these were evaluated and recommended for adoption as official county maps where appropriate. These maps include liquefaction potential, seismic slope stability (Salt Lake and Davis Counties), shallow ground water, tectonic subsidence, and dam failure inundation maps.

The purpose of the maps is to show hazard areas where detailed site investigations need to be performed prior to development. Texts were prepared to accompany each map to explain the hazard, including its location, approximate recurrence time (where appropriate), and consequences. A discussion of possible engineering and site design techniques for mitigation was included, as well as guidelines for the types of information that should be included in site investigation reports. Copies of maps and explanatory texts were distributed to each municipality for use in urban planning and are also available for consultants, developers, and the general public. Both maps and texts will be updated continuously as new information becomes available. Examples of these products are included in this volume.

\section{ORDINANCES AND REPORT REVIEWS}

Another goal of the program was to assist local government planners in using hazards maps and information to reduce casualties and damage. Emphasis was on developing and improving hazard reduction ordinances. The general approach recommended in such ordinances is outlined in UGS Circular 79 (Christenson, 1987). Essentially, engineering-geologic site-investigation reports are required in hazard areas (delineated on generalized hazards maps) prior to development, with approval of the permit dependent on a favorable review of the report by a geologist acting on behalf of the local government. The Salt Lake and Utah County Planning Departments have adopted geologic hazards ordinances that follow this approach closely and are being used by various Wasatch Front cities and counties as models. The City of Washington Terrace in Weber County has also adopted a sensitive-areas ordinance addressing geologic hazards using this approach.

Many of the larger cities in all counties have already adopted ordinances addressing geologic hazards, and the county geologists aided their administration by providing needed geologic expertise in identifying hazard areas and reviewing engineering-geologic reports. Completion of an engineering-geologic report for a site does not necessarily mean that hazards affecting the site will be avoided or mitigated. Engineering-geologic reports reviewed by the county geologists are commonly inadequate when initially submitted and must be revised and amended before they are acceptable (Nelson and others, 1987). Prior to the county hazards geologist program, engineering-geologic reports were occasionally reviewed by UGS when requested. The reviews were not done on a regular basis and had little effect on the overall quality of reports. Now that reports are reviewed regularly and returned for additional work when inadequate, a noticeable improvement in report quality has occurred.

\section{SITE INVESTIGATIONS}

The siting and construction of public waste-disposal facilities (landfills, incinerators) and critical facilities (fire 
stations, municipal buildings, water tanks and waterstorage reservoirs) is another important function of local governments. Waste-disposal facilities must be sited to avoid contamination of the environment. Critical facilities must continue to operate or be quickly returned to service after an event such as a damaging earthquake. Therefore, it is important to consider geologic hazards in siting. The county geologists performed detailed site investigations for both types of facilities, as well as field investigations after damaging geologic events. These studies generally include a field reconnaissance, literature review, air photo interpretation, and in some cases, subsurface investigation. A report addressing the geologic hazards at the site is used by local governments in planning and making decisions. The UGS has compiled a volume containing all of the site investigation reports written during the contract period (see Black and Christenson, 1988).

Many types of site investigations have been performed for a variety of agencies. County flood-control and emergency management agencies have requested aid in responding to hazardous geologic events and in assessing hazards potential, particularly flooding and landsliding. Health departments have requested on-site investigations to evaluate potential soil and ground-water problems as they relate to septic-tank systems. The county engineer's office has asked for reviews of sites for bridges and help in reducing hazards that may affect county roads and other public facilities. Building officials have requested assistance in inspecting excavations for evidence of faulting or ground failure, evaluating unstable slopes, and recommending hazard-reduction techniques. Workshops and field trips highlighting geologic hazards for building officials have also been conducted. Building inspectors have become principal users of geologic services. Various cities and counties have used the county geologist to evaluate geologic hazards affecting proposed or existing public facilities such as waterstorage tanks. The county geologist aided Davis County in evaluating the gravel resource potential and the best use of its property on the Salt Lake Salient and in evaluating geologic hazards affecting the North Davis Refuse Disposal and new burn-plant sites.

\section{OTHER SERVICES}

An important service is also provided to the public by the county geologist. Prospective real estate buyers seeking hazards information often visit the planning office, where hazards maps, geologic and emergency preparedness literature, and geologic advice are available. Community awareness about geologic hazards has also been increased through a slide-lecture program the geologists presented to community councils, civic groups, and local government organizations.

The county geologists also assist in other hazards projects. In Salt Lake County, West Valley City is completing a study involving a computerized compilation of seismic hazards data for use in municipal planning. Researchers from the University of Utah Geography Department are integrating seismic hazards data into a computer-based geographical information system for use in seismic risk assessment and loss estimation throughout Salt Lake County. Also in Salt Lake County, the geologist is advising Utah State University researchers in a project to poll public officials and private citizens regarding their perceptions of earthquake hazards and government responsibilities.

The Utah State Division of Comprehensive Emergency Management and Utah County initiated a comprehensive hazards mitigation project in the Provo-Orem area to aid emergency response personnel and planners. This project included geologic hazards map compilation and interpretation by the county geologist, UGS, and other agencies (Robison and others, 1987). Copies of the project maps are housed with the county geologist for dissemination and updating.

\section{TIME AND TASK BREAKDOWN}

The relative percentage of time spent on various tasks by each geologist (from June 1985 to March 1988) is shown in table 7 . These percentages are calculated after removing time spent for leave and professional activities. The category "UGS coordination" includes biweekly meetings, preparation of time records, and writing of articles for UGS publications such as Survey Notes and the Wasatch Front Forum. "Aid to cities" and "aid to counties" include activities that were specifically requested, such as aid in writing ordinances, review of engineering geologic reports, and site investigations. Nearly all such requests were honored in an attempt to demonstrate the need for a county geologist and the varied applications of geology to government functions.

TABLE 7.-Percentage of time spent on various tasks by the county geologists

\begin{tabular}{lccc}
\hline Task & Weber/Davis & Salt Lake & Utah/Juab \\
\hline UGS coordination......... & 7 & 7 & 9 \\
County administration..... & 7 & 11 & 9 \\
Data collection............ & 28 & 29 & 35 \\
Aid to cities ............. & 12 & 7 & 3 \\
Aid to counties .......... & 31 & 20 & 23 \\
Hazards mapping .......... & 13 & 21 & 20 \\
Public education ......... & 2 & 5 & 1 \\
$\quad$ (inquiries, lectures) & & & \\
\hline
\end{tabular}


Time spent in each activity varied from county to county, as did the types of jobs. This variation was due, in part, to the different relationships between each county planning department and the cities in the county and, in part, to the county's approach to development in unincorporated areas. For example, in Davis and Utah Counties, no services are provided to unincorporated areas, so development is in large part restricted to incorporated cities, which provide water, sewer, and other services. In general, an area must be annexed by a city before development can occur, so geologic hazards information is used both by the cities and county to evaluate incorporation plans. In contrast, considerable development occurs in unincorporated Salt Lake and Weber Counties because public services are provided; therefore geologic services are of particular interest to the county as well as cities in planning for development. Most of the larger cities in the five counties maintain their own planning departments, while the smaller cities generally contract with the county for planning services. Under the county geologist program, the geologists provided services to larger cities as well. Ogden, Layton, and Salt Lake City in particular used the geologist to review reports. As is apparent from table 7, Weber and Davis Counties made considerably more use of the county geologist's services for special projects than did Salt Lake, Utah, or Juab Counties.

\section{EVALUATION AND SUGGESTIONS}

The need for geologic services at the local government level has now been demonstrated in many areas, but initiation of a program to provide these services still requires that local government officials be made aware that they exist and be convinced that they are needed. Thus the need and usefulness must be demonstrated. In attempting to establish a county geologist position, initial funding from outside sources is a very effective and perhaps necessary first step. It is unlikely that counties could have been convinced to fund a geologist without such a demonstration program. The program also helped to determine the need for and best way to provide the services.

One aspect that contributed to the success of the program was the placement of the geologist in the planning department. Because the program was directed at geologic hazards and the protection of life and property through planning, it was most effective to make the geologists part of the review and permit process for all new development, which is principally a planning function. In the initial plan review, the geologist (or administrator using maps prepared by the geologist) needs to identify the geologic hazards that exist and must be addressed in site-investigation reports. In final review, the geologist must approve these reports prior to granting permits (Nelson and others, 1987). Other departments in which the geologist may be placed include engineering, health, flood control, building inspection, or a separate and independent office of the county geologist. These departments are perhaps a logical place for a county geologist in areas where waste disposal is a major problem, large public works projects are under way, or geologic services other than hazards are emphasized. Planning departments are preferred because of their more active role in long-range planning as opposed to short-term problem solving. A separate office of the county geologist may be the most effective means of getting geologic services to all departments, but the geologist is then left without an affiliation and requires development of a network of contacts and considerable effort in making services known and seeing that they are used. With an introductory program such as this, an unaffiliated geologist may be more vulnerable to budget cuts than one who is a part of an existing department.

The close association between the county geologists and the UGS was important to the success of the program both in maintaining consistency of approach from county to county and in providing technical support. One concern of planning directors and the regional association of government personnel was that ordinances and approaches to geologic hazards be consistent among jurisdictions along the Wasatch Front; the UGS facilitated this uniformity of approach. Local governments employ few scientists, and maintaining state-of-the-art expertise is difficult. Contact with other geologists is necessary, and the UGS staff worked with the county geologists on may occasions to foster the exchange of new ideas, information, and technology. On occasion, county geologists make recommendations that may be unpopular with local government officials; strong technical support from a State agency enhances their credibility.

One difficulty in administering the program was in the counties where geologists were shared. Under outside funding, one county took responsibility for handling the salary pass-through, and a memorandum of agreement and contract were written and signed by both counties outlining how the time was to be divided. This worked well during the period of outside funding, but when the counties took over funding, it became difficult to arrange for the geologist to be a merit employee of two different counties. Such a shared arrangement is better handled through a contract, circuit-rider program, or umbrella agency.

\section{CONCLUSIONS}

The principal goal of the project was to demonstrate the usefulness of geologic expertise at the local govern- 
ment level such that the counties would retain the geologists with county funding when the outside funding expired. This goal was achieved in three of the five counties. Salt Lake, Utah, and Davis Counties all hired the geologists as permanent merit employees on their planning department staffs. Weber County worked out a funding plan to continue the project for another year under the same shared program with Davis County, but Weber County's contribution was entirely from outside sources, i.e., there was no contribution from the county, and all indications were that Weber County would not continue the funding after 1989. The Weber County plan also required continuation of contract rather than merit employment. Davis County offered a full-time staff position, so it was decided that the geologist should stay with Davis County. Juab County is sparsely populated, has no permanent planning department, and was not able to justify having a geologist on its staff.

Little has changed in terms of the goals and administration now that counties are funding the county geologists. Most counties still provide services to cities, although Salt Lake County has worked out a fee schedule to charge cities for time spent reviewing reports. UGS continues to provide technical supervision but plays a less active role. Maps by the county geologists will be used by UGS in compiling statewide hazards maps, and data collected by the geologists is being incorporated in the UGS computerized hazards bibliography.

The program has done much to advance local government awareness and concern with regard to geologic hazards, particularly earthquake hazards, along the Wasatch Front. Planning departments now routinely require site-specific reports in hazard areas, and the systematic review of those reports by county geologists has improved their quality. The program is a very important part of both the UGS and the USGS efforts to translate and transfer geologic hazards information to users. The program, originally conceived as an experiment to demonstrate that a geologist at the local government level could be effective in carrying out these goals, has been a success. Much progress has been made in the production of "translated" hazards information usable by planners and others and in transferring this information to users. The development and adoption of effective geologic hazards ordinances to protect people and reduce property damage are just one example of this success.

\section{REFERENCES}

Black, B.D., and Christenson, G.E., compilers, 1988, Technical reports of the Wasatch Front county geologists, June 1985-June 1988: Utah Geological and Mineral Survey Report of Investigation 218, $154 \mathrm{p}$.

Christenson, G.E., 1987, Suggested approach to geologic hazards ordinances in Utah: Utah Geological and Mineral Survey Circular $79,16 \mathrm{p}$.

Nelson, C.V., Christenson, G.E., Lowe, Mike, and Robison, R.M., 1987, The review process and adequacy of engineering geologic reports, Wasatch Front, Utah, in McCalpin, James, ed., Proceedings of the 23rd annual symposium on engineering geology and soils engineering: Utah State University, Logan, Utah, p. 83-85.

Robison, R.M., Christenson, G.E., Knight, R.V., Dewsnup, Wes, and Johnson, Mike, 1987, Earthquake and slope failure hazards, Utah County Comprehensive Hazard Mitigation Project, Utah, in McCalpin, James, ed., Proceedings of the 23rd annual symposium on engineering geology and soils engineering: Utah State University, Logan, Utah, p. 499-521.

Thorsen, G.W., 1981, The circuit rider geologist: Final Report for U.S. Geological Survey Project 9-7020-26001, 29 p. 


\title{
SURFACE-FAULT RUPTURE: A GUIDE FOR LAND-USE PLANNING, UTAH AND JUAB COUNTIES, UTAH
}

\author{
By Robert M. Robison ${ }^{10}$
}

\begin{abstract}
Surface-fault rupture may be one of the most damaging effects of large-magnitude earthquakes in Utah and Juab Counties, Utah. Much research has been conducted to identify and evaluate the location and effects of surface faulting, and this paper is a compilation of the most current information available. This work is presented as an example of translated information from various sources, primarily the U.S. Geological Survey's National Earthquake Hazards Reduction Program. The principal purpose is to help identify and suggest mitigation measures for lowering the risks associated with surface-faulting earthquakes.

Large-magnitude earthquakes $\left(M_{L}=6.5+\right)$ with accompanying surface faulting have occurred repeatedly in Holocene time (past 10,000 yr) along the $213-\mathrm{mi}(343-\mathrm{km})$ trace of the Wasatch fault zone. Evidence from past earthquakes suggests a potential for surface offset of $6-9 \mathrm{ft}$ $(2-3 \mathrm{~m})$ and scarp heights of $9-15 \mathrm{ft}(3-5 \mathrm{~m})$. The Wasatch fault zone is a dip-slip (normal) fault, which commonly has a graben (downdropped block) or zone of deformation along the downthrown side. This disturbed zone may extend hundreds of feet (meters) from the main fault trace. Recent mapping by the U.S. Geological Survey indicates that there may be 10 or 11 segnients along the Wasatch fault zone, each with its own recurrence interval and rupture characteristics, which give a combined recurrence rate for a surface-faulting earthquake somewhere along the Wasatch fault zone every $340-415 \mathrm{yr}$. Recurrence on any particular segmient varies from hundreds to several thousands of years. Because of uncertainties in the timing of the most recent events and apparent irregularity in recurrence intervals, a surface-faulting earthquake could occur at any time on any of the segnients in Utah and Juab Counties.

In Utah County, special study zones have been delineated along mapped traces of the Wasatch fault zone to identify areas where more detailed study is recommended prior to development. These study zones are $250 \mathrm{ft}(76 \mathrm{~m})$ wide on the upthrown side of the fault and 500 $\mathrm{ft}(153 \mathrm{~m})$ on the downthrown side. Because surface ruptures generally occur along existing fault traces, we use minimum setback distances from traces identified in special studies to help avoid loss of life and property damage and to reduce the cost of geotechnical investigations. The recommended setbacks are $50 \mathrm{ft}(15 \mathrm{~m})$ from the 30 percent slope break on the top of the scarp and $50 \mathrm{ft}(15 \mathrm{~m})$ from the 30 percent slope break at the bottom of the scarp. If the scarp does not attain a slope of 30 percent, then the $50-\mathrm{ft}(15-\mathrm{m})$ setback on both the top and the bottom of the scarp is measured from the midpoint of the scarp. If antithetic scarps or backtilting are present, then the setback is measured from the antithetic scarp farthest from the main fault or backtilt inflection point, and the entire zone of deformation should be avoided. If
\end{abstract}

\footnotetext{
${ }^{10}$ Utah County Planning Department, Provo, Utah.
}

construction is proposed within the setbacks or zone of deformation, then a site-specific investigation is needed to accurately locate the faults and deformed strata before placement of buildings is recommended. If a building site is within the special study zone on sediments younger than $10,000 \mathrm{yr}$, then site-specific investigations would be required to prove that no faults are below the proposed structure in sediments younger than $10,000 \mathrm{yr}$.

\section{INTRODUCTION}

Surface faulting has been identified as a potential hazard in Utah and Juab Counties, Utah. This paper is an effort to address the problems associated with surface faulting, to suggest investigation methods, and to propose certain mitigation procedures. Much of the specific information on faults is from various studies by the U.S. Geological Survey and the Utah Geological Survey. Machette (1989) has prepared maps to show the known areas in Utah County where hazards exist from surfacefault ruptures. The purpose of this report is to discuss the nature of the hazard and its potential consequences and to give recommendations regarding the use of the maps and how the hazard should be addressed in land-use planning, development, and regulation. This work is one of several documents addressing natural hazards that has been translated for planners and other decisionmakers who have a limited geology background.

Utah and eastern Juab Counties are in north-central Utah (fig. 44) and along the base of the central portion of the Wasatch range. The range and the adjoining basin, of which Utah Valley is a part, are the result of millions of years of faulting, which caused the mountains to be uplifted and the basins to be downdropped along the Wasatch fault zone (WFZ). Although no surface ruptures have occurred along this fault zone in historic time, evidence gathered from detailed geologic studies of existing scarps indicates that large-magnitude earthquakes and accompanying surface ruptures have occurred repeatedly within the past $10,000 \mathrm{yr}$ and earlier.

Earthquakes are generated by movement along faults at depth. During large-magnitude earthquakes (Richter 


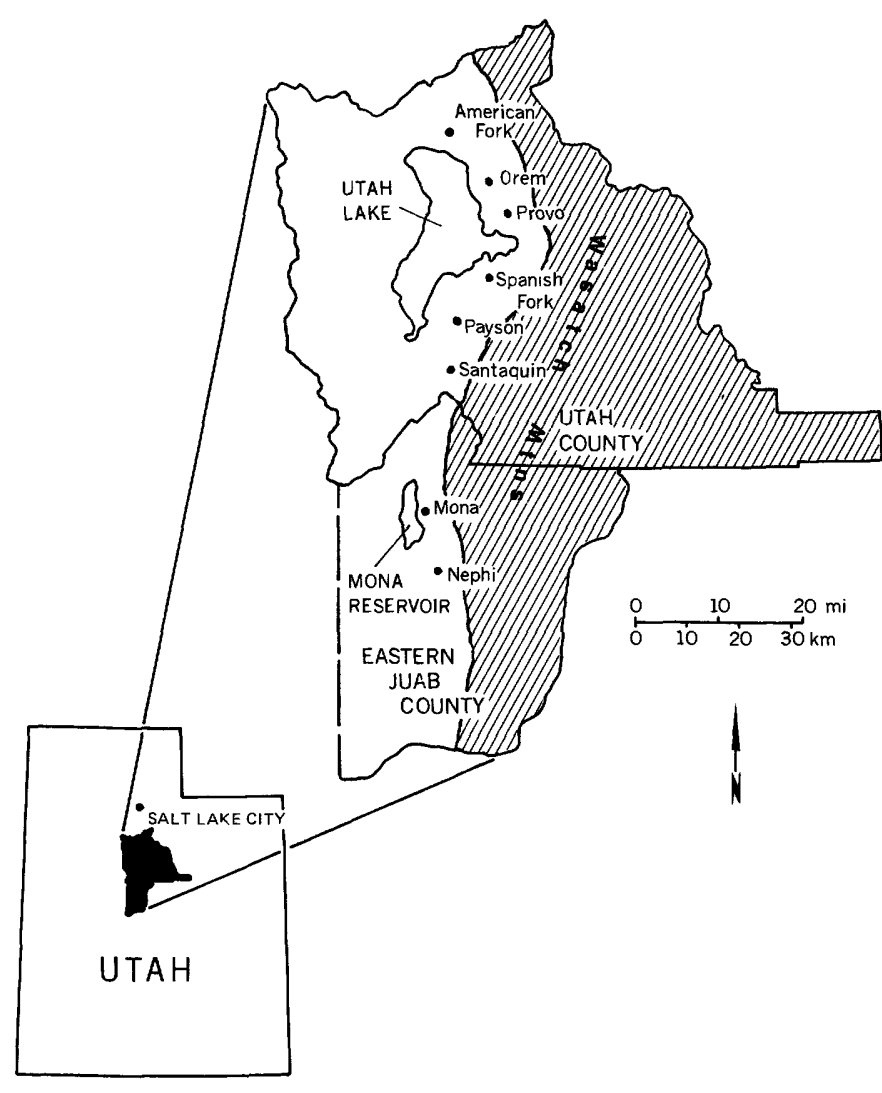

FIGURE 44. - Map showing the location of Utah and eastern Juab Counties, Utah. The Wasatch fault zone is located at the western base of the Wasatch Mountains.

magnitude $6.5+$ ), ruptures generally propagate to the surface as one side of the fault is uplifted and the other side is downdropped (fig. 45); the resulting (normal) fault scarp has a near-vertical slope. Broad subsidence of the valleys accompanying surface faulting may affect areas several miles (kilometers) away from the fault. These effects are not considered here but are covered in a separate report (Robison, "Tectonic subsidence hazard: A guide for land-use planning, Utah and Juab Counties, Utah," this volume).

\section{ACKNOWLEDGMENTS}

This paper was reviewed by Gary E. Christenson of the Utah Geological Survey (UGS), Michael N. Machette and William J. Kockelman (U.S. Geological Survey), Craig Nelson (Salt Lake County geologist), and Mike V. Lowe (Davis County geologist). William Lund (UGS) provided pertinent information as well as technical data in his review. Michael N. Machette also graciously furnished preliminary mapping from the Wasatch Front portion of the National Earthquake Hazards Reduction Program in addition to technical information. William D. Black (UGS) prepared the figures.

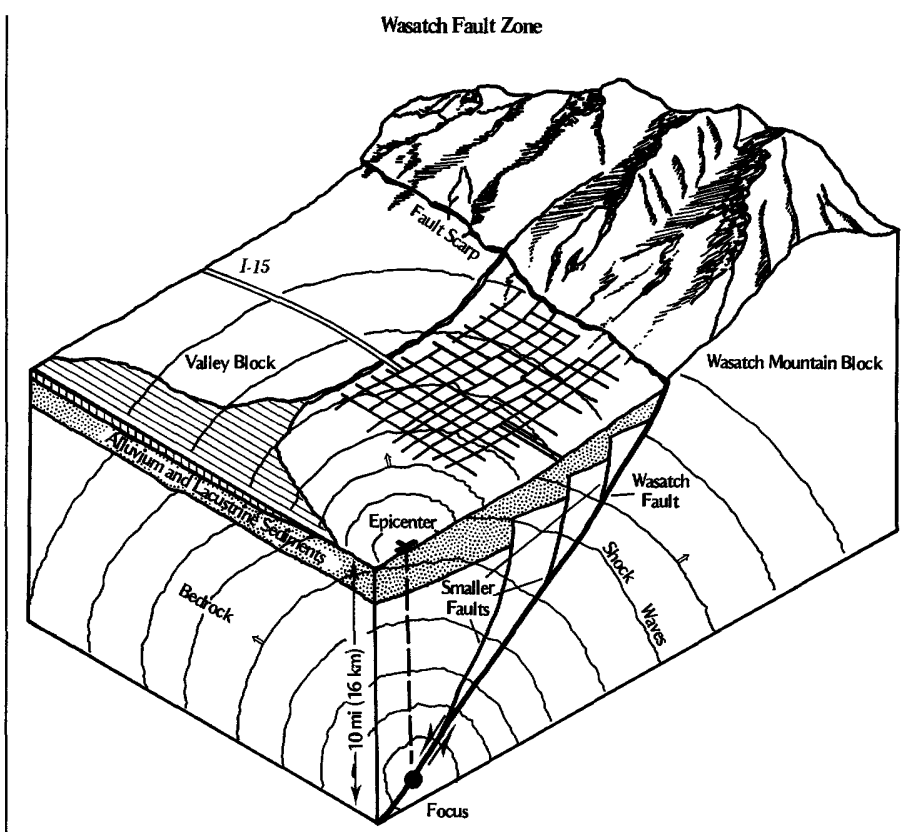

FIGURE 45. - Schematic diagram of the Wasatch fault zone showing the relation of the epicenter to the focus and the trace of the surface-fault rupture (fault scarp). The plane of the fault probably dips at $50^{\circ}-60^{\circ}$ toward the valley. The epicenter of the earthquake is located in the valley (downthrown block), not on the trace of the surface rupture (adapted from a special poster by the Utah Museum of Natural History).

\section{CHARACTERISTICS OF THE WASATCH FAULT ZONE}

The WFZ extends from near Malad City in southern Idaho to Fayette in central Utah, a distance of about 213 $\mathrm{mi}(343 \mathrm{~km})($ Machette and others, 1989). The fault zone trends roughly north-south and dips steeply to the west at the surface, as shown in figure 46 . The WFZ is not a single fault plane but a zone of deformation containing many individual subparallel faults. Where the zone intersects the surface, it commonly consists of one main down-to-the-west fault with a disturbed area, generally to the west on the downthrown side, as much as several hundred $\mathrm{ft}(\mathrm{m})$ wide, or possibly a series of down-to-thewest faults. This disturbed area, commonly termed the zone of deformation, contains small cracks and tilted or displaced blocks and may include a graben that is bounded on the west by a scarp formed by a down-tothe-east (antithetic) fault (fig. 46).

The entire length of the WFZ is not expected to rupture in any one earthquake. Instead, discrete segments of varying lengths rupture independently. Originally, 6 segments were proposed, but more recent studies indicate there may be as many as 10 or 11 (fig. 47) (Schwartz and Coppersmith, 1984; Machette and others, 1987, 1989). The most important aspect of the concept of segmentation is that segments control the length of the 


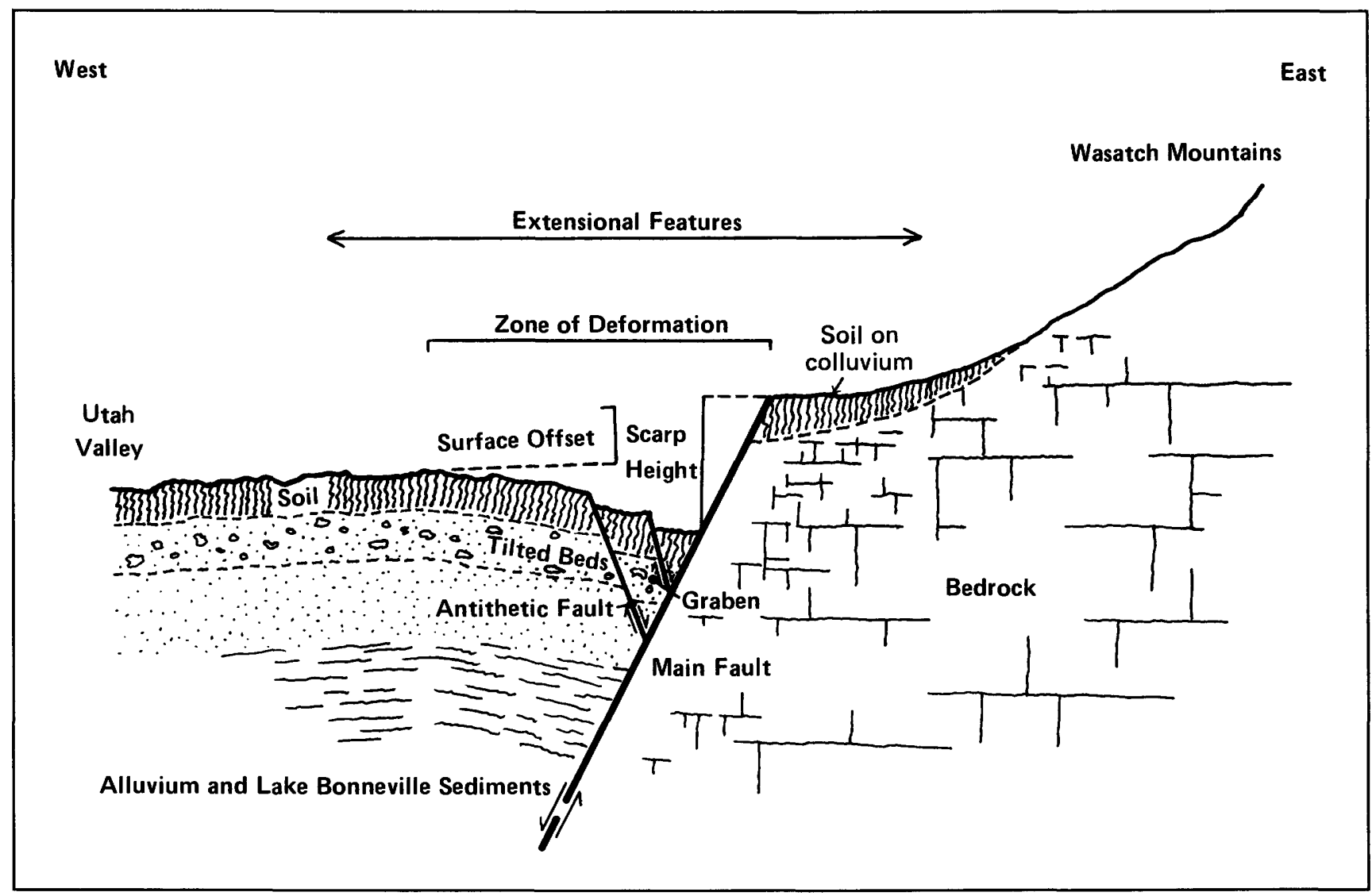

FIGURE 46. - Schematic diagram of a normal fault showing features typical of the Wasatch fault zone near the ground surface. Sketch is not to scale, but surface offset is usually about 6-9 ft (2-3 m). Note that the scarp height is commonly greater than the surface offset.

expected surface rupture, control the starting or stopping points of ruptures, and place physical constraints on the maximum magnitudes of potential earthquakes.

Several different analyses of the history of the WFZ suggest an event every $200-415$ yr. From a study that considered the number of surface-faulting earthquakes on the original 6 segments over the past $8,000 \mathrm{yr}$, Schwartz (1988) suggests that such earthquakes occur on the average every $200-400 \mathrm{yr}$, and studies that assessed 10 or 11 segments arrived at a similar recurrence of 340-415 yr (Machette and others, 1989; W.R. Lund, oral commun., 1988). The most recent rupture along the WFZ may have occurred on the Nephi fault segment in Juab County, between 300 and $500 \mathrm{yr}$ ago (Schwartz and Coppersmith, 1984), although Jackson and Ruzicka (1988) suggest a time of 500 or slightly more years ago.

Utah County and northeastern Juab County contain two (or more) of the segments defined by Machette and others (1989) (fig. 47). From north to south, these segments are the Provo segment (tentatively subdivided into the American Fork, Provo (restricted), and Spanish Fork subsegments) in Utah County and the Nephi segment in southern Utah and northeastern Juab Counties.
Details of segment length, average recurrence, and age of last movement are given in table 8 . The average recurrence of surface faulting along each segment varies but is generally between 1,300 and 2,700 yr (Machette and others, 1987).

Schwartz and Coppersmith (1984) did not differentiate subsegments for the Provo segment. The most recent studies (Machette and others, 1989; Machette, 1989), which should be consulted for a more complete discussion of segments and faulting, indicate that the Provo segment may consist of subsegments (table 8) that have nonpersistent boundaries. The Provo segment extends about $43.4 \mathrm{mi}(70 \mathrm{~km})$ from the boundary of Utah and Salt Lake Counties south to Payson Canyon (Machette and others, 1989) and includes the American Fork, Provo (restricted), and Spanish Fork subsegments.

The American Fork subsegment is $14.0 \mathrm{mi}(23 \mathrm{~km})$ long and extends from the middle of the Traverse Mountains to the mouth of Provo Canyon (Machette and others, 1987). Lake Bonneville deposits south of American Fork Canyon are offset 50-65 ft (15-20 m). Trenching investigations about $0.5 \mathrm{mi}(0.8 \mathrm{~km})$ south of the canyon revealed evidence for three surface-faulting events in the 


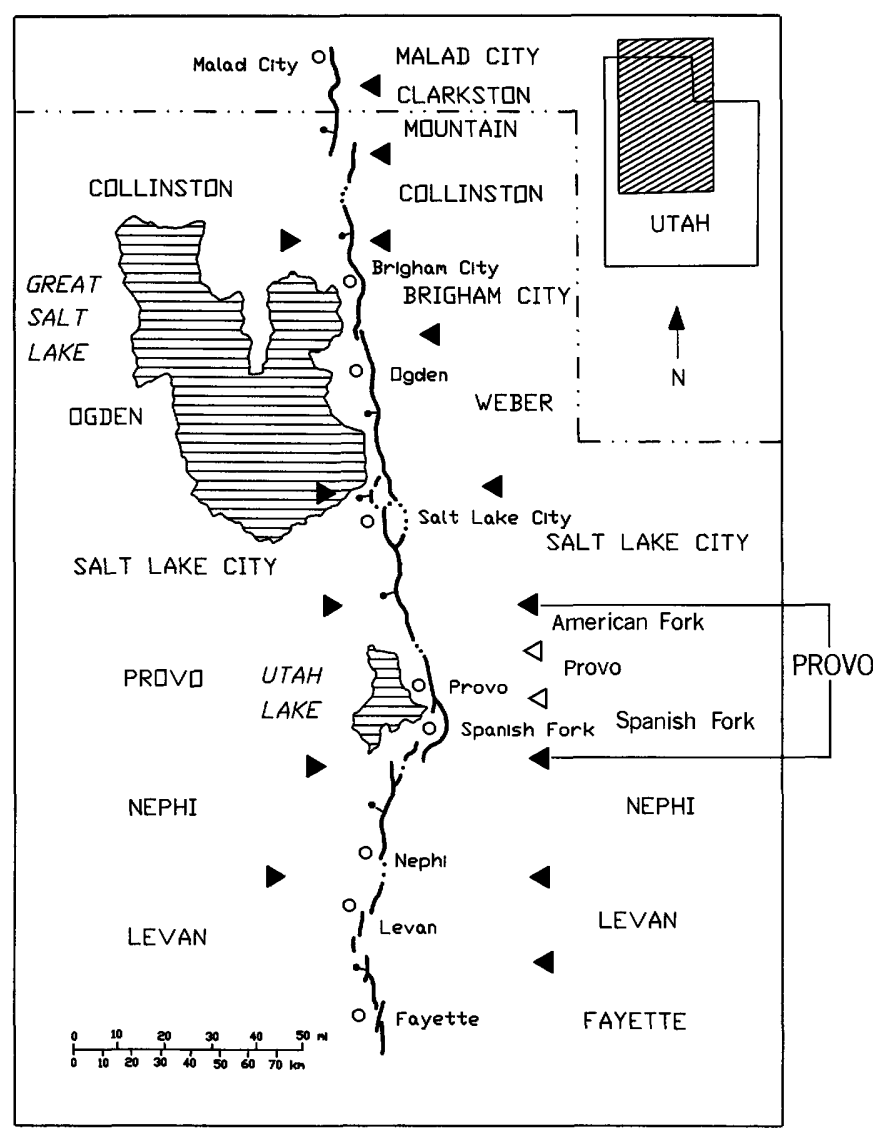

FIGURE 47. - Map showing boundaries and names for the Wasatch fault zone segments. Segment boundaries are noted by solid arrows. The left column is from Schwartz and Coppersmith (1984) and the right is from Machette and others (1989). The total number of identified segments has increased from 6 to 10 , possibly 11, depending on the persistence of the segment boundaries (represented by open arrows). The total number of segments determines the amount of potential generative earthquake zones (adapted from Machette and others, 1989). past 5,300 $\mathrm{yr}$, the most recent being about $550 \mathrm{yr}$ ago (Machette, 1988).

The Provo (restricted) subsegment extends from the Provo River south to Springville, where it overlaps the Spanish Fork subsegment, a total distance of about 11.5 $\mathrm{mi}(18.5 \mathrm{~km})$ (Machette and others, 1987). A trenching study at the mouth of Rock Creek Canyon indicated that the most recent surface rupture occurred between 500 and 1,000 yr ago. Surface offset in the trench was about $7 \mathrm{ft}(2 \mathrm{~m})$ and had an additional $8 \mathrm{ft}(2.5 \mathrm{~m})$ of tilt and deformation, which produced a scarp $15 \mathrm{ft}(4.5 \mathrm{~m})$ high.

The Spanish Fork subsegment extends from the north side of Springville City about $19.6 \mathrm{mi}(31.6 \mathrm{~km})$ south to the mountains behind Woodland Hills City. This segment was trenched about $1 \mathrm{mi}(1.2 \mathrm{~km})$ northwest of Hobble Creek (Swan and others, 1981; Schwartz and others, 1984), where evidence for six or possibly seven surfacefaulting events within the past $13,500 \mathrm{yr}$ was found. A multiple-trench investigation on the Spanish Fork segment near Mapleton revealed dates for the most recent event of 550-700 yr ago (W.R. Lund, oral commun., 1988). However, the U.S. Bureau of Reclamation found evidence for two events within the past 1,000 yr, which could suggest that the Spanish Fork subsegment had moved during earthquakes on both the Provo and Nephi segments.

The Nephi segment of the WFZ extends about $26.4 \mathrm{mi}$ $(42.5 \mathrm{~km})$ from near Payson in southern Utah County to Nephi in Juab County. This segment was first trenched at the mouth of North Creek and exhibits what is probably the most recent (about 300-500 yr old) rupture along the entire WFZ (Schwartz and Coppersmith, 1984). Jackson and Ruzicka (1988) trenched at Rock Creek near Nephi and reported three faulting events, the most recent being $500 \mathrm{yr}$ or older, which roughly agrees with previously published age estimates for the segment.

TABLE 8.-Data for the Wasatch fault zone in Utah and northeastern Juab Counties

[Segment names, lengths, recurrence intervals, displacement, and age information are taken from the references given and should be consulted for detailed explanations of the derivation of each parameter. Specific segment data are given in the text. See figure 47 for relation of listed segments to the entire Wasatch fault zone.]

\begin{tabular}{|c|c|c|c|c|c|c|c|c|c|}
\hline \multirow{3}{*}{ Segment or subsequent } & \multicolumn{4}{|c|}{ Length } & \multirow{3}{*}{$\begin{array}{l}\text { Recurrence } \\
\text { interval } \\
\text { (Average, yr) }\end{array}$} & \multirow{2}{*}{\multicolumn{2}{|c|}{$\begin{array}{l}\text { Displacement } \\
\text { per event }\end{array}$}} & \multirow{3}{*}{$\begin{array}{c}\text { Age of } \\
\text { most recent } \\
\text { surface } \\
\text { faulting (yr) }\end{array}$} & \multirow{3}{*}{ References } \\
\hline & \multicolumn{2}{|c|}{ Surface trace } & \multicolumn{2}{|c|}{ End to end } & & & & & \\
\hline & Miles & Kilometers & Miles & Kilometers & & Feet & Meters & & \\
\hline Provo (segment) & 43.1 & 69.5 & 36.9 & 59.5 & & & & & \\
\hline $\begin{array}{l}\text { American Fork } \\
\text { (subsegment). }\end{array}$ & 14.0 & 22.5 & 13.0 & 21.0 & 2,425 & $7.6-8.6$ & $2.3-2.6$ & about 550 & Machette (1988) \\
\hline $\begin{array}{l}\text { Provo (restricted, } \\
\text { subsegment). }\end{array}$ & 11.5 & 18.5 & 10.5 & 17.0 & - & & - & $>660-1000$ & $\begin{array}{l}\text { Machette and others } \\
\text { (1989). }\end{array}$ \\
\hline $\begin{array}{l}\text { Spanish Fork } \\
\text { (subsegment). }\end{array}$ & 19.5 & 31.5 & 14.9 & 24.0 & - & $5.3-7.6$ & $1.2-2.3$ & $550-700$ & $\begin{array}{l}\text { W.R. Lund (personal } \\
\text { commun., 1987). }\end{array}$ \\
\hline Nephi (segment) & 26.4 & 42.5 & 23.3 & 23.3 & $1,700-2,700$ & $6.6-8.3$ & $2.0-2.5$ & about 400 & $\begin{array}{l}\text { Jackson and Ruzicka } \\
\text { (1988); Schwartz and } \\
\text { Coppersmith (1984). }\end{array}$ \\
\hline
\end{tabular}


On individual segments of the WFZ, ruptures may occur every few hundred to a few thousand years. Detailed studies on the central segments of the fault zone indicated periods between surface faulting events that range from less than $1000 \mathrm{yr}$ to more than $3,000 \mathrm{yr}$, an individual segment average being 2035-2070 yr (Machette and others, 1989). However, it must be understood that the data are incomplete and imprecise and that events do not necessarily occur at regular intervals; recurrence on individual segments is quite variable (Schwartz, 1988). Thus, considering the previously mentioned recurrence interval of 200-666 yr for all segments and the time since the most recent event $(300-600 \mathrm{yr})$, earthquakes may be expected somewhere along the fault at any time.

There is some evidence that earthquakes on different segments may cluster in time and occur so closely together that they appear as one event in the geologic record. If clustering occurs, groups of earthquakes with very short time intervals (possibly weeks, months, or years) between events could occur sequentially along the WFZ. Then the average recurrence calculated for the entire fault (200-666 yr) could be misleading, and events may have occurred in more closely spaced clusters with larger periods between clusters. The recurrence estimates for earthquakes on individual segments would not change, however.

Other faults, perhaps capable of surface rupturing, have been located in Utah County. Dustin and Merritt (1980) reported faults beneath Utah Lake in an investigation of the hydrogeology of the lake (see Machette, 1989 , map). These faults may be $18 \mathrm{mi}(29 \mathrm{~km})$ long, are roughly parallel to the Wasatch fault, and exhibit evidence of movement within the past 15,000 yr. The faults do not pose a surface-fault rupture hazard to urbanized areas, but further work is needed to define recurrence intervals because ground shaking from an earthquake generated by these faults would significantly affect Utah Valley. Fault scarps also were noted in western Juab Valley (R.M. Robison, unpublished data, 1987), but little is known about these features.

\section{CONSEQUENCES OF SURFACE-FAULT RUPTURES AND REDUCTION OF HAZARDS}

Studies along the Wasatch fault have indicated that during a "characteristic" earthquake that produces surface faulting, offsets of $6 \mathrm{ft}(1.8 \mathrm{~m})$ or more (average 6.6 $\mathrm{ft}$, or $2 \mathrm{~m}$ ) may occur on the main trace of the fault zone (Schwartz and Coppersmith, 1984). This offset will result in formation of a near-vertical scarp, generally in unconsolidated surficial deposits, that begins to ravel and erode back to the material's angle of repose $\left(33^{\circ}-35^{\circ}\right)$ soon after formation. Antithetic faults west of the main trace may also form, generally exhibiting a lesser amount of offset, but sometimes as much as several feet (meters) (fig. 46). The zone between these two faults may be complexly faulted and tilted, with offset along minor faults of several inches or more. In some cases, a broad zone of flexure may form west of the main fault in which the surface is tilted downward toward the fault zone. An example of this warping is preserved south of the mouth of Hobble Creek, where backtilting extends more than $650 \mathrm{ft}(200 \mathrm{~m})$ from the fault, with a maximum dip of $3^{\circ}$ to the east.

It is difficult, both technically and economically, to design a structure to withstand $6 \mathrm{ft}(2 \mathrm{~m})$ or more of offset through its foundation. Youd (1980) indicates that displacements through a foundation of $2.5 \mathrm{ft}(0.76 \mathrm{~m})$ or more could cause collapses. Thus, avoidance of the main trace of the fault and preparedness to respond and rebuild are the principal reduction techniques that can be reasonably undertaken.

In some areas, adjacent to the main trace but still within the zone of deformation, avoidance may not be necessary. Less damaging (smaller) offsets and tilting may occur, and structural measures may be taken to reduce casualties and damage. However, structural damage may still be great, and buildings in the zone of deformation may not be safe for occupants following a large earthquake.

\section{USE OF SPECIAL STUDY ZONE MAPS}

Machette (1989) has prepared a map that shows the main traces of the WFZ in Utah County. This map is at a scale of 1:50,000 and clearly indicates the areas where surface-fault rupture hazards need to be considered. I have used this map as the basis to prepare the special study zone maps (fig. 48). The special study zone follows the mapped trace of the WFZ surface ruptures and is about $250 \mathrm{ft}(76 \mathrm{~m})$ wide on the upthrown side of the fault zone and $500 \mathrm{ft}(153 \mathrm{~m})$ wide on the downthrown side. The purpose of this zone is to delineate areas where site-specific investigations addressing surface-fault rupture hazards are recommended. Because the fault maps used to delineate these zones were prepared at a scale of $1: 50,000(1 \mathrm{in} .=0.79 \mathrm{mi})$, they are not detailed enough to delineate all fault traces and zones of deformation at a particular location; thus site-specific investigations are recommended in the study zone.

\section{SCOPE OF SITE INVESTIGATIONS}

The scope of site investigations will vary, depending on the proposed land use, nature of faulting, and amount 


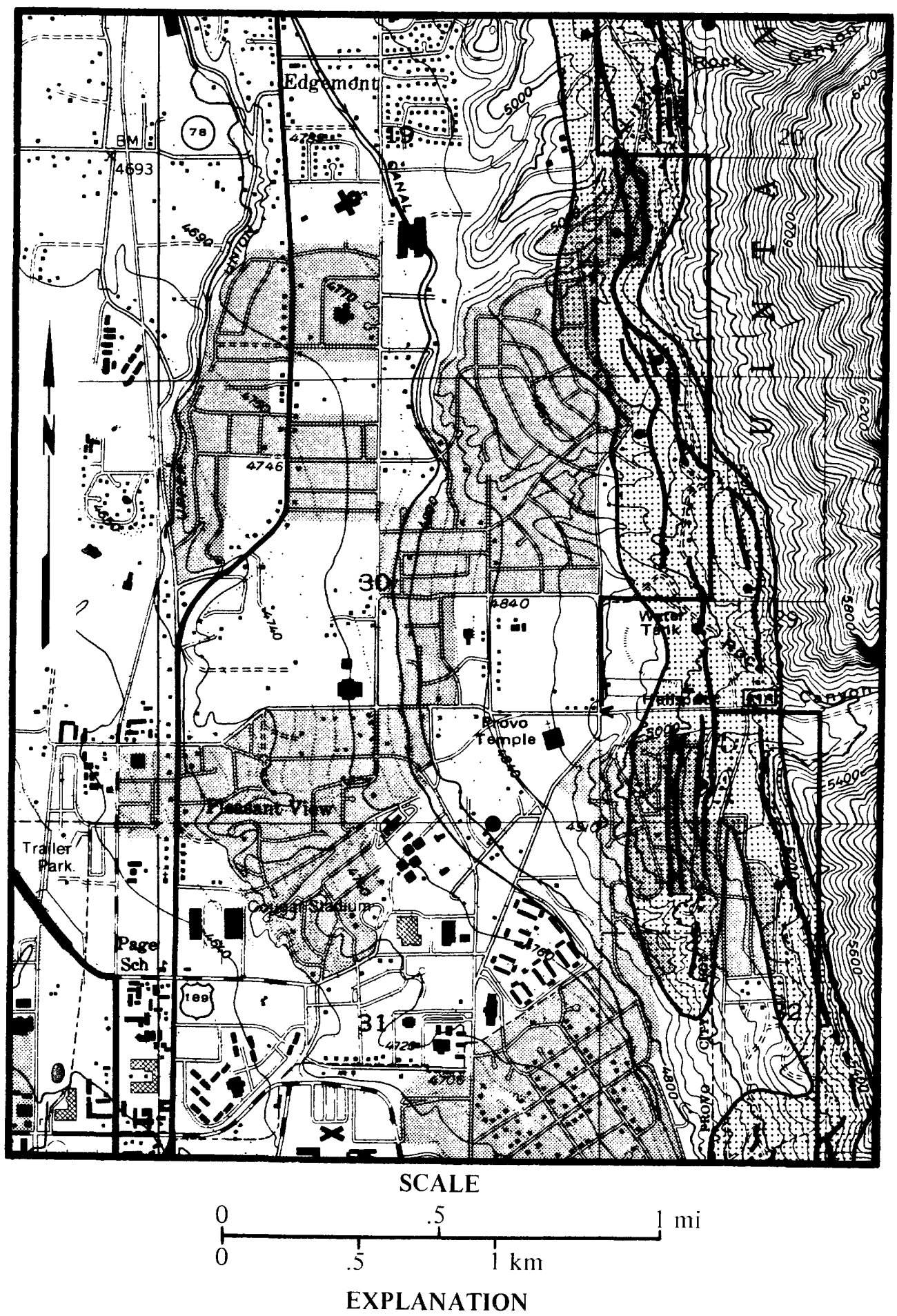

Wasatch Fault, bar and ball on downthrown side

Surface fault rupture hazard special study area

Figure 48. - Map showing the Wasatch fault zone at the mouth of Rock Canyon, Utah. Study zone surrounds the mapped trace of the fault and is 250 feet wide on the upthrown side and 500 feet wide on the downthrown side. Setback recommendations are discussed in the text. 
of preexisting disturbance of the surface. Prior to construction, a geotechnical report delineating the location of the faults and a suggested setback distance will be required. At undisturbed sites, the initial phase of the surface-faulting investigation should include mapping and topographic profiling of all suspected faults and scarps. Mapping consists chiefly of identifying fault scarps or other fault-related geomorphic features based on interpretation of aerial photographs and detailed field investigations. Topographic profiles (two-dimensional cross sections) of fault scarps should be made to define the features that are usually apparent from these profiles. Profiles should extend several hundred feet above and below the main fault scarp in order to provide the basic information needed to define standard fault setbacks.

In disturbed or geologically young areas, such as an active stream flood plain or farmed areas, the surficial material may be regraded or less than $10,000 \mathrm{yr}$ old and of sufficient thickness to conceal older faulted deposits and faults. These areas would require that site-specific studies contain recommendations for setback distances derived from projections of faults on adjacent property through the study area. If setback distances cannot be determined from projections, then trenching may be done to a depth that encounters undisturbed material older than $10,000 \mathrm{yr}$, to determine if faulting had occurred.

Studies by McCalpin (1987) indicate that a fault is commonly located at the midpoint of its scarp. It is recommended that structures be set back a minimum of $50 \mathrm{ft}(15 \mathrm{~m})$ from the midpoint of the scarp (fig. $49 \mathrm{~A})$ if the scarp angle does not reach 30 percent. If the scarp slope is 30 percent or greater, then the setback should be taken from the 30 percent slope break at the top and bottom of the scarp (fig. 49B). Following these recommendations should help keep structures from straddling the main, and potentially most dangerous trace of the fault but will not remove structures from the entire zone of deformation. If profiles indicate that backtilting, secondary faulting, or graben-bounding antithetic faults are present and a wide zone of deformation exists, a 50-ft (15-m) setback should be taken from the outermost antithetic fault (fig. $49 \mathrm{C}$ ) or, in areas of flexure and backtilting, from the area where the original prefault surface slope is regained. It is recommended that construction in the zone of deformation not be allowed unless detailed studies involving trenching are performed to define the hazard. Fault-trench investigations are used to accurately locate, characterize, and, in some cases, date past events at a specific location and to delineate the zone of deformation. Based on data from trenches, further recommendations can be made for variances from these minimum setback guidelines.

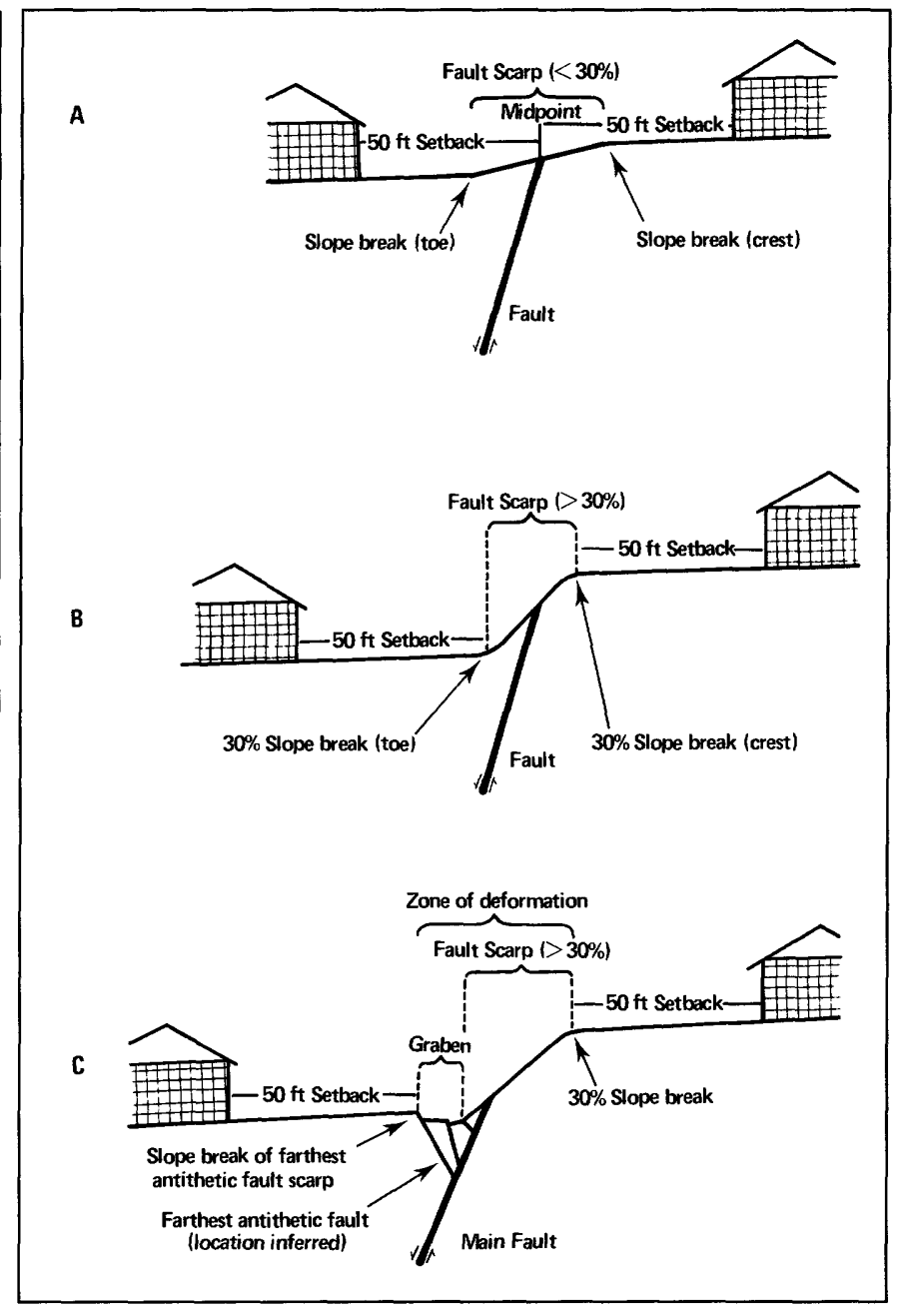

FIGURE 49.-Schematic diagram of recommended minimum setback distances relative to fault scarps in areas where trenching studies are not performed. Recommended setback distances are $(A) 50 \mathrm{ft}(\mathbf{1 5 . 2 5}$ $\mathrm{m}$ ) from the midpoint of a scarp that does not have a $30^{\circ}$ slope; $(B) 50$ $\mathrm{ft}(15.25 \mathrm{~m})$ from the top and bottom slope break on a scarp that has $30^{\circ}$ or more slope; and $(C)$ for scarps where a graben is present, $50 \mathrm{ft}$ $(15.25 \mathrm{~m})$ from the 30 percent slope break at the top and $50 \mathrm{ft}(15.25$ m) from the farthest antithetic fault scarp.

At sites where the surface is disturbed but the causative faults cannot be located on the basis of surface evidence, trenching of proposed locations of structures is recommended. In some cases, it would be advisable to offset trenches (along the strike of the fault) from actual building foundations to avoid adversely affecting soil foundation conditions with trench backfill. A publication from the Utah Section of the Association of Engineering Geologists (1987) lists guidelines for performing surfacefault rupture investigations and preparing reports, and it should be consulted prior to performing such studies. Recommendations include consulting the county geologist to further clarify the scope of investigation and types of information that should be obtained from such a study. 
Once site-specific reports have been completed, they should be reviewed by the county geologist; then problems should be discussed and resolved prior to submittal to the planning commission for approval.

The information in this paper is the most accurate available as of August 1989. Much research is being conducted along the Wasatch Front, and the text that accompanies the surface-fault rupture hazard zone maps will be updated periodically as necessary. As they become available, new and more accurate fault locations will also be added to the accompanying maps. The text and maps are kept on file at the Utah County Planning Office and Utah County recorder's office.

\section{REFERENCES}

Arabasz, W.J., 1984, Earthquake behavior in the Wasatch Front area-Association with geologic structure, space-time occurrence, and stress state, in Hays, W.W., and Gori, P.L., eds., Workshop on "Evaluation of regional and urban earthquake hazards and risk in Utah": U.S. Geological Survey Open-File Report 84-763, p. $310-339$.

Bucknam, R.C., and Anderson, R.E., 1979, Estimation of fault scarp ages from a scarp-height-slope-angle relationship: Geology, v. 7, p. 11-14.

Colman, S.M., and Watson, Ken, 1983, Ages estimated from a diffusion equation model for scarp degradation: Science, v. 221, p. 263-265.

Dustin, J.D., and Merritt, L.B., 1980, Hydrology of Utah Lake with emphasis on Goshen Bay: Utah Geological and Mineral Survey Water Resources Bulletin 23, $50 \mathrm{p}$.

Federal Emergency Management Agency, 1984, National Earthquake Hazards Reduction Program-Fiscal year 1984 activities: Report to the United States Congress, $192 \mathrm{p}$.

Hays, W.W., and Gori, P.L., eds., 1987, A workshop on "Earthquake hazards along the Wasatch Front, Utah": U.S. Geological Survey Open-File Report 87-154, 146 p.

Jackson, M.E., and Ruzicka, J., 1988, Holocene paleoseismic history of the Levan and Nephi segments, Wasatch fault zone, Utah, Application of the thermoluminescence (TL) method: Geological Society of America Abstracts With Programs, v. 20, no. 5, p. 54.

M: chette, M.N., 1988, American Fork Canyon, Utah-Holocene faulting, the Bonneville fan-delta complex, and evidence for the Keg Mountain oscillation, in Machette, M.N., ed., In the footsteps of G.K. Gilbert-Lake Bonneville and neotectonics of the eastern Basin and Range province, guidebook for field trip twelve: Utah Geological and Mineral Survey Miscellaneous Publication 88-1, $120 \mathrm{p}$.

Machette, M.N., 1989, Preliminary surficial geologic map along the Wasatch fault zone in the eastern Utah Valley, Utah County, and parts of Salt Lake and Juab Counties, Utah: U.S. Geological Survey Miscellaneous Field Studies Map MF-2109, scale 1:50,000.

Machette, M.N., and Lund, W.R., 1987, Late Quaternary history of the American Fork segment of the Wasatch fault zone, Utah:
Geological Society of America Abstracts With Programs, v. 19, no. 5, p. 317.

Machette, M.N., Personius, S.F., Scott, W.E., and Nelson, A.R., 1987, Quaternary geology along the Wasatch Front: Evidence for ten fault segments and large-scale changes in slip rate along the Wasatch fault zone, in Gori, P.L., and Hays, W.W., eds., Assessment of regional earthquake hazards and risk along the Wasatch Front, Utah: U.S. Geological Survey Open-File Report 87-585, p. A1-A72.

Machette, M.N., Personius, S.F., Nelson, A.R., Schwartz, D.P., and Lund, W.R., 1989, Segmentation models and Holocene movement history of the Wasatch fault zone, Utah, in Schwartz, D.P., and Sibson, R., eds., Proceedings of conference XLV-Fault segmentation and controls on rupture initiation and termination: U.S. Geological Survey Open-File Report 89-315, p. 229-242.

McCalpin, James, 1987, Recommended setbacks from active normal faults, in McCalpin, James, ed., Proceedings of the 23rd symposium on engineering geology and soils engineering: Utah State University Press, Logan, Utah, p. 35-56.

Nelson, A.R., and Personius, S.F., 1987, A nonconservative barrier to Holocene rupture propagation in the northern Wasatch fault zone, Utah [abs.]: Proceedings of XII INQUA congress, July 31 to August 9, Ottawa, Canada.

Robison, R.M., 1988, Surface fault rupture hazard and tectonic subsidence maps for the Wasatch Front, Utah: Geological Society of America Abstracts With Programs, v. 20, no. 6, p. 465.

Schwartz, D.P., 1988, Geologic characterization of seismic sources -Moving into the 1990s, in Von Thun, J.L., ed., Recent advances in ground-motion evaluation: American Civil Engineers Geotechnical Special Publication 20, p. 1-42.

Schwartz, D.P., and Coppersmith, K.J., 1984, Fault behavior and characteristic earthquakes-Examples from the Wasatch and San Andreas fault zones: Journal of Geophysical Research, v. 89, no. B7, p. 5681-5698.

Schwartz, D.P., Swan, F.H., and Cluff, L.S., 1984, Fault behavior and earthquake recurrence along the Wasatch fault zone, in Hayes, W.W., and Gori, P.L., A workshop on "Evaluation of regional and urban earthquake hazards and risk in Utah": U.S. Geological Survey Open-File Report 84-763, p. 113-125.

Smith, R.B., and Richins, W.D., 1984, Seismicity and earthquake hazards of Utah and the Wasatch Front-Paradigm and paradox, in Hays, W.W., and Gori, P.L., eds., A workshop on "Evaluation of regional and urban earthquake hazards and risk in Utah": U.S. Geological Survey Open-File Report 84-763, p. 73-112.

Swan, F.H., II, Hanson, K.L., Schwartz, D.P., and Kneupfer, P.L., 1981, Study of earthquake recurrence intervals on the Wasatch fault at the Little Cottonwood Canyon site, Utah: U.S. Geological Survey Open-File Report 81-450, $30 \mathrm{p}$.

Utah Section of the Association of Engineering Geologists, 1987, Guidelines for evaluating surface fault rupture hazards in Utah: Utah Geological and Mineral Survey Miscellaneous Publication N, $2 \mathrm{p}$.

Youd, T.L., 1980, Ground failure displacement and earthquake damage to buildings: American Society of Civil Engineers 2d conference on civil engineering and nuclear power, Knoxville, Tenn., v. 2, p. 7-6-2-7-6-26. 


\title{
LANDSLIDE HAZARDS: A GUIDE FOR LAND-USE PLANNING, DAVIS COUNTY, UTAH
}

\author{
By Robert M. Robison ${ }^{11}$ and Mike Lowe ${ }^{12}$
}

\begin{abstract}
Landslides pose one of the most common geologic hazards in Davis County, Utah, where more than 700 slides have been identified and mapped. Landslides are downslope, mass movements of earth materials under the influence of gravity. Many types of landslides occur in Davis County. This report addresses only translational and rotational landslides and associated earth flows. Potential for damage to structures, rupture of underground water lines and sewers, and damming of streams with resultant catastrophic flooding exists in areas susceptible to landsliding in Davis County.

Two sets of landslide-hazard maps showing where landslides exist or are considered likely to occur in the future have been produced for Davis County. The first set of landslide-hazard maps shows where landslides are likely to occur in the absence of earthquakes. This set of maps was constructed by overlaying geologic maps, slope maps, and landslide-inventory maps and combining areas of known landslides, landslide-prone geologic units, and areas having slope greater than 30 percent into a landslide-hazard special study zone. The second set of landslide-hazard maps delineates areas where landslides are likely to occur in the event of an earthquake. This set of maps was produced by combining data on the strength of earth materials, slope geometry, ground-water conditions, and magnitude of ground shaking to determine where earthquake-induced landslides may occur throughout Davis County. Zones or areas having probabilities of earthquakeinduced landslides ranging from high to very low are shown on these earthquake-induced landslide-potential maps.

Static (nonearthquake) slope-stability studies of specific sites are recommended prior to planning commission approval of new development within the special study zone for landslide hazards. It is recommended that dynamic (earthquake-induced) landslide potential be evaluated for specific sites prior to planning commission approval of critical facilities, lifelines, and high-occupancy industrial and commercial buildings in areas of high or moderate earthquake-induced landslidepotential ratings.
\end{abstract}

\section{INTRODUCTION}

Landsliding historically has been one of the most damaging geologic processes occurring in Davis County, both in the unincorporated county and in many cities. All active landslides and most older slides have been mapped at a scale of 1:24,000 to produce landslide-inventory

\footnotetext{
${ }^{11}$ Utah County Planning Department, Provo, Utah.

12 Davis County Planning Department, Farmington, Utah.
}

maps. These maps serve as an indication of unstable ground. The landslide inventories, along with slope maps and other geologic data, have been used to evaluate slope stability on a broad scale and to prepare landslide-hazard maps. These hazard maps show areas of landslides and slopes that are potentially unstable under static (nonearthquake) conditions. Separate dynamic (earthquakeinduced) landslide-hazard maps have been prepared for Davis County by Keaton and others (1987). This report describes landslide hazards and recommends guidelines for use of both landslide-hazard maps and earthquakeinduced landslide-potential maps in land-use planning. A major goal is to translate technical information so that government officials and the general public can appreciate the need to reduce landslide hazards.

\section{ACKNOWLEDGMENTS}

Gary E. Christenson, Utah Geological Survey; William J. Kockelman and Rex Baum, U.S. Geological Survey; Craig Barker, Weber County Planning Department; and Wilf Sommerkorn and Barry Burton, Davis County Planning Department, kindly reviewed this paper and provided valuable suggestions. Bill Black, Utah Geological Survey, drafted the figures.

\section{LANDSLIDE CHARAGTERISTICS}

Landslides are generally defined as "mass movements of rock or soil downslope under the direct influence of gravitational forces without an aiding transporting medium such as water, air, or ice" (Costa and Baker, 1981, p. 243). Landslides considered in the landslidehazard maps include rotational and translational slides and associated earth flows (Varnes, 1978). Rotational slides generally have a curved failure plane. The head of the rotational slide is backtilted in comparison with the slope of the original surface. Most rotational slides are termed slumps and may include an earth flow at the toe, 


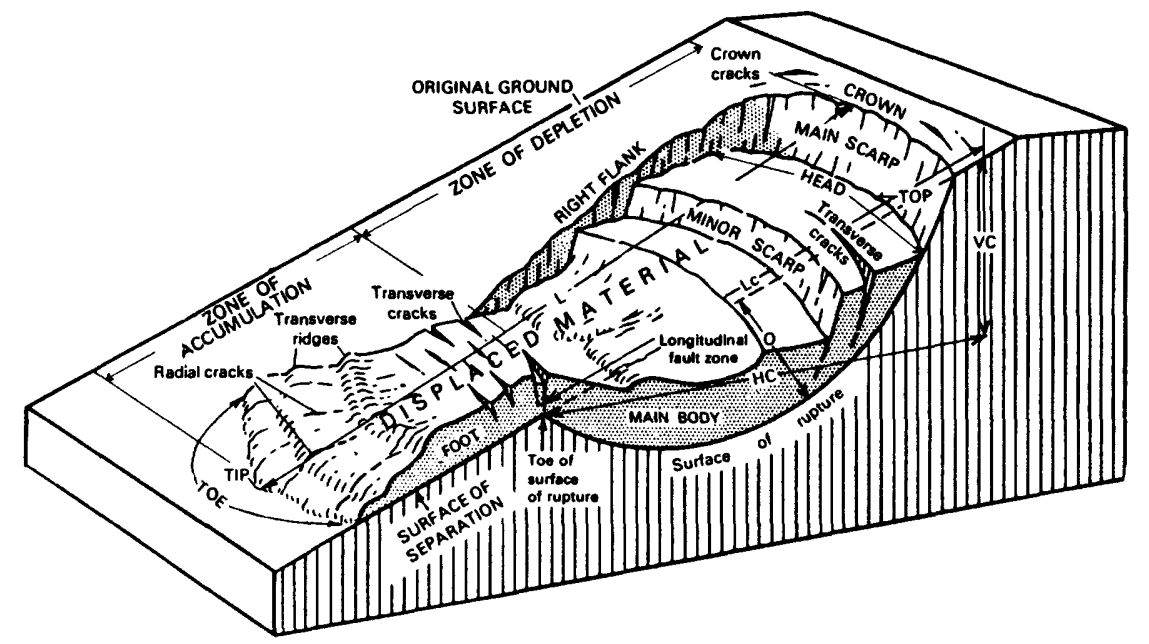

Figure 50. - Block diagram of a rotational landslide. Note the backtilt below the main scarp and material at the zone of accumulation at the toe. If this landslide was translational, then the surface of rupture (failure plane) would be planar like the surface of separation beneath the foot (adapted from Varnes, 1978).

where material moves onto the land surface below the slump (fig. 50). Translational slides generally have a more planar failure surface and may be broken into several discrete blocks. If rock is involved, the term rock slide may be used. The speed of landslides may vary. Both slide types may occur slowly and progressively over periods of years, or may be extremely rapid and occur within a few seconds. The landslide-hazard maps do not address rockfalls or debris flows, which are other types of failures commonly grouped under the term landslides.

Landslides may be caused by any of several conditions. Oversteepening of slopes, loss of lateral support, weighting of the head, increased pore pressure, and earthquake ground shaking are among the major causes of landslides. Older landslides are particularly susceptible to reactivation due to conditions that exist in a displaced soil mass such as increased permeability and established failure planes.

Landslides are likely to occur in Davis County if a moderate to strong earthquake occurs in northern Utah. Ground failures, including landslides, commonly accompany earthquakes with Richter magnitudes greater than 4.5 (Keefer, 1984). Some form of landslide or ground failure (predominantly rockfall or rockslide) has been noted in the descriptions of 12 earthquakes that occurred in or immediately adjacent to Utah from 1850-1986 with magnitudes 4.3-6.6 (Keaton and others, 1987). Geologic evidence from trench excavations across Wasatch fault zone scarps indicates that past earthquakes on the Wasatch fault had magnitudes ranging from 7.0-7.5 (Schwartz and Coppersmith, 1984). It is expected that future Wasatch fault earthquakes will have similar magnitudes. Earthquakes of magnitude 7.5 could cause slope failures as far as $185 \mathrm{mi}(300 \mathrm{~km})$ from the epicenter (Keaton and others, 1987).

Landslides are also likely to occur in years of abnormally high precipitation. Many landslides occurred in Davis County during the recent wet cycle (1982-1985), causing significant damage to homes and property. The Memorial Day 1983 Rudd Canyon debris flow damaged 35 houses, 15 severely, and resulted in deposition of more than $100,000 \mathrm{yd}^{3}\left(80,000 \mathrm{~m}^{3}\right)$ of earth material at the canyon mouth. The debris flow was initiated by landsliding of less than $20,000 \mathrm{yd}^{3}\left(15,000 \mathrm{~m}^{3}\right)$ in the Wasatch Mountains (Wieczorek and others, 1983).

\section{CONSEQUENCES}

Damage from a landslide can occur at any point on the slide mass and above or below the landslide. The tops of most landslides are characterized by an arcuate downhillfacing scarp (main scarp) created by the downward displacement of the ground surface (fig. 50). A building straddling the main scarp would lose partial foundation support and would potentially collapse. Structures upslope from the head of a landslide are endangered because the newly formed main scarp is commonly unstable and may fail, causing new scarps to form upslope. Buildings constructed within the central mass of the landslide may be subjected to differential displacement on minor scarps and movement in both vertical and horizontal directions. Table 9 shows the relationship between ground displacement and expected levels of damage to structures. The toe of a landslide will normally move horizontally and upward and may proceed downslope, causing extensive damage to structures. Cracks at 
TABLE 9.-Relationship between ground displacement and damage to structures (from Youd, 1980)

\begin{tabular}{ll}
\hline Ground displacement & Level of expected damage \\
\hline Less than 4 in. & Little damage, reparable \\
4 in. to $1 \mathrm{ft}$ & Severe damage, reparable \\
1 to $2 \mathrm{ft}$ & Severe damage, nonreparable \\
More than $2 \mathrm{ft}$ & Collapse, nonreparable \\
\hline
\end{tabular}

the head and a bulge at the toe may precede the principal landslide movement. Landslides can damage roads, railroads, and power lines. Furthermore, landslides may rupture canals, aqueducts, sewers, and water mains and thereby add water to the slide plane and promote further movement. In addition to ground movement, flooding may be caused by landslides. Flooding may occur due to discharge from springs along the basal slide plane (example, landslide located on 1500 East Street, Provo, Utah), usually in the toe area, or damming of streams that causes upstream flooding as water is ponded and possible downstream flooding if the impounded water overtops or breaches the landslide dam. Spring discharge from landslides is a minor problem and can generally be mitigated by diverting drainage. Damming of streams is a major problem (Schuster, 1987) and was a principal hazard associated with the Thistle landslide in 1983 in Utah County. Lake Thistle, which had a maximum depth of about $225 \mathrm{ft}(69 \mathrm{~m})$, formed behind the landslide mass and flooded the town of Thistle. A much larger and more populated area downstream was at risk from flooding had the landslide failed or been overtopped and washed out prior to draining of the lake. Another landslide that caused similar problems was the Gros Ventre landslide in Wyoming, where 6 or 7 people were killed in the flood that ensued $2 \mathrm{yr}$ after the landslide event (Costa and Baker, 1981).

\section{LANDSLIDE SUSCEPTIBILITY}

Several geologic units in Davis County are susceptible to landslides. Landslide-prone geologic units were identified by overlaying landslide-inventory and geologic maps and tabulating the number of landslides occurring in each geologic unit. The Precambrian Farmington Canyon Complex in the mountains in eastern Davis County weathers in a manner that provides much unstable hillside debris (colluvium), and debris slides are common. Debris slides in colluvium derived from the Farmington Canyon Complex were responsible for initiating many of the debris flows that occurred in 1983 and 1984. Landslides are also common in areas underlain by the sediments of Pleistocene Lake Bonneville. Rotational landslides (slumps) are particularly common in northern Davis County, where stream incision into the Weber River Delta has created high bluffs and exposed silts and clays deposited during the high stand of Lake Bonneville. The many springs that occur along these bluffs increase landslide susceptibility.

Existing landslides pose a particular problem for development because of their tendency to reactivate. Many landslides in the mountains and along the bluff above the city of South Weber are reactivated landslides or have developed on portions of larger older landslides.

Slope steepness is another important factor in determining slope stability. Almost any material will fail if the slope is steep enough.

Landslides may also be triggered by earthquake activity. Although the same slopes that are considered unstable under static conditions will be even less stable during an earthquake, some slopes that are stable under static conditions may fail as a result of earthquake ground shaking, particularly if the earthquake occurs when slopes are wet. Most landslides caused by earthquakes are new slope failures, not reactivated older landslides.

\section{REDUCING LANDSLIDE HAZARDS}

Many methods have been developed for reducing landslide hazards. Proper planning and avoidance are the least expensive measures, if landslide-prone areas are identified early in the planning and development process. Care in site grading with proper compaction of fills and engineering of cut slopes is a necessary followup to good land-use planning. Where avoidance is not feasible, various engineering techniques are available to stabilize slopes. Dewatering (draining) can have a major impact on stabilizing both slopes and existing landslides. Retaining structures built at the toe of a landslide may help stabilize the slide and reduce the possibility of smaller landslides. In some cases, piles may be driven through the landslide mass into stable material beneath the slide. If the dimensions of the landslide are known and the landslide is not excessively large, removing the landslide may be effective. Landslide hazards may also be reduced by bridging, weighting or buttressing slopes with compacted earth fills, and drainage diversion. A more complete list of landslide-hazard reduction techniques may be found in the works of Costa and Baker (1981) and Kockelman (1986) and other engineering geology publications. Every landslide and potentially unstable slope will probably have differing characteristics and will need to be evaluated for an appropriate hazard reduction technique.

\section{SUMMARY OF METHODS USED IN MAP PREPARATION}

Landslide-inventory maps (figs. 51 and 52) showing existing landslides in Davis County have been compiled 


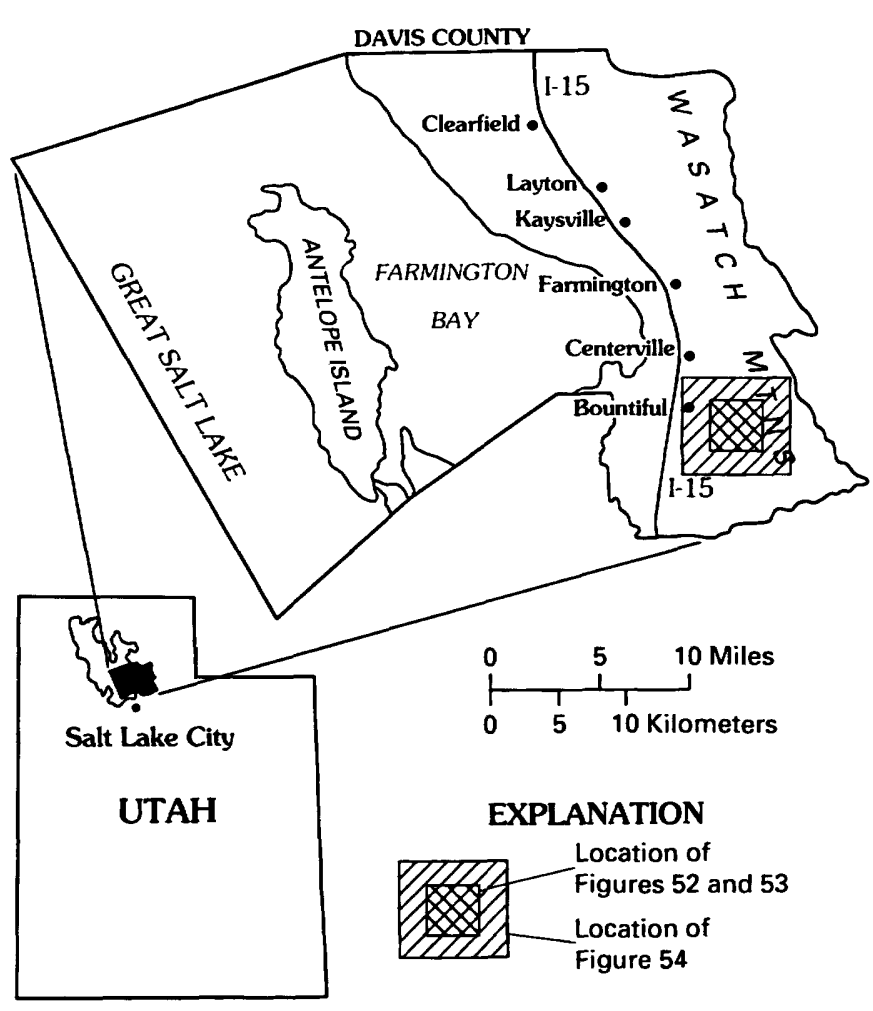

FIGURE 51. - Location map for figures 52, 53, and 54.

at 1:24,000 scale using U.S. Geological Survey topographic quadrangles as base maps. The following parameters were evaluated while preparing the landslideinventory maps: (1) landslide type, compiled from existing data and air photo interpretation using a classification scheme developed by Varnes (1978); (2) age class of landslides, using a classification scheme developed by McCalpin (1984); (3) elevation of the toe and crown of the landslide; (4) average prelandslide slope; (5) failed geologic unit, as determined from existing geologic mapping; (6) other geologic units involved; (7) slope aspect; (8) landslide complexity (multiple landslides); and (9) the role of humans in causing the failure. If the same landslide was mapped by more than one investigator and discrepancies were found in the mapping of the perimeter of the landslide, the two maps were overlaid and the outermost margin of the landslide on the combined maps was used.

The landslide-inventory maps and slope maps were then used to assess the susceptibility for slope failure on natural slopes under static conditions and to help construct 1:24,000-scale landslide-hazard maps (figs. 51 and 53). Slopes steeper than 30 percent have a relatively high potential for failure and are generally already subject to land-use restrictions for reasons other than slope stabil- ity. These slopes are therefore included in the recommended study area on the landslide-hazard maps. In certain failure-prone materials such as fine-grained Lake Bonneville deposits, failures have occurred at slopes less than 30 percent. These flatter areas with existing landslides have also been included in the recommended study area on the landslide-hazard maps.

In those areas where unstable slopes are surrounded by flatter, more stable slopes, it is necessary to extend the boundaries of the landslide-hazard study beyond the base and top of the unstable slope. This situation occurs along the bluff above South Weber and along incised drainages in Layton and Kaysville, where the potential instability in the steeper slope (bluff face) may affect areas both above and below. The width of the landslidehazard study area in this situation depends on the height, steepness, ground-water conditions, and strength of the material making up the slope. In these areas of flat land above and below landslide-prone slopes, a conservative stable slope angle was taken through the center of the steep slope to determine where slope-stability studies were needed for the flatter land. Rollins, Brown, and Gunnel, Inc. (1977) determined that this conservative slope angle should be two horizontal to one vertical (2:1, or 50 percent) for dry granular soils and 2.5:1 (40 percent) for moist fine-grained material. In general, these zones extend less than 100-150 ft from the base or top of slopes and are too narrow to be shown at the map scale.

Earthquake-induced landslide-potential maps (1:48,000 scale) for Davis County (figs. 51 and 54) have been prepared by Keaton and others (1987) using 50 percent reductions of U.S. Geological Survey topographic quadrangles as base maps. In evaluating seismic slope stability, Keaton and others (1987) considered the strength of slope materials, slope geometry, ground-water conditions, and the strength or intensity of earthquake ground shaking. These parameters were evaluated to determine the level (magnitude) of ground shaking necessary to cause slope instability in each type of earth material found in Davis County, for various slopes and slope geometries, and for dry and saturated ground-water conditions (Keaton and others, 1987). The probability that this level of ground shaking would occur during a 100-yr time period was then determined and used to define geographic areas of high, moderate, low, and very low potential for seismic slope failure (Keaton and others, 1987). Table 10 summarizes each category of earthquake-induced landslide potential with respect to the probabilities that the critical accelerations needed to induce failure in each category would be exceeded in a 100 -yr time period and the possible levels of displacement associated with that failure. 


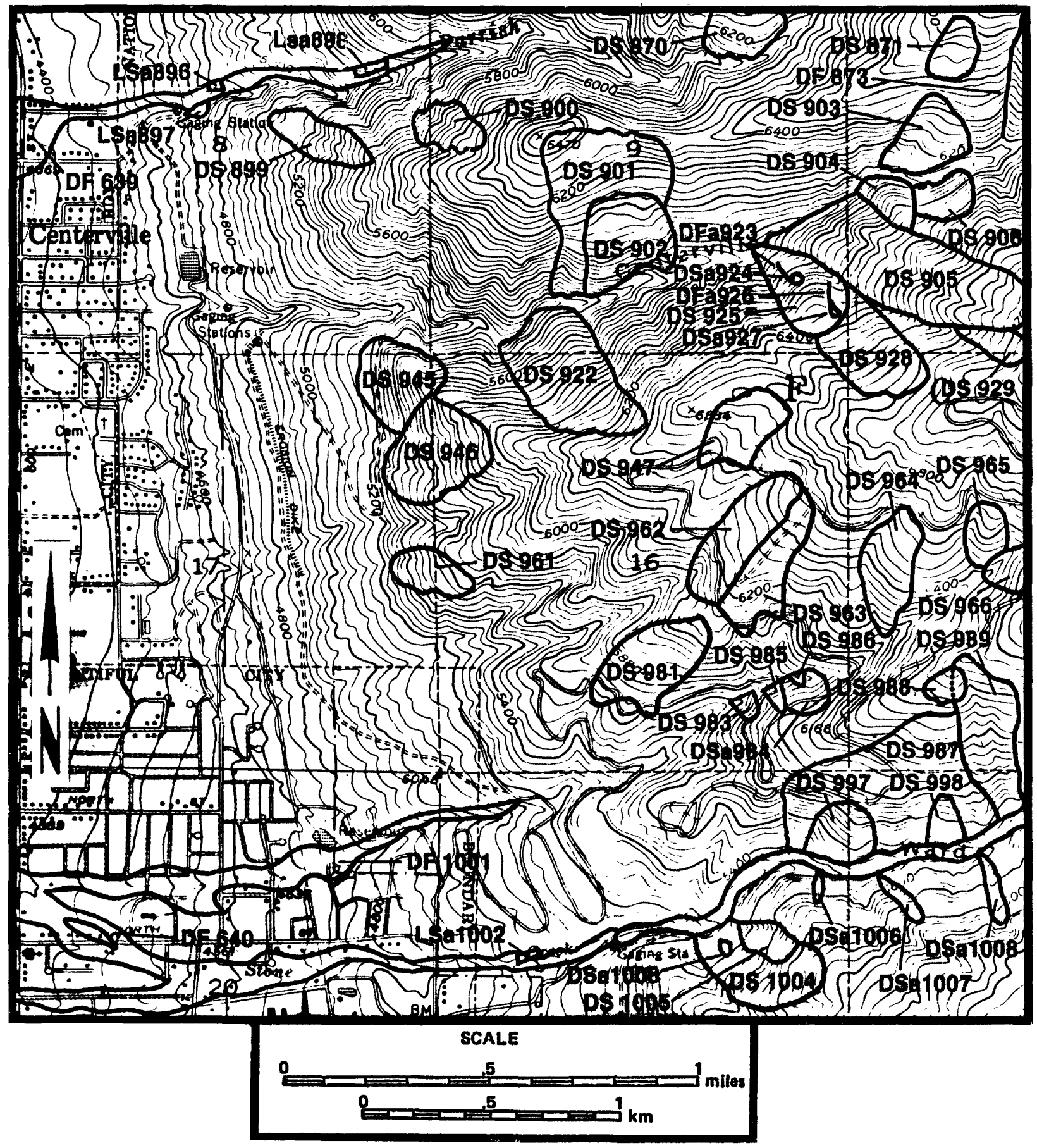

FIGURE 52. - Landslide-inventory map for the Centerville and northern Bountiful area of southern Davis County, Utah. DS, shallow failure, chiefly debris slides; DF, debris flow; LS, deep failure, chiefly slumps and earth flows; a, active (historic) slope failure; 123 , inventory number for slope failure. Reproduced

\section{RECOMMENDED USE OF MAPS FOR LAND-USE PLANNING AND DEVELOPMENT}

The landslide-hazard maps that accompany this report show areas of existing landslides and potential landslide from a portion of the slope-failure inventory map, Bountiful Peak Quadrangle. Original mapping by Keaton (1986), Nelson and Personius (1988), Olson (1981), and Lowe (unpublished Davis County Planning Commission maps).

hazard at 1:24,000 scale using U.S. Geological Survey $7 \frac{1}{2} 2^{\prime}$ (topographic) quadrangles as base maps. These maps are chiefly intended for use by planners to identify areas where site-specific investigations addressing slope stability should be performed prior to development. It is 


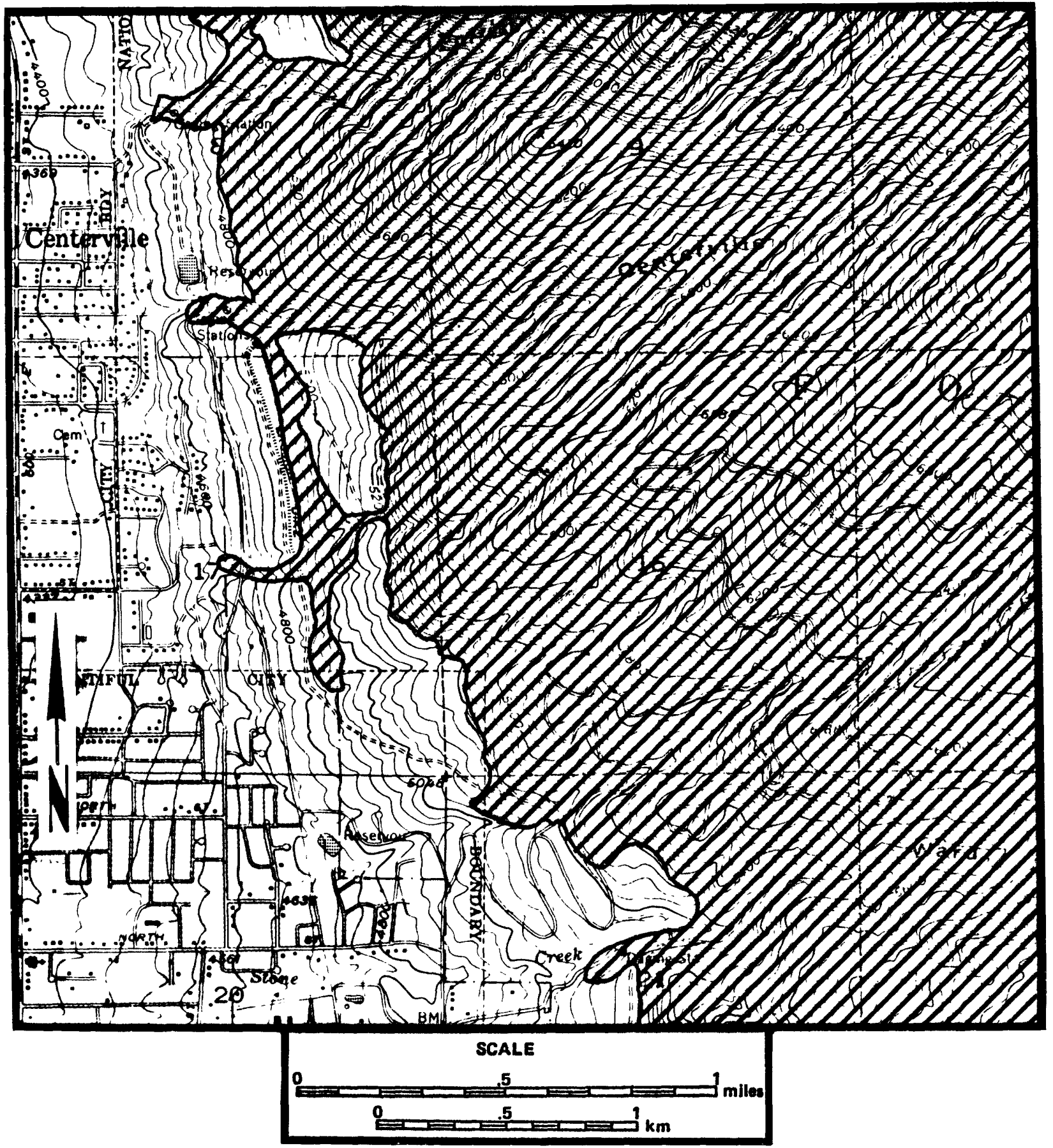

FigURE 53. - Landslide-hazard map for the Centerville and northern Bountiful area of southern Davis County, Utah. Cross hatching indicates areas where slope-stability studies are recommended prior to planning commission approval of proposed development. This figure was reproduced from a portion of the landslide-hazard map, Bountiful Peak Quadrangle, Davis County, Utah, by Lowe (unpublished Davis County Planning Commission maps).

recommended (table 11) that slope-failure potential be evaluated and, if necessary, mitigative measures be recommended by an engineering geologist in site-specific reports. The developer then submits these reports to the planning commission prior to approval of the development.

The results of the earthquake-induced landslidepotential study are presented on a 1:48,000-scale map 

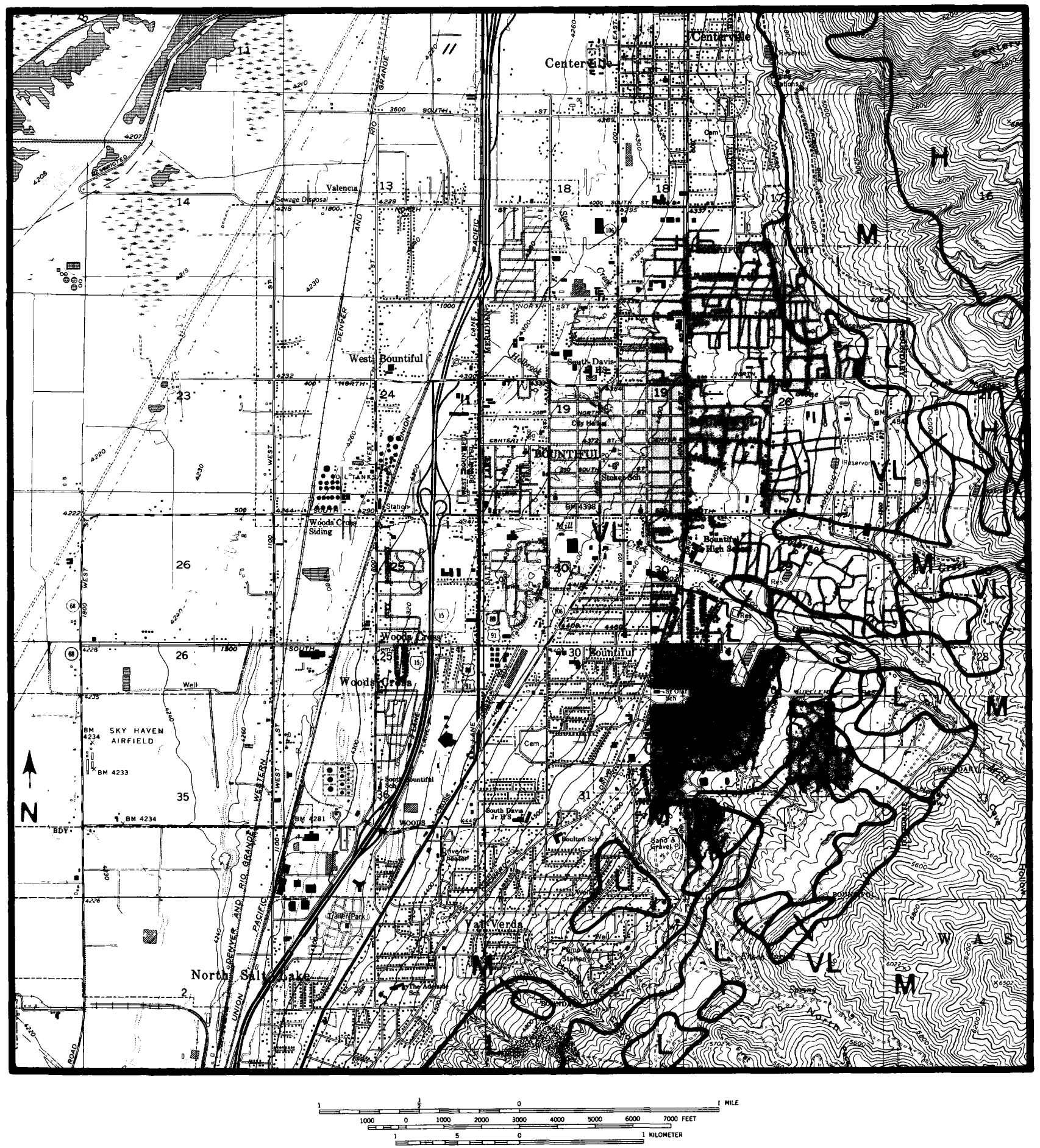

FiguRE 54. - Earthquake-induced landslide-potential map for the Centerville and northern Bountiful area of southern Davis County, Utah. Landslide potential is rated by S, landslide; VL, very low; L, low; M, moderate; and $\mathrm{H}$, high. This figure was reproduced from a portion of the earthquake-induced landslide-potential map (south half) for Davis County, Utah, by Keaton and others (1987).

that separates Davis County into a south half and a north half. The earthquake-induced landslide-potential rating for a given location can be determined by locating the site on the map. The approximate probability that ground shaking sufficient to induce slope failure, for both dry and wet soil conditions, would occur during a 100-yr period for the landslide-potential rating given on the map may then be determined by referring to the proper 
TABLE 10.-Earthquake-induced landslide potential categories, soil moisture levels considered, probability of exceedence of critical acceleration needed to cause failure during 100-yr period, and possible magnitudes of displacement (from Keaton and others, 1987)

\begin{tabular}{llll}
\hline $\begin{array}{c}\text { Seismic } \\
\text { slope-failure } \\
\text { potential }\end{array}$ & $\begin{array}{c}\text { Soil moisture } \\
\text { conditions }\end{array}$ & $\begin{array}{c}\text { Probability of critical } \\
\text { acceleration necessary } \\
\text { to cause } \\
\text { slope failure } \\
\text { being exceeded } \\
\text { in a 100-yr } \\
\text { time period (percent) }\end{array}$ & $\begin{array}{c}\text { Possible } \\
\text { levels of } \\
\text { displace- } \\
\text { ment } \\
\text { (in.) }\end{array}$ \\
\hline High & Dry and wet & 50 or greater & 4 or more \\
\hline Moderate & Dry & 10 to 50 & 1 to 4 \\
& Wet & 50 or greater & 4 or more \\
\hline Low & Dry & Less than 10 & Less than \\
& Wet & 10 to 50 & 1 \\
\hline Very low & Dry and wet & 10 or less & $\begin{array}{l}\text { Less than } \\
1\end{array}$ \\
\hline
\end{tabular}

category in table 10. It is recommended (table 12) that earthquake-induced landslide potential be evaluated and, if necessary, mitigative measures be recommended by an engineering geologist in site-specific reports. The developer then submits these reports to the planning commission prior to approval of the development.

Both the landslide-hazard and the earthquake-induced landslide-potential maps provide a general indication of where slope-failure hazards may exist and serve as a means for evaluating the need for site-specific studies. These maps are at a regional scale and, although they can be used to gain an understanding of the potential that landslides will occur in a given area, are not designed to replace site-specific evaluations. Mapped areas rated as having landslide hazards or a high potential for earthquake-induced landsliding may contain isolated

TABLE 11.-Recommended requirement for site-specific investigations of slope stability for various classes of facilities proposed within Davis County, Utah

\begin{tabular}{lcc}
\hline Facility class & $\begin{array}{c}\text { Areas within } \\
\text { landslide- } \\
\text { hazard area }\end{array}$ & $\begin{array}{c}\text { Areas outside } \\
\text { landslide-hazard } \\
\text { area }\end{array}$ \\
\hline $\begin{array}{l}\text { Critical facilities, including } \\
\text { lifelines and high- } \\
\text { occupancy buildings. }\end{array}$ & Yes & Yes \\
$\begin{array}{l}\text { Industrial and commercial } \\
\text { buildings (other than high } \\
\text { occupancy). }\end{array}$ & Yes & No \\
$\begin{array}{l}\text { Residential subdivisions } \\
\text { Residential single lots }\end{array}$ & Yes & No \\
\hline
\end{tabular}

TABLE 12.-Recommended requirement for site-specific investigations of seismic slope stability for various classes of facilities in different earthquake-induced landslide-potential zones

\begin{tabular}{lcc}
\hline Facility class & $\begin{array}{c}\text { Zones of high to } \\
\text { moderate potential } \\
\text { for earthquake- } \\
\text { induced landslides }\end{array}$ & $\begin{array}{c}\text { Zones of low to } \\
\text { very low potential } \\
\text { for earthquake- } \\
\text { induced landslides }\end{array}$ \\
\hline $\begin{array}{c}\text { Critical facilities, includ- } \\
\text { ing lifelines and high- } \\
\text { occupancy buildings }\end{array}$ & Yes & Yes \\
$\begin{array}{c}\text { Industrial and commer- } \\
\text { cial buildings (other } \\
\text { than high occupancy) }\end{array}$ & Yes & No \\
$\begin{array}{c}\text { Residential subdivisions } \\
\text { Residential single lots }\end{array}$ & $\mathrm{No}^{1}$ & \\
\hline
\end{tabular}

\footnotetext{
${ }^{1}$ Appropriate disclosure should be required.
}

areas that are not prone to landsliding, even during earthquake ground shaking. Also, areas outside the landslide-hazard study boundary, or rated as having a low earthquake-induced landslide potential, may contain isolated areas that are highly susceptible to landsliding.

\section{SCOPE OF SITE INVESTIGATIONS}

Site evaluations for landslides and potentially unstable slopes, including earthquake-induced landslides, should be performed prior to construction of any structures for human occupancy, as outlined in tables 11 and 12. The investigation should include accurate maps of the area showing the proposed development, existing landslides and steep slopes, and the site geology. An assessment of present slope stability and the effects of development on slope stability should be included. Where necessary, a factor of safety should be computed by a competent geotechnical engineer or engineering geologist to determine the stability of natural or proposed cut slopes. Slope-stability analyses should include potential for movement under static, development-induced, and earthquake-induced conditions as well as all likely ground-water conditions. Site grading, including design of cuts and fills, should comply with chapter 70 of the 1988 Uniform Building Code. A useful guide for preparing site-investigation reports is found in the publication by the Utah Section of the Association of Engineering Geologists (1986). Site-investigation reports should be reviewed by the county geologist and other appropriate officials. This review will determine if the submitted report is adequate and complete. As more accurate information becomes available, the landslide-hazard maps will be amended. 


\section{REFERENCES}

Costa, J.E., and Baker, V.R., 1981, Surficial geology, Building with the earth: New York, John Wiley and Sons, 498 p.

Keaton, J.R., 1986, Landslide inventory and preliminary hazards assessment, southeast Davis County, Utah: Association of Engineering Geologists 29th Annual Meeting Program With Abstracts, San Francisco, Calif., p. 53.

Keaton, J.R., Anderson, L.R., Topham, D.E., and Rathbun, D.J., 1987, Earthquake-induced landslide potential in and development of a seismic slope stability map of the urban corridor of Davis and Salt Lake Counties, Utah: Salt Lake City, Utah, Dames and Moore Consulting Engineers, and Logan, Utah, Department of Civil and Environmental Engineering, Utah State University, $47 \mathrm{p}$.

Keefer, D.K., 1984, Landslides caused by earthquakes: Geological Society of America Bulletin, v. 95, p. 406-421.

Kockelman, W.J., 1986, Some techniques for reducing landslide hazards: Association of Engineering Geologists Bulletin, v. 23, no. 1, p. 29-52.

McCalpin, J.P., 1984, Preliminary age classification of landslides for inventory mapping: Twenty-first annual symposium on engineering geology and soils engineering, April 5-6, 1984.

Nelson, A.R., and Personius, S.F., 1988, Preliminary surficial geologic map of the Weber segment, Wasatch fault zone, Weber and Davis Counties, Utah: U.S. Geological Survey Miscellaneous Field Studies Map MF-2132, scale 1:50,000.

Olson, E.P., 1981, Geologic hazards of the Wasatch Range, Part 1, Ward Canyon to south side Ogden Canyon: U.S. Department of
Agriculture, Forest Service, R-4 Intermountain Region, unpublished maps of selected quadrangles within U.S. Forest Service boundaries, scale 1:24,000.

Rollins, Brown, and Gunnel, Inc., 1977, Provo City hazards study: Unpublished consultant's report, $28 \mathrm{p}$.

Schuster, R.L., 1987, Landslide damming of mountain streams: Geological Society of America Abstracts With Programs, v. 19, no. 5, p. 332 .

Schwartz, D.P., and Coppersmith, K.J., 1984, Fault behavior and characteristic earthquakes-Examples from the Wasatch and San Andreas fault zones: Journal of Geophysical Research, v. 89, no. B7, p. 5681-5698.

Utah Section of the Association of Engineering Geologists, 1986, Guidelines for preparing engineering geologic reports in Utah: Utah Geological and Mineral Survey Miscellaneous Publication M, $2 \mathrm{p}$.

Varnes, D.J., 1978, Slope movement and types and processes, Landslides-Analysis and control: Washington, D.C., Transportation Research Board, National Academy of Sciences, Special Report 176, chap. 2, p. 11-33.

Wieczorek, G.F., Ellen, Stephen, Lips, E.W., Cannon, S.H., and Short, D.N., 1983, Potential for debris flow and debris flood along the Wasatch Front between Salt Lake City and Willard, Utah, and measures for their mitigation: U.S. Geological Survey Open-File Report 83-635, $45 \mathrm{p}$.

Youd, T.L., 1980, Ground failure displacement and earthquake damage to buildings: American Society of Civil Engineers conference on civil engineering and nuclear power, 2d, Knoxville, Tenn., v. 2, p. 7-6-2-7-6-26. 


\title{
ROCKFALL HAZARDS: A GUIDE FOR LAND-USE PLANNING, SALT LAKE COUNTY, UTAH
}

\author{
By Craig V. Nelson ${ }^{13}$
}

\begin{abstract}
Rockfalls along the Wasatch Front are common natural events that pose a threat to development. Rockfall hazard maps for special study areas have been prepared for Salt Lake County by identifying source areas and by computer simulating rockfall runout distances along the Wasatch Front. An existing Salt Lake County ordinance prohibits building on slopes greater than 30 percent, and computer models indicate that rocks typically do not run out onto slopes less than 30 percent. Where models suggest runout onto slopes that are less than 30 percent, the longest computed runout distance is used to define a conservative boundary to the special study area. Because of the general nature and small scale of the hazard map, new developments proposing to place structures in a rockfall hazard special study area must conduct site-specific rockfall hazard investigations to define hazard areas and either avoid or reduce the hazard.
\end{abstract}

\section{INTRODUCTION}

Rockfalls are a naturally occurring erosional process in mountain areas along the Wasatch Front. For the purposes of land-use planning, the definition of rockfall used in this study has been broadened to include both rockfalls (newly detached rocks from a bedrock source) and debris falls (rock clasts originating from coarse-grained unconsolidated deposits such as glacial till and colluvium). As urban development advances further onto the bench areas and into the canyons, the risk from falling rocks becomes greater. The purpose of this report is to explain how the rockfall hazards special study area maps were made and how they should be used. This information can benefit land-use planners, developers, real estate agents, and the general public by imparting information on potential hazards and ultimately helping to avoid casualties and damage.

\section{ACKNOWLEDGMENTS}

F.T. Lee and W.J. Kockelman (U.S. Geological Survey), Gary Christenson and Bill Case (Utah Geological

\footnotetext{
${ }^{13}$ Delta Geotechnical Consultants, Inc., Salt Lake City, Utah.
}

Survey), and Jerry Barnes (Salt Lake County Planning) all reviewed drafts of this paper and offered helpful suggestions. R.P. Sharon (Barrick Goldstrike Mines) provided the ROCKFALL program.

\section{CHARACTERISTICS OF ROCKFALLS}

Rockfalls originate when erosional processes and the pull from gravity dislodge rocks from slopes. The most susceptible slopes are those with outcrops broken by bedding surfaces, joints, or other discontinuities into abundant, loose individual fragments called clasts. Boulders in alluvium and glacial till on hillsides also contain clasts that may dislodge and fall. When the clast falls or rolls from the slope, it may travel great distances by rolling, bouncing, and sliding.

A primary mechanism responsible for triggering rockfalls is water freezing in outcrop discontinuities. When this confined water freezes and exerts pressure that exceeds the force that is keeping the discontinuity closed, frost shattering may occur. In Norway, for example, 60 percent of all rockfalls occur in April and May during maximum snowmelt and in October and November during periods of heavy rainfall (Costa and Baker, 1981). In both cases there is water seeping into the rocks when the temperature is fluctuating around the freezing point.

In mountainous areas, rockfalls are probably the most common form of slope instability initiated by the ground shaking from earthquakes (Keefer, 1984). Case (1987a) estimates that a major Wasatch Front earthquake (magnitude 7-7.5) could produce thousands of rockfalls along the Wasatch Front. Keefer (1984) indicates that rockfalls may occur in earthquakes as small as magnitude 4.0. In the August 1988 San Rafael Swell local magnitude $\left(M_{L}\right)$ 5.3 earthquake in central Utah (fig. 55), hundreds of rockfalls occurred, temporarily obscuring the surrounding cliffs in clouds of dust.

\section{EFFECTS OF ROCKFALLS}

Rockfalls present a hazard because of the potential damage that a large rock impact could cause to struc- 


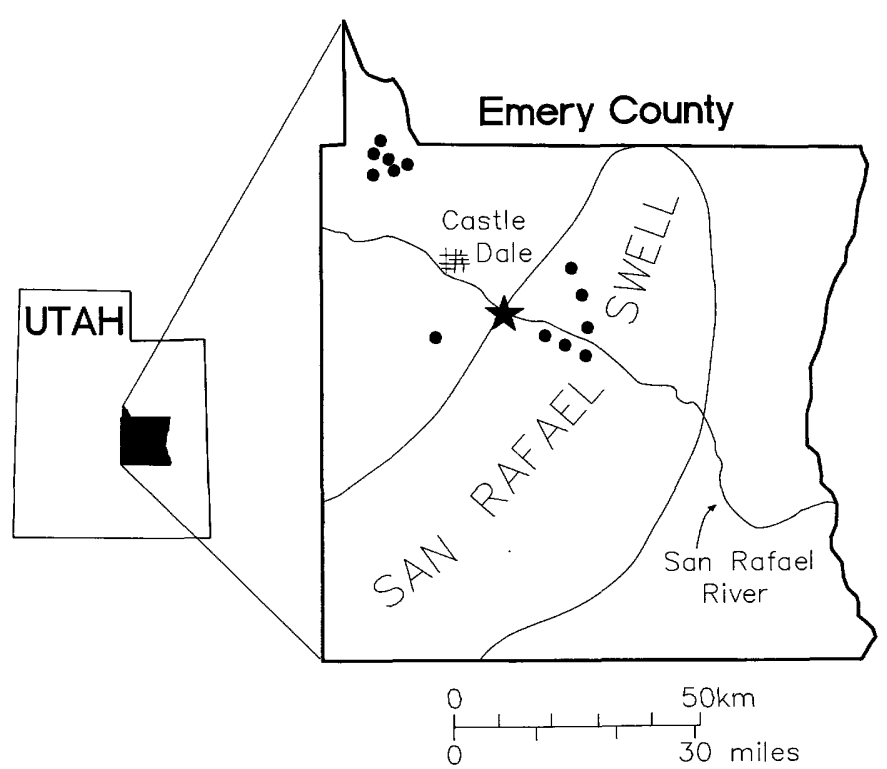

Figure 55. - Location map of the August 14, 1988, San Rafael Swell, Utah, earthquake, $M_{L} 5.3$, which triggered rockfalls up to $30 \mathrm{mi}$ (48 $\mathrm{km}$ ) from the epicenter. The star represents the location of the main shock; the solid dots represent individual rockfall locations (modified from Case (1988) and Nava and others (1988)).

tures and persons. Rockfalls that occur in remote or uninhabited regions go largely unnoticed. It is only when falling rocks pose a threat to human life that rockfalls must be considered in land-use planning and development regulations.

A 1987 rockfall event near Dead Horse Point, Utah, was large enough to register on seismographs more than $60 \mathrm{mi}(96 \mathrm{~km})$ away (fig. 56). Locally, rockfalls have historically caused problems along canyon roads by blocking traffic or occasionally striking vehicles. The structures most often affected by rockfalls in canyons are exposed aqueducts. Water service from Wasatch Front canyons has been periodically suspended due to damage to aqueducts from falling rocks. Homes built along the mountain front are also subject to rockfalls. Development in some high-foothill subdivisions in northeastern Salt Lake City has exposed boulders that become unstable through weathering of the supporting sediments and eventually roll downslope (fig. 57).

\section{EVALUATING ROCKFALL SUSCEPTIBILITY}

The primary factor in determining if an area is susceptible to rockfalls is the presence of a source for rockfall clasts. If there are no rocks on a slope, the rockfall hazard below becomes negligible. Case (1987c, 1989) identified all the range-front slopes, called spurs, along the Wasatch Front on which a rockfall source was found. The other major factor in identifying rockfall hazards is the distance a dislodged rock will travel downslope. These two factors-source and distance-can be combined to provide reasonable estimates of areas susceptible to rockfalls, which are then classified as special study areas (Nelson, 1988).

The runout limit for each susceptible spur was determined using ROCKFALL, a computer simulation model program (Hoek, 1987). The program uses representative slope profile information for each spur and is based on two assumptions: that the slope surfaces are clean, hard bedrock, and that the rockfall is initiated from a 20 -fthigh $(6.1 \mathrm{~m})$ outcrop. Rockfall events were simulated originating both at the top of each spur and at the steepest point on the spur. Rocks were started both with no initial velocity (simple gravity fall), and with an initial velocity (throw) (fig. 58). The combination of these factors (origination point and initial velocity) that yielded the longest runout distance was used as the lower limit of the special study area. It is believed that this represents a worst case rockfall event and provides some margin of safety.

The Salt Lake County Hillside Protection Zone ordinance prohibits building on slopes greater than 30 percent; therefore, all such slopes automatically fall into the special study area. The rockfall analyses suggest that, in general, most rocks would stop above the 30 percent slope break, making this slope the lower boundary of the study area. The runout continued below the 30 percent slope break onto gentler slopes on only 19 percent of the spurs. The special study area boundary between spurs follows the 30 percent slope break and includes all canyon areas. No studies have been performed in canyons, where all slopes are considered susceptible.

\section{REDUCING ROCKFALL HAZARDS}

When faced with any geologic hazard, the best alternative, where feasible, is avoidance. Therefore, it is best for developers to first try to locate buildings so that structures are not positioned in an area susceptible to rockfalls. Often, however, new developments cannot be designed around a rockfall path, or the rockfall paths cannot be accurately predicted, so hazard-reduction measures must be considered. When faced with land-use decisions, the costs of hazard reduction should be carefully compared with the costs of avoidance.

Techniques for reducing rockfall hazards may include mitigation of the actual hazard or modifying the exposed structure or facility. Rock stabilization techniques such as bolting, cable lashing, burying, and grouting discontinuities, as well as the removal or breakup of potential rockfall clasts, are all physical methods of mitigating the hazard. Deflection berms, slope benches, and rock-catch 


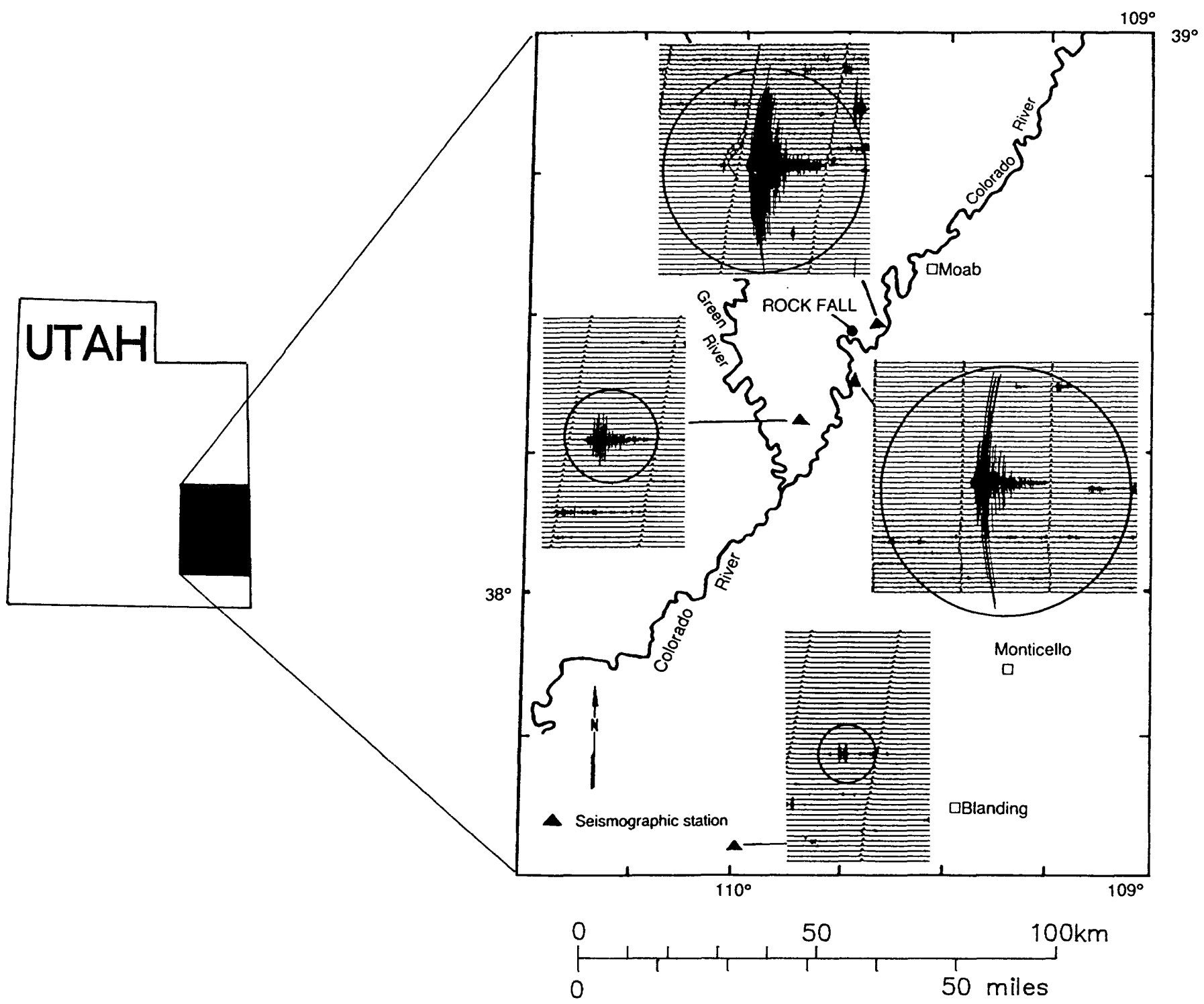

FIGURE 56. - Location map of the July 3, 1984, Dead Horse Point rockfall, which registered on seismographs more than $60 \mathrm{mi}(96 \mathrm{~km})$ away (modified from Case, 1987b).

fences may all stop or at least slow the falling rocks. Strengthening a structure to withstand impact is an example of modifying what is at risk. Twenty-seven techniques for reducing landslide hazards including rockfalls are described by Kockelman (1986). Mitigation problems can arise when the source area of the rocks is located on land not owned by the developer.

In areas where the rockfall hazard is very low, disclosure of potential hazards to land owners and residents with an acknowledgment of risk and willingness to accept liability may be an acceptable alternative to avoidance or mitigation, at least for single-family residences. In the past, Salt Lake County has used disclosure for airport noise zones and for surface-fault rupture hazards.

\section{USE OF ROCKFALL HAZARD SPECIAL STUDY AREA MAPS}

The rockfall hazards special study area map shows areas potentially susceptible to falling rocks (fig. 59) at a countywide scale (1:24,000). During the building permit approval process, the proposed site plan will be reviewed, and if any proposed structure falls within the special study area, a site investigation will be required to assess the hazard. If the site-specific data indicate that a hazard does not exist at the site, then development would proceed and the hazard map would be amended. Should the site-specific data indicate that a rockfall hazard exists, the consultant should give recommenda- 


\section{CRASS CLAST CRASHES CLAMBAKE!}

\begin{abstract}
A barbeque party was rudely interrupted when a boulder two feet in diameter made a social comment by landing on the grill. The incident occurred the evening of 5 July, 1987, in the backyard of a house in the high avenues of Salt Lake City on North Cliff Drive. The rockfall clast originated from a back yard on North View Drive which is perched on a sand and gravel slope deposited by Ice-Age Lake Bonneville when it was at the Bonneville Level (5090 feet).
\end{abstract}

Craig V. Nelson, Salt Lake County Geologist, reported that the county was first notified when the owner of the barbeque grill asked about possible legal retribution. Craig, and Salt Lake City Environmental Planner Robert H. Buchanan, visited the scene of the crime on the 10th of July but missed seeing the culprit rock, presumably because it was retrieved by its previous owner.
Other boulders, partially hidden in weeds, appeared to be ready to follow their sibling and crash a party of their own. Slopes in the area were oversteepened when toes were removed during home construction. Erosion of the slope is gradually exposing large boulders which eventually must live down to their potential energy. Craig recommended a taller railroad tie retaining wall to prevent other social interruptions.

Interesting legal precedents, albeit small scale, may be set by the incident. Should the upslope owner be responsible for "acts of God" and replace the barbeque grill? Who owned the recalcitrant intruder, the source person or the receivership plaintiff?

There are copious boulders on retreating, oversteepened, slopes in the neighborhood to cause a recurrence of the problem.

FigURE 57. - Article from the Utah Geological and Mineral Survey Survey Notes, spring 1987.

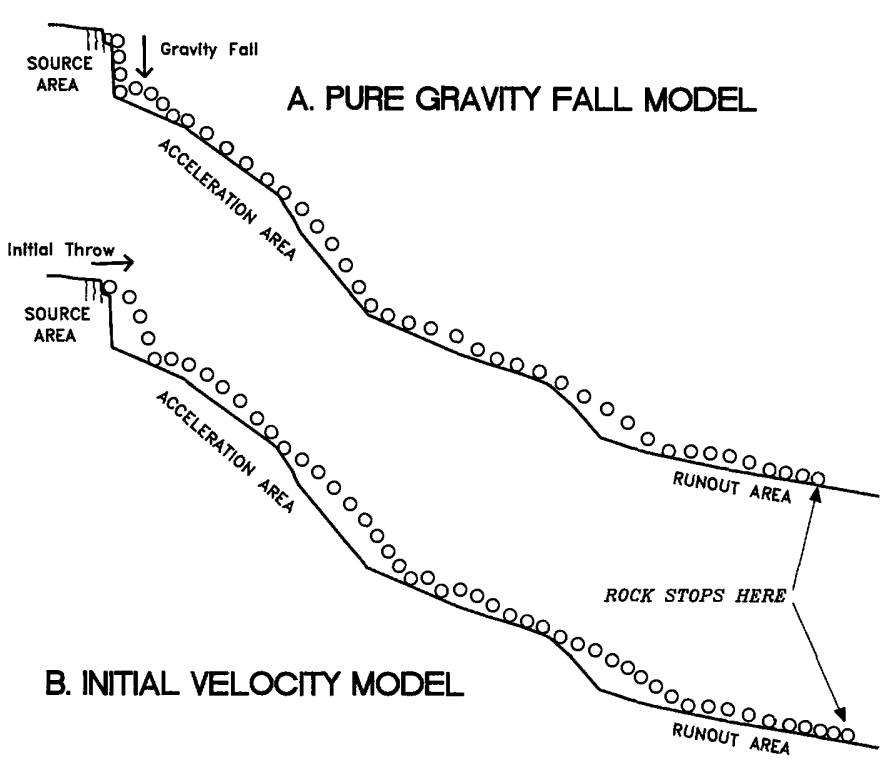

FIGURE 58. - Example of the output model generated by the computer program ROCKFALL (Hoek, 1987) for a rockfall event on a generalized slope. The total rock runout distance is estimated (A) given no initial velocity (pure gravity fall) and (B) given an initial velocity (throw).

tions for avoiding or reducing the hazard and include these considerations in the site plan. Regardless of the conclusions, results of the site-specific study should be submitted to the county geologist for review. A report discussing this review process has been prepared (Nelson and others, 1987) and is available from the county geologist. The Salt Lake County Planning Commission considers the recommendations of planning staff and consultants and makes the final decision for approval of developments.

It is important that geological input be used early in the development process. In the past, developers have faced considerable expense in redesigning subdivisions around geologic problems. The astute real estate purchaser often seeks geological counsel prior to making an offer or makes a favorable geologic report a contingency of purchase. The hazard maps may also prove useful to private citizens and real estate agents by providing information needed to make an informed decision in the purchase of property.

\section{SCOPE OF SITE INVESTIGATIONS}

When development is proposed within the rockfall hazard special study area, a qualified engineering geologist or licensed geotechnical engineer must be employed to assess the site-specific rockfall hazard. Site investigations must define rockfall sources and estimate runout paths and runout distances from each source. Rockfall sources may be outcrops or individual clasts on a slope. Size, shape, depth of burial, and slope geometry are all factors to be considered in defining sources as well as runout path and distance. Computer models are available to simulate runout (Hoek, 1987; Pfeiffer and Bowen, 1989), but physical evidence such as extent of clast accumulations below sources, topographic configuration, damaged vegetation, and natural barriers are also important. 


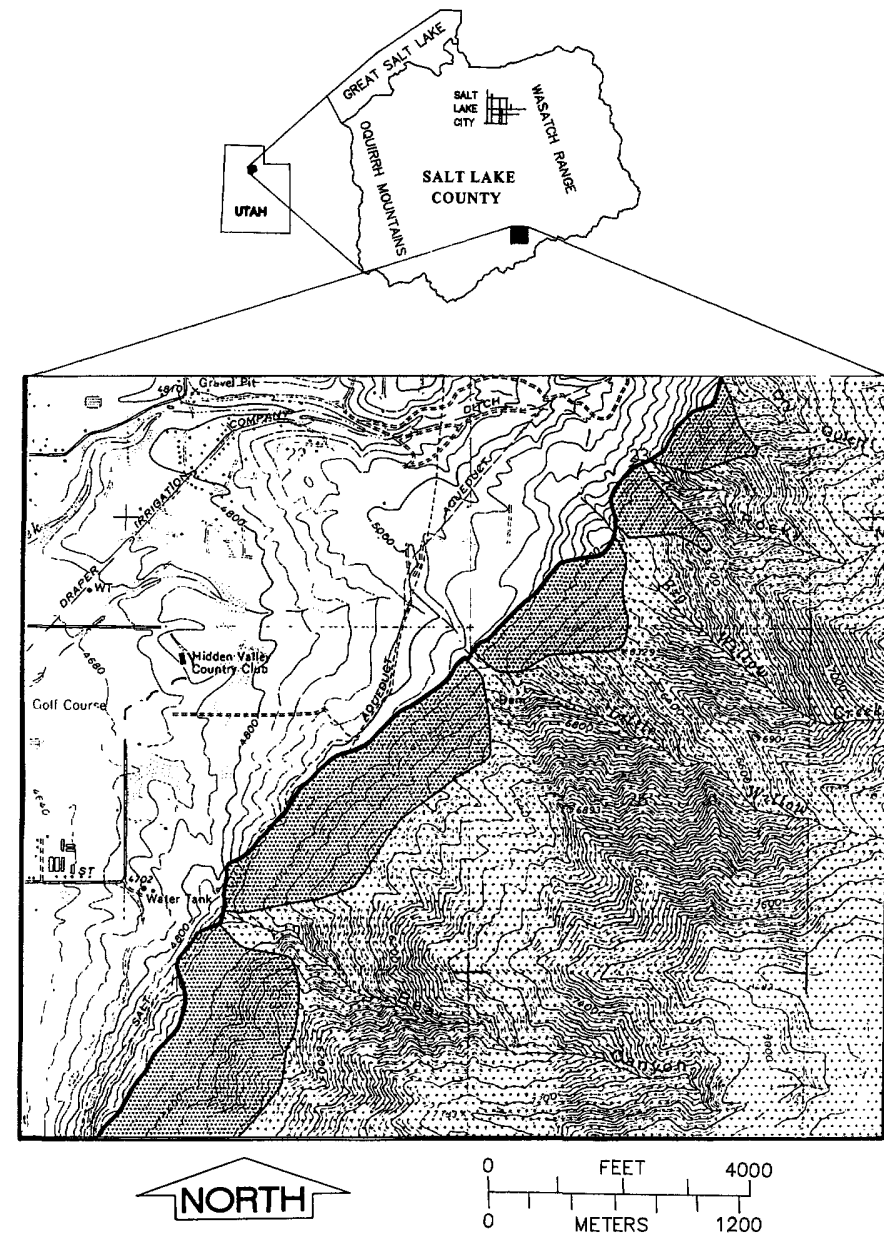

FIGURE 59. - Portion of the rockfall hazards special study area map in the Draper Quadrangle, southeast of Salt Lake City, Utah. Areas requiring site-specific investigations are stippled. Range-front source areas (spurs) are the more darkly shaded regions.

\section{SUMMARY}

The objective of special study area hazard maps, and regulation during permit approval, is not to restrict development but to help ensure that, when development does occur in geologically sensitive areas, the safety and property of citizens and their community are protected.

It must be realized that rockfalls are a natural phenomena and not every rockfall event can be accurately modeled. Therefore, the rockfall special study areas are a best estimate of the probable hazard area. The hazard map is a regional, small-scale map suitable for indicating potential hazard areas. The map is not intended to substitute for site-specific data. As improved analytical tools become available, and the results of site-specific studies are completed, the hazard map will be updated.

\section{REFERENCES}

Case, W.F., 1987a, Rock fall hazards in Utah's urban corridor: Geological Society of America Abstracts With Programs, v. 19, no. 7, p. 614 .

Case, W.F., 1987b, Dead Horse Point rockfall recorded on seismograph: Utah Geological and Mineral Survey, Survey Notes, v. 21, no. 4 , p. 5 .

Case, W.F., 1987c, Rock fall hazard susceptibility due to earthquakes, central Wasatch Front, Utah: U S. Geological Survey Open-File Report 87-585, p. V1-V36.

Case, W.F., 1988, Geology effects of the 14 and 18 August, 1988 earthquakes in Emery County, Utah: Utah Geological and Mineral Survey, Survey Notes, v. 22. no. 1-2, p. 8-15.

Case, W.F., 1989, Rock-fall hazards in Cache, Salt Lake, and Tooele valleys, Wasatch Front, Utah: Utah Geological and Mineral Survey, unpublished map, scale 1:24,000.

Costa, J.E., and Baker, V.R., 1981, Surficial geology-Building with the Earth: New York, John Wiley and Sons, 498 p.

Hoek, E., 1987, ROCKFALL-A program in BASIC for the analysis of rockfalls from slopes: Unpublished NSERC Industrial Research Professor report, July 1, 1987, Toronto, Ontario, $10 \mathrm{p}$.

Keefer, D.K., 1984, Landslides caused by earthquakes: Geological Society of America Bulletin, v. 95, p. 402-421.

Kockelman, W.J., 1986, Some techniques for reducing landslide hazards: Bulletin of the Association of Engineering Geologists, v. 23, no. 1, p. 29-52.

Nava, S.J., Pechman, J.C., and Arabasz, W.J., 1988, The magnitude 5.3 San Rafael Swell, Utah, earthquake of August 14, 1988: Utah Geological and Mineral Survey, Survey Notes, v. 22, no. 1-2, p. 16-19.

Nelson, C.V., 1988, Preparation and use of earthquake groundshaking and rock-fall hazard maps, Wasatch Front, Utah: Geological Society of America Abstracts With Programs, v. 20, no. 6, p. 459.

Nelson, C.V., Christenson, G.E., Lowe, Mike, and Robison, R.M. 1987, The review process and adequacy of engineering geologic reports, Wasatch Front, Utah, in McCalpin, James, ed., Proceedings of the 23rd annual symposium on engineering geology and soils engineering: Utah State University, April 6-8, 1987, p. $83-85$.

Pfeiffer, T.J., and Bowen, T.D., 1989, Computer simulation of rockfalls: Bulletin of the Association of Engineering Geologists, v. 26, no 1 , p. $135-146$. 


\title{
DEBRIS-FLOW HAZARDS: A GUIDE FOR LAND-USE PLANNING, DAVIS COUNTY, UTAH
}

\author{
By Mike Lowe ${ }^{14}$
}

\begin{abstract}
Debris flows, debris floods (hyperconcentrated streamflows), and clear-water flooding form a continuum of sediment and water mixtures that may be hazardous to development on alluvial fans. Debris flows can be generated either by scouring soil materials from the ground surface and stream channels during rainstorms, or by adding water to debris slides until they are fluid enough to reach a flowing stream. In Davis County, debris flows and debris floods have occurred often historically and have caused loss of life and significant damage to property.

Debris-flow hazards (including hyperconcentrated-streamflow hazards) in Davis County are mapped at a scale of 1:24,000 using U.S. Geological Survey $71 / 2^{\prime}$ (topographic) quadrangles as base maps. It is recommended that debris-flow hazards be evaluated, and if necessary, hazard reduction measures be required, prior to planning commission approval of new development proposed within the debris-flow hazard area depicted on these maps.
\end{abstract}

\section{INTRODUCTION}

Debris flows are mixtures of water, rock, soil, and organic material, 70-90 percent solids by weight (Costa, 1984), that form a muddy slurry, much like wet concrete, and flow downslope, commonly in surges or pulses, due to gravity. The flows generally remain confined to stream channels in mountainous areas but may reach and deposit debris over large areas on alluvial fans at and beyond canyon mouths. The eastern portion of Davis County is particularly susceptible to debris-flow hazards because of the steep mountains and the weathering characteristics of the bedrock (the Precambrian Farmington Canyon Complex), which provide much unstable hillside debris (Wieczorek and others, 1983; Pack, 1985). Debris flows have occurred often in Davis County during historical time and have caused damage to property and loss of life (table 13). It is the purpose of this report to discuss the nature of debris-flow hazards in Davis County, the potential consequences, the Davis County maps showing debris-flow hazards in a special study zone, and recommendations regarding use of the maps

${ }^{14}$ Davis County Planning Department, Framington, Utah. for land-use planning. A major goal is to translate technical information so that government officials and the general public can appreciate the need to reduce debris-flow hazards. The special study zone maps, which were constructed from the boundaries of active alluvial fans and areas with slopes steeper than 30 percent, identify areas where debris-flow hazards should be evaluated prior to approval of proposed development.

TABLE 13.-Historical Davis County debris flows (from Marsell, 1972; Wieczorek and others, 1983; U.S. Army Corps of Engineers, 1984)

\begin{tabular}{|c|c|c|}
\hline Drainage & Years & $\begin{array}{l}\text { Reported damage or } \\
\text { loss of life }\end{array}$ \\
\hline Dry Fork, Kays Creek & 1984 & House damaged \\
\hline $\begin{array}{l}\text { Middle Fork, Kays } \\
\text { Creek. }\end{array}$ & 1947,1953 & \\
\hline $\begin{array}{l}\text { South Fork, Kays } \\
\text { Creek. }\end{array}$ & $\begin{array}{l}1912,1923, \\
1927,1945, \\
1947 .\end{array}$ & \\
\hline $\begin{array}{l}\text { North Fork, Holmes } \\
\text { Creek. }\end{array}$ & 1983 & \\
\hline $\begin{array}{l}\text { South Fork, Holmes } \\
\text { Creek. }\end{array}$ & 1917 & \\
\hline Baer Creek & 1983 & \\
\hline Shepard Creek & $\begin{array}{l}1923,1930 \\
1983 .\end{array}$ & \\
\hline Farmington Creek & $\begin{array}{l}1878,1923 \\
1926,1930 \\
1947,1983 .\end{array}$ & $\begin{array}{l}\text { Seven deaths and } \\
\text { several houses } \\
\text { damaged (1923). }\end{array}$ \\
\hline Rudd Creek & 1983,1984 & $\begin{array}{l}35 \text { houses damaged, } \\
15 \text { severely } \\
\text { (1983). }\end{array}$ \\
\hline Steed Creek & 1923 & \\
\hline Davis Creek & $\begin{array}{l}1878,1901 \\
1923 .\end{array}$ & \\
\hline Ricks Creek & $\begin{array}{l}1923,1929 \\
1930 .\end{array}$ & $\begin{array}{l}\text { One house damaged } \\
\text { in } 1923 \text { and one in } \\
1930 .\end{array}$ \\
\hline Parrish Creek & $\begin{array}{l}1930 \text { (several } \\
\text { events). }\end{array}$ & $\begin{array}{l}\text { Several houses } \\
\text { destroyed, school } \\
\text { damaged. }\end{array}$ \\
\hline Stone Creek & 1983 & Houses damaged \\
\hline Mill Creek & 1983 & \\
\hline
\end{tabular}




\section{ACKNOWLEDGMENTS}

Gary E. Christenson (Utah Geological Survey), Barry Burton, Tim Stephens, and Wilf Sommerkorn (Davis County Planning Department), Sidney W. Smith (Davis County Public Works), Scott R. Williams (Davis County Flood Control), Craig Barker (Weber County Planning Department), and Al Chleborad, William J. Kockelman, and Gerald F. Wieczorek (U.S. Geological Survey) kindly reviewed this paper and provided valuable suggestions. Bill Black (Utah Geological Survey) drafted the figures.

\section{NATURE AND GAUSES OF DEBRIS FLOWS}

Although this report chiefly addresses debris flows, other forms of flow are also considered because debris flow, debris flood (hyperconcentrated streamflow), and normal streamflow form a continuum of sediment-water mixtures that grade into each other as the relative proportion of sediment to water changes and as stream gradient changes (Pierson and Costa, 1987). Deposition of sediment transported by these types of flows ultimately takes place on alluvial fans at and beyond canyon mouths. Deposition on alluvial fans is caused by the decrease in channel gradient and increase in channel area, resulting in a decrease in depth and velocity of flow and an increase in internal friction of the flowing debris as the stream leaves its constricted channel and enters the main valley floor (Jochim, 1986).

Debris flows can form in at least two ways. In mountainous eastern Davis County, where cloudburst rainstorms are common, overland flow and floodwaters can scour materials from the ground surface and stream channels, thereby increasing the proportion of soil materials to water until the mixture becomes a debris flow (Wieczorek and others, 1983). The size and frequency of debris-flow events generated by rainfall are dependent on several factors, including the amount of loose material available for transport, the magnitude and frequency of the storms, the density and type of vegetative cover, and the moisture content of the soil (Campbell, 1975; Pack, 1985; Wieczorek, 1987). Debris flows during the 1920's and 1930's in Davis County were generated by overland erosion during summer cloudburst storms that fell on watersheds that had been depleted of vegetative cover by overgrazing and burning (Copeland, 1960).

Debris flows can also mobilize directly from debris slides. A debris slide is a type of landslide in which the material involved is predominantly coarse-grained debris, chiefly colluvium, and the form of movement is mainly translational (Varnes, 1978). A debris flow may be generated when the debris slide reaches a stream, or when the water content is increased in the debris slide by some other means until sufficient to permit flow. Debris flows during the springs of 1983 and 1984 in Davis County were mobilized from debris slides caused by rapid melting of an unusually thick snowpack (Wieczorek and others, 1983).

As the relative proportion of water to sediment increases with either the addition of more water or removal of sediment by deposition, debris flows become hyperconcentrated streamflows. Hyperconcentrated streamflows are often referred to as debris floods or mud floods because soil materials are transported by fastmoving floodwaters (Wieczorek and others, 1983). Solids account for 40 to 70 percent of the material by weight (Costa, 1984). These flows can originate either through progressive incorporation of materials into floodwaters or through dilution of debris flows (Waitt and others, 1983; Wieczorek and others, 1983). Because of difficulties in distinguishing hyperconcentrated streamflow from flood stages of normal streamflow, there is no adequate record of historical hyperconcentrated-streamflow events in Davis County.

In normal streamflow, solids account for less than 40 percent of the water-sediment mixture by weight (Costa, 1984). Snowmelt flooding in Davis County is a nearly annual event, and abnormally high snowmelt floods occurred in Davis County in 1922, 1952 (Marsell, 1972), 1983, and 1984. Snowmelt-induced flood magnitudes are somewhat predictable and depend on the volume of snow in the mountains and the rate of temperature increase in the spring. Summer cloudburst floods account for more localized but often very destructive flooding and can occur with little warning. Davis County experienced 39 cloudburst floods between 1850 and 1969 (Butler and Marsell, 1972). The clear-water flooding hazard has been significantly reduced in recent years by the construction of flood detention structures and improvements in stormsewer systems and stream channels.

\section{EFFECTS OF DEBRIS FLOWS}

Loss of life during debris-flow, hyperconcentratedstreamflow, and normal-streamflow events may result from drowning, high-velocity impact, or burial. The following discussion of damages associated with debris flows is taken chiefly from Campbell (1975). The effects on residential structures range from simple inundation to complete destruction by high-velocity impact.

The velocity of a debris flow is an important consideration in determining the level of damage to structures. Many debris flows move with speeds on the order of 27 $\mathrm{mi} / \mathrm{h}(40 \mathrm{ft} / \mathrm{s}, 12 \mathrm{~m} / \mathrm{s})$, but others move as slowly as $1 \mathrm{ft} / \mathrm{s}$ $(0.3 \mathrm{~m} / \mathrm{s})$ down relatively gentle slopes. Debris flows of sufficient volume and momentum have destroyed residential structures and moved the remains off their 
foundations. Debris flows of relatively small volume but high momentum have broken through outside walls and even completely through structures. Low-velocity debris flows may enter dwellings through open doors or push laterally through windows and doorways to flood interiors. All three types of flows may fill basements with mud, water, and debris or pile debris around structures. Debris may also bury yards, streets, parks, driveways, parking lots, and any ground-level structure. In the distal portions of the alluvial fans, damage is usually comparatively minor, consisting primarily of mud and water damage to outer walls of buildings, basements, and yards. Keaton and others (1988) have devised an intensity scale, generally related to thickness of deposition, for damages associated with debris-flow events (table 14). Table 14 gives a good indication of the types and severity of potential damage.

\section{DEBRIS-FLOW HAZARD REDUCTION}

Methods for reducing debris-flow hazards include avoidance, source-area stabilization, transportation-zone (debris-flow track between the source area and the depositional zone) modification, and defense measures in the depositional zone (Hungr and others, 1987). Different methods or combinations of methods may be appropriate for different drainages or types of development.

Debris-flow hazards may be reduced by avoiding, either permanently or at the time of imminent danger, areas at risk from debris flows (source areas, transportation zones, and depositional zones). Permanent avoidance is not possible in some areas because many Davis County cities have large numbers of existing structures on active alluvial fans (potential depositional zones), where damage due to debris flows may occur. Permanent avoidance of debris-flow hazards could be required for proposed new development in most Davis County cities through enforcement of existing ordinances concerning foothill development (zoning), but this is generally not politically acceptable unless other mitigation techniques are not feasible.

Warning systems may be used to avoid life threats from debris flows at the time of imminent danger, generally through evacuation of threatened areas. Hungr and others (1987) identify three categories of debris-flow warning systems: pre-event, event, and post-event. Pre-event warning systems are designed to identify periods of time when climatic conditions have increased the potential for debris-flow occurrence. Davis County has established a computer-linked remote weather station ALERT system that allows real-time evaluation of rainfall, wind, soil moisture, streamflow, and landslide-movement data. Although this ALERT system has not yet been used to predict debris-flow
TABLE 14.-Alluvial-fan sedimentation intensity scale proposed by Keaton and others (1988)

\begin{tabular}{|c|c|c|}
\hline Intensity & Damage & Description \\
\hline 0 & None & No damage. \\
\hline 1 & Negligible & $\begin{array}{l}\text { Damage to landscape and access; no } \\
\text { damage to structures; minor scour } \\
\text { and (or) sediment deposition. }\end{array}$ \\
\hline 2 & Slight & $\begin{array}{l}\text { Sediment generally less than } 3.3 \mathrm{ft} \\
(1 \mathrm{~m}) \text { thick deposited against build- } \\
\text { ings without structural damage; sedi- } \\
\text { ment flooded around parked vehicles. }\end{array}$ \\
\hline 3 & Moderate & $\begin{array}{l}\text { Sediment generally greater than } 3.3 \mathrm{ft} \\
(1 \mathrm{~m}) \text { thick deposited against build- } \\
\text { ings with easily reparable structural } \\
\text { damage; basements partially filled } \\
\text { with sediment; reparable damage to } \\
\text { parked vehicles shoved by sediment. }\end{array}$ \\
\hline 4 & Severe & $\begin{array}{l}\text { Sediment greater than } 3.3 \mathrm{ft}(1 \mathrm{~m}) \\
\text { thick deposited against buildings with } \\
\text { reparable structural damage; base- } \\
\text { ments completely filled with sedi- } \\
\text { ment; wood structures detached from } \\
\text { foundations; nonreparable damage to } \\
\text { parked vehicles shoved by sediment } \\
\text { (e.g., distorted frames). }\end{array}$ \\
\hline 5 & Extreme & $\begin{array}{l}\text { Sediment greater than } 3.3 \mathrm{ft}(1 \mathrm{~m}) \\
\text { thick deposited against buildings with } \\
\text { nonreparable damage; structures col- } \\
\text { lapsed by force (drag or impact) of } \\
\text { flow; wood structures shoved from } \\
\text { foundations; parked vehicles so badly } \\
\text { damaged that they have small sal- } \\
\text { vage value. }\end{array}$ \\
\hline
\end{tabular}

events, this use of the system may be possible in the future as the relationship between climatic conditions and the initiation of debris flows in Davis County becomes better understood.

Event warning systems are designed to provide an alarm when a debris-flow event is occurring (Hungr and others, 1987). Two types of event warning systems are being implemented in Davis County. Computer-linked remote extensometers have been used to monitor realtime movement of detached landslides in Rudd and Baer Canyons. Computer-linked remote streamflow gages, which have been placed on most Davis County streams, can sound alarms if streamflow drops below or rises above preset levels. In both cases, the event warnings are designed to alert Davis County Flood Control and Davis County Sheriff Department personnel of potential debris-flow events.

Post-event warning systems, such as slide-warning fences, are usually designed to warn of disruption of transportation routes (Hungr and others, 1987). This type of warning system has not been used in Davis County, where most transportation routes are in urban areas and where mass-media warnings, barricades, and detours have been sufficient in the past. 
Source-area stabilization consists of reducing the amount of hillside material available for incorporation into debris-flow or hyperconcentrated-streamflow events. Improving drainage-basin vegetation is one method of source-area stabilization. The prevention of wildfires and forest fires combined with restrictions against overlogging and overgrazing will protect existing vegetation. Terracing of mountain slopes, such as was done in the 1930's in Davis County by the Civilian Conservation Corps under the supervision of the U.S. Forest Service (Bailey and Croft, 1937), is useful in preventing debris flows caused by erosion during cloudburst storms. Oversteepened slopes comprising the source-area scars of former debris flows may be the source of additional hillside material during future landslide-initiated debris-flow events (Baldwin and others, 1987). Landslide-mitigation techniques that have been used in California to reduce debris-flow hazards include control of subsurface drainage, diversion of surface drainage, grading of source-area scars to a uniform slope, riprap repair of the source-area scar, and use of retaining walls (Baldwin and others, 1987). Stabilization of source areas for landslide-initiated debris flows has not been attempted in Davis County.

Transportation-zone modifications are generally designed to reduce the incorporation of channel material into debris flows and improve the ability of the channel to pass debris surges downstream. Scour of unconsolidated material in streambeds and undercutting of unstable streambanks are two of the most important processes contributing to the growth of debris-flow surges (Hungr and others, 1987). Check dams are small debris-retention structures placed in unstable channel areas to prevent incorporation of material from that part of the channel into debris flows. These check dams are used extensively in Europe and Japan to arrest or reduce debris-flow surges (Hungr and others, 1987). Streambed stabilization may also be achieved by lining the channel. The ability of stream channels to pass debris surges downstream may be improved through removal of channel irregularities, enlargement of culverts combined with installation of upstream removable grates to prevent blockage, and construction of flumes, baffles, deflection walls, and dikes (Jochim, 1986; Baldwin and others, 1987). Structures crossing potential debris-flow channels may be protected by bridging the channels with sufficient clearance to allow debris surges to pass under structures, construction of debris sheds designed to allow debris flows to pass over structures, and designing structures to withstand debris-flow impact, burial, and reexcavation (Hungr and others, 1987). Transportationzone modifications in Davis County have been restricted to some stream channels below canyon mouths and consist mainly of dikes and deflection walls constructed in the 1920's and 1930's and removal of channel irregularities and lining of channels in the 1980's. Stream channels above canyon mouths have generally not been modified.

Defense measures in the deposition zone are designed to control both the areal extent of deposition and damage to any structures located there (Hungr and others, 1987). Defense measures include deflection devices, impact walls, and debris basins. Deflection devices are used to control the direction and reduce the velocity of debris flows (Baldwin and others, 1987). Types of deflection devices include pier-supported deflection walls, debris fences (a series of steel bars or cables placed horizontally at increasing elevations above the stream channel), berms, splitting-wedge walls (reinforced concrete wall in the shape of a "V" with the point facing uphill), and gravity structures like gabions (hollow wicker-works or iron cylinders filled with earth) (Baldwin and others, 1987; Jochim, 1986).

Impact walls are designed to sustain the instantaneous force of impact from debris flows while containing the soil and vegetation debris until it can be removed (Baldwin and others, 1987). This impact force may be as high as $125 \mathrm{lb} / \mathrm{ft}^{3}\left(19,640 \mathrm{~N} / \mathrm{m}^{3}\right)$ (Hollingsworth and Kovacs, 1981). Types of impact walls employed in the United States include concrete walls, soldier pile walls, and soil and (or) rock gravity walls (including gabions) (Baldwin and others, 1987).

Two types of debris basins, open and closed, are commonly employed to reduce debris-flow hazards. Both types are designed to constrain the area of debris deposition to predetermined limits laterally, upstream, or downstream (Hungr and others, 1987). Open debris basins commonly have a basin-overflow spillway designed to direct excess material to an insensitive area or back into the stream channel, but straining outlets to remove water from entrapped debris are not generally provided. Closed debris barriers and basins can be located in the lower part of the transportation zone as well as in the deposition zone or on the alluvial fan (Hungr and others, 1987). Any suitable location along the lower part of the debris-flow path can be chosen to erect a barrier across the path and create a basin upstream. Closed debris barriers are provided with both straining outlets to pass water discharges and spillways to handle emergency debris overflows (Hungr and others, 1987). Both types of debris basins require access for maintenance and for removal of entrapped debris. Debris basins, both open (constructed in the 1930's) and closed (constructed in the 1980's), are the primary debris-flow hazard reduction technique employed in Davis County. Figure 60 shows the location of these debris basins. The Davis County debris basins vary greatly in storage 


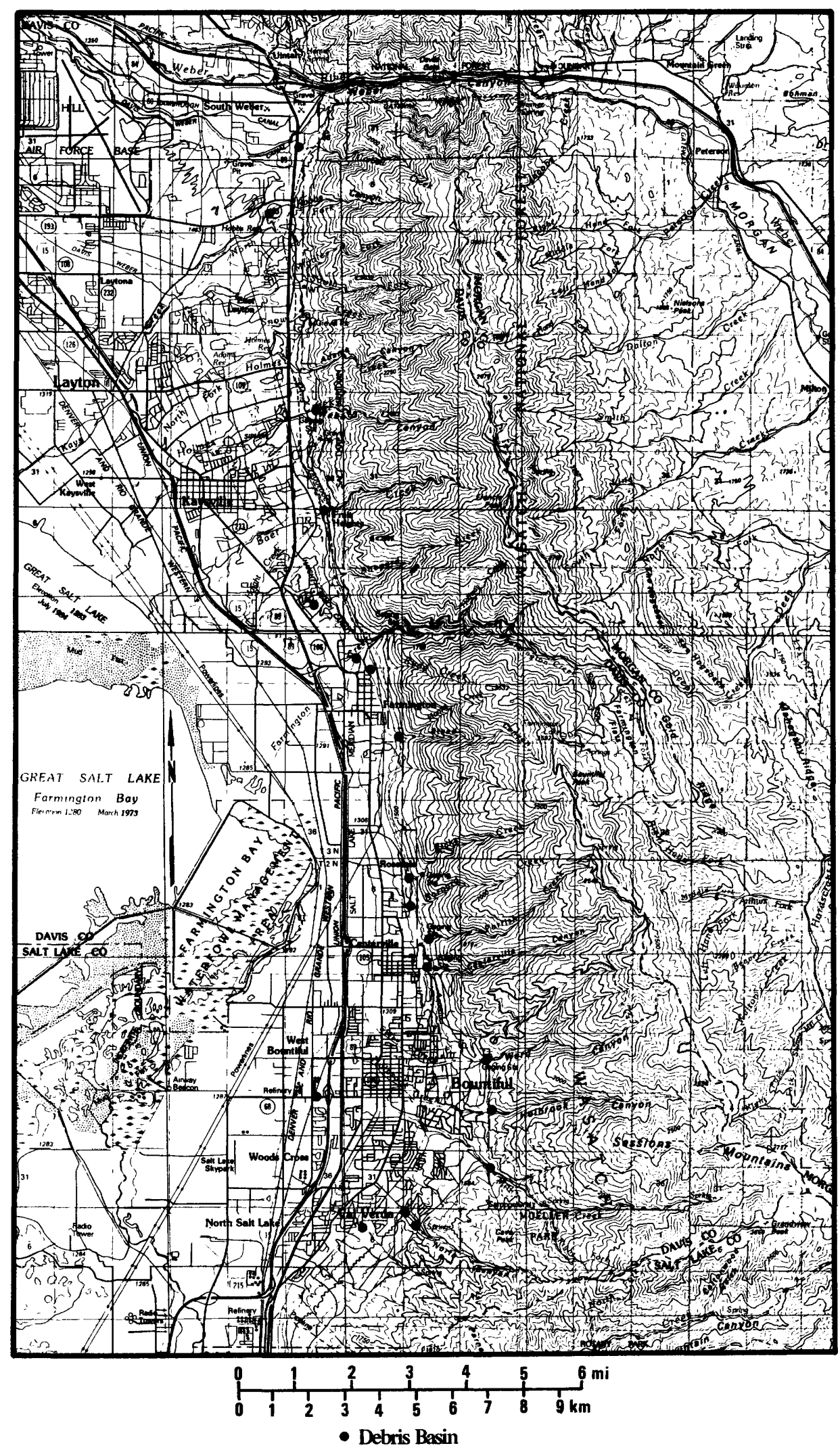

FIgURE 60.-Location map for debris basins in Davis County. 


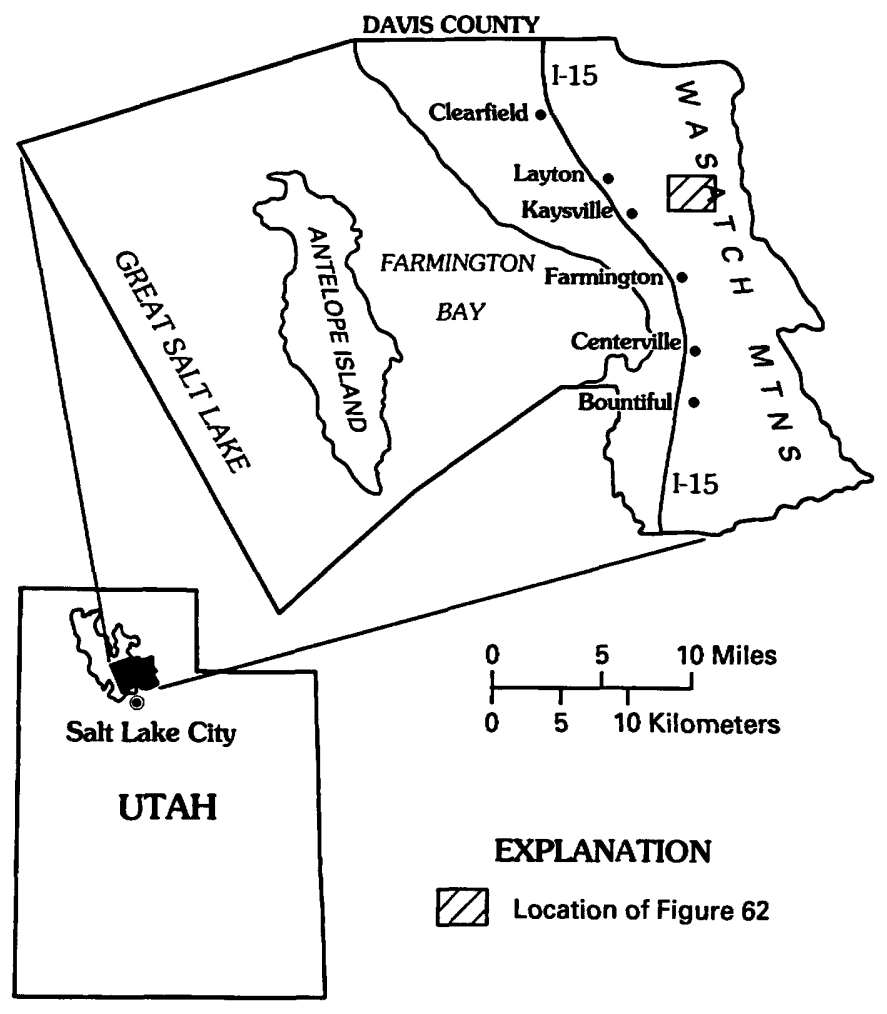

FIGURE 61.-Location map for figure 62.

capacity, and their adequacy to contain the debris from events of various magnitudes has generally not been evaluated.

\section{SUMMARY OF METHODS USED IN MAP PREPARATION}

Preliminary surficial geologic mapping by A.R. Nelson and S.F. Personius (unpublished mapping, 1987) was used to define debris-flow hazard areas at the mountain front. These maps differentiate active alluvial fans, where deposition during debris-flow and hyperconcentrated-streamflow events may occur, from areas not subject to debris flows, including older fans that are no longer active. Upper Holocene alluvial fans and undivided young alluvial fans, as mapped by A.R. Nelson and S.F. Personius (unpublished mapping, 1987), were combined and redesignated younger Holocene (active) alluvial fans. These fans represent areas that are considered susceptible to debris-flow hazards. In addition, all mountainous areas with slopes greater than 30 percent are considered to be susceptible to debris-flow initiation. The adequacy of existing debris basins or structures built to divert debris flows was not considered during preparation of the special study zone maps. The existence and adequacy of these structures should be considered for site-specific studies, however.
The frequency of occurrence (recurrence) of debrisflow events in a drainage basin depends on climatic factors as well as the availability of debris. Recurrence intervals vary among drainage basins and depend on the magnitude of the event (volume of sediment transported). For example, the recurrence interval for sedimentation events exceeding $40,000 \mathrm{yd}^{3}\left(30,600 \mathrm{~m}^{3}\right)$ of material deposited at the Ricks Creek debris basin has been calculated to range between 55 and $1,590 \mathrm{yr}$, but the recurrence interval for sedimentation events exceeding $65,000 \mathrm{yd}^{3}\left(49,700 \mathrm{~m}^{3}\right)$ of material deposited at the Rudd Creek debris basin has been calculated to range between 155 and 5,845 yr (Keaton and others, 1988). These numbers are significant because the volumes given represent the capacity of debris basins constructed at the mouths of Ford (Ricks Creek) and Rudd Canyons, respectively (Keaton and others, 1988). Recurrence intervals for debris-flow events of different magnitudes are not currently available for the other Davis County drainages.

\section{RECOMMENDED USE OF MAPS IN LAND-USE PLANNING}

The debris-flow hazard special study zone maps (figures 61 and 62) show areas where site-specific studies addressing debris-flow hazards are recommended prior to development. These maps are at a scale of 1:24,000 and are designed to show potential hazard areas for planning purposes only. It is recommended (see table 15) that debris-flow hazards be evaluated and any necessary hazard reduction measures be described by an engineering geologist in site-specific reports. The reports are then submitted by the developer to the planning commission prior to approval for all construction in the debrisflow hazard special study zone. Because of the relatively small scale of the maps, the possibility exists that some small hazard areas are not shown; studies concerning debris flows are therefore recommended for critical facilities even outside the special study zones. The impor-

TABLE 15.-Matrix indicating recommended report requirements for debris-flow hazards, Davis County, Utah

\begin{tabular}{|c|c|c|}
\hline \multirow{2}{*}{ Type of development } & \multicolumn{2}{|c|}{$\begin{array}{l}\text { Debris-flow hazard } \\
\text { special study zone }\end{array}$} \\
\hline & Inside & Outside \\
\hline $\begin{array}{l}\text { Critical facilities such as lifelines and high- } \\
\text { occupancy buildings. }\end{array}$ & $\mathrm{Yes}^{1}$ & $\mathrm{Yes}^{1}$ \\
\hline $\begin{array}{l}\text { Industrial and commercial buildings } \\
\text { (other than high occupancy). }\end{array}$ & $\mathrm{Yes}^{2}$ & No \\
\hline Residential subdivisions & $\mathrm{Yes}^{2}$ & No \\
\hline Residential single lots & $\mathrm{Yes}^{2}$ & No \\
\hline
\end{tabular}




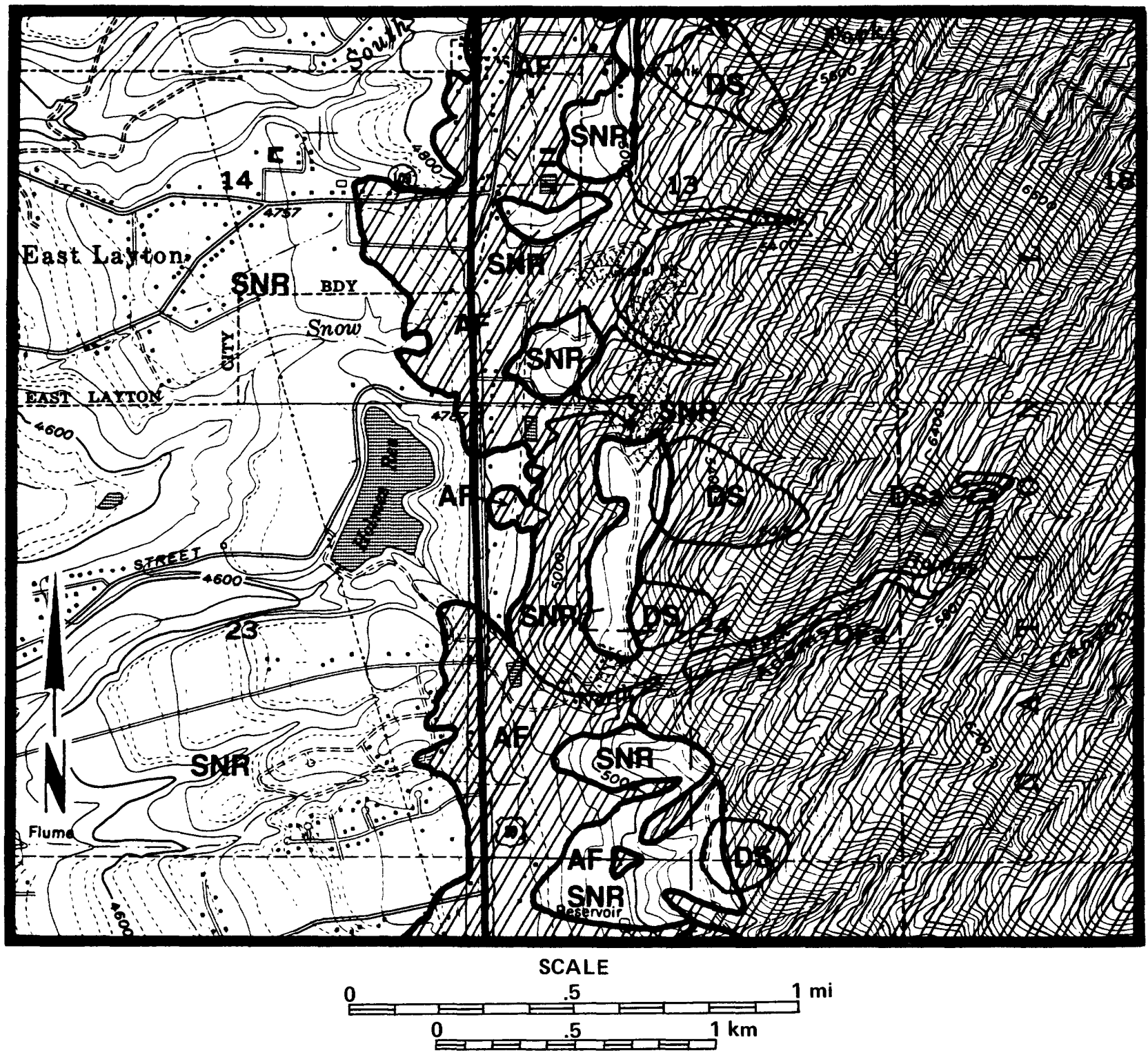

Figure 62. - Example of a debris-flow hazard special study zone map for the east Layton area of northern Davis County, Utah. Cross hatching indicates areas where debris-flow hazard studies are recommended prior to planning commission approval of proposed development. SNR, area where debris-flow studies should not be required; DS, debris slide; DF, debris flow; a, active (historic) slope failure; $\mathrm{AF}$, younger Holocene (active) alluvial fan. This figure was reproduced from a portion of the debris-flow hazard special study zone map, Kaysville Quadrangle, Davis County, Utah, and is based on information from A.R. Nelson and S.F. Personius (unpublished mapping, 1987), G. Kappeser (written commun., 1986), Bryant (1984), Olson (1981), and M. Lowe (unpublished mapping, 1987).

ment should include (1) an analysis of the potential for the drainage basin to produce debris flows based on the presence of debris slides and colluvium-filled slope concavities and an estimate of the largest probable volumes likely to be produced during a single event; (2) an analysis of the stream channel to determine if the channel will supply additional debris, impede flow, or contain debris flows in the area of the proposed development; (3) an analysis of manmade structures upstream that may divert or deflect debris flows; and (4) recommendations
The scope of investigations for site-specific reports evaluating debris-flow hazards for proposed develop-

tance in terms of life safety of such structures merits this and either confirm that it does not exist or perform the necessary study if a potential hazard is found.

\section{SCOPE OF SITE INVESTIGATIONS}


concerning any channel improvements, flow modification and catchment structures, direct protection structures, or flood-proofing measures, if necessary, to help protect the proposed development.

For critical facilities within the special study zone, any debris basins upstream from the site must be evaluated in terms of the storage capacity to reduce the debris-flow hazard. The quality of maintenance on these debris basins should also be addressed. The U.S. Army Corps of Engineers (1988) has evaluated the adequacy of many of the central Davis County basins to contain the 100-yr debris-flow event volumes, but Davis County is challenging the methodology used in determining the values for those 100-yr event volumes (Williams and others, 1989). Wieczorek and others (1983), Pack (1985), and Keaton and others (1988) identified factors to be considered when evaluating debris-flow hazards, and these references should be consulted during site investigations. Sitespecific reports should be reviewed by the county, and, once approved, should be forwarded to the planning commission along with review comments. The planning commission then has sufficient information to make decisions regarding the proposed development.

\section{REFERENCES}

Bailey, R.W., and Croft, A.R., 1937, Contour trenches, control floods, and erosion on range lands: Washington, D.C., U.S. Government Printing Office, Emergency Conservation Work Forestry Publication $4,22 \mathrm{p}$.

Baldwin, J.E., II, Donley, H.F., and Howard, T.R., 1987, On debris flow/avalanche mitigation and control, San Francisco Bay area, California, in Costa, J.E., and Wieczorek, G.F., eds., Debris flows/avalanches-Process, recognition, and mitigation: Geological Society of America Reviews in Engineering Greology, v. 7, p. 223-236.

Bryant, Bruce, 1984, Reconnaissance geologic map of the Precambrian Farmington Canyon Complex and surrounding rocks in the Wasatch Mountains between Ogden and Bountiful, Utah: U.S. Geological Survey Miscellaneous Investigation Series Map I-1447, scale 1:50,000.

Butler, Elmer, and Marsell, R.E., 1972, Cloudburst floods in Utah, 1939-69: Utah Department of Natural Resources, Division of Water Resources, Cooperative Investigations Report 11, 103 p.

Campbell, R.H., 1975, Soil slips, debris flows, and rainstorms in the Santa Monica Mountains and vicinity, southern California: U.S. Geological Survey Professional Paper 851, 51 p.

Copeland, O.L., 1960, Watershed restoration: A photo-record of conservation practices applied in the Wasatch Mountains of Utah: Journal of Soil and Water Conservation, v. 15, no. 3, p. 105-120.

Costa, J.E., 1984, Physical geomorphology of debris flows, in Costa, J.E., and Fleisher, P.J., eds., Developments and applications of geomorphology: New York, Springer-Verlag, p. 268-317.
Hollingsworth, Robert, and Kovacs, G.S., 1981, Soil slips and debris flows-Prediction and protection: Association of Engineering Geologists Bulletin, v. 18, no. 1, p. 17-28.

Hungr, Oldrich, VanDine, D.F., and Lister, D.R., 1987, Debris flow defenses in British Columbia, in Costa, J.E., and Wieczorek, G.F., eds., Debris flows/avalanches-Process, recognition, and mitigation: Geological Society of America Reviews in Engineering Geology, v. 7, p. 201-222.

Jochim, C.L., 1986, Debris-flow hazard in the immediate vicinity of Ouray, Colorado: Colorado Geological Survey Special Publication $30,63 \mathrm{p}$.

Keaton, J.R., Anderson, L.R., and Mathewson, C.C., 1988, Assessing debris flow hazards on alluvial fans in Davis County, Utah: Proceedings of the 24th symposium on engineering geology and soils engineering, p. 89-108.

Marsell, R.E., 1972, Cloudburst and snownelt floods, in Hilpert, L.S., ed., Environmental geology of the Wasatch Front, 1971: Utah Geological Association Publication 1, p. N1-N18.

Olson, E.P., 1981, Geologic hazards of the Wasatch Range, Part 1, Ward Canyon to south side Ogden Canyon: U.S. Department of Agriculture, Forest Service, R-4 Intermountain Region, unpublished maps of selected quadrangles within U.S. Forest Service boundaries, scale 1:24,000.

Pack, R.T., 1985, Multivariate analysis of relative landslide susceptibility in Davis County, Utah: Logan, Utah State University, Ph.D. dissertation, $233 \mathrm{p}$.

Pierson, T.C., and Costa, J.E., 1987, A rheologic classification of subaerial sediment-water flows, in Costa, J.E., and Wieczorek, G.F., eds., Debris flows/avalanches-Process, recogmition, and mitigation: Geological Society of America Reviews in Engineering Geology, v. 7, p. 1-12.

U.S. Army Corps of Engineers, 1984, Wasatch Front and central Utah flood control study, Utah: Sacramento District, $180 \mathrm{p}$.

U.S. Army Corps of Engineers, 1988, Mudflow modeling, one- and two-dimensional, Davis County, Utah: Omaha District, $53 \mathrm{p}$.

Varnes, D.J., 1978, Slope movement types and processes, in Schuster, R.L., and Krizek, R.S., eds., Landslides-Analysis and control: Washington D.C., National Academy of Sciences, Transportation Research Board, Special Report 176, p. 12-33.

Waitt, R.B., Pierson, T.C., Maclead, N.S., Janda, R.J., Voight, B., and Holcomb, R.T., 1983, Eruption-triggered avalanche, flood, and lahar at Mount St. Helens-Effects of winter snowpack: Science, v. 221, no. 4618, p. 1394-1397.

Wieczorek, G.F., 1987, Effect of rainfall intensity and duration on debris flows in central Santa Cruz Mountains, California, in Costa, J.E., and Wieczorek, G.F., eds., Debris flows/avalanches -Process, recognition, and mitigation: Geological Society of America Reviews in Engineering Geology, v. 7, p. 93-104.

Wieczorek, G.F., Ellen, Stephen, Lips, E.W., Cannon, S.H., and Short, D.N., 1983, Potential for debris flow and debris flood along the Wasatch Front between Salt Lake City and Willard, Utah, and measures for their mitigation: U.S. Geological Survey Open-File Report 83-635, 45 p.

Williams, S.R., Lowe, Mike, and Smith, S.W., 1989, The discrete debris-mud flow risk analysis method: Proceedings of the 1988 conference of the Arid West Committee of the Association of State Floodplain Managers, Las Vegas, Nevada, October 19-21, 1988, p. 157-167. 


\title{
LIQUEFACTION HAZARDS: A GUIDE FOR LAND-USE PLANNING, DAVIS COUNTY, UTAH
}

\author{
By Mike Lowe ${ }^{15}$
}

\begin{abstract}
Ground shaking during earthquakes may cause saturated sandy soils to "liquefy" as a result of increased pore-water pressures. Soil liquefaction can result in bearing capacity failure, ground oscillation, lateral spreading, or flow landsliding. The potential for liquefaction is dependent both on soil and ground-water conditions and on the severity and duration of ground shaking. In general, an earthquake of Richter magnitude 5 or greater is needed to induce soil liquefaction.

Five lateral-spread landslides that are believed to have resulted from liquefaction during prehistoric earthquakes have been mapped in Davis County. Also, generalized maps depicting liquefaction potential in Davis County are available and can be used to indicate hazard areas where site-specific studies should be required prior to development. The purpose of this report is to make recommendations concerning how these maps should be used as part of the development approval process.

It is recommended that planning commissions require site-specific liquefaction-hazard evaluations for all critical facilities such as lifelines and high-occupancy buildings. For industrial and commercial building sites, it is recommended that liquefaction-hazard evaluations be required only in areas with susceptibility ratings that are high or moderate on the liquefaction-potential maps. Site-specific studies are generally not recommended for residential subdivisions or single lots because of the lower risk in terms of life loss and property damage in such structures, and the relatively high costs of study and mitigation.
\end{abstract}

\section{INTRODUCTION}

Ground shaking during earthquakes causes a variety of phenomena that can damage structures and threaten lives. One such phenomenon is termed soil liquefaction. Ground shaking tends to increase the pressure in the pore water between soil grains, which decreases the stresses between the grains. The loss of intergranular stress can cause the strength of some soils to decrease nearly to zero. The soil then behaves like a liquid and therefore is said to have liquefied. When liquefaction occurs, foundations may crack, buildings may tip, buoyant buried structures such as septic tanks and storage tanks may rise, and even gentle slopes may fail as liquefied soils and overlying materials move downslope.

${ }^{15}$ Davis County Planning Department, Farmington, Utah.
The potential for liquefaction depends both on soil and ground-water conditions and on the severity and duration of ground shaking. Soil liquefaction most commonly occurs in areas of shallow ground water (less than $30 \mathrm{ft}$, or $9 \mathrm{~m}$ ) and loose sandy soils such as are found in western Davis County. In general, an earthquake of Richter magnitude 5 or greater is needed to induce liquefaction (Kuribayashi and Tatsuoka, 1975, 1977; Youd, 1977). For larger earthquakes, liquefaction is more likely to occur and will occur at greater distances from the epicenter (the point on the Earth's surface directly above the focus of the earthquake). Earthquakes of Richter magnitude 7.0-7.5 are the largest expected along the Wasatch front (Schwartz and Coppersmith, 1984). During such earthquakes, liquefaction has occurred up to $170 \mathrm{mi}(273 \mathrm{~km})$ from the epicenter (1977 Romanian earthquake, magnitude 7.2) (Youd and Perkins, 1987).

Anderson and others (1982) have produced maps depicting liquefaction potential for Davis County. It is the purpose of this report to discuss the nature of the hazard, the potential consequences, and commonly used techniques to reduce the hazard, and to recommend how these maps should be used by Davis County and its cities for land-use planning. A major goal is to translate technical information so that government officials and the general public can appreciate the need to reduce liquefaction hazards.

\section{ACKNOWLEDGMENTS}

Gary E. Christenson (Utah Geological Survey), Loren R. Anderson (Department of Civil and Environmental Engineering, Utah State University), Jeffrey R. Keaton (Sergent, Hauskins and Beckwith), Craig Barker (Weber County Planning Department), Barry Burton and Tim Stephens (Davis County Planning Department), and William J. Kockelman and Hal Olsen (U.S. Geological Survey) kindly reviewed this paper and provided valuable suggestions. Bill Black (Utah Geological Survey) drafted the figures. 
TABLE 16.-Ground slope and expected failure mode resulting from liquefaction

[modified from Youd, 1978a; Anderson and others, 1982]

\begin{tabular}{ll}
\hline Ground surface slope & Failure mode \\
\hline $\begin{array}{l}\text { Less than } 0.5 \text { percent } \\
\text { Less than } 0.5 \text { percent, } \\
\text { liquefaction at depth. }\end{array}$ & Bearing capacity \\
0.5 to 5.0 percent & Ground oscillation \\
Greater than 5.0 percent & Lateral-spread landslide \\
\hline
\end{tabular}

\section{NATURE OF THE LIQUEFACTION HAZARD}

Liquefaction itself does not necessarily cause damage, but it may induce ground failure of various types that can be very damaging. The four types of ground failure that commonly result from liquefaction are loss of bearing strength, ground oscillation, lateral-spread landslides, and flow landslides (Youd, 1978a, b; Tinsley and others, 1985). Youd and others (1975) relate these types of ground failure to the slope of the ground surface (table 16).

Loss of bearing strength beneath a structure can occur during ground shaking when the underlying soil liquefies and loses strength (Tinsley and others, 1985) in areas where slopes are generally less than about 0.5 percent (Anderson and others, 1982) (fig. 63). The soil mass can then deform, allowing buildings to settle and (or) tilt (Tinsley and others, 1985). Buoyant buried structures such as gasoline storage or septic tanks may float upward in liquefied soils (Tinsley and others, 1985). Among the more spectacular examples of a bearing capacity failure was the tilting of four 4-story buildings, some as much as 60 degrees, in the Kwangishicho apartment complex during the 1964 Niigata, Japan, earthquake (National Research Council, 1985). Buried septic tanks rose as much as $3 \mathrm{ft}(1 \mathrm{~m})$ during the same earthquake (Tinsley and others, 1985).

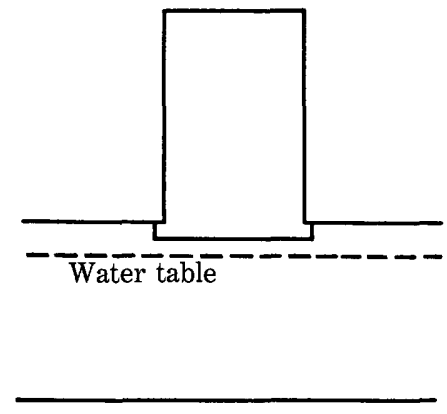

Before liquefaction

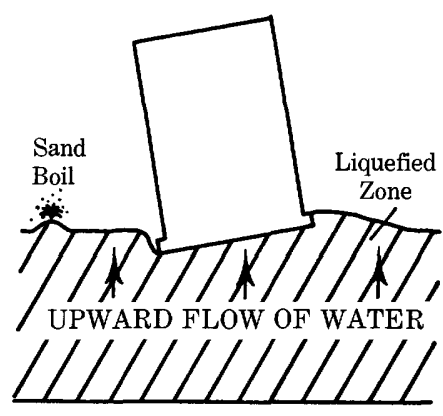

After liquefaction
FIGURE 63. - Tilting of a building due to liquefaction and loss of bearing strength in the underlying soil. Liquefaction reduces shear strength of the soil, which provides foundation support, allowing the building to settle and tilt (Youd, 1984, in National Research Council, 1985).

Ground oscillation takes place when liquefaction occurs beneath soil layers that do not liquefy and where slopes are too gentle for lateral displacement to occur (Tinsley and others, 1985). Under these conditions, "liquefaction at depth commonly decouples overlying soil blocks, allowing them to jostle back and forth on the liquefied layer during an earthquake" (National Research Council, 1985) (fig. 64). The decoupled layer vibrates in a different mode than the underlying and surrounding firm ground, causing fissures to form and impacts to occur between oscillating blocks and adjacent firm ground (National Research Council, 1985; Tinsley and others, 1985). Overlying structures and buried facilities can be damaged as a result of ground settlement, the opening and closing of fissures, and sand boils, which commonly accompany the oscillations (Tinsley and others, 1985).

Where the ground surface slope ranges between 0.5 and 5.0 percent, failure by lateral spreading may occur (Anderson and others, 1982). Lateral spreads occur as surficial blocks of sediment are displaced laterally downslope as a result of liquefaction in a subsurface layer

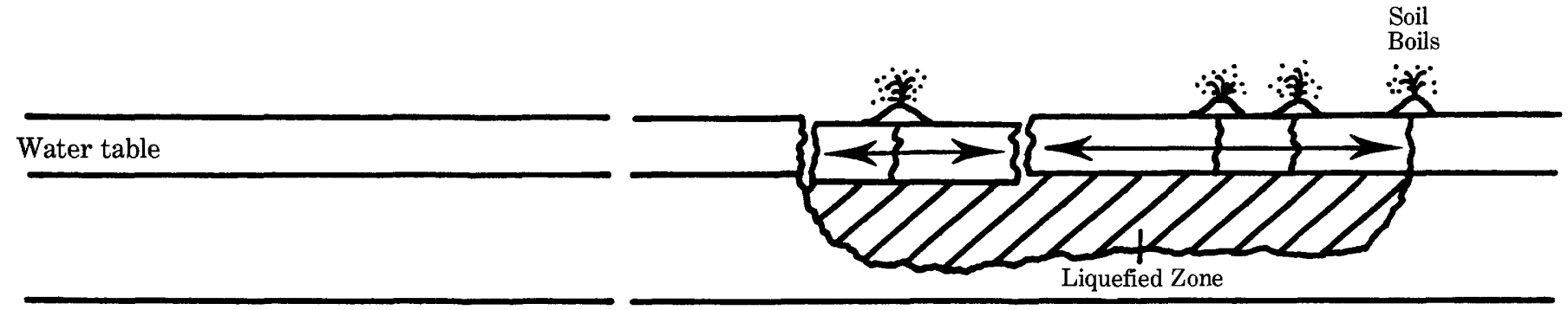

Before liquefaction
After liquefaction

FIGURE 64.-Diagram of liquefaction-induced ground oscillation. Liquefaction (cross-hatched zone) causes the surface layer to decouple from the surrounding firm ground, resulting in ground settlement, the opening and closing of fissures, and sand boils (Youd, 1984, in National Research Council, 1985). 

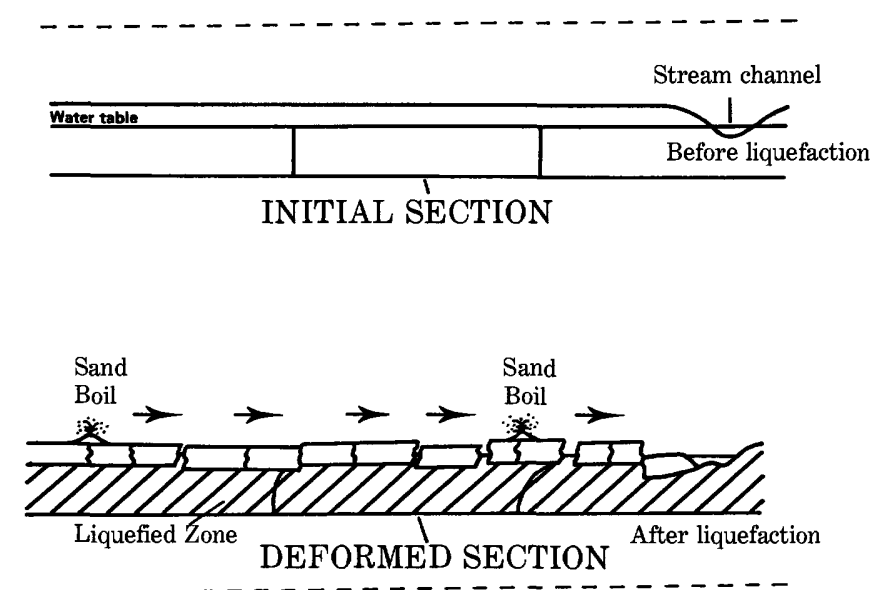

FiguRE 65. - Diagram of a lateral spread. Liquefaction occurs in the cross-hatched zone (Youd, 1984, in National Research Council, 1985). The ground surface slopes slightly to the right.

(National Research Council, 1985) (fig. 65). The surface layer commonly breaks up into blocks bounded by fissures, which may tilt and settle differentially with respect to one another (National Research Council, 1985). The ground surface can be displaced laterally several yards, perhaps tens of yards, depending on soil and ground-water conditions and the duration of earthquake shaking (Tinsley and others, 1985). As shown in table 17, significant damage to structures may result from lateral spreading.

Lateral-spread landsliding can be especially destructive to pipelines, utilities, bridge piers, and other structures with shallow foundations (Tinsley and others, 1985). Lateral-spread landslides with ground displacements of only a few feet caused every major pipeline break in San Francisco during the 1906 earthquake (Youd, 1978a); hence, liquefaction was largely responsible for the inability to control the fires that caused 85 percent of the damage to the city (Tinsley and others, 1985).

Where ground surface slopes are steeper than about 5.0 percent, slope failure may occur in the form of flow landslides (Anderson and others, 1982) (fig. 66). Flow failure is the most catastrophic mode of liquefactioninduced ground failure (Tinsley and others, 1985). Flow landslides consist chiefly of liquefied soil or blocks of intact material riding on a liquefied layer (National Research Council, 1985). Flow failures can cause soil masses to be displaced tens of yards; under favorable conditions, flow failure has displaced materials for miles at relatively high velocities (Tinsley and others, 1985). Extensive damage due to flow landslides occurred in Seward and Valdez, Alaska, during the 1964 Alaska earthquake (Tinsley and others, 1985). A flow landslide

\begin{tabular}{|c|c|}
\hline Ground displacement & Level of expected damage \\
\hline $\begin{array}{l}\text { Less than } 4 \text { in. } \\
4 \text { in. to } 1 \mathrm{ft} \\
1 \text { to } 2 \mathrm{ft} \\
\text { More than } 2 \mathrm{ft}\end{array}$ & $\begin{array}{l}\text { Little damage, reparable } \\
\text { Severe damage, reparable } \\
\text { Severe damage, nonreparable } \\
\text { Collapse, nonreparable }\end{array}$ \\
\hline
\end{tabular}

during the 1906 San Francisco earthquake knocked a powerhouse near the Mount Olivet Cemetery from its foundation (Youd, 1973).

\section{REDUCTION OF LIQUEFACTION HAZARDS}

Earthquake-induced soil liquefaction or liquefactioninduced ground failures have the potential to cause damage to most types of structures. Structures that are particularly sensitive include buildings with shallow foundations, railway lines, highways and bridges, buried structures, dams, canals, retaining walls, port structures, utility poles, and towers (National Research Council, 1985). The National Research Council (1985) identifies several alternative approaches that can be taken if earthquake-induced liquefaction is determined to be a threat to existing or proposed structures. For an existing structure the choices include (1) retrofitting the structure and (or) site to reduce the potential for liquefactioninduced damage, (2) abandoning the structure if the retrofit costs exceed the potential benefits derived from maintaining the structure, or (3) accepting the risk.

Possible actions that may be taken if a liquefaction hazard exists at the site for a proposed structure include (1) improving site conditions to lower the potential for liquefaction, (2) designing the structure to withstand the

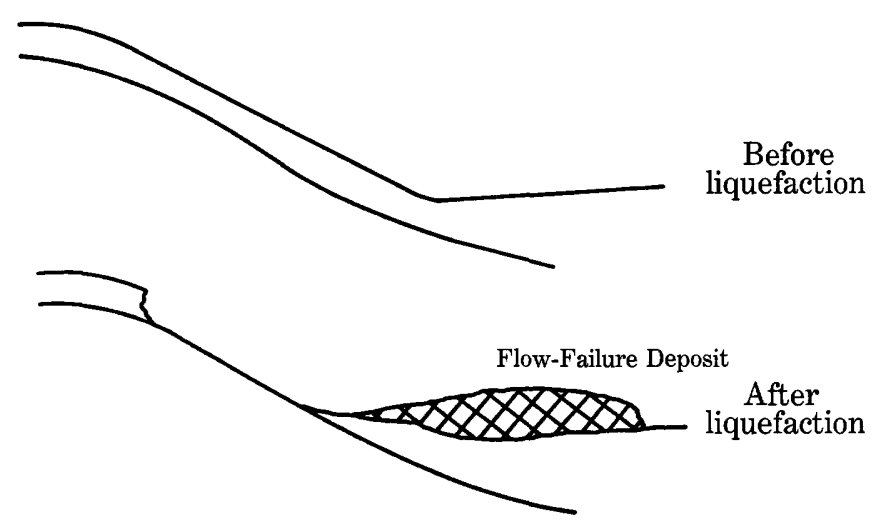

FIGURE 66.-Diagram of a flow failure. Liquefaction beneath the ground surface causes loss of shear strength, allowing the soil mass to flow down the steep slope (Youd, 1984, in National Research Council, 1985). 
effects of liquefaction, (3) avoiding the risk by moving the proposed development to a less hazardous site, (4) insuring the development so that, if liquefaction-induced damage occurs, funds will be available to repair the damage, or (5) accepting the risk if the potential for and consequences of liquefaction are clearly understood.

Structural solutions to reduce the effects of liquefied soils can take several forms. For buildings, foundationsupport problems in liquefiable soils may be avoided by using end-bearing piles, caissons, or fully compensated mat foundations designed for the predicted liquefaction phenomena at the site (National Research Council, 1985). Methods of improving liquefiable soil foundation conditions are (1) densification of soils through vibration or compaction, (2) grouting, (3) dewatering with drains or wells, and (4) loading or buttressing to increase confining pressures (National Research Council, 1985). Costs of site improvement techniques range from less than $\$ 0.50$ to more than $\$ 500.00$ per cubic yard of soil foundation material treated (National Research Council, 1985).

\section{INFORMATION FOR DAVIS COUNTY ON LIQUEFACTION POTENTIAL}

The results of the liquefaction study are summarized in four maps. Each map consists of two parts: a southern and a northern half of Davis County (Anderson and others, 1982). The base maps are 50 percent reductions of U.S. Geological Survey $712^{\prime}$ (topographic) quadrangles and have a scale of $1 \mathrm{in.}=4,000 \mathrm{ft}$ (scale 1:48,000). The four maps are Selected Geologic Data Map, Soils and Ground Water Data Map, Ground Slope and Critical Acceleration Map, and Liquefaction-Potential Map. Figure 67 shows the location of figure 68 , which is a reproduction of a portion of the Anderson and others (1982) Liquefaction Potential Map (South Half) for Davis County.

A summary of the methods used in preparing the maps follows; for a detailed discussion of the technical aspects of map preparation, refer to Anderson and others (1982). Maps prepared by Anderson and others (1982) take into consideration soil and ground-water conditions and earthquake probability in determining liquefaction potential in Davis County. Soil and ground-water conditions were evaluated on the basis of subsurface data, chiefly boreholes and cone penetrometer tests, obtained from private engineering consultants, State and local government agencies, and tests run as part of the liquefaction-potential investigation. A calculation of the level of ground shaking needed to induce liquefaction was then made at each data point. Peak horizontal ground acceleration was used as the measure of ground shaking,

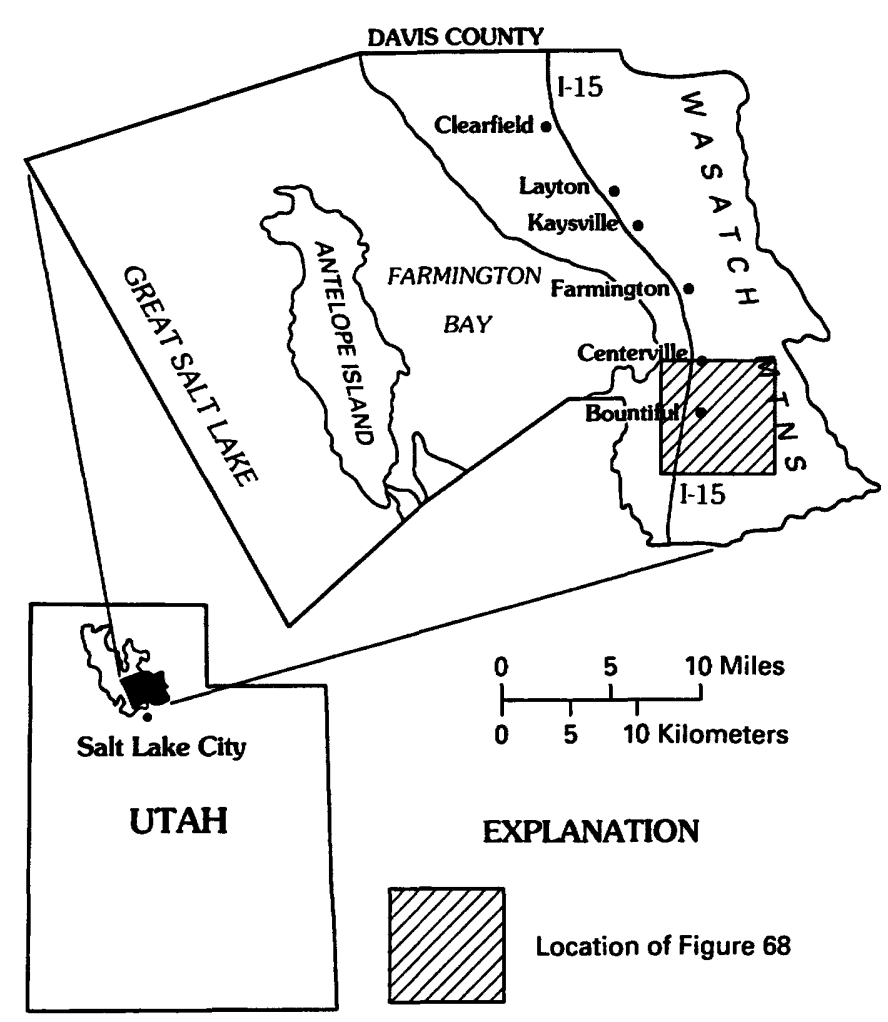

FIGURE 67.-Location map for figure 68.

and the level needed to induce liquefaction under a particular set of soil and ground-water conditions was termed the critical acceleration. The liquefaction potential in Davis County has been rated on the basis of the probability that the critical acceleration needed to induce soil liquefaction will be exceeded during a 100 -yr return period (table 18). Local geological conditions were also considered in refining liquefaction-potential boundaries (Anderson and others, 1982). As shown on the Selected Geologic Data Map, five slope failures covering more than $10 \mathrm{mi}^{2}\left(26 \mathrm{~km}^{2}\right)$ in three areas of Davis County have been mapped and interpreted as prehistoric lateralspread failures, probably induced by past earthquake ground shaking (Van Horn, 1975, 1982; Miller, 1980; Anderson and others, 1982).

The liquefaction-potential rating for a given location can be determined by locating the site on the Liquefaction Potential Map. The approximate probability of ground shaking sufficient to induce liquefaction at that site in the next $100 \mathrm{yr}$ may then be determined by referring to the proper category in table 18. The expected mode of ground failure if liquefaction occurs at a given location may be evaluated by determining the approximate ground surface slope at the site on the Ground Slope and Critical Acceleration Map and referring to table 16. Contours depicting areas of less than 0.5 percent, 0.5 to 5.0 percent, and greater than 5.0 percent 


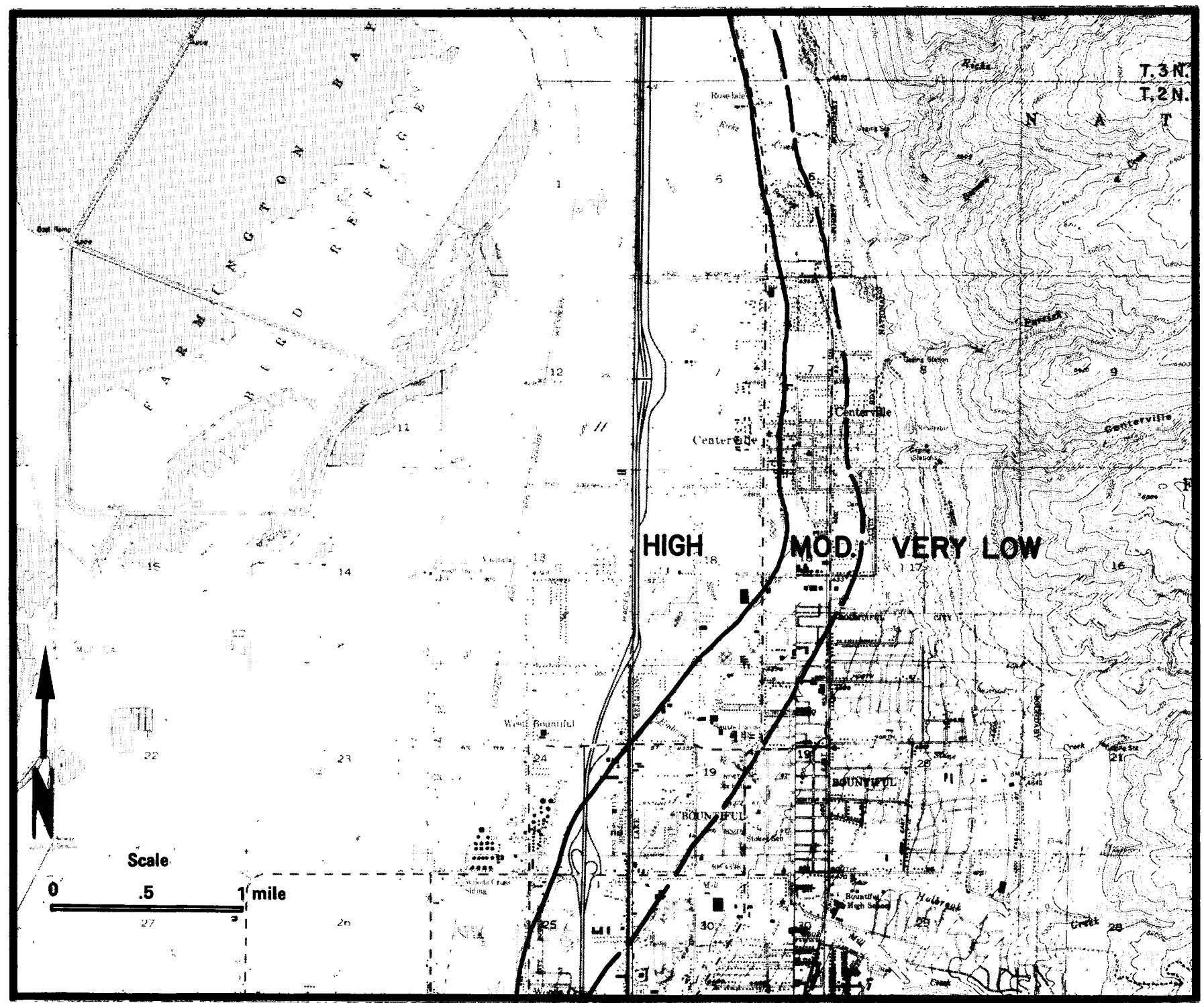

FIGURE 68. - Liquefaction-potential map for the Centerville and northern Bountiful area of southern Davis County. High, Mod. (moderate), and Very Low refer to liquefaction potential ratings determined by Anderson and others (1982). This figure was reproduced from a portion of the Liquefaction Potential Map (South Half) for Davis County, Utah, by Anderson and others (1982).

slope are included in this map. To differentiate between the two failure modes-bearing capacity and soil oscillation-in areas of less than 0.5 percent slope, the depth of the liquefiable layer must be known. This depth can be determined for specific sites by using the Soils and Ground-Water Data Map to determine the depth to liquefiable soils and the nature of overlying and underlying units. However, the map does not interpret depths to liquefiable layers between data points, so the two failure modes can only be differentiated at specific sites where data were collected.

\section{RECOMMENDED USE OF MAPS IN LAND-USE PLANNING}

These maps are at a regional scale and, although they can be used to gain an understanding of probable potential of a given area for liquefaction during earthquake ground shaking, they are not designed to replace sitespecific evaluations. Mapped areas rated as having a low liquefaction potential may contain isolated areas with a high liquefaction potential, and areas rated as having a high liquefaction potential may contain isolated areas 
TABLE 18.-Criteria used to evaluate liquefaction potential [Anderson and others, 1982]

\begin{tabular}{|c|c|c|}
\hline $\begin{array}{l}\text { Liquefaction } \\
\text { potential }\end{array}$ & $\begin{array}{l}\text { Critical acceleration } \\
\text { needed to induce } \\
\text { liquefaction }(g)\end{array}$ & $\begin{array}{l}\text { Approximate probability } \\
\text { that the critical acceler- } \\
\text { ation needed to induce } \\
\text { liquefaction will be } \\
\text { exceeded during the } \\
\text { next } 100 \mathrm{yr} \text { (percent) }\end{array}$ \\
\hline High & Less than 0.12 & Great \\
\hline Moderate & Between 0.12 and 0.20 & een 10 and 50 \\
\hline Low & Between 0.20 and 0.30 & Between 5 and 10 \\
\hline Very low & More than 0.30 & Less than 5 \\
\hline
\end{tabular}

The unit of measure $g$ is the force of gravity.

that are not prone to liquefaction. Site-specific studies of liquefaction potential should be conducted where this information is needed.

Large areas of Davis County have moderate to high potential for liquefaction during earthquake ground shaking, including most of the area west of State Highway 89 . The liquefaction potential maps provide a general indication of where the hazard may exist and serve as a means of evaluating the need for site-specific studies. Because of the distribution of data points and the relatively small scale of the maps, this information does not preclude the necessity for site-specific evaluations. The point data may be useful in a site evaluation, depending on the quality of the data. Liquefaction potential should be evaluated (see table 19) and any necessary mitigative measures should be recommended in site investigation reports submitted by the developer prior to planning commission approval. Areas of moderate to high liquefaction potential need not be avoided because structural measures and site modification techniques are available to reduce hazards. Reports addressing liquefaction potential in such areas are recommended for large structures but not for single-family dwellings, according to the engineers and geologists who conducted the liquefaction-potential study (Anderson and others, 1987). This is because the cost of reducing liquefaction hazards

TABLE 19.-Matrix indicating recommended report requirements for liquefaction hazards, Davis County, Utah

\begin{tabular}{|c|c|c|}
\hline \multirow{2}{*}{ Type of development } & \multicolumn{2}{|c|}{ Liquefaction-potential rating } \\
\hline & High/moderate & Low/very low \\
\hline $\begin{array}{l}\text { Critical facilities including life- } \\
\text { lines and high-occupancy } \\
\text { buildings. }\end{array}$ & Yes & Yes \\
\hline $\begin{array}{l}\text { Industrial and commercial } \\
\text { buildings (other than high } \\
\text { occupancy). }\end{array}$ & Yes & No \\
\hline Residential subdivisions & $\mathrm{No}^{1}$ & No \\
\hline Residential single lots & $\mathrm{No}^{1}$ & No \\
\hline
\end{tabular}

${ }^{1}$ Appropriate disclosure should be required. commonly exceeds the value of single-family dwellings (L.R. Anderson, personal commun., August 31, 1987), and liquefaction is generally not a life-threatening hazard.

\section{SCOPE OF SITE INVESTIGATIONS}

A liquefaction-potential evaluation should be part of a standard soil foundation investigation for the proposed development. Initial evaluations for liquefaction potential should be based on depth to ground water and on soil types. If soil and ground-water conditions indicate that liquefiable soils may be present, standard penetration tests and (or) cone penetration tests should be conducted to determine critical accelerations needed to induce liquefaction. A site-specific liquefaction-potential report should include accurate maps of the area of the proposed development, the location of boreholes and test pits, and the site geology. Logs of boreholes and test pits should be included in the report, and any ground water encountered should be noted. The location of and depths to liquefiable soils should be noted, and the probability should be determined that the critical accelerations needed to induce liquefaction in these soils will be exceeded for appropriate time periods. Recommendations for hazard reduction techniques should be included. The county planing department and county engineer should meet to plan the site-specific liquefaction studies and decide what types of information should be obtained.

A useful guide for preparing reports has been published by the Utah Section of the Association of Engineering Geologists (1986). Site-specific reports addressing liquefaction hazards should be reviewed by the county and, once approved, submitted to the planning commission along with review comments, so that the planning commission has sufficient information available to make decisions regarding the proposed development.

\section{REFERENCES}

Anderson, L.R., Keaton, J.R., Aubry, Kevin, and Ellis, S.J., 1982, Liquefaction potential map for Davis County, Utah: Logan, Utah, Department of Civil and Environmental Engineering, Utah State University, and, Salt Lake City, Utah, Dames and Moore Consulting Engineers, $50 \mathrm{p}$.

Anderson, L.R., Keaton, J.R., Bay, J.A., and Rice, J.D., 1987, Liquefaction potential mapping, Wasatch Front, Utah, in McCalpin, James, ed., Proceedings of the 23rd annual symposium on engineering geology and soils engineering: Boise, Idaho Department of Transportation, p. 1-17.

Kuribayashi, Eiichi, and Tatsuoka, Fumio, 1975, Brief review of liquefaction during earthquakes in Japan: Soils and Foundations, v. 15 , no. 4 , p. $81-92$.

1977, History of earthquake-induced liquefaction in Japan: Japan Ministry of Construction, Public Works Research Institute Bulletin, v. 31, p. 26. 
Miller, R.D., 1980, Surficial geologic map along part of the Wasatch Front, Great Salt Lake Valley, Utah: U.S. Geological Survey Miscellaneous Field Studies Map MF-1198, scale 1:100,000.

National Research Council, 1985, Liquefaction of soils during earthquakes: Washington, D.C., National Academy Press, 240 p.

Schwartz, D.P., and Coppersmith, K.J., 1984, Fault behavior and characteristic earthquakes -Examples from the Wasatch and San Andreas fault zones: Journal of Geophysical Research, v. 20, p. 261-285.

Tinsley, J.C., Youd, T.L., Perkins, D.M., and Chen, A.T.F., 1985, Evaluating liquefaction potential, in Ziony, J.I., ed., Evaluating earthquake hazards in the Los Angeles region-An earth science perspective: U.S. Geological Survey Professional Paper 1360, p. 263-315.

Utah Section of the Association of Engineering Geologists, 1986, Guidelines for preparing engineering geologic reports in Utah: Utah Geological and Mineral Survey Miscellaneous Publication M, $2 \mathrm{p}$.

Van Horn, Richard, 1975, Largest known landslide of its type in the United States-A failure by lateral spreading in Davis County, Utah: Utah Geology, v. 2, no. 1, p. 83-87.

1982, Surficial geologic map of the Salt Lake City North Quadrangle, Davis and Salt Lake Counties, Utah: U.S. Geological Survey Miscellaneous Investigation Series Map I-1404, scale $1: 24,000$.
Youd, T.L., 1973, Liquefaction, flow, and associated ground failure: U.S. Geological Survey Circular 688, 12 p.

1977, Discussion of "Brief review of liquefaction during earthquakes in Japan" by Kuribayashi, Eiichi, and Tatsuoka, Fumio, 1975: Soils and Foundations, v. 17, no. 1, p. 82-85.

1978a, Major cause of earthquake damage is ground failure: Civil Engineering, v. 48, no. 4, p. 47-51.

1978b, Mapping liquefaction-induced ground failure potential: Proceedings of the American Society of Civil Engineers, Journal of Geotechnical Engineering Division, v. 4 no. 674, p. 433-446.

1980, Ground failure displacement and earthquake damage to buildings: American Society of Civil Engineers conference on civil engineering and nuclear power, 2d, Knoxville, Tenn., 1980, v. 2, p. 7-6-2-7-6-26.

1984, Geologic effects-Liquefaction and associated ground failure: U.S. Geological Survey Open-File Report 84-760, p. 210-232.

Youd, T.L., Nichols, D.R., Helley, E.J., and Lajoie, K.R., 1975, Liquefaction potential, in Studies for seismic zonation in the San Francisco Bay region: U.S. Geological Survey Professional Paper 941-A, p. A68-A74.

Youd, T.L., and Perkins, D.M., 1987, Mapping of liquefaction severity index: Journal of Geotechnical Engineering, v. 113, p. 1374-1392. 


\title{
TECTONIC SUBSIDENCE HAZARD: A GUIDE FOR LAND-USE PLANNING, UTAH AND JUAB COUNTIES, UTAH
}

\author{
By ROBERT M. ROBISON ${ }^{16}$
}

\begin{abstract}
Tectonic subsidence (seismic tilting) is the downwarping and tilting of the valley floor relative to the mountains during a surface-faulting earthquake ( $>M$ 6.5). The maximum vertical subsidence occurs at the base of the fault and decreases toward the valley. Two historic earthquakes in the Intermountain Seismic Belt are used as models for the Wasatch fault zone (WFZ): the 1959 Hebgen Lake, Mont., and the 1983 Borah Peak, Idaho, earthquakes. Although the maximum subsidence was $20 \mathrm{ft}(6 \mathrm{~m})$ at Hebgen Lake, the average offset of the WFZ is expected to produce surface offset of about $6-9 \mathrm{ft}(2-3 \mathrm{~m})$ with less tectonic subsidence. The affected area could extend for about $10 \mathrm{mi} \mathrm{(16}$ $\mathrm{km}$ ) basinward from the fault with maximum tilt within about $3 \mathrm{mi}(5$ $\mathrm{km}$ ). The lateral extent of subsidence is controlled by the length of fault rupture, which is expected to coincide with segment lengths that are generally $15-20 \mathrm{mi}(24-32 \mathrm{~km})$. The recurrence interval for tectonic subsidence along a particular fault segment is the same as that of surface-faulting earthquakes, ranging from hundreds to several thousands of years.

Hazards associated with tectonic subsidence in Utah and Juab Counties include shoreline flooding along Utah Lake and other bodies of water tilted by faulting, inundation from shallow ground water, and damage to facilities that cannot tolerate small changes in gradient, such as waste-water treatment facilities. Tectonic subsidence maps for the WFZ that show areas of potential flooding and tilting have been prepared for Utah and Juab Counties. However, the maps are based on theoretical models and are approximations of what may actually occur. Site-specific studies are recommended for certain vulnerable facilities within zones of flooding and maximum tilting such as electricitygenerating plants, waste-water treatment facilities, and other structures that, if tilted or inundated, could cause public health and safety problems as well as economic losses. The site-specific report should determine the depth to ground water and the site elevation with respect to projected lake and ground-water levels and should recommend hazard reduction techniques. Mitigation could include provisions to relevel after subsidence or to build more freeboard or tolerance for containers that hold toxic or other dangerous materials. Reports would be reviewed by the county geologist and county engineer.
\end{abstract}

\section{INTRODUCTION}

Tectonic subsidence is the warping, lowering, and tilting of a valley floor that accompanies surfacerupturing earthquakes on normal (dip-slip) faults such as

\footnotetext{
${ }^{16}$ Utah County Planning Department, Provo, Utah.
}

the Wasatch fault zone (WFZ). Subsidence occurred during the 1959 Hebgen Lake, Mont., earthquake and the 1983 Borah Peak, Idaho, earthquake, and there is geologic evidence for tectonic subsidence, such as backtilting adjacent to the fault zone, during prehistoric earthquakes along the Wasatch Front (Keaton, 1987). Inundation along the shores of lakes and reservoirs and the ponding of water in areas with a shallow water table may be caused by tectonic subsidence. Also, tectonic subsidence may adversely affect certain structures that require gentle gradients or horizontal floors, particularly waste-water treatment facilities and sewer lines (Keaton, 1987). In this report, I discuss the consequences of possible tectonic subsidence in Utah and eastern Juab Counties (fig. 69) and make recommendations concerning the use of hazard maps for mitigation of subsidence hazards in land-use planning.

\section{ACKNOWLEDGMENTS}

Special thanks are given to Gary E. Christenson (Utah Geological Survey), Stephen F. Personius, and William J. Kockelman (U.S. Geological Survey) for their support and review of this paper. Jeff Keaton (Senior Engineering Geologist, Sergent, Hauskins and Beckwith Consultants) is responsible for a large portion of the research on tectonic subsidence along the Wasatch Front and provided valuable comments in his review. Craig Nelson (Salt Lake County geologist) and Mike Lowe (Davis County geologist) also made helpful suggestions.

\section{CHARACTERISTICS OF TECTONIC SUBSIDENCE}

Tectonic subsidence, also termed seismic tilting, occurs during large-magnitude earthquakes ( $>M$ 6.5) generated along normal faults that have accompanying deformation or displacement at the ground surface. The extent of seismic tilting is controlled chiefly by the amount and length of surface displacement and normally 


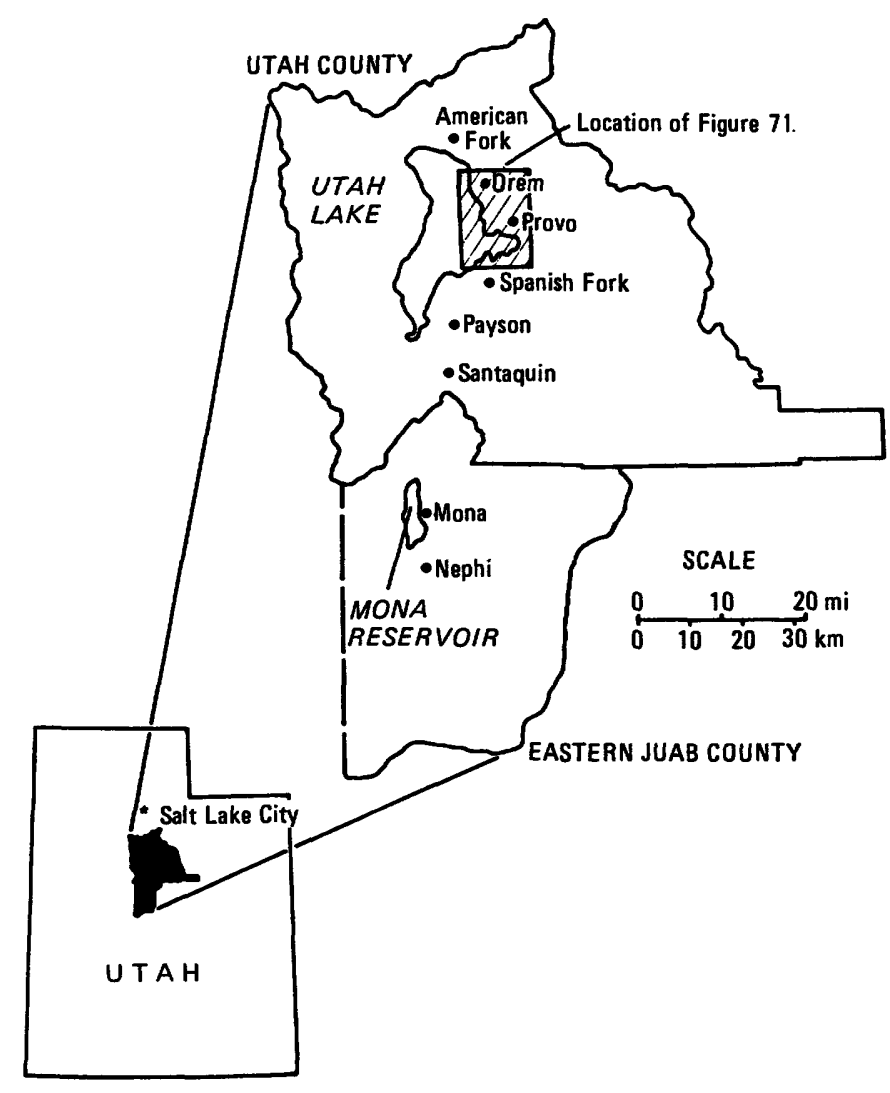

FIGURE 69. - Map showing the location of Utah and northeastern Juab Counties.

occurs only along the portion of the fault that experiences surface deformation. The area of subsidence is controlled by the length of the fault rupture, and subsidence should extend only a short distance beyond the ends of the fault rupture.

The WFZ consists of 10-11 distinct segments, which probably break independently and average about 20.6-22.7 $\mathrm{mi}(33.3-36.6 \mathrm{~km})$ in length (Machette and others, 1989). The WFZ segments in Utah and eastern Juab Counties are the Provo (unrestricted) and Nephi, which are $43 \mathrm{mi}(69.5 \mathrm{~km})$ and $26.4 \mathrm{mi}(42.5 \mathrm{~km})$ long, respectively (Machette and others, 1989); these are discussed further elsewhere (Robison, "Surface-fault rupture: A guide for land-use planning, Utah and Juab Counties, Utah," this volume).

The probability that tectonic subsidence will occur is the same as that for a large earthquake ( $>M 6.5)$, namely, 340-415 yr for the average composite recurrence interval for large earthquakes on the WFZ. However, for any given individual segment, the average recurrence interval is 2035-2070 yr (Machette and others, 1989). Because of the dispersion in the timing of events and the catastrophic losses that will occur during a large-magnitude earthquake, the most conservative esti- mate, 340-415 yr, should be used. This figure becomes even more significant when the timing of the most recent event, about $400 \mathrm{yr}$ ago (Machette and others, 1989), is considered.

Two earthquakes have occurred in the northern Basin and Range province that are models for the WFZ; the largest is the $1959 M_{s} 7.5$ Hebgen Lake, Mont., earthquake (Doser, 1985). The area of tilting, measured perpendicular to the fault, extended up to $10 \mathrm{mi}(16 \mathrm{~km})$ from the fault at Hebgen Lake (Meyers and Hamilton, 1964). The amount of subsidence at Hebgen Lake is larger than that expected for the "characteristic earthquake" (Schwartz and Coppersmith, 1984) of the Wasatch Front and was not used as a direct analog for the Utah and Juab Counties area. The maximum subsidence at Hebgen Lake was $20 \mathrm{ft}(6 \mathrm{~m})$, whereas the WFZ has an expected offset of 6-9 ft (2-3 m) (Schwartz and Coppersmith, 1984). Also, the hazard maps for Utah and Juab Counties will show average expected offset for the WFZ, not the largest displacement that has occurred locally. The second earthquake model, the 1984 Borah Peak event, also formed subsidence, but lack of preearthquake survey and profile control eliminated evaluation of tectonic subsidence adjacent to the fault (Keaton, 1987).

The expected area of subsidence for the WFZ extends for about $10 \mathrm{mi}(16 \mathrm{~km})$ west of the fault zone, the majority of the deformation being within about $3 \mathrm{mi}(5$ $\mathrm{km}$ ) (Keaton, 1986). The maximum amount of subsidence should occur at the fault and decrease gradually on the downdropped valley block (Keaton, 1986).

Tectonic subsidence may cause flooding (Smith and Richins, 1984) (fig. 70). The amount of inundation along shorelines will depend on lake levels at the time of the event. Several zones of flooding have been delineated by Keaton (1986) for Utah Lake that correlate to lake elevations of 4485,4490 , and $4495 \mathrm{ft}(1368,1370$, and 1371 $\mathrm{m})$. These levels cover the range of lake fluctuations since 1935, when the lake reached its historical low of $4478 \mathrm{ft}(1365 \mathrm{~m})$. The normal operating or "compromise" level of the lake is about $4490 \mathrm{ft}(1370 \mathrm{~m})$. Also plotted on the maps prepared for the counties are areas where the ground water may pond in the event of seismic tilting. Ground water was considered to be $3 \mathrm{ft}$ from the ground surface prior to subsidence. A portion of the tectonic subsidence maps prepared by Keaton (1986) was adapted and is shown in figure 71. Also, the east shore of Mona Reservoir in Juab County may experience flooding due to tectonic subsidence similar to the shoreline of Utah Lake.

\section{MITIGATION}

The two major types of hazards associated with tectonic subsidence are tilting of the ground surface and 
$\boldsymbol{A}$

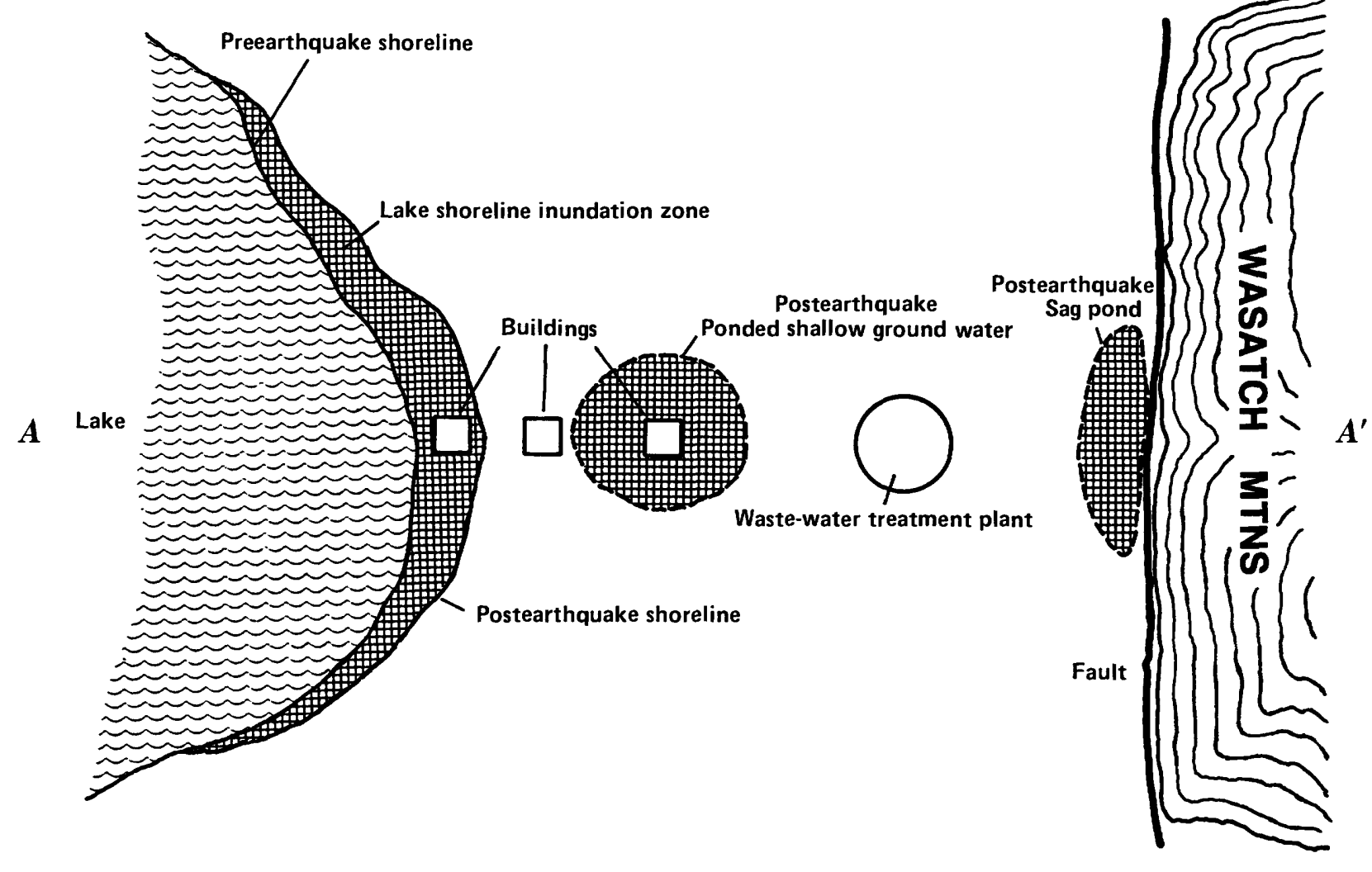

Preearthquake

$\boldsymbol{B}$

$\boldsymbol{A}$

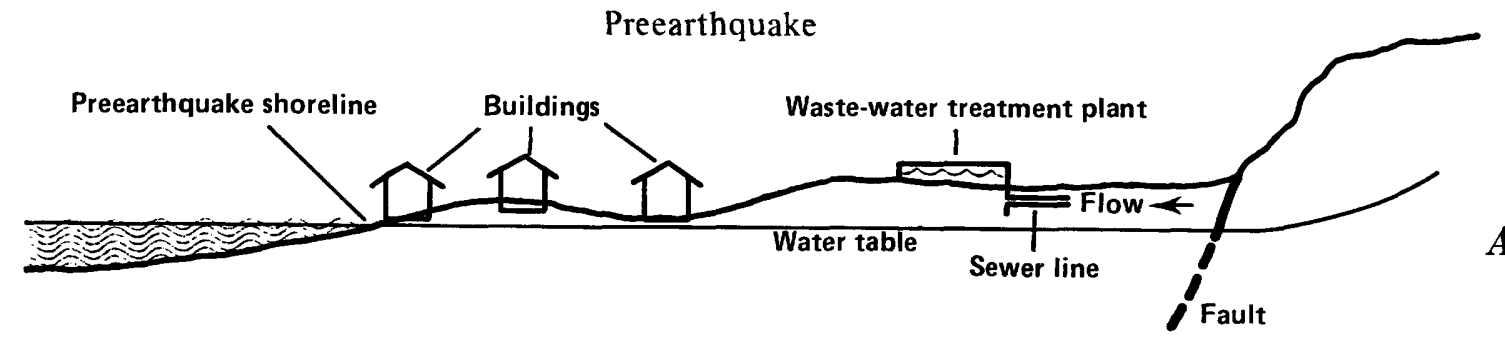

Postearthquake

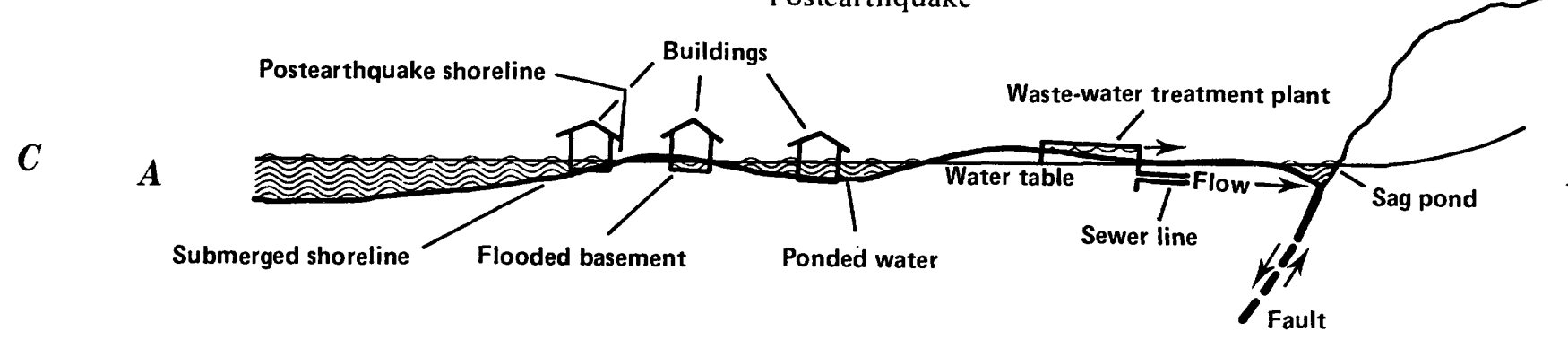

FIGURE 70.-(A) Map (not to scale) showing surface rupture and tectonic subsidence accompanying a hypothetical earthquake along the Wasatch fault zone. Areas that may be inundated with water after an earthquake are shown with a checkerboard pattern. A cross-sectional view between points $A-A^{\prime}$ is given as a reference in parts $B$ and $C$ to show the possible effects from tectonic subsidence. (B) Cross-sectional view between points $\mathrm{A}-\mathrm{A}^{\prime}$ (from part $A$ ) showing an imaginary plane (water table) at its preearthquake position. Buildings and a waste-water treatment plant are represented to illustrate some of the possible effects of tectonic subsidence. Subsidence would probably not be as uniform as depicted in this figure. Also, most of the deformation would likely occur adjacent to the fault, and total effects may extend over a much wider area. $(C)$ Cross-sectional view between points $\mathrm{A}-\mathrm{A}^{\prime}$ (from parts $A$ and $B$ ) showing potential postearthquake effects from tectonic subsidence. Note the areas of lake flooding as well as flooding from shallow ground water. Gravity-flow systems such as waste-water treatment plant may experience problems from reversed flows. 


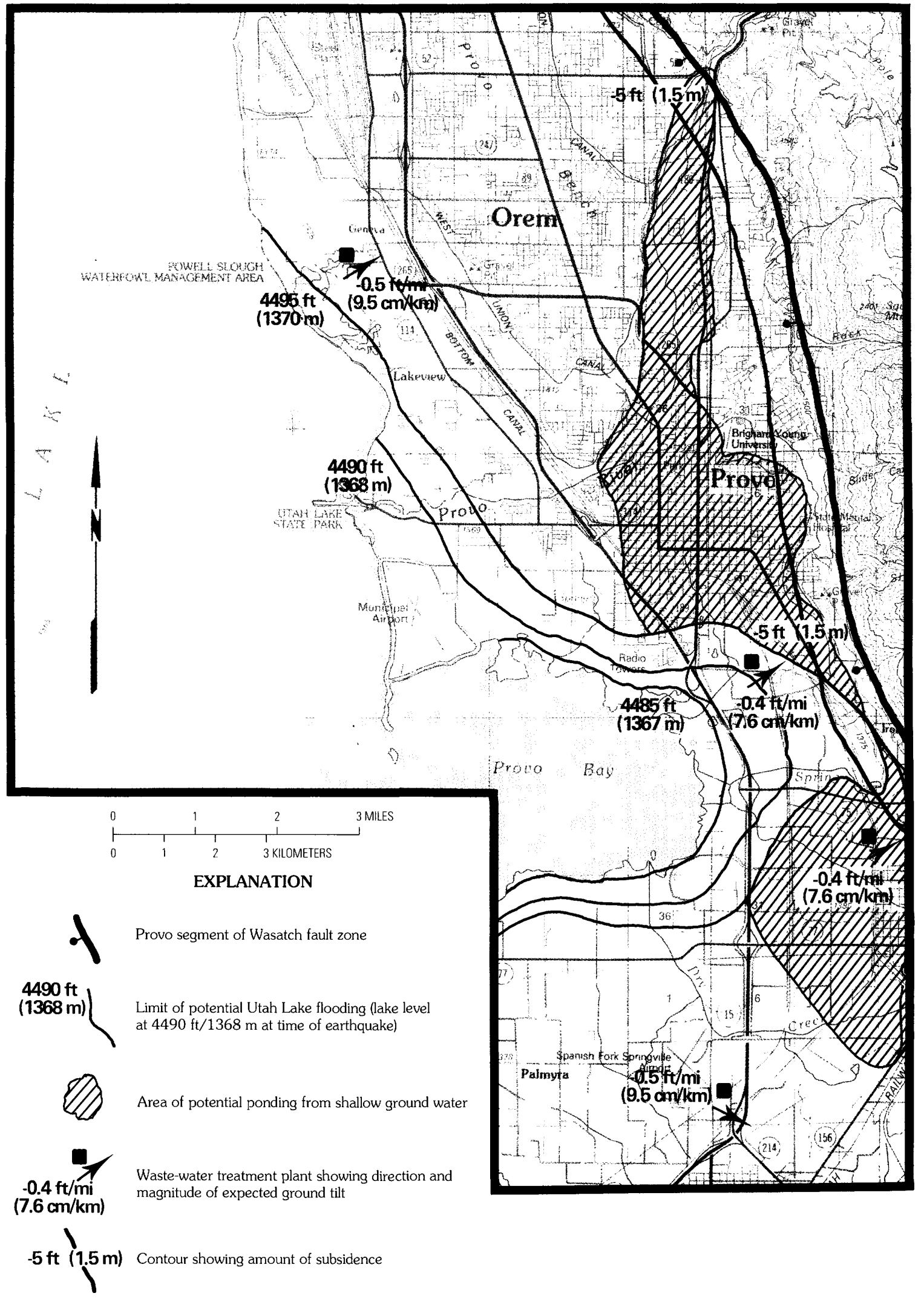

FIGURE 71.-Map showing area of potential tectonic subsidence in part of Utah Valley, based on an $M$ 7-7.5 earthquake with about $6-9 \mathrm{ft}(2-3 \mathrm{~m})$ of surface rupture. Heavy (numbered) lines around Utah Lake indicate potential postearthquake shorelines at three possible elevations of the lake at the time of the event (modified from Keaton, 1986). 
flooding from lakes, reservoirs, or shallow ground water (fig. 70). Because subsidence may occur over large areas (tens of square miles), it is generally not practical to avoid the use of potentially affected land except in narrow areas of hazard due to lake shoreline flooding. For gravity-flow structures such as waste-water treatment plants that are within areas of possible subsidence, it is advisable to consider the tolerance of such structures to slight changes in gradient. Some structures may have to be releveled after a large-magnitude earthquake. Critical facilities that contain dangerous substances should have safety features to protect the structure, its occupants, and the environment from both tilting and flooding.

Flooding problems along lakes from tectonic subsidence can be reduced using standard techniques. Structures can be raised above expected flood levels and dikes can be built. Land-use regulations around lakes or reservoirs can prohibit or restrict development in a zone along the shoreline that may be inundated. A buffer or safety zone of several feet of elevation above projected lake levels could be adopted to protect against natural rises from wet periods, storm waves, and earthquakeinduced seiching, as well as hazards associated with tectonic subsidence.

Rises in the water table accompanying tectonic subsidence may cause water to pond, flood basements, and disrupt buried facilities, chiefly along a zone $3 \mathrm{mi}(5 \mathrm{~km})$ wide adjacent to the fault (Keaton, 1987). In addition, shallow ground-water conditions in areas where earthquake-induced liquefaction could also occur may compound mitigation problems. In areas of shallow ground water or standing water, structures can be elevated and basements flood proofed.

\section{USE OF HAZARD MAPS}

Keaton (1986) has mapped the areas of potential tectonic subsidence along the WFZ in Utah and Juab Counties and estimated the amount of tilting and flooding. This mapping is based on a theoretical model, and it must be considered preliminary and approximate but will be adopted as published (Robison, 1988). Tectonic subsidence is a poorly understood phenomenon along the Wasatch Front, and these maps represent an initial attempt to depict the nature and extent of the hazard. The principal application of the maps is to make land-use planners and others aware of the hazard and to indicate those areas where further study may be necessary. Site-specific studies concerning tectonic subsidence are recommended only for critical facilities in areas of potential flooding. However, certain vulnerable facilities, such as high-cost waste-water treatment plants and hazardous-waste facilities, should also consider potential tilting. It would also be prudent to consider this hazard for other types of development within the area of potential subsidence and to take precautions, but specific reports are not required by the county.

\section{SCOPE OF SITE INVESTIGATIONS}

Site-specific studies of tectonic subsidence hazards should determine the depth to ground water and the site elevation with respect to projected lake and groundwater levels. These results would then be compared with expected amounts of subsidence shown on the map by Keaton (1986). Recommendations regarding hazard reduction should be based on the extent of flooding or ground tilt indicated. These reports will be reviewed by the County Surveyor and County Geologist. The hazard maps of Keaton (1986) will be amended as more accurate information becomes available.

\section{REFERENCES}

Doser, D.I., 1985, Source parameters and faulting processes of the 1959 Hebgen Lake, Montana, earthquake sequence: Journal of Geophysical Research, v. 90, no. B12, p. 4537-4555.

Keaton, J.R., 1986, Potential consequences of tectonic deformation along the Wasatch fault: Utah State University, Final report to the U.S. Geological Survey for Earthquake Hazards Reduction Program, Grant 14-08-0001-G1174.

1987, Potential consequences of earthquake-induced regional tectonic deformation along the Wasatch Front, north-central Utah, in McCalpin, James, ed., Proceedings of the 23rd annual symposium on engineering geology and soils engineering: Boise, Idaho Department of Transportation, p. 19-34.

Machette, M.N., Personius, S.F., Nelson, A.R., Schwartz, D.P., and Lund, W.R., 1989, Segmentation models and Holocene movement history of the Wasatch fault zone, Utah, in Schwartz, D.P., and Sibson, R.H., eds., Proceedings of conference XLV-Fault segmentation and controls on rupture initiation and termination: U.S. Geological Survey Open-File Report 89-314, p. 229-242.

Meyers, W.B., and Hamilton, W., 1964, Deformation accompanying the Hebgen Lake earthquake of August 17, 1959: U.S. Geological Survey Professional Paper 435-I, p. 55-98.

Robison, R.M., 1988, Surface fault rupture hazard and tectonic subsidence maps for the Wasatch Front, Utah: Geological Society of America Abstracts With Programs, v. 20, no. 6, p. 465.

Schwartz, D.P., and Coppersmith, K.J., 1984, Fault behavior and characteristic earthquakes - Examples from the Wasatch and San Andreas fault zones: Journal of Geophysical Research, v. 89, no. B7, p. 5681-5698.

Smith, R.B., and Richins, W.D., 1984, Seismicity and earthquake hazards of Utah and the Wasatch Front-Paradigm and paradox, in Hays, W.W., and Gori, P.L., eds., A workshop on "Evaluation of regional and urban earthquake hazards and risk in Utah," Proceedings of conference XVII: U.S. Geological Survey OpenFile Report 84-763, p. 73-112. 


\title{
HAZARDS FROM EARTHQUAKE-INDUCED GROUND FAILURE IN SENSITIVE GLAYS, VIBRATORY SETTLEMENT, AND FLOODING DUE TO SEICHES, SURFACE-DRAINAGE DISRUPTIONS, AND INCREASED GROUND-WATER DISCHARGE, DAVIS COUNTY, UTAH
}

\author{
By Mike Lowe ${ }^{17}$
}

\begin{abstract}
There are a number of potential hazards associated with earthquakes along the Wasatch Front that have not been sufficiently studied to determine probability of occurrence for various exposure periods or to produce maps showing areas at risk. These potentially damaging but poorly understood hazards include ground failure in sensitive clays, vibratory settlement in granular materials, and flooding due to seiches, surface-drainage disruptions, and increased ground-water discharge. Many of the consequences of these hazards are identified in this report. Additional study is required before these hazards can be considered in city and county planning. Some of these hazards, however, can be evaluated at the site-specific level and should be considered for major construction projects and, in particular, for critical facilities.
\end{abstract}

\section{INTRODUCTION}

A variety of phenomena that can cause damage to property and (or) threaten lives may accompany earthquakes. The principal hazards are addressed in other reports covering surface-fault rupture, ground shaking, liquefaction, tectonic subsidence, and landslide and rockfall hazards. It is the purpose of this report to discuss other potentially damaging but less well-understood phenomena associated with earthquakes, including ground failure due to loss of strength in sensitive clays, subsidence caused by vibratory settlement in granular materials, flooding caused by seiches in Great Salt Lake, flooding due to surface-drainage disruptions, and flooding from increased ground-water discharge. A major goal is to translate technical information so that government officials and the general public can appreciate the need to reduce earthquake hazards.

\section{ACKNOWLEDGMENTS}

Gary E. Christenson (Utah Geological Survey), Tim Stephens and Barry Burton (Davis County Planning

\footnotetext{
${ }^{17}$ Davis County Planning Department, Farmington, Utah.
}

Department), Craig Barker (Weber County Planning Department), and William J. Kockelman and Robert L. Schuster (U.S. Geological Survey) kindly reviewed this paper and provided valuable suggestions.

\section{GROUND FAILURE DUE TO LOSS OF STRENGTH IN SENSITIVE CLAYS}

\section{NATURE AND CAUSES}

Fine-grained lake deposits underlie much of western Davis County. Near Farmington these deposits are about $810 \mathrm{ft}(247 \mathrm{~m})$ thick (Feth and others, 1966), and some areas of Davis County may be underlain by as much as $1,000 \mathrm{ft}(300 \mathrm{~m})$ of sediments (Parry, 1974) deposited by lakes occupying the Great Salt Lake basin during the last 15 million years (Currey and others, 1984). Much of these lake sediments are silicate clays, some of which are classified as sensitive (Parry, 1974).

Most clays lose strength when disturbed; sensitive clays are those that experience a particularly large loss of strength. The sensitivity of clays is defined as the ratio of shear strength in an undisturbed condition to shear strength after being remolded (severely disturbed) (Costa and Baker, 1981). One proposed origin for these clays holds that the platy clay particles were deposited in an edge-to-edge "house of cards" (flocculated) structure in saline (generally marine) environments in which the sodium and other cations in the water provided bonding strength (Rosenqvist, 1953, 1966). Later, when this saline water is leached out by fresh ground water, the clays are left in an unstable arrangement, subject to collapse and liquefaction when disturbed or shaken. After disturbance, the clays may revert from a floceulated soil structure, in which ground water fills the interstitial pore spaces, to a dispersed soil structure, in which the interstitial water is expelled, often liquefying the clay (Costa and Baker, 1981). 


\section{EFFECTS}

The principal effect of disturbance of sensitive clays is ground failure. The kinds of ground failures associated with sensitive clays are similar to those accompanying liquefaction and include flow failures, slump-type landslides, and lateral spreads or translational landslides (Earthquake Engineering Research Institute, 1986; Costa and Baker, 1981). Liquefied sensitive clays may flow downhill on slopes of $1^{\circ}$ or less (Costa and Baker, 1981). One triggering mechanism for ground failure in sensitive clays is intense ground vibration generated by earthquakes. The most devastating damage resulting from the 1964 Anchorage, Alaska, magnitude 8.6 earthquake was the result of translational landslides accompanying failure in sensitive clays. The largest of these landslides, located in the Turnagain Heights residential area, damaged 75 homes (Hansen, 1966).

The potential for ground failure in sensitive clays is related to the intensity and duration of ground shaking and to the sensitivity of the clays. Clays with sensitivities of $\mathbf{1 0}$ or more may be prone to failure during seismic ground shaking (Earthquake Engineering Research Institute, 1986). Clays exceeding sensitivities of 10 have been identified in Davis County along the Weber River and at the Interstate 15 Parrish Lane overpass (Parry, 1974), indicating that sensitive clays are present and may be widely distributed in Davis County. The intensity and duration of ground shaking needed to induce failure in these sensitive clays have not been investigated, and therefore the probability that this type of ground failure would occur in Davis County cannot be currently determined.

\section{HAZARD REDUCTION}

Earthquake-induced ground failure due to sensitive clays has the potential to cause damage to most types of structures. Possible actions that may be taken if sensitive clays are present include (1) improving site conditions by converting the clays from a flocculated soil structure to a dispersed soil structure (preconstruction vibration techniques, etc.) and (or) dewatering the site and (2) designing the structure to withstand the effects of the potential ground failure using structural solutions such as end-bearing piles (placed below the sensitive clay), caissons, or fully compensated mat foundations designed for the anticipated failure type.

\section{LAND-USE PLANNING}

Maps have not been produced that show the extent of sensitive clay deposits in Davis County, but assessment of this hazard can be undertaken at the site-specific level as a standard part of foundation investigations. The assessment involves laboratory tests (unconfined compression tests) in which axial loads are applied to unconfined cylindrical samples, first in an undisturbed state and then in a remolded state (Spangler and Handy, 1973). The ratio of the strength of the soil under undisturbed versus disturbed conditions is then determined. Additional study is needed to determine the levels of ground shaking necessary to cause ground failure in sensitive clays before this hazard can be considered in regional land-use planning. Sensitive clays are a factor that should be considered in site-specific studies for all major construction, however, including critical facilities.

\section{SUBSIDENCE CAUSED BY VIBRATORY SETTLEMENT IN GRANULAR MATERIALS}

\section{NATURE AND CAUSES}

Loose granular materials such as some sands and gravels can be effectively compacted by vibration. The material assumes a denser form when particles move closer together and decrease the volume. Earthquakeinduced ground shaking is one source of vibrations that may cause this type of subsidence. During the 1964 Alaska earthquake, vibratory settlement caused the ground to subside at some locations by as much as $5.9 \mathrm{ft}$ $(1.8 \mathrm{~m})$ (Costa and Baker, 1981). Large areas of western Davis County are underlain by clean sand and gravel deposited in Pleistocene Lake Bonneville, where the potential for settlement may exist. Also, the county has many areas of fill that may be susceptible to vibrationinduced settlement. No studies have been conducted in Davis County to determine what levels of ground shaking are necessary to induce vibratory settlement in susceptible soils. Therefore, the probabilities that this hazard would occur are unknown.

\section{EFFECTS}

Differential settlement can occur if foundations are built across deposits with varying physical properties such as sorting and texture, possibly resulting in severe building damage as one part of the foundation settles more than another (Costa and Baker, 1981). Structural failure of building members (Dunn and others, 1980) and foundation cracking may also be caused by excessive settlement. Earthen fill is commonly used for construction of railway embankments, highway foundations, bridge abutments, and dikes and levees. Even minor differential settlement can cause extensive damage to these structures. If not adequately compacted during placement, these fills may be susceptible to this hazard because of the granular material commonly used 
(Schmidt, 1986). Utility lines and connections may be severed due to vibratory settlement. Rate of settlement is an important factor that must be considered in evaluating the potential for damage (Dunn and others, 1980). Settlements due to earthquake ground shaking would be nearly instantaneous.

\section{HAZARD REDUCTION}

Structural methods to reduce damage due to settlement include supporting structures on piles, piers, caissons, or walls that are founded below the susceptible material (U.S. Bureau of Reclamation, 1985). Where structural measures to reduce vibratory settlement in granular soils are not possible, actions that may be taken to mitigate the hazard include (1) removing or precompacting the in situ granular materials prior to construction to improve site conditions, and (2) making sure that fills are properly engineered and compacted.

\section{LAND-USE PLANNING}

Maps delineating areas susceptible to vibratory settlement have not been completed for Davis County. Also, the level of ground shaking necessary to induce settlement varies with conditions, and assessment of this hazard must be undertaken at specific sites as a standard part of a foundation evaluation. Vibratory settlement, therefore, may not be properly considered in regional land-use planning in Davis County. Standard penetration and cone penetrometer tests are commonly used to evaluate the potential for vibratory settlement (Dunn and others, 1980). The potential for vibratory settlement should be evaluated for all major construction, especially for critical facilities.

\section{FLOODING CAUSED BY SEICHES IN GREAT SALT LAKE}

\section{NATURE AND GAUSES}

A seiche is the oscillation of the surface of a lake or other landlocked body of water, similar to the oscillations produced by sloshing water in a bowl or a bucket when it is shaken or jarred (Nichols and Buchanan-Banks, 1974). Seiches vary in period from a few minutes to several hours. The magnitude of oscillation of the water surface is determined by the degree of resonance between the water body and the periodic driving force such as earthquake ground shaking and wind. When the periodic driving force is oscillating at the same frequency at which the water body tends to oscillate naturally, the magnitude of the oscillation is greatest and may cause unusu- ally large waves (seiches) that "break at considerable height and with great suddenness along the coastline" (Costa and Baker, 1981).

The effects of seiches are in part determined by water depth, lake size and shape, and the configuration of the local shoreline. These parameters determine the lake's natural period of oscillation and inherent system of long waves, much as the natural frequency of a pendulum is determined by its physical characteristics (Lin and Wang, 1978). "The system of long waves includes an infinite number of species of waves, usually called the normal modes; the fundamental mode refers to the wave with the longest wavelength" (Lin and Wang, 1978). It is the fundamental mode that is generally observed during surging and seiching (Lin and Wang, 1978). The period of the fundamental mode of Great Salt Lake's south basin is $6 \mathrm{~h}$ (Lin and Wang, 1978). Studies from other areas have shown that seiches may raise and lower a water surface from inches to many yards, causing damage from wave action as well as severe flooding (Blair and Spangle, 1979).

Seiches may be generated by wind, landslides, and (or) earthquakes (ground shaking, surface-fault rupture, and earthquake-induced landslides). The principal area at risk from seiches in Davis County is the shore of Great Salt Lake. Wind seiches in Great Salt Lake have been studied, and the maximum wave amplitude generated by this type of seiche is expected to be about $2 \mathrm{ft}(0.6 \mathrm{~m})$ (Lin and Wang, 1978). No systematic or theoretical studies of landslide or earthquake-induced seiching in Great Salt Lake have been completed. Seiches were reported along the southern shoreline of Great Salt Lake at Saltair and at the trestle at Lucin during the magnitude 6 Hansel Valley earthquake of October 5, 1909 (Williams and Tapper, 1953). The elevation of Great Salt Lake was $4,202.0 \mathrm{ft}$ (1280.77 m) on October 1, 1909 (U.S. Geological Survey lake elevation records). The seiche generated by the 1909 Hansel Valley earthquake overtopped the Lucin cutoff railroad trestle, which had an elevation of 4,214.85 ft $(1284.69 \mathrm{~m})$ (Southern Pacific Transportation Company records). Assuming the reports that the seiche overtopped the trestle are true and that lake and trestle elevation records were accurately reported, the seiche wave was more than $12 \mathrm{ft}(3.7 \mathrm{~m})$ high.

\section{EFFECTS}

Damage from seiches is primarily related to flooding, erosion, and forces exerted by waves. Seiches are a potential hazard to shoreline development and in-lake structures and are a concern to the proposed interisland diking project in Great Salt Lake. 


\section{HAZARD REDUCTION}

Dikes that are protected against erosion on the lakeward side and engineered breakwaters can be used to protect development or dissipate wave energy. Shoreline buildings can also be floodproofed, elevated, and constructed or reinforced to withstand the lateral forces of seiches (Costa and Baker, 1981).

\section{LAND-USE PLANNING}

Maps have not been produced that show areas that may be affected by seiches in Davis County. No comprehensive studies of landslide or earthquake-generated seiches have been completed for Great Salt Lake, but eyewitness accounts of the seiche generated by the 1909 Hansel Valley earthquake suggest that maximum wave amplitudes generated by earthquakes may far exceed maximum wave amplitudes associated with wind seiches. Landslide and earthquake-generated seiches are a hazard to shoreline development and in-lake construction and should be taken into consideration during planning phases of development in Great Salt Lake and within the proposed Great Salt Lake Beneficial Development Area (Utah Division of Comprehensive Emergency Management, 1985).

\section{FLOODING DUE TO SURFACE-DRAINAGE DISRUPTIONS DURING EARTHQUAKES}

Flooding may be caused by earthquake ground shaking, surface-fault rupture, ground tilting, and landsliding during earthquakes if water tanks, reservoirs, pipelines, or aqueducts are ruptured or if stream courses are blocked or diverted. The areas where such flooding may occur can be predicted to some extent by defining where such structures and streams cross known active faults, active landslides, and potentially unstable slopes. Damming of streams by landslides can cause upstream inundation and, if the landslide dam subsequently fails, cause catastrophic downstream flooding (Schuster, 1987). Maps delineating active faults and landslides are available at the Davis County Planning Department. Sitespecific studies addressing earthquake and slope-failure hazards should be completed prior to construction for all major water-retention structures or conveyance systems, so that mitigative measures can be recommended. Studies can be done for existing facilities to evaluate the possible extent of flooding and to recommend drainage modifications to prevent damaging floods. Potential flooding from diversion of stream courses is more difficult to evaluate but should be considered during hazard evaluations for critical facilities.

\section{INCREASED GROUND-WATER DISCHARGE DUE TO EARTHQUAKES}

The effects of earthquakes on ground-water systems have not been extensively studied and, consequently, are not well understood. During the 1983 Borah Peak, Idaho, earthquake, local surface flooding and erosion were caused by increases in spring flow and expulsion of water from shallow bedrock aquifers. Resulting increases in streamflow of more than 100 percent occurred following the earthquake, and flow remained high for about 2 weeks before declining to near original levels (Whitehead, 1985). Although this earthquake appeared to be one in which the ground water was especially affected, similar effects may occur during large-magnitude earthquakes in the vicinity of Davis County. Increased flow from springs in mountain drainages will be confined to stream channels, and adherence to Federal Emergency Management Agency flood-plain regulations should effectively reduce the risk. Increased flow from springs on the valley floor may result in ponded water and basement flooding.

\section{CONCLUSIONS AND RECOMMENDATIONS}

This report identifies a variety of phenomena associated with earthquakes that can damage property and threaten lives. Although many of the consequences of these hazards have been identified, the probability of occurrence has not been evaluated for Davis County, and maps that delineate areas in Davis County where hazards associated with these phenomena may occur are not available. Much study is required before these phenomena can be considered in regional planning for Davis County. However, some of these hazards can be evaluated on a site-specific basis; such studies should be considered for major construction projects, particularly critical facilities.

\section{REFERENCES}

Blair, M.L., and Spangle, W.E., 1979, Seismic safety and land-use planning-selected examples from California: U.S. Geological Survey Professional Paper 941-B, 82 p.

Costa, J.E., and Baker, V.R., 1981, Surficial geology-Building with the Earth: New York, John Wiley and Sons, 498 p.

Currey, D.R., Atwood, Genevieve, and Mabey, D.R., 1984, Major levels of Great Salt Lake and Lake Bonneville: Utah Geological and Mineral Survey Map 73, scale 1:750,000.

Dunn, I.S., Anderson, L.R., and Kiefer, F.W., 1980, Fundamentals of geotechnical analysis: New York, John Wiley and Sons, $414 \mathrm{p}$.

Earthquake Engineering Research Institute, 1986, Reducing earthquake hazards-Lessons learned from earthquakes: Publication 86-02, $208 \mathrm{p}$.

Feth, J.H., Barker, D.A., Moore, L.G., Brown, R.J., and Veirs, C.E., 1966, Lake Bonneville-Geology and hydrology of the Weber 
Delta District, including Ogden, Utah: U.S. Geological Survey Professional Paper 518, $76 \mathrm{p}$.

Hansen, W.R., 1966, Effects of the earthquake of March 27, 1964, at Anchorage, Alaska: U.S. Geological Survey Professional Paper 542-A, 68 p.

Lin, Anching, and Wang, Po, 1978, Wind tides of the Great Salt Lake: Utah Geology, v. 5, no. 1, p. 17-25.

Nichols, D.R., and Buchanan-Banks, J.M., 1974, Seismic hazards and land-use planning: U.S. Geological Survey Circular 690, $33 \mathrm{p}$.

Parry, W.T., 1974, Earthquake hazards in sensitive clays along the Wasatch Front, Utah: Geology, v. 2, no. 11, p. 559-560.

Rosenqvist, I. Th., 1953, Consideration of the sensitivity of Norwegian quick clays: Geotechnique, v. 3, p. 195-200.

-1966 , Norwegian research into the properties of quick clay $-\mathrm{A}$ review: Engineering Geology, v. 1, p. 445-450.

Schmidt, R.G., 1986, Geology, earthquake hazards, and land-use in the Helena area, Montana-A review: U.S. Geological Survey Professional Paper 1316, 64 p.
Schuster, R.L., 1987, Landslide damming of mountain streams: Geological Society of America Abstracts With Programs, v. 19, no. 5, p. 332 .

Spangler, M.G., and Handy, R.L., 1973, Soil engineering: New York, Intext Educational Publishers, 748 p.

U.S. Bureau of Reclamation, 1985, Earth manual-A water resources technical publication: U. S. Department of the Interior, $810 \mathrm{p}$.

Utah Division of Comprehensive Emergency Management, 1985, State hazard mitigation plan, 1985, Executive summary, Great Salt Lake Beneficial Development Area: Utah Division of Comprehensive Emergency Management, 21 p.

Whitehead, R.L., 1985, Hydrologic changes following the Idaho Borah Peak earthquake, Proceedings of workshop XXVIII on the Borah Peak, Idaho, earthquake, v. A: U.S. Geological Survey Open-File Report 85-290, p. 556-572.

Williams, J.S., and Tapper, M.L., 1953, Earthquake history of Utah, 1850-1948: Bulletin of the Seismological Society of America, v. 43, no. 3 , p. 191-218. 